$\mathbf{M}^{\mathrm{a}}$ Victoria Carrillo Durán/Margarita Pérez Pulido (Coords)

\title{
Metodologías y experiencias de investigación en comunicación e información
}
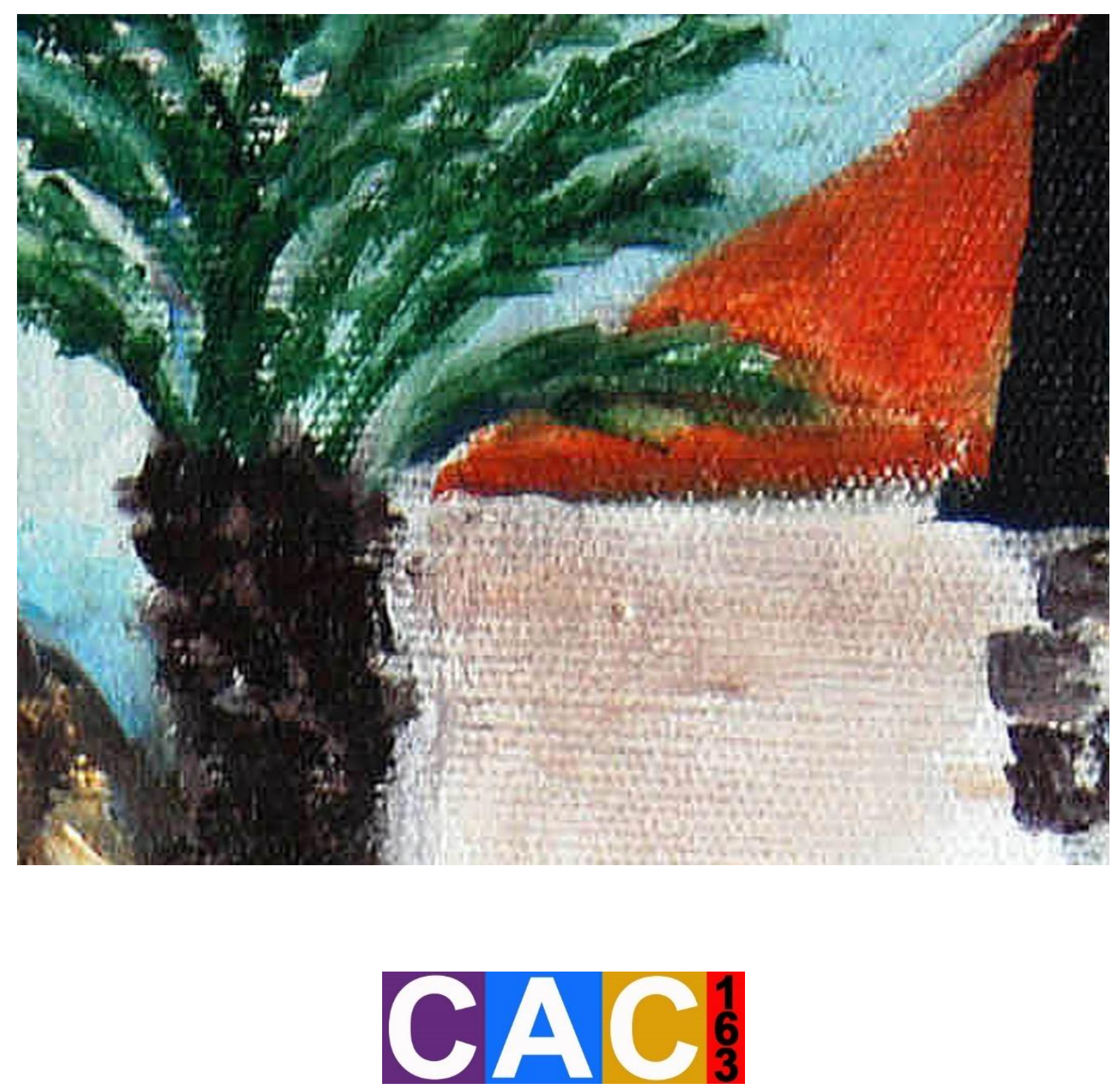

Cuadernos Artesanos de Comunicación/ 163

JUNTA DE EXTREMADURA

Consejería de Economía e Infraestructuras

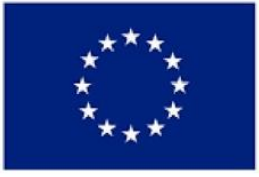

Unión Europea

Fondo Europeo

de Desarrollo Regional

"Una manera de hacer Europa" 
$\mathbf{M}^{\mathrm{a}}$ Victoria Carrillo Durán/Margarita Pérez Pulido (Coords)

\section{Metodologías y experiencias de investigación en comunicación e información}

$\mathrm{N}$ este trabajo se contextualiza el estado de la investigación
en las áreas de Ciencias de la Comunicación y de Ciencias de la Información y se presentan nuevas experiencias metodológicas nacionales e internacionales que permiten enriquecer la experiencia investigadora de los grupos y las líneas de investigación desarrolladas en ambas áreas temáticas.

Se exploran las intersecciones entre las metodologías cualitativas y cuantitativas, los casos y formas de abordar las investigaciones, y se aporta nuevo conocimiento tanto de estudio del contexto de situación como de las prácticas reales que permiten abrir puertas y consolidar la investigación de áreas emergentes, como son la comunicación y la información.

La transferencia de conocimiento que se realiza en este trabajo es fruto de la labor investigadora de grupos de investigación consolidados que desarrollan sus investigaciones financiadas por organismos públicos y privados de primer orden y que se desarrollan en centros de Educación Superior.

El resultado es un volumen dirigido a investigadores y realizado por investigadores que buscan la intersección y la colaboración en experiencias que permitan el enriquecimiento y el progreso de la investigación. 
Coordinado por:

María Victoria Carrillo Durán

Margarita Pérez Pulido

Metodologías y experiencias de investigación en comunicación e información

MARÍA VICTORIA CARRILLO/MARGARITA PÉREZ/CRISTINA FABA-PÉREZ/JUAN JOSÉ IGARTUA/SOLEDAD RUANO/MARÍA DEL ROSARIO FERNÁNDEZ-FALERO/SANDRA MIRANDA/ ANA GONZÁLEZ/JAVIER TRABADELA/MARÍA GARCÍA/JOSÉ LUIS HERRERA/ANA ISABEL CALDES/PAULA SEQUEIROS/JÉRÔME THOMAS

Cuadernos Artesanos de Comunicación / 163 


\section{Cuadernos Artesanos de Comunicación \\ Coordinador editorial: José Manuel de Pablos - jpablos@ull.edu.es \\ Comité Científico \\ Presidencia: José Luis Piñuel Raigada (UCM) \\ Secretaría: Milena Trenta}

- Victoria Tur (Universidad de Alicante, UA)

- Miguel Vicente (Universidad de Valladolid, UVA)

- Ramón Zallo (Universidad del País Vasco, UPV-EHU)

- Núria Almiron (Universidad Pompeu Fabra, UPF)

- Francisco Campos Freire (Universidad de Santiago de Compostela)

- José Cisneros (Benemérita Universidad Autónoma de Puebla, BUAP)

- Bernardo Díaz Nosty (Universidad de Málaga, UMA)

- Carlos Elías (Universidad Carlos III de Madrid, UC3M)

- Paulina B. Emanuelli (Universidad Nacional de Córdoba, UNC)

- José Luis González Esteban (Universidad Miguel Hernández de Elche, UMH)

- Marisa Humanes (Universidad Rey Juan Carlos, URJC)

- Juan José Igartua (Universidad de Salamanca, USAL)

- Xosé López (Universidad de Santiago de Compostela)

- Maricela López-Ornelas (Universidad Autónoma de Baja California, UABC)

- Octavio Islas (Universidad de los Hemisferios, Ecuador)

- Javier Marzal (Universidad Jaume I, UJI)

- José Antonio Meyer (Benemérita Universidad Autónoma de Puebla, BUAP)

- Ramón Reig (Universidad de Sevilla, US)

- Miquel Rodrigo Alsina (Universidad Pompeu Fabra, UPF)

- Xosé Soengas (Universidad de Santiago de Compostela)

- José Luis Terrón (Universidad Autónoma de Barcelona, UAB)

- José Miguel Túñez (Universidad de Santiago, USC)

\footnotetext{
* Queda expresamente autorizada la reproducción total o parcial de los textos publicados en este libro, en cualquier formato o soporte imaginables, salvo por explícita voluntad en contra del autor o autora o en caso de ediciones con ánimo de lucro. Las publicaciones donde se incluyan textos de esta publicación serán ediciones no comerciales y han de estar igualmente acogidas a CreativeCommons. Harán constar esta licencia y el carácter no venal de la publicación.
}

\section{@)}

Este libro y cada uno de los capítulos que contiene (en su caso) así como las imágenes incluidas, si no se indica lo contrario, se encuentran bajo una Licencia CreativeCommons Atribución-No Comercial-Sin Derivadas 3.0 Unported. Puede ver una copia de esta licencia en http:/ / creativecommons.org/licenses/bync-nd/3.0/ Esto significa que Ud. es libre de reproducir y distribuir esta obra, siempre que cite la autoría, que no se use con fines comerciales o lucrativos y que no haga ninguna obra derivada. Si quiere hacer alguna de las cosas que aparecen como no permitidas, contacte con los coordinadores del libro o con el autor del capítulo correspondiente.

* La responsabilidad de cada texto es de su autor o autora. 


\section{Coordinado por:}

$\mathbf{M}^{\mathrm{a}}$ Victoria Carrillo Durán/Margarita Pérez Pulido

\section{Metodologías y experiencias de investigación en comunicación e información}

Cuadernos Artesanos de Comunicación / 163 
CAC $163^{\circ}$ - Metodologías y experiencias de investigación en comunicación e información

Coordinado por: $\mathrm{M}^{\mathrm{a}}$ Victoria Carrillo Durán y Margarita Pérez Pulido

| Precio social: 11,05€ | Precio en librería. 14,35€ |

Editores: Javier Herrero y Milena Trenta

Diseño: F. Drago

Ilustración de portada: Fragmento del cuadro Mujer pensando de Vale (Bolonia)

Imprime y distribuye: F. Drago. Andocopias S. L.

c/ La Hornera, 41. La Laguna. Tenerife.

Teléfono: 922250554 | fotocopiasdrago@,telefonica.net

Edita: Sociedad Latina de Comunicación Social - edición no venal - La Laguna (Tenerife) 2019 - CreativeCommons

http://www.revistalatinacs.org/14SLCS/portada2014.html

Descargar en pdf:

http://www.cuadernosartesanos.org/\#163

Protocolo de envío de manuscritos con destino a CAC: (la colección que corresponda) http://www.cuadernosartesanos.org/protocolo.html

ISBN - 13: 978-84-17314-17-0

DL: TF-37-2020

DOI: $10.4185 / \operatorname{cac} 163$ 


\section{Metodologías y experiencias de investigación en comunicación e información}

\section{Resumen}

En este trabajo se contextualiza el estado de la investigación en las áreas de Ciencias de la Comunicación y de Ciencias de la Información y se presentan nuevas experiencias metodológicas nacionales e internacionales que permiten enriquecer la experiencia investigadora de los grupos y las líneas de investigación desarrolladas en ambas áreas temáticas.

Se exploran las intersecciones entre las metodologías cualitativas y cuantitativas, los casos y formas de abordar las investigaciones, y se aporta nuevo conocimiento tanto de estudio del contexto de situación como de las prácticas reales que permiten abrir puertas y consolidar la investigación de áreas emergentes, como son la comunicación y la información.

La transferencia de conocimiento que se realiza en este trabajo es fruto de la labor investigadora de grupos de investigación consolidados que desarrollan sus investigaciones financiadas por organismos públicos y privados de primer orden y que se desarrollan en centros de Educación Superior.

El resultado es un volumen dirigido a investigadores y realizado por investigadores que buscan la intersección y la colaboración en experiencias que permitan el enriquecimiento y el progreso de la investigación.

\section{Palabras claves}

metodologías de investigación, experiencias de investigación, ciencias de la comunicación, ciencias de la información, investigación cualitativa, investigación cuantitativa, contexto de investigación nacional, experiencias de investigación internacionales.

Forma de citar este libro:

Ma V Carrillo Durán, M Pérez Pulido (Eds.) (2019) Metodologías y experiencias de investigación en comunicación e información Cuadernos Artesanos de Comunicación, cac163. La Laguna (Tenerife): Latina. DOI: $10.4185 / \operatorname{cac} 163$ 


\section{Indice}

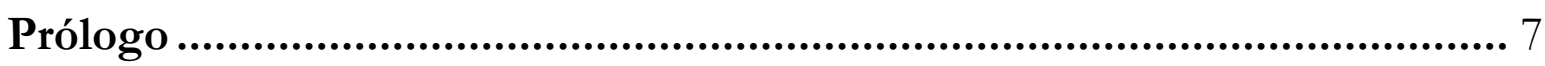

1. La investigación y los estudios de doctorado en comunicación en España

María Victoria Carrillo Durán.................................................................................. 13

2. Tendencias en Metodología de Investigación en Información y Documentación

Cristina Faba-Pérez y Margarita Pérez Pulido

3. Claves metodológicas de la investigación experimental en Comunicación. Aplicaciones prácticas en persuasión narrativa Juan José Igartua Perosanz.

4. Metodología de estudio de la audiciencia social de televisión: análisis por indicadores

Soledad Ruano López y María del Rosario Fernández-Falero

5. La cara "sombría" de los procesos de liderazgo: el papel de la comunicación interpersonal del líder

Sandra Miranda

6. Propuestas de metodología de investigación sobre estereotipos de género en los medios de comunicación. Casos prácticos

Ana González Delgado

7. La revisión sistemática de la literatura como método de investigación Javier Trabadela Robles y María García García

8. Propuestas metodológicas sobre la investigación de fondos antiguos José Luis Herrera Morillas.

9. Análisis de la información en páginas Web de Portugal, España, Reino Unido y Francia. El caso del comercio electrónico de libros Ana Caldes

10. Lectura, género, penitenciaría: apuntes sobre metodología de una investigación cualitativa

Paula Sequeiros

11. La técnica de entrevista appreciative inquiry como método cualitativo para el estudio de la función de comunicación

Jérôme Thomas.

El contenido de este libro ha sido sometido a un proceso

de revisión de doble ciego por pares, semejante al sistema de revisión de un artículo científico para un journal. 


\section{1 \\ Prólogo}

— STE libro pretende acercarse al complicado entorno de las 1 ciencias de la comunicación y la información. Hablar de comunicación e información es una tarea inabarcable en su propia definición, puesto que ambos campos han evolucionado mucho y muy rápidamente en los últimos años. Las últimas décadas han conferido a estos ámbitos científicos una madurez sin precedentes.

Considerando que estamos aún en los inicios y que los cambios sucedidos han alterado sucesivamente el entorno de la investigación, no está de más reflexionar sobre el papel y evolución de algunos aspectos relacionados con estas áreas de estudio.

Por tanto, este libro pretende ser un volumen que surge de indagar en la necesidad de delimitar algunas de las principales lagunas actuales en el ámbito de la investigación, no sin que sirva, además, de mapa de posición sobre el entorno de la comunicación y la información para jóvenes investigadores que están buscando un área de especialización posible.

Así, planteamos un trabajo que se asoma a ese ingente conjunto de perspectivas posibles y que supone centrarse en aquellos aspectos concretos. El objetivo básico de este trabajo es la difusión de experiencias y métodos de investigación en comunicación e información.

Para ello, el libro se ha estructurado en once capítulos que dan cabida a las preocupaciones observadas. Abrimos este volumen con una revisión de las principales líneas de trabajo en comunicación e información que enriquecen el panorama de estas ciencias en proceso de consolidación y que representan avances en las diferentes líneas de trabajo. 
Se comienza abordando el ámbito de la incipiente investigación experimental en comunicación, y se ofrecen algunas de sus claves metodológicas. Incidiendo en sus aplicaciones prácticas en persuasión narrativa, se destacan las principales áreas de interés en esta línea. Por una parte, el análisis del impacto de los atributos de los personajes y de las características de los mensajes narrativos. También, el análisis de las condiciones y "estados de exposición” y, por último, el análisis de los mecanismos explicativos del impacto actitudinal de los mensajes narrativos y de las relaciones dinámicas entre los mecanismos (mediadores primarios y secundarios).

En cuanto al ámbito de la investigación de medios y audiencias, se muestra la metodología de evaluación por indicadores, en redes sociales, de series de ficción españolas emitidas por canales generalistas. Además, se incluye el estudio de un caso: análisis de un curso televisivo de series, programadas en prime time, de Antena 3, La 1 y Tele 5.

Con el propósito de aportar nuevas y diferentes perspectivas de trabajo en comunicación para cubrir las diferentes líneas más destacadas en el contexto actual, y dado que la política y los comportamientos políticos en las organizaciones son un campo de investigación fértil y con un enorme alcance para el progreso de la sociedad, en este libro se encuentra una colaboración para comprender hasta qué punto los líderes de las organizaciones, a través de la forma en que se comunican en términos interpersonales, ejercen acción e influencia política con sus empleados. Con este fin, se realizó una investigación mixta que, utilizando encuestas de empleados y entrevistas con líderes, descubrió que los comportamientos de liderazgo político se relacionan en gran medida con la forma en que los líderes se comunican en términos interpersonales y sociales.

En el afán por aportar nuevas formas de investigar dentro de los estudios de género, se aborda también en este volumen, cómo estudiar la representación de los estereotipos masculino y femenino, planteando distintas líneas metodológicas de investigación que nos acercan de forma fidedigna a las representaciones, que tanto medios de comunicación, como las potentes y emergentes redes sociales, hacen para distinguir los géneros masculino y femenino y los patrones que se han establecido para otorgar roles. 
Un espacio proclive a dotar de herramientas a estudiosos de este fenómeno ante la necesidad de que, desde un punto de vista y determinación ética, se realice un acercamiento a una realidad y preocupación de nuestro entorno. Con ello, se trata de evitar que dichos estereotipos socioculturales sigan lastrando la igualdad entre ambos sexos y se perpetúen formas de discriminación comunicativas por motivos de género.

Por otra parte, se trata de recopilar las líneas de investigación que se han realizado en torno a los estereotipos de género en España, categorizarlos y mostrar otras líneas posibles de investigación para abordar futuros proyectos donde indagar en la brecha existente entre hombres y mujeres desde el ámbito de la comunicación.

Entre las metodologías que afloran en el panorama de la investigación teórica, emergen nuevas formas de producir resultados de investigación. La revisión sistemática de la literatura se ha convertido en un método relevante, a pesar de lo cual su aplicación en las ciencias sociales es aun limitada. Esta metodología de trabajo no consiste únicamente en elaborar un mapa concienzudo de la literatura relativa a la cuestión de estudio, sino que debe ser una búsqueda rigurosa y sistemática para que los hallazgos sean considerados representativos.

En este libro, se pretende contribuir a su uso en el contexto de la comunicación, lo que no constituye en sí mismo la realización de una revisión sistemática, sino aportar una visión global de los puntos más importantes a tener en cuenta para que pueda ser aplicado a futuros trabajos en el ámbito de la disciplina.

Por otra parte, en esta tendencia actual hacia la interdisciplinariedad, se plantean varias propuestas para realizar trabajos de investigación sobre colecciones de fondo antiguo, centradas en dos aspectos que desde el punto de vista metodológico se fundamentan en la conservación de las colecciones y en los aspectos artísticos de estas.

En el primer aspecto, se entiende que los trabajos de investigación sobre la conservación de colecciones de fondo antiguo deben centrarse en el estudio de cómo se incluye la tarea de conservación dentro de la política de gestión de la colección y para ello, se debe partir del conocimiento de los principales aspectos relacionados con la 
conservación de este tipo de colecciones, que implica conocer desde un punto de vista teórico todo lo relacionado con ella.

En la línea de los trabajos sobre información, se aborda en un capítulo de este volumen, el estudio del contenido presente en los sitios $W e b$ que realizan la venta electrónica de libros en Portugal, España, Reino Unido y Francia. El estudio se aplica en direcciones $W e b$ recuperadas a través del motor de búsqueda Google, con el objetivo de conocer lo que encuentra el usuario cuando navega en la Red. Se estudia el comportamiento del usuario ante la información a través de un instrumento de análisis que nos permite evaluar de forma cuantitativa y cualitativa lo que está disponible en el sitio $W e b$. Este trabajo sirve de orientación a los $W e b$ designer en el diseño de las páginas $W e b$ y ofrece información importante sobre los contenidos con el objetivo de satisfacer al usuario/cliente durante su navegación por el sitio Web.

Como el propósito de este volumen es exponer experiencias innovadoras, es importante destacar los estudios realizados en ciencias sociales, pero en los que se trabaja en contextos difíciles. Se muestra en este libro una experiencia de investigación que trata de compartir dudas y comentarios, así como traer a debate algunas cuestiones relacionadas con la investigación en cárceles. En concreto, el proyecto fue llevado a cabo por medio de un trabajo de campo en una prisión femenina. La aportación se realiza desde el cruce interdisciplinario de algunas áreas: lectura, bibliotecas penitenciarias, sociología de la cultura y de la vida en la cárcel.

En la misma línea, se describen nuevas técnicas de investigación cualitativas, como la técnica llamada appreciative inquiry, para investigar los valores y prácticas profesionales de los vigilantes penitenciarios de una cárcel francesa de máxima seguridad. Entre las prácticas estudiadas figuran las capacidades relacionales y comunicacionales de los vigilantes. Esta técnica original, aunque conlleva sesgos, se plantea como un método cualitativo muy interesante y relevante para estudiar un ámbito que tiene representaciones negativas en la sociedad y, en particular, para tratar las formas de comunicación que pueden desarrollarse en un contexto tan difícil como el de las cárceles. En especial, el delicado desarrollo de la relación con los internos y de la gestión de la distancia adecuada con respecto a ellos. La técnica permite superar la intimidante barrera entre el investigador y el sujeto 
y, así, provocar relatos íntimos, auténticos y positivos sobre las prácticas y los trucos profesionales, habitualmente omitidos en los discursos públicos de los vigilantes o en las investigaciones que usan métodos comprensivos más clásicos. Esta técnica permite obtener resultados inéditos sobre una profesión que la investigación o los medios de comunicación suelen mostrar únicamente bajo la forma del sufrimiento, de lo negativo o la denuncia de actos represivos, o bien, de las dificultades psicosociales. Se trata de describir el método y, asimismo, los aspectos concretos de su uso y los tipos de resultados que se pueden obtener a partir de su implementación.

Con todo ello, este libro se convierte así en una recopilación de experiencias investigadoras que ayudarán a debatir y abrir nuevos caminos y que nos servirán de hoja de ruta para abundar en el entorno de las ciencias de la comunicación y de la información.

Para terminar, decir que este libro ha sido realizado gracias a la financiación a grupos de investigación de la Junta de Extremadura y Fondos Feder "Una manera de hacer Europa".

\section{JUNTA DE EXTREMADURA}

Consejería de Economía e Infraestructuras

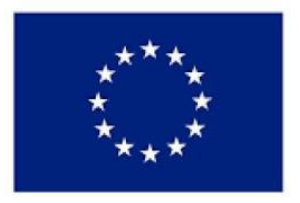

\section{Unión Europea}

Fondo Europeo

de Desarrollo Regional

"Una manera de hacer Europa" 



\title{
La investigación y los estudios de doctorado en comunicación en España
}

\author{
$M^{a}$ Victoria Carrillo Durán \\ Profesora Titular de Comunicación Audiovisual y Publicidad. \\ Universidad de Extremadura
}

\section{Resumen}

Este trabajo se acerca al ámbito de las ciencias de la comunicación y su investigación en los últimos años. La aportación se divide en dos partes, la primera presenta una revisión de las principales líneas de investigación en comunicación, los objetivos más destacados y las metodologías más frecuentes. Para ello, se han revisado referencias recientes que abordan el estado de la investigación en comunicación en España. Por otra parte, se han actualizado las líneas de trabajo de las principales organizaciones de comunicación en las que participan investigadores de todo el mundo.

La segunda parte del capítulo dibuja el panorama actual de los estudios de doctorado en Comunicación en España en el momento presente, sobre todo desde la modificación de los estudios de Tercer Ciclo a partir del Real Decreto 99/2011. Para ello se ha partido de la información oficial de la base de datos del Ministerio de Educación (España) llamada QEDU (Qué Estudiar y Dónde en la Universidad) para determinar los programas de doctorado oficiales existentes. Por último, se han recogido manualmente, a través de sus páginas webs, las líneas de investigación que abordan todos los programas de comunicación en España.

Con todo esto se concluye, por una parte, que la investigación en comunicación está en consolidación a pesar de los esfuerzos realizados 
por los investigadores en los últimos años. Las razones de su lento avance se centran en la falta de apoyo económico por parte de los organismos de financiación de la investigación, la dejadez metodológica de los autores en el pasado, la urgencia por publicar y la constante dispersión de líneas y temas a desarrollar a lo largo de los últimos años. Por otra parte, los programas de doctorado parecen presentar una clara especialización en comunicación y a la vez una tendencia a la interdisciplinariedad, sobresaliendo las líneas específicas de comunicación a pesar de la diversidad multidisciplinar de algunos de los programas de doctorado estudiados en este trabajo.

\section{El estado de la investigación en comunicación en España}

$\mathrm{P}$ ARA analizar el estado de la investigación en comunicación en España, en el momento presente, se realizará una revisión bibliográfica de las últimas referencias en el tema de estudio, buscando las sinergias que nos permitan dibujar este panorama que hemos esbozado para este epígrafe, sobre todo, se recurrirá a los estudios de Carrillo, García, Tato y Castillo (2013), los resultados del proyecto MAPCOM publicados por Caffarel, Ortega y Gaitán (2018) y el reciente trabajo de Nicolás, Lapiedra y Campos (2019) y de Rodríguez, Goyanes y Rosique (2018).

Se puede entender, a priori, que los núcleos de la investigación en cualquier campo científico se reflejan claramente en los artículos en revistas académicas (Nicolás et al., 2019), las tesis doctorales y los proyectos de investigación competitivos (Caffarel et al., 2018).

En primer lugar, según Cafffarel et al. (2018), una forma de medir las tendencias en investigación en comunicación en España son las tesis doctorales y proyectos de investigación. Los autores observaron que la investigación en comunicación va aumentando de forma progresiva en el período estudiado por ellos (hasta 2014), pero que su proporción sobre el total, no supone más de una tesis doctoral por cada veinte de las leídas en Ciencias Sociales y Humanas y, de igual modo, un proyecto de investigación por cada cuarenta desarrollados dentro de este mismo ámbito de investigación en España.

En segundo lugar, los artículos publicados son un termómetro del avance de la investigación en comunicación en España. Así, artículos 
recientes abordan el estudio de temas y metodologías de la investigación española sobre comunicación, tales como Nicolás et al., 2019 y Rodríguez et al., (2018).

Después de la revisión de los citados trabajos, delimitamos el estado de la investigación en comunicación en España abordando estas dos partes:

- Las principales líneas de trabajo y objetivos planteados.

- Las metodologías más usadas.

\subsection{Principales líneas de trabajo}

Como ya se dijo en Carrillo et al. (2013), la reflexión científica sobre la comunicación como objeto de estudio ha llevado al desarrollo y la consolidación de numerosas organizaciones y asociaciones que velan porque el esfuerzo de los investigadores y académicos de la comunicación tenga la difusión y visibilidad necesaria en el seno de la comunidad científica internacional. De esta forma, las principales líneas de investigación que dichas organizaciones proponen, pueden mostrar las tendencias e inquietudes de los investigadores en comunicación, en lo que a temas de estudio se refiere.

Para el estudio de las principales líneas y objetos de investigación en comunicación, se realizó en 2013, una revisión de las secciones de estudio propuestas por las asociaciones de investigación en comunicación más relevantes del panorama nacional e internacional. En esta ocasión, se han vuelto a revisar actualmente, con el fin de ver las diferencias existentes.

Las principales asociaciones de comunicación a nivel internacional y nacional siguen siendo las siguientes:

-International Association for Media and Communication Research (IAMCR).

-La Asociación Latinoamericana de Investigadores de la Comunicación (ALAIC).

-La European Communication Research and Education Association (ECREA). 
-La International Communication Association (ICA).

-La Asociación Española de Investigación de la Comunicación (AEIC).

Estas organizaciones sitúan el mapa de la investigación en comunicación a nivel mundial y nacional, siendo el principal referente para los investigadores en materia de congresos a los que asistir y líneas de trabajo en las que trabajar.

A simple vista, ya se percibe el carácter interdisciplinar y global de las ciencias de la comunicación. La tabla 1, es un fiel reflejo de la diversidad de temas que se abordan.

Como se ve en la tabla 1 , no ha habido grandes cambios en los últimos años (comparar columnas en la tabla 1), destacando la incorporación de nuevas líneas que sobre todo han venido a reforzar el ámbito de la digitalización, abriendo camino a la investigación en videojuegos y la comunicación en redes sociales. Se destaca también el refuerzo de la investigación periodística y las mejoras de acceso a la educación y a otras libertades, así como la incorporación de algunas líneas que refuerzan el ámbito de la comunicación empresarial y las relaciones públicas, tales como la comunicación de crisis. Por otra parte, ninguna línea ha sido eliminada en los últimos años.

No obstante, los descriptores principales de los estudios de comunicación parecen ser, la educación, el deporte, la salud, el periodismo, la comunicación intercultural, las teorías de la comunicación, los estudios de recepción y audiencias, la comunicación organizacional y publicitaria, la digitalización, el derecho, la historia y la filosofía de la comunicación, la comunicación para el cambio, los estudios de género y feministas, la comunicación política, las industrias culturales y la economía de la comunicación.

Estos campos se pueden aglutinar en las mismas áreas ya descritas en Carrillo et al. (2013), asumiendo en esta ocasión, que la digitalización de la comunicación no es un área en sí misma, sino que corta trasversalmente a todas las que se proponen a continuación. 
Tabla 1. Repertorio de temas de estudio de las distintas asociaciones de investigación en comunicación 2013-2019.

\begin{tabular}{|c|c|c|c|c|c|c|c|c|c|}
\hline IAMCR 2013 & 2019 & ALAIC 2013 & 2019 & ECREA 2013 & 2019 & ІГА 2013 & 2019 & AE-IC 2D13 & 2019 \\
\hline Audiencias & Audiencias & $\begin{array}{l}\text { Comunicación } \\
\text { Intercultural y } \\
\text { folkcamunicación }\end{array}$ & $\begin{array}{l}\text { Comunicación } \\
\text { Intercultural y } \\
\text { folkcomunicación }\end{array}$ & $\begin{array}{l}\text { Estudios de } \\
\text { audiencia y } \\
\text { гесерción }\end{array}$ & $\begin{array}{l}\text { Estudios de } \\
\text { audiencia y } \\
\text { гесерсión }\end{array}$ & $\begin{array}{l}\text { Los Media en } \\
\text { relación a los } \\
\text { niños y los } \\
\text { adolescentes }\end{array}$ & $\begin{array}{l}\text { Los Media en } \\
\text { relación a los } \\
\text { niños y los } \\
\text { adalescentes }\end{array}$ & $\begin{array}{l}\text { Camunicación } \\
\text { estratégica y } \\
\text { organizacional }\end{array}$ & $\begin{array}{l}\text { Camunicación } \\
\text { estratégica y } \\
\text { arganizacional }\end{array}$ \\
\hline $\begin{array}{l}\text { Políticas y } \\
\text { tecnología } \\
\text { de la } \\
\text { comunicación }\end{array}$ & $\begin{array}{l}\text { Políiticas y } \\
\text { tecnología } \\
\text { de la } \\
\text { comunicación }\end{array}$ & $\begin{array}{l}\text { Comunicación } \\
\text { organizacional y } \\
\text { relaciones } \\
\text { públicas }\end{array}$ & $\begin{array}{l}\text { Camunicación } \\
\text { Organizacional y } \\
\text { relaciones } \\
\text { públicas }\end{array}$ & $\begin{array}{l}\text { Comunicación y } \\
\text { demacracia }\end{array}$ & $\begin{array}{l}\text { Comunicación y } \\
\text { demacracia }\end{array}$ & $\begin{array}{l}\text { Comunicación y } \\
\text { tecnología }\end{array}$ & $\begin{array}{l}\text { Comunicación y } \\
\text { tecnolagía }\end{array}$ & $\begin{array}{l}\text { Camunicación } \\
\text { y cultura } \\
\text { digital }\end{array}$ & $\begin{array}{l}\text { Camunicación } \\
\text { y cultura } \\
\text { digital }\end{array}$ \\
\hline $\begin{array}{l}\text { Comunicación } \\
\text { compartida }\end{array}$ & $\begin{array}{l}\text { Comunicación } \\
\text { compartida y } \\
\text { medios de } \\
\text { comunicación } \\
\text { alternativas. }\end{array}$ & $\begin{array}{l}\text { Camunicación } \\
\text { para el cambio } \\
\text { sacial }\end{array}$ & $\begin{array}{l}\text { Camunicación } \\
\text { para el Cambio } \\
\text { Sacial }\end{array}$ & $\begin{array}{l}\text { Histaria de la } \\
\text { comunicación }\end{array}$ & $\begin{array}{l}\text { Historia de la } \\
\text { comunicación }\end{array}$ & $\begin{array}{l}\text { Histaria de la } \\
\text { comunicación }\end{array}$ & $\begin{array}{l}\text { Histaria de la } \\
\text { comunicación }\end{array}$ & $\begin{array}{l}\text { Estructuras y } \\
\text { políticas de la } \\
\text { comunicación }\end{array}$ & $\begin{array}{l}\text { Estructuras y } \\
\text { políticas de la } \\
\text { camunicación }\end{array}$ \\
\hline $\begin{array}{l}\text { Red de } \\
\text { Investigadares } \\
\text { Emergentes } \\
\end{array}$ & $\begin{array}{l}\text { Red de } \\
\text { investigadares } \\
\text { emergentes }\end{array}$ & $\begin{array}{l}\text { Comunicación } \\
\text { política y medias }\end{array}$ & $\begin{array}{l}\text { Comunicación } \\
\text { Política y Medias }\end{array}$ & $\begin{array}{l}\text { Derecha y } \\
\text { políticas de } \\
\text { comunicación }\end{array}$ & $\begin{array}{l}\text { Derecha y } \\
\text { políticas de } \\
\text { camunicación }\end{array}$ & $\begin{array}{l}\text { Derecho y } \\
\text { políticas de } \\
\text { camunicación }\end{array}$ & $\begin{array}{l}\text { Derecho y } \\
\text { políticas de } \\
\text { comunicación }\end{array}$ & $\begin{array}{l}\text { Estudios de } \\
\text { audiencia y } \\
\text { recepción } \\
\end{array}$ & $\begin{array}{l}\text { Estudios de } \\
\text { audiencia y } \\
\text { гесерсión }\end{array}$ \\
\hline $\begin{array}{l}\text { Génera y } \\
\text { Comunicación }\end{array}$ & $\begin{array}{l}\text { Génera y } \\
\text { camunicación }\end{array}$ & $\begin{array}{l}\text { Comunicación } \\
\text { popular, } \\
\text { comunitaria y } \\
\text { ciudadanía }\end{array}$ & $\begin{array}{l}\text { Camunicación } \\
\text { Popular. } \\
\text { comunitaria y } \\
\text { ciudadanía }\end{array}$ & $\begin{array}{l}\text { Diáspora, } \\
\text { migración y } \\
\text { medias }\end{array}$ & $\begin{array}{l}\text { Diáspora, } \\
\text { migración y } \\
\text { medios }\end{array}$ & $\begin{array}{l}\text { Comunicación } \\
\text { medioambiental }\end{array}$ & $\begin{array}{l}\text { Comunicación } \\
\text { medioambiental }\end{array}$ & $\begin{array}{l}\text { Estudios } \\
\text { sabre el } \\
\text { discurso }\end{array}$ & $\begin{array}{l}\text { Estudios } \\
\text { sobre el } \\
\text { discurso }\end{array}$ \\
\hline Histaria & Histaria & $\begin{array}{l}\text { Comunicación } \\
\text { publicitaria }\end{array}$ & $\begin{array}{l}\text { Comunicación } \\
\text { publicitaria }\end{array}$ & $\begin{array}{l}\text { Cultura digital } \\
\text { y comunicación }\end{array}$ & $\begin{array}{l}\text { Cultura digital } \\
\text { y comunicación }\end{array}$ & $\begin{array}{l}\text { Etniticidad y } \\
\text { raza en } \\
\text { camunicación }\end{array}$ & $\begin{array}{l}\text { Etniticidad y } \\
\text { raza en } \\
\text { camunicación }\end{array}$ & $\begin{array}{l}\text { Praducción y } \\
\text { circulación } \\
\text { de cantenidas }\end{array}$ & $\begin{array}{l}\text { Producción y } \\
\text { circulación de } \\
\text { contenidas }\end{array}$ \\
\hline $\begin{array}{l}\text { Comunicación } \\
\text { internacional }\end{array}$ & $\begin{array}{l}\text { Camunicación } \\
\text { internacional }\end{array}$ & $\begin{array}{l}\text { Comunicación y } \\
\text { ciudad }\end{array}$ & $\begin{array}{l}\text { Comunicación y } \\
\text { ciudad }\end{array}$ & $\begin{array}{l}\text { Estudios } \\
\text { filmicos }\end{array}$ & $\begin{array}{l}\text { Estudios } \\
\text { filmicas }\end{array}$ & $\begin{array}{l}\text { Estudias } \\
\text { feministas }\end{array}$ & $\begin{array}{l}\text { Estudios } \\
\text { feministas }\end{array}$ & $\begin{array}{l}\text { Tearías y } \\
\text { métadas de } \\
\text { investigación } \\
\text { en } \\
\text { comunicación }\end{array}$ & $\begin{array}{l}\text { Tearías y } \\
\text { métadas de } \\
\text { investigación } \\
\text { en } \\
\text { comunicación }\end{array}$ \\
\hline Derecho & Derecho & $\begin{array}{l}\text { Comunicación y } \\
\text { educación }\end{array}$ & $\begin{array}{l}\text { Comunicación y } \\
\text { educación }\end{array}$ & $\begin{array}{l}\text { Génera y } \\
\text { comunicación }\end{array}$ & $\begin{array}{l}\text { Génerc y } \\
\text { comunicación }\end{array}$ & $\begin{array}{l}\text { Estudios sobre } \\
\text { los juegos }\end{array}$ & $\begin{array}{l}\text { Estudios sobre } \\
\text { los juegos }\end{array}$ & & \\
\hline $\begin{array}{l}\text { Medios y } \\
\text { Deporte }\end{array}$ & $\begin{array}{l}\text { Medios y } \\
\text { deportes }\end{array}$ & $\begin{array}{l}\text { Comunicación y } \\
\text { estudias } \\
\text { sacioculturales }\end{array}$ & $\begin{array}{l}\text { Comunicación y } \\
\text { Estudios } \\
\text { Sacioculturales }\end{array}$ & $\begin{array}{l}\text { Comunicación } \\
\text { internacional e } \\
\text { intercultural }\end{array}$ & $\begin{array}{l}\text { Comunicación } \\
\text { internacional e } \\
\text { intercultural }\end{array}$ & $\begin{array}{l}\text { Estudios sobre } \\
\text { gay, lesbianas, } \\
\text { bisexuales y } \\
\text { transexuales }\end{array}$ & $\begin{array}{l}\text { Estudios sabre } \\
\text { gay, lesbianas, } \\
\text { bisexuales y } \\
\text { transexuales }\end{array}$ & & \\
\hline $\begin{array}{l}\text { Educación y } \\
\text { medios }\end{array}$ & $\begin{array}{l}\text { Investigación } \\
\text { en educación } \\
\text { y medios }\end{array}$ & $\begin{array}{l}\text { Comunicación y } \\
\text { salud }\end{array}$ & $\begin{array}{l}\text { Comunicación y } \\
\text { salud }\end{array}$ & $\begin{array}{l}\text { Camunicación } \\
\text { interpersanal e } \\
\text { interacción } \\
\text { sacial }\end{array}$ & $\begin{array}{l}\text { Comunicación } \\
\text { interpersanal e } \\
\text { interacción } \\
\text { sacial }\end{array}$ & $\begin{array}{l}\text { Comunicación } \\
\text { global y cambio } \\
\text { sacial }\end{array}$ & $\begin{array}{l}\text { Comunicación } \\
\text { global y cambio } \\
\text { sacial }\end{array}$ & & \\
\hline $\begin{array}{l}\text { Comunicación } \\
\text { mediada, } \\
\text { opinión } \\
\text { pública y } \\
\text { sociedad }\end{array}$ & $\begin{array}{l}\text { Camunicación } \\
\text { mediada, } \\
\text { opinión } \\
\text { pública y } \\
\text { saciedad }\end{array}$ & $\begin{array}{l}\text { Comunicación, } \\
\text { tecnología y } \\
\text { desarrollo }\end{array}$ & $\begin{array}{l}\text { Comunicación, } \\
\text { tecnología y } \\
\text { desarrolla }\end{array}$ & $\begin{array}{l}\text { Estudios sobre } \\
\text { periodismo }\end{array}$ & $\begin{array}{l}\text { Estudios sobre } \\
\text { periodismo }\end{array}$ & $\begin{array}{l}\text { Comunicación } \\
\text { para la salud }\end{array}$ & $\begin{array}{l}\text { Comunicación } \\
\text { para la salud }\end{array}$ & & \\
\hline $\begin{array}{l}\text { Comunicación } \\
\text { participativa }\end{array}$ & $\begin{array}{l}\text { Investigación } \\
\text { en } \\
\text { comunicación } \\
\text { participativa }\end{array}$ & $\begin{array}{l}\text { Discursa y } \\
\text { camunicación }\end{array}$ & $\begin{array}{l}\text { Discursa y } \\
\text { camunicación }\end{array}$ & $\begin{array}{l}\text { Comunicación } \\
\text { organizacional } \\
\text { y estratégica }\end{array}$ & $\begin{array}{l}\text { Comunicación } \\
\text { organizacional } \\
\text { y estratégica }\end{array}$ & $\begin{array}{l}\text { Sistemas de } \\
\text { infarmación }\end{array}$ & $\begin{array}{l}\text { Sistemas de } \\
\text { infarmación }\end{array}$ & & \\
\hline $\begin{array}{l}\text { Comunicación } \\
\text { política }\end{array}$ & $\begin{array}{l}\text { Camunicación } \\
\text { política }\end{array}$ & $\begin{array}{l}\text { Economía } \\
\text { política de las } \\
\text { comunicaciones }\end{array}$ & $\begin{array}{l}\text { Economía } \\
\text { Política de las } \\
\text { Comunicaciones }\end{array}$ & $\begin{array}{l}\text { Filasofía de la } \\
\text { comunicación }\end{array}$ & $\begin{array}{l}\text { Filosofía de la } \\
\text { comunicación }\end{array}$ & $\begin{array}{l}\text { Comunicación } \\
\text { instrumental y } \\
\text { para el } \\
\text { desarrollo } \\
\end{array}$ & $\begin{array}{l}\text { Camunicación } \\
\text { instrumental y } \\
\text { para el } \\
\text { desarrolla } \\
\end{array}$ & & \\
\hline \multirow[t]{8}{*}{$\begin{array}{l}\text { Econamía } \\
\text { Política }\end{array}$} & $\begin{array}{l}\text { Ecanomía } \\
\text { política }\end{array}$ & $\begin{array}{l}\text { Estudios de } \\
\text { recepción }\end{array}$ & $\begin{array}{l}\text { Estudios de } \\
\text { recepción }\end{array}$ & $\begin{array}{l}\text { Comunicación } \\
\text { política }\end{array}$ & $\begin{array}{l}\text { Comunicación } \\
\text { política }\end{array}$ & $\begin{array}{l}\text { Comunicación } \\
\text { intercultural }\end{array}$ & $\begin{array}{l}\text { Camunicación } \\
\text { intercultural }\end{array}$ & & \\
\hline & $\begin{array}{l}\text { lnvestigación } \\
\text { en periodismo } \\
\text { y educación }\end{array}$ & $\begin{array}{l}\text { Estudios sobre } \\
\text { periadismo }\end{array}$ & $\begin{array}{l}\text { Estudios sobre } \\
\text { Periodismo }\end{array}$ & $\begin{array}{l}\text { Investigación } \\
\text { sobre radio }\end{array}$ & $\begin{array}{l}\text { Investigación } \\
\text { sobre radio }\end{array}$ & $\begin{array}{l}\text { Camunicación } \\
\text { interpersonal }\end{array}$ & $\begin{array}{l}\text { Comunicación } \\
\text { interpersanal }\end{array}$ & & \\
\hline & & $\begin{array}{l}\text { Tearía y } \\
\text { metadalagía de } \\
\text { la investigación } \\
\text { en comunicación }\end{array}$ & $\begin{array}{l}\text { Tearía y } \\
\text { Metadalagía de la } \\
\text { Investigación en } \\
\text { Comunicación }\end{array}$ & $\begin{array}{l}\text { Comunicación } \\
\text { científica y } \\
\text { medioambiental }\end{array}$ & $\begin{array}{l}\text { Comunicación } \\
\text { científica y } \\
\text { mediaambiental }\end{array}$ & $\begin{array}{l}\text { Estudios sobre } \\
\text { periodismo }\end{array}$ & $\begin{array}{l}\text { Estudios sobre } \\
\text { periodismo }\end{array}$ & & \\
\hline & & & $\begin{array}{l}\text { Historia de la } \\
\text { Comunicación }\end{array}$ & $\begin{array}{l}\text { Estudios sabre } \\
\text { televisión }\end{array}$ & $\begin{array}{l}\text { Estudios sobre } \\
\text { televisión }\end{array}$ & $\begin{array}{l}\text { Lenguaje e } \\
\text { interacción } \\
\text { sacial } \\
\end{array}$ & $\begin{array}{l}\text { Lenguaje e } \\
\text { interacción } \\
\text { sacial } \\
\end{array}$ & & \\
\hline & & & $\begin{array}{l}\text { Ética, Libertad de } \\
\text { Expresión y } \\
\text { Derecho a la } \\
\text { Comunicación }\end{array}$ & & $\begin{array}{l}\text { Investigación } \\
\text { en videajuegus }\end{array}$ & $\begin{array}{l}\text { Camunicación } \\
\text { de masas }\end{array}$ & $\begin{array}{l}\text { Comunicación } \\
\text { de masas }\end{array}$ & & \\
\hline & & & $\begin{array}{l}\text { Comunicación } \\
\text { Digital, Redes y } \\
\text { Procesos } \\
\end{array}$ & & $\begin{array}{l}\text { Camunicación y } \\
\text { mediación }\end{array}$ & $\begin{array}{l}\text { Comunicación } \\
\text { arganizacional }\end{array}$ & $\begin{array}{l}\text { Comunicación } \\
\text { arganizacional }\end{array}$ & & \\
\hline & & & & & $\begin{array}{l}\text { Producción e } \\
\text { industrias } \\
\text { culturales } \\
\end{array}$ & $\begin{array}{l}\text { Filasafía, teoría } \\
\text { y crítica }\end{array}$ & $\begin{array}{l}\text { Filosofía, teoría } \\
\text { y crítica }\end{array}$ & & \\
\hline & & & & & $\begin{array}{l}\text { Comunicación } \\
\text { de crisis }\end{array}$ & $\begin{array}{l}\text { Comunicación } \\
\text { política }\end{array}$ & $\begin{array}{l}\text { Comunicación } \\
\text { política }\end{array}$ & & \\
\hline
\end{tabular}




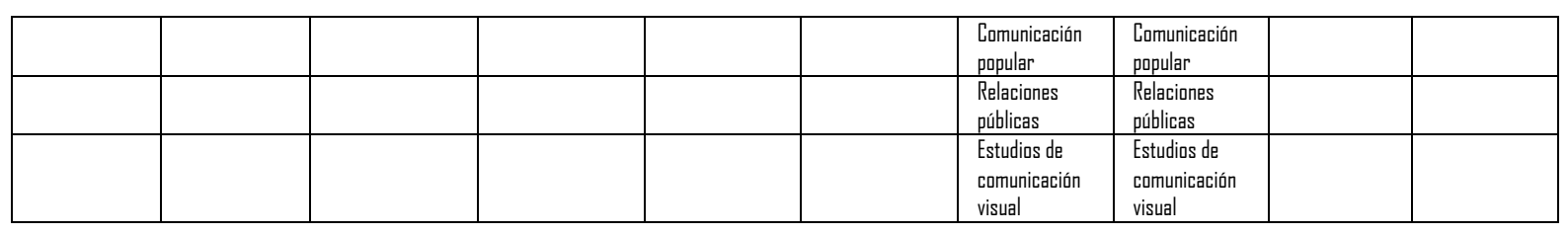

Fuente: elaboración propia a partir de Carrillo et al. (2013).

Los estudios sobre comunicación y educación, centrados en la alfabetización mediática o la incorporación de las nuevas tecnologías en los procesos de enseñanza y aprendizaje.

Los estudios periodísticos, con sus diferentes vertientes hacia la investigación sobre las fuentes, el periodismo digital, la redefinición del periodismo, la prensa gratuita y la agenda setting.

Los estudios sobre las industrias culturales y el entorno digital, la novedad de formas en la que se presentan los productos culturales, tales como el videojuego, como medio artístico, así como por las grandes inversiones que genera o sus posibilidades educativas, han hecho que haya recibido especial atención en los últimos años.

Los estudios sobre comunicación política que aluden a la estrecha relación entre los medios y la política. El tratamiento y la cobertura de los medios de comunicación sobre cuestiones electorales, tanto en el entorno online como offline, cobra especial importancia.

Los estudios sobre medios y contenidos, con Internet como eje transversal, han provocado un nuevo panorama mediático. Los cambios sufridos por las dinámicas en los sistemas de distribución y de consumo de productos audiovisuales, los estudios sobre los efectos de los medios, la evolución del consumo y los hábitos de recepción.

Los estudios sobre comunicación en las organizaciones y publicidad han seguido siendo un foco de atención para los investigadores que se esfuerzan por conocer el futuro de la comunicación en el seno de las organizaciones (Benavides, 2012).

Los estudios de género y los estudios sobre comunicación ydesarrollo son también áreas de interés destacadas, con especial protagonismo en los últimos años.

Aparte de las líneas abordadas por las grandes asociaciones, y de acuerdo con Caffarel et al. (2018:63), según los resultados de la 
aplicación del método Phillip 66 en el contexto de la primera fase del proyecto MAPCOM, se establece que, después de analizar el repositorio de tesis doctorales y proyectos de investigación, de todo el universo disponible entre 2007-2014 (Caffarel et al. 2017), un 56,64\% de los proyectos de investigación tienen por objeto el estudio de los medios de comunicación de masas, el análisis de las organizaciones ocupa el segundo lugar con un 16,16\%, en tercera posición los trabajos que analizan la comunicación interpersonal, con un 8\%. Los autores observaron diferencias significativas en los objetos de estudio entre tesis doctorales y proyectos de investigación, siendo más frecuente que estos últimos aborden el estudio de organizaciones, frente a las tesis doctorales, más proclives al estudio de la comunicación grupal y/o interpersonal.

Por su parte, visto el panorama, Caffarel et al. (2018:66), proponen que "se requiere renovar los objetos de estudio y aventurar la exploración fuera de la zona de confort de metodologías «tradicionales» y objetos «conocidos»".

Por otra parte, según Nicolás et al. (2019), en el abordaje de los artículos científicos, sí parece existir una progresiva diversificación de los objetos de estudio, destacando los trabajos sobre contenidos mediáticos, el decaimiento de la investigación teórica y la desatención a las empresas, profesionales, mercados, políticas públicas, etc.

También Rodríguez et al. (2018) abundan en que, en el contexto de los artículos, los datos revelan un nivel conveniente de especialización en los objetos de estudio, consecuencia de un sistema científico que evoluciona en la precisión técnica y temática. No obstante, los propios autores avisan de que un aumento continuado del nivel de especialización puede ser un problema y podría alcanzarse incluso un nivel de excesiva especialización. Del mismo modo, esta mayor diversificación de objetos de estudio en los artículos, no necesariamente puede significar un enriquecimiento de la ciencia de la comunicación, sino una búsqueda apresurada de algo que publicarpor parte de los autores, cada día más presionados por obtener resultados en términos de publicaciones. 


\subsection{Metodologías de investigación}

La investigación comunicativa española no parece haber alcanzado, hasta hace poco tiempo, el nivel de rigor metodológico exigible. Castillo, Almansa y Álvarez Nobell (2013) constataban que el porcentaje de los "artículos sin ningún tipo de referencia textual de metodología pasaba del 26,1\% para el conjunto de la muestra en 2000 al 15,0\% en 2012. Martínez y Saperas (2016) observaron también que alrededor del $20 \%$ de la investigación empírica publicada por cinco revistas académicas españolas, entre 2018 y 2014, presentaba este tipo de deficiencias.

No obstante, la investigación en comunicación en España parece haberse acercado en los últimos años, a los estándares establecidos por la comunidad científica para garantizar la validez del conocimiento.

En relación a las metodologías de investigación, según Caffarel et al. (2018), los proyectos de investigación presentan una preponderancia de metodologías documentales y descriptivas, frente a las experimentales y/o de intervención. Esta pauta en las metodologías predominantes se repite en las tesis doctorales. Se precisa pues la introducción activa y urgente de metodologías de contraste de hipótesis, no solo descriptivas sino exploratorias, prospectivas e incluso experimentales.

Por su parte, Nicolás et al., (2019) concluyen ante una evidente mejora paulatina de la calidad metodológica de los trabajos publicados, que las tendencias observadas son discutibles. Así, según los autores, es posible que la mayor presencia de los estudios cuantitativos de contenidos, sobre todo, obedezca a motivos meramente pragmáticos, dada la mayor facilidad de acceso a estos análisis, y por eso, según Rodríguez et al. (2018), el número de artículos científicos en el área de la comunicación se ha duplicado. Para estos autores, el hecho de que el análisis de contenido sea el método más recurrente entre los investigadores, parece evidenciar el restringido uso de las encuestas y de otras formas de recoger la información.

En resumen, la investigación en comunicación en los últimos años, se caracteriza por ser intensiva y mezclar la excelencia con la cuestionable rigurosidad científica. No obstante, se camina hacia el perfeccionamiento de instrumentos de recopilación y análisis de datos, 
con nuevas técnicas aun incipientes en cuanto a uso y desarrollo efectivo, mostrándose, además, una clara tendencia hacia la especialización de los objetos de estudio.

\section{Los programas de doctorado en comunicación en España}

En esta parte del trabajo se pretende mostrar el conjunto de los programas de doctorado que existen en el contexto de las universidades españolas, vinculadas de manera directa o indirecta con los estudios de comunicación, a raíz de los cambios legislativos producidos en el Real Decreto 99/2011.

La transformación de los estudios de doctorado en España, para adaptarse a las directrices del Espacio Europeo de Educación Superior, no ha estado exenta de dificultades y ha conllevado una nueva forma de generar investigación. Para Jiménez (2017), el objetivo de armonizar la formación doctoral con las directrices europeas de internacionalización delimita una nueva estructura organizativa, apoyada en los grupos de investigación, y que requiere el cumplimiento de una serie de requisitos de excelencia no exigidos hasta ahora.

La intención en esta parte, no es solo mostrar el número y nivel de especialización de los programas en materia de comunicación, sino también aportar una panorámica sobre las principales líneas de investigación desarrolladas en los mismos.

Para tal fin, se ha realizado un análisis de todos los programas de doctorado existentes en España sobre comunicación. Se ha recurrido a la base de datos del Ministerio de Educación, QEDU (Qué Estudiar y Dónde en la Universidad) (https://www.educacion.gob.es/notasdecorte/compBdDo).

Esta aplicación ofrece oficialmente información de títulos y universidades en España. Los títulos disponibles son Estudios Oficiales que han sido verificados por el Consejo de Universidades y las programaciones conjuntas de los mismos.

Se ha realizado una búsqueda relativa a todo el territorio nacional, aplicando como primera variable, el nivel de estudios: doctorados en el ámbito de estudios de las ciencias sociales y jurídicas, y como segunda variable, filtrando solo los programas relativos a comunicación. 
Los resultados arrojaron 42 universidades con programas de doctorado en comunicación en España (Tabla 2). En esta tabla se pueden ver las universidades y centros de los que dependen, sus denominaciones concretas, el tipo de estudio (público o privado) y los principales descriptores de las líneas de investigación recogidas en sus memorias de verificación. La información sobre las líneas de investigación se obtuvo en una segunda fase, en la que se accedió a cada una de las memorias de verificación o información oficial publicada en los sitios webs de cada programa. De esas líneas se extrajeron los indicadores claves, para así tener una visión clara de las principales líneas de trabajo de cada programa.

Tabla 2. Universidades, programas y sus líneas de investigación en España.

\begin{tabular}{|c|c|c|c|}
\hline Universidad & Centro & Denominación & Líneas de investigación \\
\hline $\begin{array}{l}\text { Universidad } \\
\text { Complutense } \\
\text { de Madrid }\end{array}$ & $\begin{array}{l}\text { Facultad de } \\
\text { Ciencias de } \\
\text { la } \\
\text { Información }\end{array}$ & $\begin{array}{l}\text { Doctorado en } \\
\text { Periodismo }\end{array}$ & 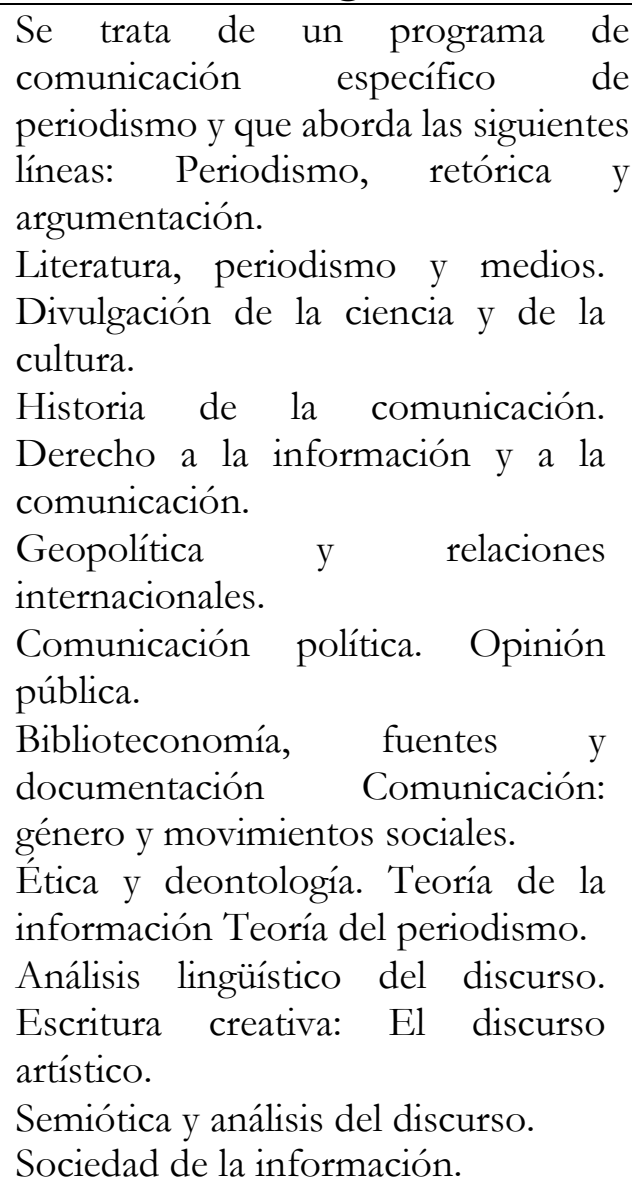 \\
\hline
\end{tabular}




\begin{tabular}{|c|c|c|c|}
\hline & & & $\begin{array}{l}\text { Organización y gestión de la empresa } \\
\text { de comunicación. } \\
\text { Economía, finanzas e investigación de } \\
\text { mercados. } \\
\text { Tecnologías emergentes. } \\
\text { Big data, programación y periodismo } \\
\text { investigativo. } \\
\text { Comunicación } \\
\text { Periodismo audiovisual. } \\
\text { Medios de comunicación. } \\
\text { Estructuras de la comunicación. }\end{array}$ \\
\hline $\begin{array}{l}\text { Universidad } \\
\text { de Alcalá }\end{array}$ & $\begin{array}{l}\text { Escuela de } \\
\text { Doctorado } \\
\text { de la } \\
\text { Universidad } \\
\text { de Alcalá }\end{array}$ & $\begin{array}{l}\text { Doctorado en } \\
\text { Comunicación, } \\
\text { Información y } \\
\text { Tecnología en la } \\
\text { Sociedad en Red }\end{array}$ & $\begin{array}{l}\text { Programa que aglutina a las ciencias de } \\
\text { la información y la documentación con } \\
\text { la comunicación, abordando las } \\
\text { siguientes líneas: } \\
\text { Ciencia de la Web y Sociedad en Red. } \\
\text { Comunicación digital e interactiva. } \\
\text { Documentación digital. }\end{array}$ \\
\hline $\begin{array}{l}\text { Universidad } \\
\text { de A Coruña }\end{array}$ & $\begin{array}{l}\text { Escuela } \\
\text { Internacional } \\
\text { de } \\
\text { Doctorado } \\
\text { de la } \\
\text { Universidad } \\
\text { de A Coruña }\end{array}$ & $\begin{array}{l}\text { Doctorado en } \\
\text { Nuevas } \\
\text { Perspectivas en } \\
\text { Documentación, } \\
\text { Comunicación y } \\
\text { Humanidades }\end{array}$ & $\begin{array}{l}\text { Este programa presenta más de } \\
\text { cincuenta líneas de investigación de las } \\
\text { cuales aproximadamente un tercio } \\
\text { están relacionadas con la comunicación } \\
\text { y el periodismo, tales como las que } \\
\text { siguen: } \\
\text { Prensa escrita y exclusión social de la } \\
\text { mujer. } \\
\text { Televisión y digitalización. } \\
\text { Comunicación y diseño. } \\
\text { Cibercultura y comunicación. } \\
\text { Comunicación organizacional. } \\
\text { Comunicación de crisis. } \\
\text { Comunicación y documentación para } \\
\text { el desarrollo. } \\
\text { Comunicación y grupos sociales. } \\
\text { Comunicación e Innovación } \\
\text { Concentración informativa. } \\
\text { Consumo cultural. } \\
\text { Análisis de productos audiovisuales. } \\
\text { Documentación periodística, } \\
\text { audiovisual y cinematográfica. } \\
\text { Economía de los medios. } \\
\text { Estructura del sector audiovisual. } \\
\text { Formatos y nuevos medios. } \\
\text { Programación en televisión: televisión } \\
\text { digital. } \\
\text { Políticas y diseños en medios de } \\
\text { comunicación. } \\
\text { Producción de comunicación } \\
\text { Promoción y marketing. } \\
\text { Teoría da Comunicación. }\end{array}$ \\
\hline
\end{tabular}




\begin{tabular}{|c|c|c|c|}
\hline & & & $\begin{array}{l}\text { Teoría y metodología de } \\
\text { investigación en comunicación. }\end{array}$ \\
\hline $\begin{array}{l}\text { Universidad } \\
\text { Complutense } \\
\text { de Madrid }\end{array}$ & $\begin{array}{l}\text { Facultad de } \\
\text { Ciencias de } \\
\text { la } \\
\text { Información }\end{array}$ & $\begin{array}{l}\text { Doctorado en } \\
\text { Comunicación } \\
\text { Audiovisual, } \\
\text { Publicidad y } \\
\text { Relaciones } \\
\text { Públicas }\end{array}$ & $\begin{array}{l}\text { Se trata de un programa de } \\
\text { comunicación específico que aborda } \\
\text { todas las líneas, tanto en el ámbito de } \\
\text { los medios como de las } \\
\text { organizaciones, aportando un amplio } \\
\text { panorama que engloba a la } \\
\text { comunicación organizacional y } \\
\text { mediática. } \\
\text { Procesos de creación audiovisual } \\
\text { Teoría, análisis y estética de los } \\
\text { textos. } \\
\text { Narrativa audiovisual, hipermedia y } \\
\text { publicitaria. } \\
\text { Tendencias artísticas y estéticas en la } \\
\text { comunicación. } \\
\text { Gestión económica y social de la } \\
\text { producción de contenidos. } \\
\text { Cultura digital en el audiovisual y la } \\
\text { publicidad. } \\
\text { Aspectos jurídicos y éticos de la } \\
\text { comunicación. } \\
\text { Las relaciones internacionales en la } \\
\text { comunicación. } \\
\text { Diagnóstico, evaluación y gestión de } \\
\text { intangibles. } \\
\text { Procesos de planificación de la } \\
\text { comunicación. } \\
\text { Aplicación de la comunicación } \\
\text { audiovisual y de las organizaciones } \\
\text { Formación y perfiles profesionales. } \\
\text { Tecnologías audiovisuales. } \\
\text { Historia de la comunicación. Gestión } \\
\text { del patrimonio audiovisual y } \\
\text { publicitario. } \\
\text { Procesos de interacción y recepción. } \\
\text { Fundamentos de la eficacia de la } \\
\text { comunicación. } \\
\text { Efectos de los medios para las } \\
\text { organizaciones. } \\
\text { Cultura y consumo de masas. }\end{array}$ \\
\hline $\begin{array}{l}\text { Universidad } \\
\text { Carlos III de } \\
\text { Madrid }\end{array}$ & $\begin{array}{l}\text { Escuela de } \\
\text { Doctorado } \\
\text { de la } \\
\text { Universidad } \\
\text { Carlos III de } \\
\text { Madrid }\end{array}$ & $\begin{array}{l}\text { Doctorado en } \\
\text { Investigación en } \\
\text { Medios de } \\
\text { Comunicación }\end{array}$ & $\begin{array}{l}\text { Se trata de un programa de } \\
\text { comunicación específico que aborda } \\
\text { las siguientes líneas: } \\
\text { Efectos de los medios. } \\
\text { El futuro de la profesión periodística. } \\
\text { Estudios fílmicos y televisivos. } \\
\text { Economía política de los medios } \\
\text { Audiovisuales. }\end{array}$ \\
\hline
\end{tabular}




\begin{tabular}{|c|c|c|c|}
\hline & & & $\begin{array}{l}\text { Innovación mediática en entornos } \\
\text { digitales. } \\
\text { Medios de comunicación y sociedad. } \\
\text { Tendencias de los medios. Ética, } \\
\text { deontología. }\end{array}$ \\
\hline $\begin{array}{l}\text { Universidad } \\
\text { Cardenal } \\
\text { Herrera-CEU }\end{array}$ & $\begin{array}{l}\text { CEU Escuela } \\
\text { Internacional } \\
\text { de } \\
\text { Doctorado } \\
\text { (CEINDO) }\end{array}$ & $\begin{array}{l}\text { Doctorado en } \\
\text { Comunicación } \\
\text { Social }\end{array}$ & \begin{tabular}{ll} 
Se trata de un programa de \\
comunicación específico que aborda \\
las siguientes líneas: \\
\multicolumn{3}{l}{ Sociedad Digital, Comunicación y } \\
Públicos Vulnerables. \\
Comunicación, Esfera Pública y \\
Ciudadanía. \\
Comunicación Especializada. \\
Innovación y Tecnologías.
\end{tabular} \\
\hline $\begin{array}{l}\text { Universidad } \\
\text { Autónoma de } \\
\text { Barcelona }\end{array}$ & $\begin{array}{l}\text { Escuela de } \\
\text { Doctorado } \\
\text { de la } \\
\text { Universidad } \\
\text { Autónoma } \\
\text { de Barcelona }\end{array}$ & $\begin{array}{l}\text { Doctorado en } \\
\text { Comunicación } \\
\text { Estratégica, } \\
\text { Publicidad y } \\
\text { Relaciones } \\
\text { Públicas }\end{array}$ & $\begin{array}{l}\text { Se trata de un programa de } \\
\text { comunicación específico que aborda } \\
\text { las siguientes líneas: } \\
\text { Análisis Instrumental de la } \\
\text { Comunicación. } \\
\text { Investigación experimental orientada } \\
\text { a la comunicación publicitaria. } \\
\text { Marketing, imagen de marca, } \\
\text { brandequity y comportamiento del } \\
\text { consumidor. } \\
\text { Publicidad sonora y nuevos formatos. } \\
\text { Análisis de los formatos publicitarios. } \\
\text { Historia de la radio y su publicidad. } \\
\text { Psicología, Publicidad } \\
\text { Comunicación. } \\
\text { Creatividad publicitaria. Diseño } \\
\text { gráfico. } \\
\text { Investigación experimental orientada } \\
\text { a la eficacia comunicativa. } \\
\text { Publicidad social. Representación de } \\
\text { la diversidad. sociocultural en la } \\
\text { publicidad. }\end{array}$ \\
\hline $\begin{array}{l}\text { Universidad } \\
\text { Autónoma de } \\
\text { Barcelona }\end{array}$ & $\begin{array}{l}\text { Escuela de } \\
\text { Doctorado } \\
\text { de la } \\
\text { Universidad } \\
\text { Autónoma } \\
\text { de Barcelona }\end{array}$ & $\begin{array}{l}\text { Doctorado en } \\
\text { Medios, } \\
\text { Comunicación y } \\
\text { Cultura }\end{array}$ & $\begin{array}{l}\text { Se trata de un programa de } \\
\text { comunicación específico que aborda } \\
\text { las siguientes líneas: } \\
\text { Análisis crítico del discurso. } \\
\text { Sub-línea: periodismo de conflictos. } \\
\text { Antropología de la comunicación. } \\
\text { Comunicación política y opinión } \\
\text { pública. } \\
\text { Economía de la empresa mediática. } \\
\text { Estructuras y políticas de } \\
\text { comunicación. } \\
\text { Sub-línea: Economía política de la } \\
\text { información, la comunicación y la } \\
\text { cultura. } \\
\text { Ética. }\end{array}$ \\
\hline
\end{tabular}




\begin{tabular}{|c|c|c|c|}
\hline & & & $\begin{array}{l}\text { Género, comunicación y medios } \\
\text { Periodismo, literatura. } \\
\text { Teorías de la sociedad de la } \\
\text { información. } \\
\text { Sub-línea: Internet, sociedad y análisis } \\
\text { prospectiva. } \\
\text { Sub-línea: Metodología de la } \\
\text { investigación en comunicación. }\end{array}$ \\
\hline $\begin{array}{l}\text { Universidad } \\
\text { Autónoma de } \\
\text { Barcelona }\end{array}$ & $\begin{array}{l}\text { Escuela de } \\
\text { Doctorado } \\
\text { de la } \\
\text { Universidad } \\
\text { Autónoma } \\
\text { de Barcelona }\end{array}$ & $\begin{array}{l}\text { Doctorado en } \\
\text { Comunicación y } \\
\text { Periodismo }\end{array}$ & $\begin{array}{l}\text { Se trata de un programa de } \\
\text { comunicación específico que aborda } \\
\text { las siguientes líneas: } \\
\text { Contenidos audiovisuales. Estructura } \\
\text { y políticas de comunicación. } \\
\text { Comunicación aplicada. Contenidos y } \\
\text { estudios culturales Periodismo. } \\
\text { Laboratorio de Periodismo y } \\
\text { Comunicación. }\end{array}$ \\
\hline $\begin{array}{l}\text { Universidad } \\
\text { Autónoma de } \\
\text { Barcelona }\end{array}$ & $\begin{array}{l}\text { Escuela de } \\
\text { Doctorado } \\
\text { de la } \\
\text { Universidad } \\
\text { Autónoma } \\
\text { de Barcelona }\end{array}$ & $\begin{array}{l}\text { Doctorado en } \\
\text { Comunicación } \\
\text { Audiovisual y } \\
\text { Publicidad }\end{array}$ & $\begin{array}{l}\text { Se trata de un programa de } \\
\text { comunicación específico que aborda } \\
\text { las siguientes líneas: } \\
\text { Comunicación corporativa y } \\
\text { publicitaria. } \\
\text { Comunicación interactiva. } \\
\text { Comunicación y deporte. } \\
\text { Comunicación y género. } \\
\text { Comunicación y salud. } \\
\text { Estudios cinematográficos. } \\
\text { Estudios de audiencia. } \\
\text { Estudios televisivos y publicitarios } \\
\text { Historia de los medios. } \\
\text { Interculturalidad, migraciones y } \\
\text { diásporas. } \\
\text { Investigación experimental en imagen, } \\
\text { sonido y síntesis. } \\
\text { Políticas de comunicación, estructura } \\
\text { del sistema. } \\
\text { Programación radiofónica y televisiva. }\end{array}$ \\
\hline $\begin{array}{l}\text { Universidad } \\
\text { de Murcia }\end{array}$ & $\begin{array}{l}\text { Escuela } \\
\text { Internacional } \\
\text { de } \\
\text { Doctorado } \\
\text { de la } \\
\text { Universidad } \\
\text { de Murcia }\end{array}$ & $\begin{array}{l}\text { Doctorado en } \\
\text { Gestión de la } \\
\text { Información y de } \\
\text { la Comunicación } \\
\text { en las } \\
\text { Organizaciones }\end{array}$ & $\begin{array}{l}\text { Este programa es un plan } \\
\text { interdisciplinar que aborda los } \\
\text { ámbitos de la gestión de la } \\
\text { información y la comunicación con } \\
\text { dos líneas a principales } \\
\text { correspondiendo cada una a cada } \\
\text { ámbito. } \\
\text { Gestión y uso de la información. } \\
\text { El ecosistema del contenido digital. }\end{array}$ \\
\hline $\begin{array}{l}\text { Universidad } \\
\text { de Málaga }\end{array}$ & $\begin{array}{l}\text { Facultad de } \\
\text { Ciencias de }\end{array}$ & $\begin{array}{l}\text { Doctorado en } \\
\text { Educación y }\end{array}$ & $\begin{array}{l}\text { Aunque este programa se haya a } \\
\text { medio camino entre la educación, la }\end{array}$ \\
\hline
\end{tabular}




\begin{tabular}{|c|c|c|c|}
\hline & $\begin{array}{l}\text { la } \\
\text { Comunicación }\end{array}$ & $\begin{array}{l}\text { Comunicación } \\
\text { Social }\end{array}$ & $\begin{array}{l}\text { psicología y la comunicación, las } \\
\text { líneas que se desarrollan desde la } \\
\text { facultad de comunicación abordan } \\
\text { aspectos sustanciales de la } \\
\text { comunicación: } \\
\text { Innovación en Comunicación Social: } \\
\text { Periodismo, Comunicación } \\
\text { Audiovisual, y Publicidad y } \\
\text { Relaciones Públicas. }\end{array}$ \\
\hline $\begin{array}{l}\text { Universidad } \\
\text { de Málaga }\end{array}$ & $\begin{array}{l}\text { Escuela de } \\
\text { Doctorado } \\
\text { de la } \\
\text { Universidad } \\
\text { de Málaga }\end{array}$ & $\begin{array}{l}\text { Doctorado en } \\
\text { Comunicación }\end{array}$ & $\begin{array}{l}\text { Se trata de un programa de } \\
\text { comunicación específico que aborda } \\
\text { las siguientes líneas: } \\
\text { Comunicación Audiovisual. } \\
\text { Publicidad y Relaciones Públicas. } \\
\text { Periodismo. } \\
\text { Educomunicación. } \\
\text { Comunicación, Industrias Culturales } \\
\text { y Espectáculo. } \\
\text { Comunicación, Literatura, Ética y } \\
\text { Estética. }\end{array}$ \\
\hline $\begin{array}{l}\text { Universidad } \\
\text { de Huelva }\end{array}$ & $\begin{array}{l}\text { Escuela de } \\
\text { Doctorado } \\
\text { de la } \\
\text { Universidad } \\
\text { de Huelva }\end{array}$ & $\begin{array}{l}\text { Doctorado en } \\
\text { Comunicación }\end{array}$ & $\begin{array}{l}\text { Se trata de un programa de } \\
\text { comunicación específico que aborda } \\
\text { las siguientes líneas: } \\
\text { Comunicación Audiovisual } \\
\text { Publicidad y Relaciones Públicas. } \\
\text { Periodismo. } \\
\text { Educomunicación. } \\
\text { Comunicación, Industrias Culturales } \\
\text { y Espectáculo. } \\
\text { Comunicación, Literatura, Ética y } \\
\text { Estética. }\end{array}$ \\
\hline $\begin{array}{l}\text { Universidad } \\
\text { de } \\
\text { Extremadura }\end{array}$ & $\begin{array}{l}\text { Escuela } \\
\text { Internacional } \\
\text { de Postgrado } \\
\text { de la } \\
\text { Universidad } \\
\text { de } \\
\text { Extremadura }\end{array}$ & $\begin{array}{l}\text { Doctorado en } \\
\text { Información y } \\
\text { Comunicación }\end{array}$ & $\begin{array}{l}\text { Este programa se erige nuevamente } \\
\text { como una apuesta interdisciplinar } \\
\text { entre las ciencias de la información y } \\
\text { la documentación, y la propia } \\
\text { comunicación, destacando las líneas } \\
\text { que se abordan en el ámbito de la } \\
\text { comunicación. } \\
\text { Gestión estratégica de la } \\
\text { comunicación en entornos públicos y } \\
\text { privados. } \\
\text { Estructuras y procesos narrativos de } \\
\text { la comunicación audiovisual: } \\
\text { aspectos estéticos, culturales, } \\
\text { económicos e influencias sociales, } \\
\text { éticas y jurídicas. }\end{array}$ \\
\hline $\begin{array}{l}\text { Universidad } \\
\text { de Cádiz }\end{array}$ & $\begin{array}{l}\text { Escuela de } \\
\text { Doctorado } \\
\text { de la } \\
\text { Universidad } \\
\text { de Cádiz }\end{array}$ & $\begin{array}{l}\text { Doctorado en } \\
\text { Comunicación }\end{array}$ & $\begin{array}{l}\text { Se trata de un programa de } \\
\text { comunicación específico que aborda } \\
\text { las siguientes líneas: } \\
\text { Comunicación audiovisual. } \\
\text { Publicidad y relaciones públicas. }\end{array}$ \\
\hline
\end{tabular}




\begin{tabular}{|c|c|c|c|}
\hline & & & $\begin{array}{l}\text { Periodismo. Educomunicación. } \\
\text { Comunicación, industrias culturales y } \\
\text { espectáculo. } \\
\text { Comunicación, literatura, ética y } \\
\text { Estética. }\end{array}$ \\
\hline $\begin{array}{l}\text { Universidad } \\
\text { de Burgos }\end{array}$ & $\begin{array}{l}\text { Escuela de } \\
\text { Doctorado } \\
\text { de la } \\
\text { Universidad } \\
\text { de Burgos }\end{array}$ & $\begin{array}{l}\text { Doctorado en } \\
\text { Humanidades y } \\
\text { Comunicación }\end{array}$ & $\begin{array}{l}\text { Este programa es otra apuesta } \\
\text { interdisciplinar entre los estudios de } \\
\text { comunicación y las humanidades, } \\
\text { desarrollando líneas de comunicación } \\
\text { por parte de algunos grupos de } \\
\text { trabajo, tales como el grupo de } \\
\text { Investigación de Comunicación } \\
\text { Audiovisual para el Desarrollo } \\
\text { Económico, Turístico y Empresarial } \\
\text { (CADETE) con estas líneas: } \\
\text { La espectacularización en los medios } \\
\text { de comunicación. } \\
\text { Los discursos audiovisuales y sus } \\
\text { fronteras. } \\
\text { Representación cinematográfica de la } \\
\text { Historia. } \\
\text { Comunicación comercial y gestión } \\
\text { empresarial. } \\
\text { Grupo de investigación de } \\
\text { Comunicación, difusión y publicidad } \\
\text { de la cultura y el patrimonio } \\
\text { (CAYPAT) con estas líneas: } \\
\text { Cultura y patrimonio en los medios de } \\
\text { comunicación social. } \\
\text { Prospectiva de uso de interés en la } \\
\text { cultura del siglo XXI. } \\
\text { Evolución histórica de la difusión de } \\
\text { las humanidades en los medios de } \\
\text { comunicación. }\end{array}$ \\
\hline $\begin{array}{l}\text { Universidad } \\
\text { de Barcelona }\end{array}$ & $\begin{array}{l}\text { Escuela de } \\
\text { Doctorado } \\
\text { de la } \\
\text { Universidad } \\
\text { de Barcelona }\end{array}$ & $\begin{array}{l}\text { Doctorado en } \\
\text { Información y } \\
\text { Comunicación }\end{array}$ & $\begin{array}{l}\text { Nuevamente, este programa es una } \\
\text { apuesta entre las ciencias de la } \\
\text { documentación y la comunicación, } \\
\text { con dos líneas que atienden a cada } \\
\text { ámbito por separado: } \\
\text { Bibliotecas y servicios de información. } \\
\text { Comunicación y medios } \\
\text { audiovisuales. }\end{array}$ \\
\hline $\begin{array}{l}\text { Universidad } \\
\text { Jaume I de } \\
\text { Castellón }\end{array}$ & $\begin{array}{l}\text { Escuela de } \\
\text { Doctorado } \\
\text { de la } \\
\text { Universidad } \\
\text { Jaume I de } \\
\text { Castellón } \\
\end{array}$ & $\begin{array}{l}\text { Doctorado en } \\
\text { Ciencias de la } \\
\text { Comunicación }\end{array}$ & $\begin{array}{l}\text { Se trata de un programa de } \\
\text { comunicación específico que aborda } \\
\text { las siguientes líneas: } \\
\text { Comunicación, publicitad y cultura } \\
\text { digital. }\end{array}$ \\
\hline
\end{tabular}




\begin{tabular}{|c|c|c|c|}
\hline & & & $\begin{array}{l}\text { Narrativas de los relatos } \\
\text { audiovisuales. } \\
\text { Periodismo e industrias culturales y } \\
\text { comunicación política. }\end{array}$ \\
\hline $\begin{array}{l}\text { Universidad } \\
\text { Internacional } \\
\text { de La Rioja }\end{array}$ & $\begin{array}{l}\text { Facultad de } \\
\text { Educación }\end{array}$ & $\begin{array}{l}\text { Doctorado en } \\
\text { Sociedad del } \\
\text { Conocimiento y } \\
\text { Acción en los } \\
\text { Ámbitos de la } \\
\text { Educación, la } \\
\text { Comunicación, } \\
\text { los Derechos y } \\
\text { las Nuevas } \\
\text { Tecnologías }\end{array}$ & $\begin{array}{l}\text { Este programa se plantea desde las } \\
\text { ciencias de la educación, abordando } \\
\text { procesos y líneas de investigación en } \\
\text { comunicación, que enriquecen el } \\
\text { ámbito de la educación. } \\
\text { Se destacan algunas líneas de abordaje } \\
\text { de la comunicación. } \\
\text { La teoría de la comunicación y su } \\
\text { incidencia en la comprensión y } \\
\text { articulación de lo social y en la } \\
\text { estructuración de la acción educativa. } \\
\text { Los contenidos de la comunicación } \\
\text { de masas y las redes sociales. } \\
\text { Información, entretenimiento y } \\
\text { persuasión. } \\
\text { Tecnologías emergentes, } \\
\text { comunicación y educación. }\end{array}$ \\
\hline $\begin{array}{l}\text { Universidad } \\
\text { del País } \\
\text { Vasco/Euskal } \\
\text { HerrikoUnibe } \\
\text { rtsitatea }\end{array}$ & $\begin{array}{l}\text { Escuela de } \\
\text { Doctorado } \\
\text { de la } \\
\text { UPV/EHU }\end{array}$ & $\begin{array}{l}\text { Doctorado en } \\
\text { Comunicación } \\
\text { Social }\end{array}$ & $\begin{array}{l}\text { Se trata de un programa de } \\
\text { comunicación específico que aborda } \\
\text { las siguientes } \\
\text { Ciberperiodismo. } \\
\text { Comunicación y relaciones públicas. } \\
\text { Efectos de los massmedia. } \\
\text { Estrategias corporativas e internet. } \\
\text { Estructura y economía de la } \\
\text { comunicación. } \\
\text { Estudios visuales. } \\
\text { Sociedad de la información. } \\
\text { Teorías de la comunicación y todas } \\
\text { aquellas que tienen que ver con la } \\
\text { comunicación social. }\end{array}$ \\
\hline $\begin{array}{l}\text { Universidad } \\
\text { de Zaragoza }\end{array}$ & $\begin{array}{l}\text { Escuela de } \\
\text { Doctorado } \\
\text { de la } \\
\text { Universidad } \\
\text { de Zaragoza }\end{array}$ & $\begin{array}{l}\text { Doctorado en } \\
\text { Información y } \\
\text { Comunicación }\end{array}$ & $\begin{array}{l}\text { Como viene siendo la tónica, este } \\
\text { programa se erige entre los campos } \\
\text { de la documentación y la } \\
\text { comunicación, abordando líneas } \\
\text { diferentes que ocupan los dos } \\
\text { ámbitos, tales como: } \\
\text { Bibliotecas y servicios de } \\
\text { información. Comunicación y medios } \\
\text { audiovisuales. } \\
\text { Cultura y contenidos digitales } \\
\text { Estudios sobre el valor y el uso de la } \\
\text { Información. }\end{array}$ \\
\hline $\begin{array}{l}\text { Universidad } \\
\text { de Vigo }\end{array}$ & $\begin{array}{l}\text { Facultad de } \\
\text { Filología y } \\
\text { Traducción }\end{array}$ & $\begin{array}{l}\text { Doctorado en } \\
\text { Comunicación } \\
\text { Vigo-Pontevedra }\end{array}$ & $\begin{array}{l}\text { Este programa se imparte tanto en la } \\
\text { facultad de Filología y Traducción } \\
\text { como en la facultad de Comunicación, }\end{array}$ \\
\hline
\end{tabular}




\begin{tabular}{|c|c|c|c|}
\hline & $\begin{array}{l}\text { Facultad de } \\
\text { Ciencias } \\
\text { Sociales y de la } \\
\text { Comunicación }\end{array}$ & & $\begin{array}{l}\text { abordando líneas de comunicación } \\
\text { tales como: Comunicación virtual, } \\
\text { ciberperiodismo e tecnologías de } \\
\text { tradución. } \\
\text { Tradución y comunicación } \\
\text { especializada. } \\
\text { Tradución multimedia. } \\
\text { Literatura, lingǘstica y traducción. } \\
\text { Sociologías de la traducción y la } \\
\text { comunicación, aproximaciones } \\
\text { cualitativas y cuantitativas. } \\
\text { Teoría e historia de la comunicación. } \\
\text { Comunicación de servicio público. } \\
\text { Comunicación organizacional y } \\
\text { relaciones públicas. } \\
\text { Comunicación } \\
\text { ciberperiodismo. }\end{array}$ \\
\hline $\begin{array}{l}\text { Universidad } \\
\text { de Valladolid }\end{array}$ & $\begin{array}{l}\text { Escuela de } \\
\text { Doctorado } \\
\text { de la } \\
\text { Universidad } \\
\text { de Valladolid }\end{array}$ & $\begin{array}{l}\text { Doctorado en } \\
\text { Español: } \\
\text { Lingüística, } \\
\text { Literatura y } \\
\text { Comunicación }\end{array}$ & $\begin{array}{l}\text { El programa aborda de modo } \\
\text { interdisciplinar líneas relativas a la } \\
\text { filología y a la comunicación, } \\
\text { destacando entre las líneas de } \\
\text { investigación las desarrolladas por los } \\
\text { grupos de investigación en } \\
\text { comunicación, tales como: } \\
\text { Grupo de investigación en cultura } \\
\text { digital, innovación, creatividad y } \\
\text { participación social en comunicación: } \\
\text { observatorio del ocio y el } \\
\text { entretenimiento digital (OCENDI). } \\
\text { Grupo de investigación en nuevas } \\
\text { tendencias en comunicación } \\
\text { (NUTECO). }\end{array}$ \\
\hline $\begin{array}{l}\text { Universidad } \\
\text { de Sevilla }\end{array}$ & $\begin{array}{l}\text { Escuela } \\
\text { Internacional } \\
\text { de } \\
\text { Doctorado }\end{array}$ & $\begin{array}{l}\text { Doctorado en } \\
\text { Comunicación }\end{array}$ & $\begin{array}{l}\text { Se trata de un programa de } \\
\text { comunicación específico que aborda } \\
\text { las siguientes líneas: } \\
\text { Comunicación audiovisual Publicidad } \\
\text { y relaciones públicas. } \\
\text { Periodismo. } \\
\text { Educomunicación. } \\
\text { Comunicación, Industrias Culturales y } \\
\text { Espectáculo. } \\
\text { Comunicación, Literatura, Ética y } \\
\text { Estética. }\end{array}$ \\
\hline $\begin{array}{l}\text { Universidad } \\
\text { de Santiago de } \\
\text { Compostela }\end{array}$ & $\begin{array}{l}\text { Facultad de } \\
\text { Ciencias de la } \\
\text { Comunicación }\end{array}$ & $\begin{array}{l}\text { Doctorado en } \\
\text { Comunicación e } \\
\text { Información } \\
\text { Contemporánea }\end{array}$ & $\begin{array}{l}\text { Se trata de un programa de } \\
\text { comunicación específico que aborda } \\
\text { las siguientes líneas: } \\
\text { Estudios audiovisuales. Nuevos } \\
\text { medios. } \\
\begin{array}{l}\text { Ciudadanía y comunicación y } \\
\text { desarrollo. }\end{array}\end{array}$ \\
\hline
\end{tabular}




\begin{tabular}{|c|c|c|c|}
\hline $\begin{array}{l}\text { Universidad } \\
\text { de Navarra }\end{array}$ & $\begin{array}{l}\text { Facultad de } \\
\text { Comunicación }\end{array}$ & $\begin{array}{l}\text { Doctorado en } \\
\text { Comunicación }\end{array}$ & $\begin{array}{l}\text { Se trata de un programa de } \\
\text { comunicación específico que aborda } \\
\text { las siguientes líneas: } \\
\text { Economía, mercados y estructura de } \\
\text { la comunicación. } \\
\text { Comunicación y nuevas tecnologías } \\
\text { Medios y sociedad. } \\
\text { Comunicación estratégica en las } \\
\text { organizaciones. } \\
\text { En la universidad de Navarra existe } \\
\text { además un Doctorado en Creatividad } \\
\text { Aplicada, que aborda de forma } \\
\text { directa una línea de trabajo dirigida al } \\
\text { estudio y aplicación de los procesos } \\
\text { creativos e incluyendo a la creación } \\
\text { audiovisual. }\end{array}$ \\
\hline $\begin{array}{l}\text { UniversitatPol } \\
\text { itècnica de } \\
\text { València }\end{array}$ & $\begin{array}{l}\text { Escuela de } \\
\text { Doctorado } \\
\text { de la } \\
\text { UniversitatP } \\
\text { olitècnica de } \\
\text { València }\end{array}$ & $\begin{array}{l}\text { Doctorado en } \\
\text { Industrias de la } \\
\text { Comunicación y } \\
\text { Culturales }\end{array}$ & $\begin{array}{l}\text { Se trata de un programa de } \\
\text { comunicación específico que aborda } \\
\text { las siguientes líneas: } \\
\text { Patrimonio cultural y sus } \\
\text { innovaciones en las industrias } \\
\text { culturales. } \\
\text { Comunicación digital 2.0. } \\
\text { Social media. } \\
\text { Nueva cultura digital, transparencia y } \\
\text { movimientos abiertos y análisis, } \\
\text { gestión y preservación de datos. } \\
\text { Gestión de información en las } \\
\text { organizaciones. } \\
\text { Estudios fílmicos, de fotografía y su } \\
\text { postproducción digital. }\end{array}$ \\
\hline $\begin{array}{l}\text { Universitat } \\
\text { Internacional } \\
\text { de Catalunya }\end{array}$ & $\begin{array}{l}\text { Escuela de } \\
\text { Doctorado } \\
\text { de la } \\
\text { Universidad } \\
\text { Internacional } \\
\text { de Catalunya }\end{array}$ & $\begin{array}{l}\text { Doctorado en } \\
\text { Comunicación, } \\
\text { Educación y } \\
\text { Humanidades }\end{array}$ & $\begin{array}{l}\text { Programa interdisciplinar entre la } \\
\text { educación, la comunicación y las } \\
\text { humanidades, desarrollando líneas } \\
\text { que recogen cada una de las áreas } \\
\text { citadas: } \\
\text { Investigación en comunicación. } \\
\text { Investigación en educación. } \\
\text { Investigación en humanidades. }\end{array}$ \\
\hline $\begin{array}{l}\text { Universitat de } \\
\text { València } \\
\text { (Estudi } \\
\text { General) }\end{array}$ & $\begin{array}{l}\text { Escuela de } \\
\text { Doctorado } \\
\text { de la } \\
\text { Universitat } \\
\text { de València - } \\
\text { Estudi } \\
\text { General }\end{array}$ & $\begin{array}{l}\text { Doctorado en } \\
\text { Comunicación e } \\
\text { Interculturalidad }\end{array}$ & $\begin{array}{l}\text { Como en casos anteriores, se busca la } \\
\text { interdisciplinariedad entre la } \\
\text { comunicación y las humanidades con } \\
\text { varias líneas específicas en cada } \\
\text { ámbito. } \\
\text { Comunicación y cencia. } \\
\text { Comunicación visual, historia e } \\
\text { imaginario social. } \\
\text { Comunicación, lenguaje y cultura. }\end{array}$ \\
\hline $\begin{array}{l}\text { UniversitatAb } \\
\text { atOliba CEU }\end{array}$ & $\begin{array}{l}\text { CEU Escuela } \\
\text { Internacional } \\
\text { de }\end{array}$ & $\begin{array}{l}\text { Doctorado en } \\
\text { Comunicación } \\
\text { Social }\end{array}$ & $\begin{array}{l}\text { Se trata de un programa de } \\
\text { comunicación específico que aborda } \\
\text { las siguientes líneas: }\end{array}$ \\
\hline
\end{tabular}




\begin{tabular}{|c|c|c|c|}
\hline & $\begin{array}{l}\text { Doctorado } \\
\text { (CEINDO) }\end{array}$ & & $\begin{array}{l}\text { Sociedad digital, comunicación y } \\
\text { públicos vulnerables. } \\
\text { Comunicación, esfera pública y } \\
\text { ciudadanía. } \\
\begin{array}{l}\text { Comunicación especializada, } \\
\text { innovación y tecnologías. }\end{array}\end{array}$ \\
\hline $\begin{array}{l}\text { Universidad } \\
\text { San Pablo- } \\
\text { CEU }\end{array}$ & $\begin{array}{l}\text { CEU Escuela } \\
\text { Internacional } \\
\text { de } \\
\text { Doctorado } \\
\text { (CEINDO) }\end{array}$ & $\begin{array}{l}\text { Doctorado en } \\
\text { Comunicación } \\
\text { Social }\end{array}$ & $\begin{array}{l}\text { Se trata de un programa de } \\
\text { comunicación específico que aborda } \\
\text { las siguientes líneas: } \\
\text { Sociedad digital, comunicación y } \\
\text { públicos vulnerables. } \\
\text { Comunicación, esfera pública y } \\
\text { ciudadanía. especializada, } \\
\text { Comunicación a } \\
\text { innovación y tecnologías. }\end{array}$ \\
\hline $\begin{array}{l}\text { Universidad } \\
\text { Rovira i Virgili }\end{array}$ & $\begin{array}{l}\text { Escuela de } \\
\text { Posgrado } \\
\text { Universidad } \\
\text { Rovira i } \\
\text { Virgili } \\
\end{array}$ & $\begin{array}{l}\text { Doctorado en } \\
\text { Antropología y } \\
\text { Comunicación }\end{array}$ & $\begin{array}{l}\text { Programa interdisciplinar con } \\
\text { antropología, pero desarrollando, no } \\
\text { obstante, alguna línea de } \\
\text { comunicación específica centrada en } \\
\text { la comunicación y el riesgo. }\end{array}$ \\
\hline $\begin{array}{l}\text { Universidad } \\
\text { Ramón Llull }\end{array}$ & $\begin{array}{l}\text { Facultat de } \\
\text { Comunicación } \\
\text { y relaciones } \\
\text { Internacionales } \\
\text { Blanquerna. }\end{array}$ & $\begin{array}{l}\text { Doctorado en } \\
\text { Comunicación }\end{array}$ & $\begin{array}{l}\text { Se trata de un programa de } \\
\text { comunicación específico que aborda } \\
\text { las siguientes líneas: } \\
\text { Sociología de la comunicación. } \\
\text { Comunicación empresarial. } \\
\text { Cine y televisión. Tecnología y } \\
\text { comunicación. } \\
\text { Periodismo, política y democracia. } \\
\text { Relaciones internacionales. }\end{array}$ \\
\hline $\begin{array}{l}\text { Universidad } \\
\text { Pompeu } \\
\text { Fabra }\end{array}$ & $\begin{array}{l}\text { Escuela de } \\
\text { Doctorado } \\
\text { de la } \\
\text { Universidad } \\
\text { Pompeu } \\
\text { Fabra }\end{array}$ & $\begin{array}{l}\text { Doctorado en } \\
\text { Comunicación }\end{array}$ & $\begin{array}{l}\text { Se trata de un programa de } \\
\text { comunicación específico que aborda } \\
\text { las siguientes líneas: } \\
\text { CAS: comunicación y publicitad. } \\
\text { CINEMA: estética de los medios } \\
\text { audiovisuales. } \\
\text { GRP: ética y excelencia en el } \\
\text { periodismo, periodismo, política e } \\
\text { historia, análisis del periodismo en } \\
\text { Internet. } \\
\text { DIGIDOC: documentación digital; } \\
\text { comunicación interactiva. } \\
\text { GRECC: comunicación científica. } \\
\text { JOVIS.com: Juventud, cultura, } \\
\text { movimientos sociales, participación. } \\
\text { historia y epistemología; política } \\
\text { pública, educación y mercado laboral; } \\
\text { Comunicación digital y competencia } \\
\text { mediática. } \\
\text { POLCOM: comunicación Política, } \\
\text { medios y democracia. }\end{array}$ \\
\hline
\end{tabular}




\begin{tabular}{|l|l|l|}
\hline & $\begin{array}{l}\text { UNICA: comunicación política y } \\
\text { audiovisual, producción audiovisual; } \\
\text { políticas de comunicación en la era } \\
\text { digital, televisión, comunicación e } \\
\text { interculturalitad, comunicación y } \\
\text { grupos de influencia; narrativas } \\
\text { transmedia/alfabetismo mediático. } \\
\text { MEDIUM: cultura pop, discursos } \\
\text { sociales, transmedia y media evolution. } \\
\text { CRITICC: comunicación y grupos de } \\
\text { influencia, género, comunicación } \\
\text { intercultural, historia crítica de la } \\
\text { comunicación estratégica, estudios } \\
\text { críticos sobre animales y ética } \\
\text { ambiental, comunicación } \\
\text { interpersonal, etnometodología y } \\
\text { análisis del discurso. }\end{array}$ \\
\hline
\end{tabular}

Fuente: elaboración propia.

Según los datos arrojados inicialmente por la base de datos, de estas 42 universidades se han eliminado seis programas que aunque en su denominación tenían el término "comunicación" no abordaban líneas de investigación que contribuyeran al desarrollo de las ciencias de la comunicación, tales como la Universidad de Alicante con su Doctorado en Estudios Históricos y Sociales sobre Ciencia, Medicina y Comunicación Científica, en el que, de las cinco líneas propuestas, la más cercana solo abordaba el entorno de la investigación en comunicación científica, circulación del conocimiento y periodismo científico y médico.

La Universidad de Málaga y su Doctorado en Educación y Comunicación Social que se imparte en las facultades de Educación y Comunicación, siendo las líneas que se abordan en la facultad de Educación nada coincidentes con las ciencias de la comunicación.

Universidad de Barcelona y su programa de doctorado en Psicología de la Comunicación y Cambio. Este programa aborda la comunicación como parte de los procesos psicológicos, y no desarrolla claramente determinadas líneas de investigación en comunicación.

Universitat de València (Estudi General) y su programa de Doctorado en Estudios Históricos y Sociales sobre Ciencia, Medicina y Comunicación Científica, que no aporta conocimiento directo al de las ciencias de la comunicación, aunque abunda en el tema de la comunicación científica. 
Universidad Miguel Hernández de Elche y su programa de Doctorado en Estudios Históricos y Sociales sobre Ciencia, Medicina y Comunicación Científica, tampoco aborda directamente líneas de comunicación aparte de la comunicación científica.

Universidad Autónoma de Barcelona, con el programa de Doctorado en Psicología de la Comunicación y Cambio, que no aborda sustancialmente líneas de trabajo en el ámbito de la comunicación.

Por tanto, después del filtrado inicial, resultó un corpus de 36 programas de doctorado en comunicación. Entre estos, se destacan los programas interuniversitarios en los que las líneas de trabajo son las mismas en diferentes universidades, como es el caso del programa de Doctorado en Comunicación, impartido en la Universidades de Málaga, Universidad de Sevilla, Universidad de Huelva y Universidad de Cádiz.

El otro programa interuniversitario, denominado igualmente Doctorado en Comunicación, es el que se desarrolla en las universidades de Vigo y Pontevedra.

La mayoría de los programas dependen de las escuelas de postgrado y solo unos pocos programas parecen depender directamente de las facultades.

Todos los programas son públicos, menos el caso de las universidades siguientes, que son privados: Universidad Ramón Llull, Universidad San Pablo-CEU, UniversitatAbatOliba CEU, Universitat Internacional de Catalunya, Universidad de Navarra, Universidad Internacional de La Rioja, Universidad Cardenal Herrera-CEU.

El análisis inicial de los programas de doctorado permite observar una notable interdisciplinaridad.

Cinco programas de los 36 mantienen una sinergia equitativa con las Ciencias de la Información y la Documentación, abordada desde los ámbitos de la gestión de la información, la documentación y la biblioteconomía, en mayor o menor grado. 
Así los programas que responden a esta particularidad son los de la Universidad de Zaragoza (Doctorado en Información y Comunicación), Universidad de Alcalá (Doctorado en Comunicación, Información y Tecnología en la Sociedad en Red), Universidad de A Coruña (Doctorado en Nuevas Perspectivas en Documentación, Comunicación y Humanidades), Universidad de Barcelona (Doctorado en Información y Comunicación), Universidad de Extremadura (Doctorado en Información y Comunicación), Como nota añadida, decir que el doctorado en Periodismo de la UCM contempla entre sus líneas una referida a la documentación.

Por otra parte, existe un programa que aúna los saberes de comunicación con la antropología (Universidad Rovira i Virgili, Doctorado en Antropología y Comunicación) y otro con la filología (Universidad de Valladolid, Doctorado en Español: Lingüística, Literatura y Comunicación) tres programas buscan sinergias con las humanidades (Universidad de Burgos, Doctorado en Humanidades y Comunicación, Universitat Internacional de Catalunya, Doctorado en Comunicación, Educación y Humanidades; Universitat de València, Estudi General, Doctorado en Comunicación e Interculturalidad) y dos con la educación (Universidad Internacional de La Rioja, Doctorado en Sociedad del Conocimiento y Acción en los Ámbitos de la Educación, la Comunicación, los Derechos y las Nuevas Tecnologías y la Universidad de Málaga, Doctorado en Educación y Comunicación Social).

Aunque la comunicación es un ámbito interdisciplinar, el Número de programas de doctorado específicos de comunicación, y que contribuyen directamente al corpus de las ciencias de la comunicación es el más numeroso, con 22 programas específicos, de los cuales, solo uno se refiere explícitamente en su denominación al periodismo, siendo la denominación más frecuente Doctorado en Comunicación.

Solo aquellas universidades más antiguas en los estudios de comunicación descienden a un nivel mayor de especialización en torno a las diferencias entre, periodismo, comunicación audiovisual y publicidad y relaciones públicas, como son las UCM y la UAB. 
Existe, además, dentro del contexto de los programas de la Universidad de Navarra un doctorado en creatividad, que no fue arrojado por la base de datos inicialmente, pero que se incorporó dado que abordaba la creatividad audiovisual.

En cuanto a las líneas de investigación, se aprecia que algunos programas desglosan mucho sus líneas, mientras que otros las engloban en grandes bloques.

En cualquier caso, se aprecia la notable especialización de la se hablaba en la primera parte de este trabajo. En términos generales, es frecuente ver líneas muy específicas de los entornos de la comunicación, tales como la historia de los medios, la ética, los estudios de recepción y efectos, los estudios de género, las nuevas tecnologías de la comunicación, la opinión pública, la comunicación política, periodismo, la teoría de la comunicación, la comunicación digital e interactiva, la economía de la comunicación, la comunicación audiovisual, los medios, las estructuras de la comunicación, la programación, la producción o la cibercultura, combinadas con líneas que abordan cada vez más la comunicación aplicada a las organizaciones, en el ámbito de la publicidad y las relaciones públicas, destacando la comunicación estratégica y la comunicación de crisis.

Es frecuente, además, que en los programas específicos de comunicación aparezcan algunas líneas más trasversales y cercanas a la filología, las humanidades, la educación, la documentación, y otros ámbitos como la sociología, la psicología y la antropología, que han sido, por otra parte, ciencias que han convivido con la comunicación desde su nacimiento y que se abordan también en programas de doctorado ya citados aquí y menos específicos de comunicación.

Es por otra parte evidente que, aunque los programas se aborden desde distintas ciencias, las líneas de investigación en comunicación aparecen diferenciadas claramente de las otras.

\section{Conclusión}

En este trabajo se aprecia que la interdisciplinariedad en el entorno de la comunicación es evidente, pero que la tendencia hacia la especialización y, sobre todo, la especificación de los parámetros que 
rigen la investigación en comunicación (en cuando a métodos y técnicas de trabajo) son cada día más sólidos. Se adivina que el estado de la investigación en España necesita madurar y consolidarse en trabajos académicos excelentes, que permitan realmente el avance social y no la acumulación de artículos.

Aunque la proliferación de investigaciones en los últimos años, no necesariamente permita mejorar el número de trabajos excelentes, contribuirá necesariamente a que convivan trabajos de menor empaque con otros trabajos mejores, que de otra manera igual no hubieran surgido, si no es por la presión investigadora actual.

Se estima oportuno virar hacia nuevos objetos y métodos que aporten conocimiento real a la sociedad y permitan entrar en la liga de honor de las ciencias y las publicaciones de mayor impacto.

Hay varios factores que parecen haber influido en este panorama: el contexto académico actual con la presión por publicar, la necesidad de romper con la desidia metodológica de años atrás, la investigación individualizada y no en grupo, la dispersión en grandes líneas de investigación, la escasez de recursos para la investigación y el escaso apoyo gubernamental para la financiación de proyectos de investigación relevantes.

Por otra parte, los nuevos programas de doctorado han creado un nuevo marco para la investigación, desarrollada desde los grupos de investigación, y partiendo de unos criterios de excelencia, lo que puede contribuir a la mejora de la investigación en comunicación en España en los próximos años.

A favor, se manifiesta la existencia de programas específicos en comunicación, sin menosprecio de aquellos en los que se convive con otras ciencias como la educación, la filología, las humanidades y la antropología.

No obstante, se sigue viendo una gran dispersión de líneas en algunos de los programas, que denotan una adición de las mismas más que el resultado de la puesta en común y la búsqueda de sinergias entre los grupos. Por otra parte, también hay programas que generalizan en pocas líneas, como resultado, bien de esa puesta en común, o de la de 
voluntad para especificar y complicar así la propia gestión de los programas. En resumen, se constatan algunos hechos tales como, que la especialización convive con la excesiva generalización de líneas de investigación, la falta de innovación en temas y objetos de estudio, la escasez de recursos dedicados a la investigación en comunicación, la necesidad de mejorar en la forma de hacer y publicar los trabajos, la diversidad de programas de doctorado interdisciplinares (donde las líneas de investigación en comunicación aparecen claramente diferenciadas) quizá, más bien fruto de una relación obligada entre grupos, que como resultado de una real interdisciplinaridad temática.

Por último, se adivinan nuevos caminos que se espera sean mejorados y explorados en el futuro. La necesidad de innovar en temas de estudio y objetos de investigación, que a pesar de existir interdisciplinariedad entre los programas de doctorado, no se manifiesta de forma real en las líneas de investigación, el aumento de trabajos que permitan la relación con empresas e instituciones, la realización de estudios aplicados, y la mejora en el uso de métodos y técnicas de investigación. Todo esto, influirá sin duda en el nuevo estándar de publicación en revistas con alto impacto y en la concesión de proyectos de investigación que permitirán la realización de tesis doctorales, cuyos temas de estudio estén vinculados a proyectos, y no meramente a gustos o intereses individuales.

Los factores en contra de este avance parecen ser factores internos y externos, los externos se centran en la presión exterior por parte de organismos como ANECA o CNAI que han contribuido al aumento de trabajos sin que la calidad de los mismos sea necesariamente mejor. Factores legislativos como el cambio en los estudios de doctorado, que han obligado a los grupos de investigación a unirse con otros por razones más administrativas que científicas, y la desatención gubernamental en cuanto a la concesión de proyectos de investigación sobre comunicación.

Como factores internos, pesan en las áreas de comunicación una tradición individualista a la hora de trabajar, una fuerte resistencia al cambio de líneas y temas, una escasez de formación en metodologías de investigación novedosas y de gestión de datos, y un menor tiempo de evolución de esta ciencia en relación a otras áreas de investigación. 


\section{Bibliografía}

Benavides, J. (2012). La investigación en comunicación y publicidad: nuevos temas y problemas Questiones publicitarias, 1(17), 71-93. Disponible en http://www.maecei.es/pdf/n17/articulos/A5 La investigacion en comunicacion y publicidadnuevos temas y problemas.pdf.

Caffarel-Serra, C., Ortega, F. y Gaitán, J. A. (2018). Communication research in Spain: Weaknesses, threats, strengths and opportunities. Comunicar, 26(56), 61-70.

Caffarel-Serra, C., Ortega-Mohedano, F. y Gaitán-Moya, J. A. (2017). Investigación en Comunicación en la universidad española en el período 2007-2014. El profesional de la información, 26(2), 218-227.

Carrillo, M. V., García, M., Tato, J. L. y Castillo, A. (2013). Los retos de la comunicación. México: Pearson.

Esparcia, A. C., Martínez, A. A. y Nobell, A. Á. (2013). Metodología científica en las revistas españolas de comunicación. En Investigar la Comunicación hoy. Revisión de politicas cientificas y aportaciones metodológicas: Simposio Internacional sobre Politica Cientifica en Comunicación (pp. 107-122) Facultad de Ciencias Sociales, Jurídicas y de la Comunicación.

Jiménez-Ramírez, M. (2017). Los nuevos estudios de doctorado en España: avances y retos para su convergencia con Europa. Revista iberoamericana de educación superior, 8(21), 123-137.

Martínez-Nicolás, M., y Saperas-Lapiedra, E. (2016). Objetos de estudio y orientación metodológica de la reciente investigación sobre comunicación en España (2008-2014). Análisis de los trabajos publicados en revistas científicas españolas. Revista Latina de Comunicación Social, (71), 1365-1384.

Nicolás, M. M., Lapiedra, E. S. y Campos, A. C. (2019). La investigación sobre comunicación en España en los últimos 25 años (19902014). Objetos de estudio y métodos aplicados en los trabajos publicados en revistas españolas especializadas. Empiria: Revista de metodología de ciencias sociales(42), 37-69. 
Rodríguez Gómez, E. F., Goyanes, M. y Rosique Cedillo, G. (2018). La investigación en comunicación en España: temporalidad laboral, producción intensiva y competitividad. Communication \& Society, 31 (4) 229-242.

Rodríguez, J. M. P., Von Sprecher, R. y Trenta, M. (2010). Cómics y video juegos. Dos industrias culturales en conexión/comics and video games. Two cultural industries in connection. Área Abierta, 25 . 


\section{Tendencias en Metodología de Investigación en Información y Documentación}

\section{Cristina Faba-Pérez}

Profesora Titular de Información y Documentación. Universidad de Extremadura

\section{Margarita Pérez Pulido}

Profesora Titular de Información y Documentación. Universidad de Extremadura

\section{Resumen}

El objetivo del trabajo es comprobar la evolución que han sufrido los métodos de investigación en la disciplina de Información y Documentación a lo largo de los últimos años, con la finalidad de comprobar si han cambiado, han desaparecido o han surgidométodos nuevos. Para ello, partiendo de investigaciones anteriores que nos permiten contrastar los resultados, en el presente trabajo se analizan las tesis doctorales defendidas durante el periodo 2008/09-2018/19 en los Departamentos de la Universidad española relacionados con la temática investigada. Aunque existen diversos tipos documentales que permiten conocer las tendencias en métodos de investigación, se han escogido las tesis doctorales por considerarse la culminación de la trayectoria investigadora. Las conclusiones presentan un carácter multidisciplinar de la Información y la Documentación debido a su dependencia orgánica como consecuencia de la política universitaria española, que se refleja en la elección y uso de diferentes métodos y técnicas de investigación, la incorporación de algunos nuevos a lo largo del tiempo, y una evolución hacia un equilibrio entre lo cuantitativo y lo cualitativo. 


\section{Introducción}

$\mathrm{N}$

UESTRA disciplina ha sufrido muchos avatares a lo largo del tiempo a pesar de encontrarse todavía en un primer grado de madurez. La consideración de la Biblioteconomía y Documentación, hoy llamada Información y Documentación (denominación que se seguirá en este documento), como ciencia surge en el siglo XIX unida a la profesión, aunque aún hoy todavía se sigue discutiendo sobre su carácter científico o técnico. Atendiendo a los parámetros clásicos de consideración de una disciplina como ciencia, la inicial Biblioteconomía y Documentación los cumple sobradamente, aunque resulta imprescindible, una vez más, establecer las características, los límites, los sujetos, los productos y resultados que ayudan a comprender esta aseveración tan firme.

La cientificidad de una disciplina se justifica por la investigación que se realiza y su resultado, manifestado fundamentalmente en las tesis doctorales, los artículos que se publican y las contribuciones a congresos y demás literatura gris que gira en torno a los campos científicos de pertenencia de sus investigadores. En estos documentos se reflejan los problemas y sus soluciones desde un punto de vista más o menos riguroso y de sofisticación metodológica, por este motivo, es importante hacer especial énfasis en los métodos y técnicas de investigación que son empleados. En general, en una investigación lo más importante es el diseño metodológico, parte del cual se encuentra el método de investigación, como el camino elegido para buscar una solución a un problema planteado, y las técnicas de investigación, como las herramientas adecuadas que hacen posible llegar al final de este camino y, por tanto, a la solución del problema.

El objetivo de este trabajo es comprobar la evolución que han sufrido los métodos y técnicas de investigación en la disciplina de Información y Documentación a lo largo de los últimos años, con la finalidad de comprobar si han cambiado, han desaparecido o han surgido algunos nuevos. Para ello, partiendo de investigaciones anteriores que permiten contrastar los resultados, en el presente trabajo se analizan las tesis doctorales defendidas durante el periodo 2008/09-2018/19 en los departamentos de la universidad española relacionados con la temática investigada. Aunque, como ya se ha comentado, existen diversos tipos 
documentales que permiten conocer las tendencias en métodos de investigación, en esta ocasión se han escogido las tesis doctorales por considerar estas la culminación de una trayectoria investigadora y porque de su producción primaria surge el resto de documentos de carácter científico (artículos de revistas, actas de congresos y literatura gris). Delgado (2002) opina que la cantidad de investigación generada en tesis doctorales es un indicador de la vitalidad de la disciplina. A pesar de ello, los estudios que existen para conocer estos aspectos de la investigación han sido realizados en su mayoría sobre las revistas científicas, siendo minoritarios aquellos sobre las tesis doctorales, quizá porque las fuentes de localización nunca han estado normalizadas del todo.

No obstante, se pueden nombrar algunos estudios interesantes realizados en un contexto internacional sobre métodos y técnicas de investigación en tesis doctorales de nuestra disciplina. Schlachter y Thomison (1974) analizan 660 tesis doctorales desde los comienzos del postgrado en USA $(1925 / 72)$ y establecen categorías para definir los métodos de investigación. Otro trabajo de estos autores (Schlachter y Thomison ,1982, citado por Delgado, 2002), cuenta con la particularidad del desglose de las tesis obtenidas en dos periodos, 1925/72 y 1973/81, en los que se detectan diferentes métodos en función de la evolución temporal. Igualmente, Blake en varios trabajos diferentes (1994, 2001, citado por Gauchi, 2015, 2003 citado por Gauchi, 2016) analiza los métodos de investigación utilizados en las tesis doctorales aparecidas en el Dissertations Abstract International entre los años 1975/94. Su interés se encuentra en la utilización del resumen para establecer una categorización de métodos de investigación y, además, en la unión de las dos tendencias paralelas de la disciplina existentes, llamadas en el ámbito anglosajón, Library Science Information Science, hoy unidas en Library and Information Science (LIS), y que tantos resultados dispares había producido su separación en estudios anteriores. Powell (1995, citado por Gauchi, 2015) establece una categorización de métodos de investigación en tesis doctorales a partir de las clasificaciones realizadas previamente por otros tres autores diferentes. Finalmente, Grotzinger (1981, citado por Delgado, 2002) estudia las tesis doctorales incluidas en otras áreas (educación, sociología, periodismo) además de Information Science, en las que detecta 
la aparición de un nuevo método de investigación que llegará a tener mucha importancia en el futuro de nuestra disciplina, el método descriptivo.

En España, existen varios estudios sobre tesis doctorales que pueden mencionarse pertenecientes a la década de los 90. Se trata de los trabajos de Román y Sorli (1994) y Abadal (1994). La particularidad de estos trabajos se encuentra, según Delgado (2002), en la definición de la estrategia de búsqueda realizada en la base de datos TESEO, donde se encuentran las tesis españolas que se leen en las diferentes universidades. Una herramienta, a decir verdad, que se ha ido perfeccionando con el tiempo, no siendo muy fiable en la década de los 90, debido a una ausencia de normalización de los diferentes campos de introducción de datos, y de su rigor en hacerlo por parte de los investigadores, cuestión que en la actualidad se encuentra solventada. Con una estrategia de búsqueda basada en los campos título y resumen, López (1996) limita el estudio a las tesis leídas sobre bibliometría, un método de investigación, el bibliométrico, en auge desde esta década hasta la actualidad. De igual modo, Bonal (2000) utiliza el mismo tipo de estrategia de búsqueda para tesis leídas sobre archivos y archivística durante el periodo 1977/99.

Delgado (2002) realiza un análisis sobre tesis doctorales en Información y Documentación leídas en diferentes facultades y departamentos de 6 universidades españolas para los años 1976/96, de donde resulta una curva ascendente de producción desde los años 1976/80 hasta 1993/96. El mismo autor, para el periodo 2002/04 (Delgado, 2007) analiza las tesis doctorales de 15 universidades españolas y hace una categorización de métodos y técnicas de investigación. Como resultado, define unas características comunes de la investigación en Información y Documentación en España, entre las que destacan, la escasa cantidad de investigación, de tipo empírico fundamentalmente, el carácter multidisciplinar de la misma, y la gran variedad metodológica. Este autor identifica la problemática de las clasificaciones por categorías de los métodos y técnicas de investigación realizadas por diferentes autores, en aspectos como la claridad de las fuentes de dónde han sido obtenidas, lo que presenta un inconveniente si se quieren realizar estudios comparativos. 
En los trabajos sobre tesis doctorales en España, se evidencia una relación entre la temática de las mismas y la institución a la que pertenecen, en concreto, la facultad, departamento o área de conocimiento en donde estas tesis han sido presentadas. Este hecho se refleja, en consecuencia, en la temática de las tesis, en los métodos y técnicas de investigación utilizados, así como en la evolución de la dependencia orgánica universitaria del momento.

Así pues, como parte de este análisis inicial de los trabajos sobre tesis doctorales se podría llegar a unas cuestiones preliminares que van a marcar el carácter de nuestra disciplina en general y, en concreto, en España: un carácter multidisciplinar manifestado en el uso de una gran diversidad de métodos y técnicas de investigación, como resultado de las diferentes adscripciones orgánicas administrativas en el funcionamiento de la universidad, una ausencia de categorización normalizada de estos métodos y técnicas, además de una evolución en el tiempo en donde, como se verá, han sido predominantes unos tipos de métodos y técnicas sobre otros.

\section{Material y metodología}

Como se ha mencionado con anterioridad, en esta investigación se estudian los métodos y técnicas usados en las tesis doctorales relacionadas con la disciplina de Información y Documentación (IyD) que se han defendido en los últimos 10 años (2009/18), en los departamentos de la universidad española relacionados con la temática investigada. Dichos años se incluyen en los cursos académicos 2008/09-2018/19. Se han escogido las tesis doctorales porque representan la culminación del proceso investigador y se consideran un indicador de la institucionalización de la investigación en una disciplina concreta.

Dada la dimensión de la universidad española, y teniendo en cuenta la magnitud y disparidad de departamentos que la conforman, se han seleccionado aquellas que, según el Ministerio de Ciencia, Innovación y Universidades de España ${ }^{1}$, han ofertado el Título de Grado en Información y Documentación (INDO), en su modalidad presencial y/o no presencial, en el curso académico 2018/19.

\footnotetext{
${ }^{1} 1$ https://www.educacion.gob.es/notasdecorte/busquedaSimple.action
} 
En la tabla 1, alfabéticamente por la universidad, se muestran las 10 universidades que conforman la muestra.

Tabla 1. Universidades españolas que ofertan Grado INDO en el curso académico 2018-2019.

\begin{tabular}{|l|l|}
\hline $\begin{array}{l}\text { Universidades con Grado } \\
\text { en INDO }\end{array}$ & Facultad de impartición \\
\hline Univ. A Coruña & Fac. Humanidades y Documentación \\
\hline Univ. Barcelona & Fac. Biblioteconomía y Documentación \\
\hline Univ. Complutense Madrid & Fac. Ciencias de la Documentación \\
\hline Univ. Extremadura & $\begin{array}{l}\text { Fac. Ciencias de la Documentación y la } \\
\text { Comunicación }\end{array}$ \\
\hline Univ. Granada & Fac. Comunicación y Documentación \\
\hline Univ. León & Fac. Filosofía y Letras \\
\hline Univ. Murcia & Fac. Comunicación y Documentación \\
\hline Univ. Salamanca & Fac. Traducción y Documentación \\
\hline Univ. Valencia & Fac. Geografía e Historia \\
\hline Univ. Zaragoza & Fac. Filosofía y Letras \\
\hline
\end{tabular}

Fuente: elaboración propia.

Una vez seleccionadas las universidades, y utilizando la base de datos TESEO ${ }^{2}$ del Ministerio de Educación, Cultura y Deporte de España, se han buscado, en cada una de ellas, los departamentos relacionados con $\mathrm{IyD}$ con el fin de recuperar las tesis doctorales defendidas en ellos entre los cursos académicos 2008/09-2018/19, y extraer solamente aquellas leídas en el periodo 2009/18 cuya temática se relaciona específicamente con IyD (dicha búsqueda se realizó durante el mes de julio de 2019). Para aclarar este concepto pensemos, por ejemplo, en el Departamento de Información y Comunicación de la Universidad de Extremadura, que está relacionado con $\mathrm{IyD}$, pero en él también se defienden tesis referentes a las áreas de Comunicación Audiovisual y Publicidad.

\footnotetext{
${ }^{2}$ https://www.educacion.gob.es/teseo/irBusquedaAvanzada.do
} 
Tabla 2. Tesis defendidas en departamentos relacionados con IyD vs tesis específicas sobre IyD (2009-2018).

\begin{tabular}{|l|l|l|l|}
\hline $\begin{array}{l}\text { Universidades con Grado } \\
\text { en INDO }\end{array}$ & $\begin{array}{l}\text { Tesis en } \\
\text { departamentos } \\
\text { relacionados con } \\
\text { IyD }\end{array}$ & $\begin{array}{l}\text { Tesis } \\
\text { específicas } \\
\text { sobre IyD }\end{array}$ & $\%$ \\
\hline Univ. A Coruña & 30 & 5 & 16,67 \\
\hline Univ. Barcelona & 43 & 32 & 74,42 \\
\hline Univ. Complutense Madrid & 37 & 27 & 72,97 \\
\hline Univ. Extremadura & 41 & 25 & 60,98 \\
\hline Univ. Granada & 92 & 66 & 71,74 \\
\hline Univ. León & 24 & 3 & 12,50 \\
\hline Univ. Murcia & 48 & 35 & 72,92 \\
\hline Univ. Salamanca & 46 & 46 & 100,00 \\
\hline Univ. Valencia & 47 & 18 & 38,30 \\
\hline Univ. Zaragoza & 27 & 27 & 100,00 \\
\hline Total & 435 & $\mathbf{2 8 4}$ & \\
\hline
\end{tabular}

Fuente: elaboración propia.

En la tabla 2, ordenada alfabéticamente por universidad, se muestra la diferencia entre las tesis defendidas en los departamentos relacionados con $\mathrm{IyD}$ (435) y aquellas cuya temática es específica de la materia, teniendo en cuenta los descriptores usados, el resumen, o el título (284). Del total, el 65,29\% son específicas en IyD. En esta tabla se puede ver la potencialidad de compartir departamento con otras áreas o no. Por ejemplo, se observa que hay universidades en las que coinciden las tesis totales de los departamentos con el total de tesis leídas sobre $\mathrm{IyD}$, mientras que en otras, hay un porcentaje menor o mayor en relación con las otras áreas de los departamentos. Esto se debe a la diversa estructura organizativa de cada universidad, que posibilita una variada adscripción de las áreas a los departamentos y de estos a las facultades dependiendo de cada universidad. Este hecho 
repercute, sin duda, en el mayor o menor carácter multidisciplinar de los departamentos y, por consiguiente, de las tesis defendidas en ellos.

Tras identificar las 284 tesis, se estableció un cuadro de clasificación con los métodos y técnicas de investigación usados en tesis doctorales. Para ello, se partió de métodos y/o técnicas ya utilizados y definidos en otros trabajos sobre tesis doctorales (Blake, 1994, Gauchi, 2015, Ferran-Ferrer, et al., 2017), a los que se incorporó algunos ítems surgidos en la presente investigación. En la Tabla 3, puede apreciarse el cuadro de clasificación resultante junto con la descripción del método o técnica de investigación.

Tabla 3. Métodos (M) y Técnicas (T) utilizados.

\begin{tabular}{|l|l|l|}
\hline M/T & Métodos/Técnicas & Descripción \\
\hline M & Bibliográfico & $\begin{array}{l}\text { Estudios bibliográficos } \\
\text { descriptivos que evalúan } \\
\text { publicaciones o bibliografías } \\
\text { sistemáticas de autor o materias. }\end{array}$ \\
\hline M & Bibliométrico & $\begin{array}{l}\text { Aplicación de métodos } \\
\text { matemáticos y estadísticos al } \\
\text { estudio de la ciencia, de la } \\
\text { producción científica, de los } \\
\text { autores que la producen y de su } \\
\text { uso. }\end{array}$ \\
\hline M & Cibermétrico & $\begin{array}{l}\text { Estudios sobre el análisis y } \\
\text { medición cuantitativa de todas las } \\
\text { clases y medios de información } \\
\text { que existen en el internet. }\end{array}$ \\
\hline M & Descriptivo & $\begin{array}{l}\text { Trabajos sobre la descripción de } \\
\text { fenómenos para conocer cómo es } \\
\text { la realidad. }\end{array}$ \\
\hline M & Diseño de Sistemas de Información & $\begin{array}{l}\text { Estudios sobre el análisis y } \\
\text { diseño de sistemas de } \\
\text { información y de herramientas de } \\
\text { recuperación y de } \\
\text { almacenamiento de la } \\
\text { información. }\end{array}$ \\
\hline
\end{tabular}




\begin{tabular}{|c|c|c|}
\hline M & Encuesta & $\begin{array}{l}\text { Estudios que reúnen los } \\
\text { resultados de múltiples } \\
\text { cuestionarios aplicados a una } \\
\text { población determinada, para que } \\
\text { al final el análisis estadístico y las } \\
\text { tendencias puedan derivarse de } \\
\text { los datos agregados. }\end{array}$ \\
\hline M & Estudio de caso & $\begin{array}{l}\text { Análisis y descripciones } \\
\text { detalladas de uno o pocos } \\
\text { individuos u organizaciones } \\
\text { representativos del conjunto al } \\
\text { que pertenecen. }\end{array}$ \\
\hline M & Evaluación & $\begin{array}{l}\text { Investigación aplicada que tiene } \\
\text { como objetivo juzgar el valor, la } \\
\text { utilidad, etc. de los sistemas de } \\
\text { acuerdo con unos determinados } \\
\text { criterios. }\end{array}$ \\
\hline M & Experimental & $\begin{array}{l}\text { Investigaciones que establecen } \\
\text { una relación causal entre diversas } \\
\text { variables. }\end{array}$ \\
\hline M & Histórico & $\begin{array}{l}\text { Estudios que describen y e } \\
\text { intentan comprender hechos } \\
\text { pasados y experiencias humanas } \\
\text { mediante el análisis de datos } \\
\text { históricos. }\end{array}$ \\
\hline M & Propuesta de modelo & $\begin{array}{l}\text { Desarrollo de modelos que } \\
\text { ayudan a la toma de decisiones } \\
\text { generando soluciones óptimas. }\end{array}$ \\
\hline M & Teórico & $\begin{array}{l}\text { Desarrollo de marcos teóricos } \\
\text { por medio de la reflexión y el } \\
\text { análisis lógico. }\end{array}$ \\
\hline $\mathrm{T}$ & Análisis de contenido & $\begin{array}{l}\text { Estudios cuantitativos de } \\
\text { documentos y otras formas de } \\
\text { comunicación que examinan la } \\
\text { presencia y frecuencia de } \\
\text { patrones de palabras, frases, } \\
\text { conceptos, etc. }\end{array}$ \\
\hline
\end{tabular}




\begin{tabular}{|l|l|l|}
\hline T & Análisis transaccional (logs) & $\begin{array}{l}\text { Estudio de las acciones realizadas } \\
\text { por el usuario en su interacción } \\
\text { con un sistema informático } \\
\text { obtenidas a través de su registro } \\
\text { en un archivo. }\end{array}$ \\
\hline $\mathrm{T}$ & Cuestionario & $\begin{array}{l}\text { Conjunto de preguntas escritas } \\
\text { que se utiliza para obtener } \\
\text { información indistinta para } \\
\text { evaluar a una sola persona. } \\
\text { Aunque lo puede responder más } \\
\text { de una persona, las respuestas no } \\
\text { son parte de un análisis } \\
\text { estadístico. }\end{array}$ \\
\hline $\mathrm{T}$ & Entrevista & $\begin{array}{l}\text { Instrumento para obtener } \\
\text { información mediante la } \\
\text { comunicación verbal cuyas } \\
\text { respuestas son escritas por el } \\
\text { encuestador, quien hace las } \\
\text { preguntas personalmente. }\end{array}$ \\
\hline $\mathrm{T}$ & Observación & $\begin{array}{l}\text { Reuniones de grupos reducidos } \\
\text { de personas que se organizan } \\
\text { para analizar sus experiencias y } \\
\text { puntos de vista sobre un } \\
\text { determinado tema. }\end{array}$ \\
\hline Grupo de discusión & $\begin{array}{l}\text { Vigilancia directa y grabación de } \\
\text { los distintos aspectos del } \\
\text { fenómeno que se estudia. }\end{array}$ \\
\hline
\end{tabular}

Fuente: adaptados de Blake, 1994, Gauchi, 2015, Ferran-Ferrer et al., 2017 y elaboración propia.

Una vez establecido el cuadro de clasificación, se procedió a la lectura de los resúmenes de las 284 tesis doctorales, aportados por los autores de las mismas en la base de datos TESEO, para identificar los métodos y/o técnicas de investigación utilizados en las tesis y mencionados en dichos resúmenes, con el fin de ver la evolución sufrida a lo largo de los años de análisis, así como para compararla con investigaciones anteriores al respecto. 
Mediante la aplicación del método descriptivo y la técnica de análisis de contenido, se ha podido avanzar en una temática tan compleja como la detección de métodos y técnicas de investigación en IyD.

\section{Resultados y discusión}

En este apartado se muestran los resultados obtenidos tras aplicar la metodología descrita. En primer lugar, se analiza la proporción de tesis sobre IyD en las universidades de la muestra. En la tabla 4, ordenada descendentemente por el porcentaje de tesis, y su gráfico representativo (figura 1), se observa el despunte de la Universidad de Granada, en primer lugar (23,24\%), seguido de la Universidad de Salamanca (16,20\%) y de la Universidad de Murcia (12,32\%). Entre ellas suman más del $50 \%$ de las tesis sobre la materia en cuestión. En la parte más desfavorable de la distribución se encuentran las Universidades de A Coruña (1,76\%) y León (1,06\%).

Tabla 4. Porcentaje de tesis sobre IyD en el periodo 2009-2018.

\begin{tabular}{|l|l|l|}
\hline $\begin{array}{l}\text { Universidades con Grado } \\
\text { en INDO }\end{array}$ & $\begin{array}{l}\text { Tesis específicas } \\
\text { sobre IyD }\end{array}$ & \% \\
\hline Univ. Granada & 66 & 23,24 \\
\hline Univ. Salamanca & 46 & 16,20 \\
\hline Univ. Murcia & 35 & 12,32 \\
\hline Univ. Barcelona & 32 & 11,27 \\
\hline Univ. Complutense Madrid & 27 & 9,51 \\
\hline Univ. Zaragoza & 27 & 9,51 \\
\hline Univ. Extremadura & 25 & 8,80 \\
\hline Univ. Valencia & 18 & 6,34 \\
\hline Univ. A Coruña & 5 & 1,76 \\
\hline Univ. León & 3 & 1,06 \\
\hline Total & $\mathbf{2 8 4}$ & $\mathbf{1 0 0}$ \\
\hline
\end{tabular}

Fuente: elaboración propia. 
Figura 1. Tesis sobre IyD defendidas entre los años 2009-2018.

Tesis sobre ByD defendidas entre 2009 y 2018

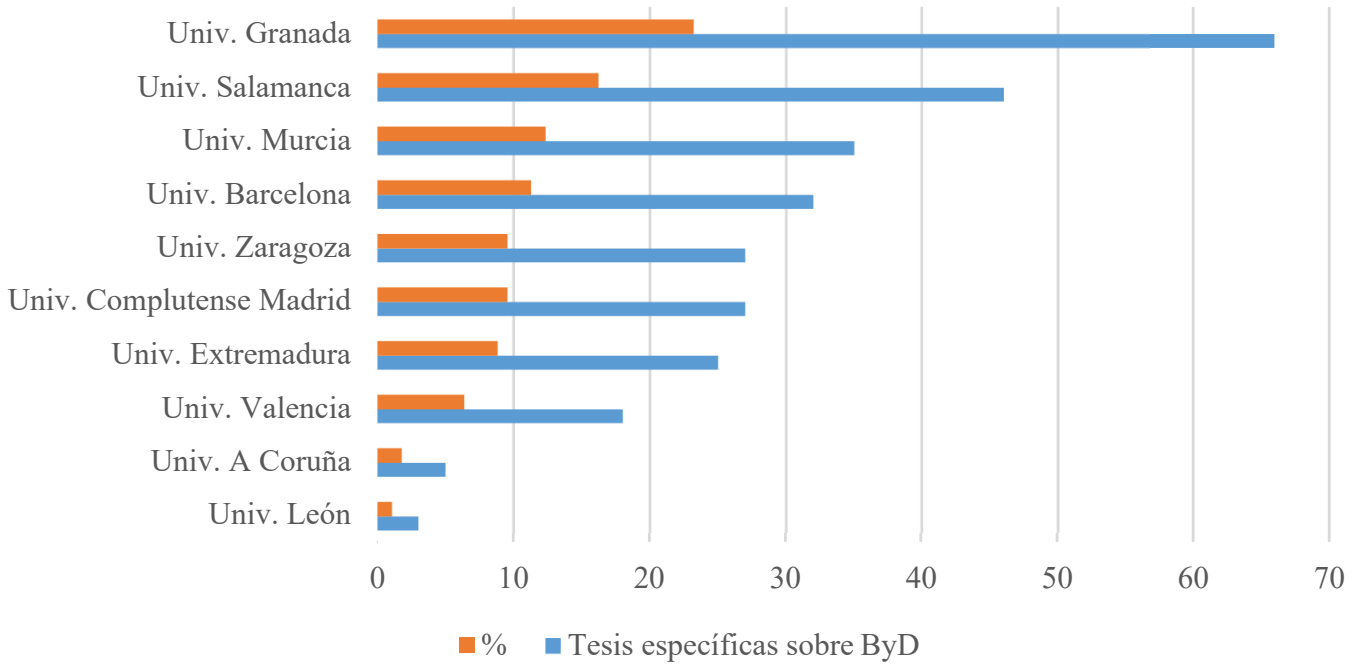

Fuente: elaboración propia.

Se ha querido comprobar si existe alguna relación entre la clasificación o posición de las universidades analizadas atendiendo a las tesis defendidas sobre IyD (reflejada en la anterior tabla 4) y atendiendo a su posición en el ranking web de universidades ${ }^{33}$ (edición julio 2019), publicado por el Laboratorio de Cibermetría del Consejo Superior de Investigaciones Científicas -CSIC-, el mayor centro nacional de investigación de España que las clasifica según los indicadores de presencia, impacto, apertura y excelencia (tabla 5, ordenada por la variable "Posición tesis sobre IyD" ). La correlación Pearson entre ambas clasificaciones ha sido $r=0,44$ lo que señala que sí hay una relación positiva moderada, más representativa en las posiciones más bajas de las clasificaciones.

${ }^{3}$ http:/ /www.webometrics.info/ 
Tabla 5. Relación entre la posición de las universidades según las tesis defendidas sobre IyD (2009-2018) y según el Ranking Web de Universidades.

\begin{tabular}{|c|c|c|c|c|}
\hline $\begin{array}{l}\text { Posición } \\
\text { tesis sobre } \\
\text { IyD }\end{array}$ & $\begin{array}{l}\text { Posición } \\
\text { Ranking } \\
\text { Web }\end{array}$ & Universidad & $\begin{array}{ll}\text { Ranking } & \text { Web } \\
\text { (posición } & \text { entre } \\
260 & \text { univ. } \\
\text { españolas) } & \end{array}$ & $\begin{array}{l}\text { Ranking } \\
\text { Mundial } \\
\text { (posición en el } \\
\text { Ranking } \\
\text { Mundial) }\end{array}$ \\
\hline $1^{\mathrm{a}}$ & $4^{a}$ & Univ. Granada & 5 & 242 \\
\hline $2^{\mathrm{a}}$ & $6^{a}$ & Univ. Salamanca & 14 & 453 \\
\hline $3^{a}$ & $7^{a}$ & Univ. Murcia & 19 & 499 \\
\hline $4^{a}$ & $1^{\mathrm{a}}$ & Univ. Barcelona & 1 & 133 \\
\hline $5^{\mathrm{a}}$ & $5^{a}$ & Univ. Zaragoza & 12 & 364 \\
\hline $6^{\mathrm{a}}$ & $2^{\mathrm{a}}$ & $\begin{array}{ll}\text { Univ. } & \text { Complutense } \\
\text { Madrid } & \end{array}$ & 2 & 190 \\
\hline $7^{\mathrm{a}}$ & $8^{a}$ & Univ. Extremadura & 33 & 816 \\
\hline $8^{a}$ & $3^{a}$ & Univ. Valencia & 3 & 220 \\
\hline $9^{a}$ & $9^{a}$ & Univ. A Coruña & 34 & 827 \\
\hline $10^{\mathrm{a}}$ & $10^{\mathrm{a}}$ & Univ. León & 40 & 998 \\
\hline
\end{tabular}

Fuente: elaboración propia.

En segundo lugar, se ha estudiado la evolución del número de tesis defendidas a lo largo del periodo de análisis. La tabla 6 , ordenada ascendentemente por el año de defensa, y su representación gráfica (figura 2) muestran una distribución muy desigual, marcada positivamente por el año 2016 y desfavorablemente por 2018. Sin duda, una de las causas del pico tan favorable marcado en 2016 (22,53\%) se debe al Real Decreto 99/2011, de 28 de enero de 2011, que reguló la organización de los estudios de doctorado correspondientes al tercer ciclo de las enseñanzas universitarias oficiales conducentes a la obtención del Título de Doctor o Doctora y la extinción de los programas regulados por el RD 778/1998 y por el RD 1393/2007, en cuya disposición transitoria primera señalaba: "los estudiantes que a la entrada en vigor de este real decreto se encuentren cursando estudios de doctorado disponen de 5 años para la presentación y defensa de la tesis doctoral. Transcurrido dicho plazo sin que se baya producido ésta, el doctorando causará baja definitiva en 
el programa". La proximidad de dicha fecha favoreció la lectura de numerosas tesis doctorales a comienzos del año 2016.

Tabla 6. Año de lectura de tesis sobre IyD.

\begin{tabular}{|c|c|c|}
\hline $\begin{array}{ll}\text { Año } & \text { de } \\
\text { defensa }\end{array}$ & $\mathbf{N}^{\circ}$ de Tesis & $\%$ \\
\hline 2009 & 16 & 5,63 \\
\hline 2010 & 36 & 12,68 \\
\hline 2011 & 24 & 8,45 \\
\hline 2012 & 28 & 9,86 \\
\hline 2013 & 28 & 9,86 \\
\hline 2014 & 15 & 5,28 \\
\hline 2015 & 31 & 10,92 \\
\hline 2016 & 66 & 23,24 \\
\hline 2017 & 30 & 10,56 \\
\hline 2018 & 10 & 3,52 \\
\hline Total & 284 & 100 \\
\hline
\end{tabular}

Fuente: elaboración propia.

Figura 2. Año de defensa de tesis doctorales relacionadas con IyD.

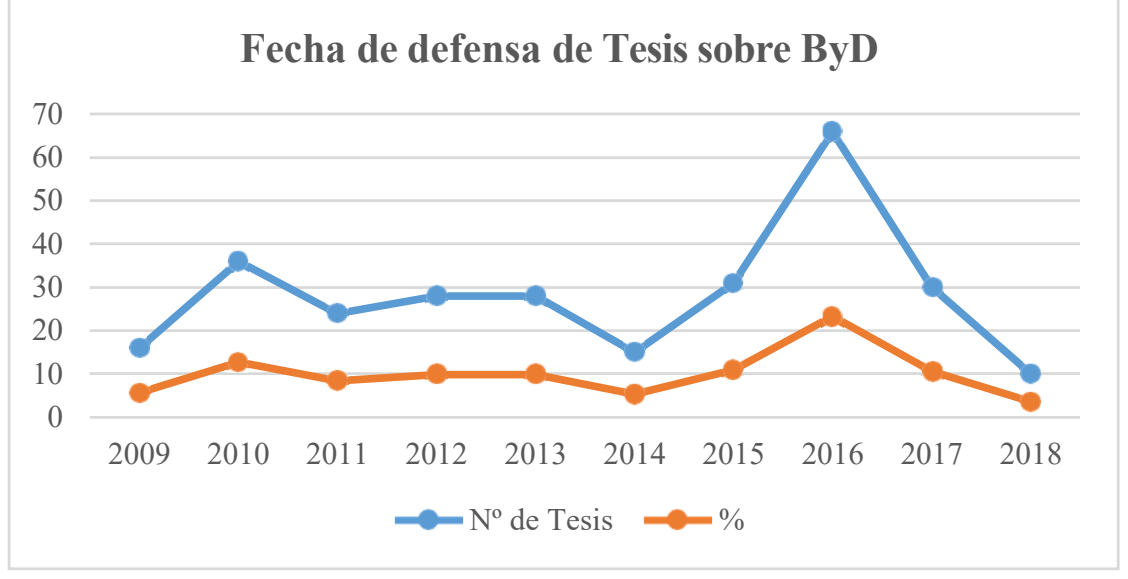

Fuente: elaboración propia. 
En general, se observa una evolución positiva, en cuanto al aumento del número de tesis, en los estudios internacionales llevados a cabo desde los años 70/80 (Blake, 1994), y se apunta a un ritmo creciente en las siguientes décadas (Delgado, 2002, 2007). Sin embargo, existe la posibilidad de que nuestro país no siga el ritmo internacional marcado sino un "crecimiento sostenido" como lo denomina Delgado (2002). En el resultado del número de tesis de la década estudiada (2009/18) se puede constatar una evolución irregular (creciente-decreciente) que puede deberse a la política universitaria y el modo en que aparecen regulados los estudios de doctorado en nuestro país. Puede significar igualmente una lenta consolidación de la disciplina, debido a su implantación tardía en España, y al ritmo de actividad científica de la comunidad investigadora respecto al resto de países de referencia.

Con respecto a los métodos y técnicas de investigación empleados en las tesis sobre IyD defendidas en las universidades analizadas a lo largo de los años 2009/18, hay que señalar que el número de casos encontrados (375) es mayor que el número de tesis doctorales (284), puesto que una misma tesis puede presentar uno o varios métodos $\mathrm{y} / \mathrm{o}$ técnicas. Asimismo, tal y como se ha mencionado en el apartado de Metodología, los métodos y técnicas identificados emergen del resumen reflejado en las tesis de la base de datos TESEO. En la tabla 7 , ordenada descendentemente por el porcentaje de métodos/técnicas, y en su representación gráfica (figura 3) se reflejan los métodos y/o técnicas detectadas entre 2009 y 2018, siendo el método descriptivo el más utilizado (17,87\%), seguido del bibliográfico (12,27\%), histórico $(11,73 \%)$ y propuesta de modelo $(11,20 \%)$. Entre los cuatro acumulan el 53\% del total. En el otro extremo de la distribución, en último lugar, se halla el método experimental (con un $0,27 \%$ del total). En cuanto a las técnicas, las más utilizadas son el cuestionario (5,07\%), la entrevista $(4,27 \%)$ y el análisis de contenido (3,20\%), apareciendo en los últimos lugares, el análisis transaccional $(0,27 \%)$ y los grupos de discusión $(0,80 \%)$. 
Tabla 7. Métodos/Técnicas de investigación en tesis sobre IyD (20092018).

\begin{tabular}{|l|l|l|l|}
\hline M/T & Métodos/Técnicas & Casos & $\%$ \\
\hline $\mathrm{M}$ & Descriptivo & 67 & 17,87 \\
\hline $\mathrm{M}$ & Bibliográfico & 46 & 12,27 \\
\hline $\mathrm{M}$ & Histórico & 44 & 11,73 \\
\hline $\mathrm{M}$ & Propuesta de modelo & 42 & 11,20 \\
\hline $\mathrm{M}$ & Bibliométrico & 40 & 10,67 \\
\hline $\mathrm{M}$ & Estudio de caso & 24 & 6,40 \\
\hline $\mathrm{M}$ & Cibermétrico & 21 & 5,60 \\
\hline $\mathrm{T}$ & Cuestionario & 19 & 5,07 \\
\hline $\mathrm{T}$ & Entrevista & 16 & 4,27 \\
\hline $\mathrm{M}$ & Encuesta & 12 & 3,20 \\
\hline $\mathrm{T}$ & Análisis de contenido & 12 & 3,20 \\
\hline $\mathrm{M}$ & Evaluación & 8 & 2,13 \\
\hline $\mathrm{M}$ & Teórico & 7 & 1,87 \\
\hline $\mathrm{M}$ & Diseño de Sist. de Información & 6 & 1,60 \\
\hline $\mathrm{T}$ & Observación & 6 & 1,60 \\
\hline $\mathrm{T}$ & Grupo de discusión & 3 & 0,80 \\
\hline $\mathrm{M}$ & Experimental & 1 & 0,27 \\
\hline $\mathrm{T}$ & Análisis transaccional (logs) & 1 & 0,27 \\
\hline Total & & $\mathbf{3 7 5}$ & $\mathbf{1 0 0}$ \\
\hline & & 6 & \\
\hline
\end{tabular}

Fuente: elaboración propia. 
Figura 3. Métodos/Técnicas usados en tesis sobre $\mathrm{IyD}$ en 10 universidades españolas durante 2009-2018.

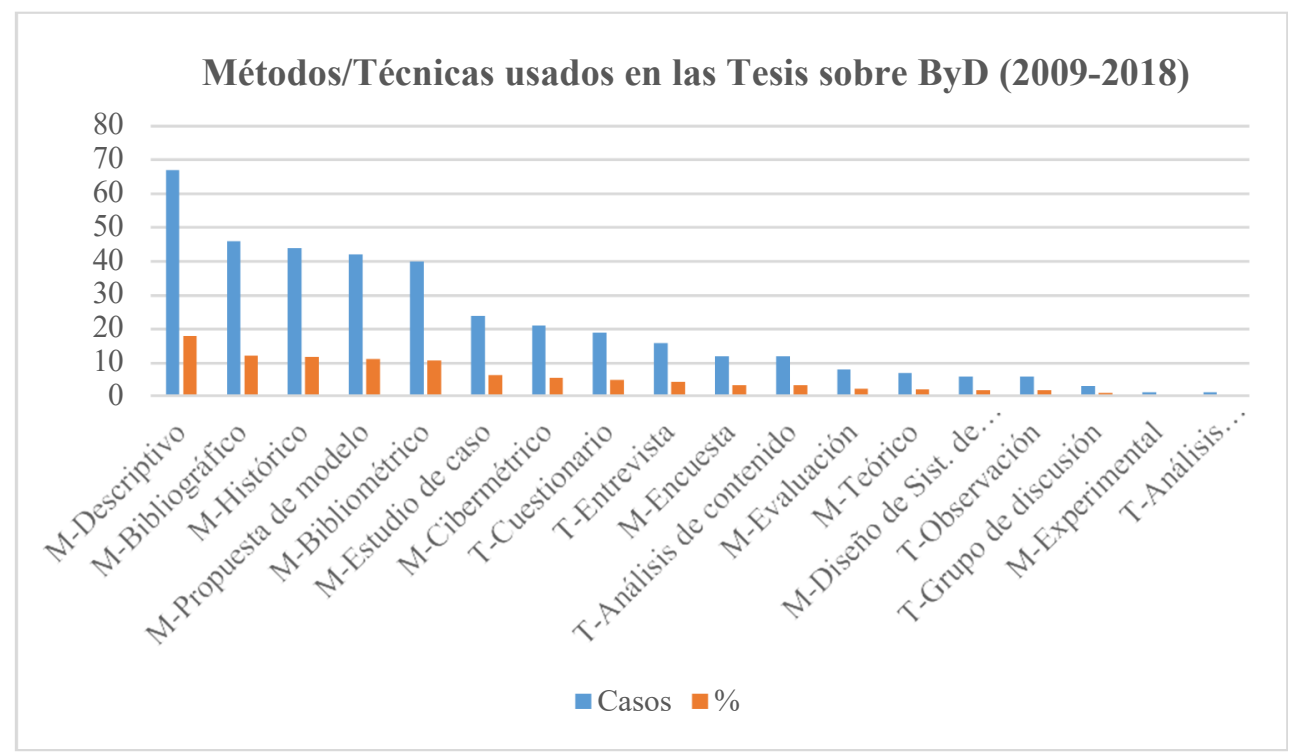

Fuente: elaboración propia.

Este resultado no difiere tanto del que se puede reconstruir atendiendo a los diferentes autores consultados. De este modo, en el estudio de Schlachter y Thomison (1974) sobre tesis doctorales en USA, realizado para el periodo 1925/72, aparecen en las primeras posiciones los métodos, descriptivo, bibliográfico y método histórico, tal y como puede observarse en este mismo estudio. Blake (1994, 2001, citado por Gauchi, 2015) para las décadas 80/90 establece una diferencia de uso de métodos de investigación y su popularidad dependiendo de las dos tendencias que considera divergentes en ese momento, Information Science y Library Science. De este modo, los métodos se inclinan hacia la encuesta y lo experimental en el primer caso, y hacia la encuesta y el método histórico en el segundo. Una vez fusionadas estas dos tendencias, Library and Information Science (LIS), el método histórico va desapareciendo para dar paso a un aumento del método de encuesta. En los trabajos de otros autores como Grotzinger (1981, citado por Delgado, 2002), aparece el método descriptivo como influencia del estudio de otras áreas de las ciencias sociales relacionadas con la Information Science, como ya se ha comentado. Por su parte, Delgado (2002), en su estudio sobre tesis españolas para el periodo 1976/98, identifica como métodos punteros el bibliométrico, y el de modelo (unido a diseño de sistemas), métodos que aparecen en las siguientes posiciones en nuestro cuadro de clasificación. Lo cierto es que en las 
últimas décadas se va observando un aumento del método bibliométrico, como ya apunta Chu (2015) en su estudio para revistas científicas en la década del $2000(2001 / 10)$.

Por otra parte, se ha querido comparar la distribución de métodos y/o técnicas de investigación halladas en este trabajo dividiéndola en dos periodos distintos de 5 años cada uno, 2009/13 y 2014/18, para comprobar si hay variaciones considerables. En la tabla 8 (ordenada alfabéticamente por el método, seguido de la técnica) y su figura 4 se observan unas distribuciones muy homogéneas en los dos periodos. De hecho, existe una correlación Pearson positiva muy fuerte $(\mathrm{r}=0,87)$ entre las posiciones de los métodos/técnicas en ambos periodos. Lo más sobresaliente es la prevalencia del método bibliométrico en los 5 primeros años, y de las técnicas del cuestionario y análisis de contenido en 2014/18. Schlachter y Thomison (1974, 1982, citado por Delgado, 2002) también dividieron su trabajo en dos periodos de tiempo 1925/72 y 1973/81, encontrando cuestiones significativas en su comparativa, como el descenso del método histórico y el aumento de la encuesta.

Tabla 8. Métodos/Técnicas de investigación en tesis sobre IyD (20092013 y 2014-2018).

\begin{tabular}{|l|l|l|l|l|l|}
\hline $\mathbf{M} / \mathbf{T}$ & Métodos/Técnicas & $\mathbf{2 0 0 9 - 2 0 1 3}$ & $\mathbf{( \% )}$ & $\mathbf{2 0 1 4 - 2 0 1 8}$ & $\mathbf{( \% )}$ \\
\hline $\mathrm{M}$ & Bibliográfico & 23 & 13,77 & 23 & 11,06 \\
\hline $\mathrm{M}$ & Bibliométrico & 23 & 13,77 & 17 & 8,17 \\
\hline $\mathrm{M}$ & Cibermétrico & 10 & 5,99 & 11 & 5,29 \\
\hline $\mathrm{M}$ & Descriptivo & 28 & 16,77 & 39 & 18,75 \\
\hline $\mathrm{M}$ & Diseño de Sist. de Información & 3 & 1,80 & 3 & 1,44 \\
\hline $\mathrm{M}$ & Encuesta & 7 & 4,19 & 5 & 2,40 \\
\hline $\mathrm{M}$ & Estudio de caso & 8 & 4,79 & 16 & 7,69 \\
\hline $\mathrm{M}$ & Evaluación & 4 & 2,40 & 4 & 1,92 \\
\hline $\mathrm{M}$ & Experimental & 0 & 0,00 & 1 & 0,48 \\
\hline $\mathrm{M}$ & Histórico & 20 & 11,98 & 24 & 11,54 \\
\hline
\end{tabular}




\begin{tabular}{|l|l|l|l|l|l|}
\hline $\mathrm{M}$ & Propuesta de modelo & 20 & 11,98 & 22 & 10,58 \\
\hline $\mathrm{M}$ & Teórico & 6 & 3,59 & 1 & 0,48 \\
\hline $\mathrm{T}$ & Análisis de contenido & 2 & 1,20 & 10 & 4,81 \\
\hline $\mathrm{T}$ & Análisis transaccional (logs) & 1 & 0,60 & 0 & 0,00 \\
\hline $\mathrm{T}$ & Cuestionario & 4 & 2,40 & 15 & 7,21 \\
\hline $\mathrm{T}$ & Entrevista & 5 & 2,99 & 11 & 5,29 \\
\hline $\mathrm{T}$ & Grupo de discusión & 1 & 0,60 & 2 & 0,96 \\
\hline $\mathrm{T}$ & Observación & 2 & 1,20 & 4 & 1,92 \\
\hline Total & & $\mathbf{1 6 7}$ & $\mathbf{1 0 0}$ & $\mathbf{2 0 8}$ & $\mathbf{1 0 0}$ \\
\hline
\end{tabular}

Fuente: elaboración propia.

Figura 4. Métodos/Técnicas usados en tesis sobre IyD en los periodos 2009-2013 у 2014-2018.

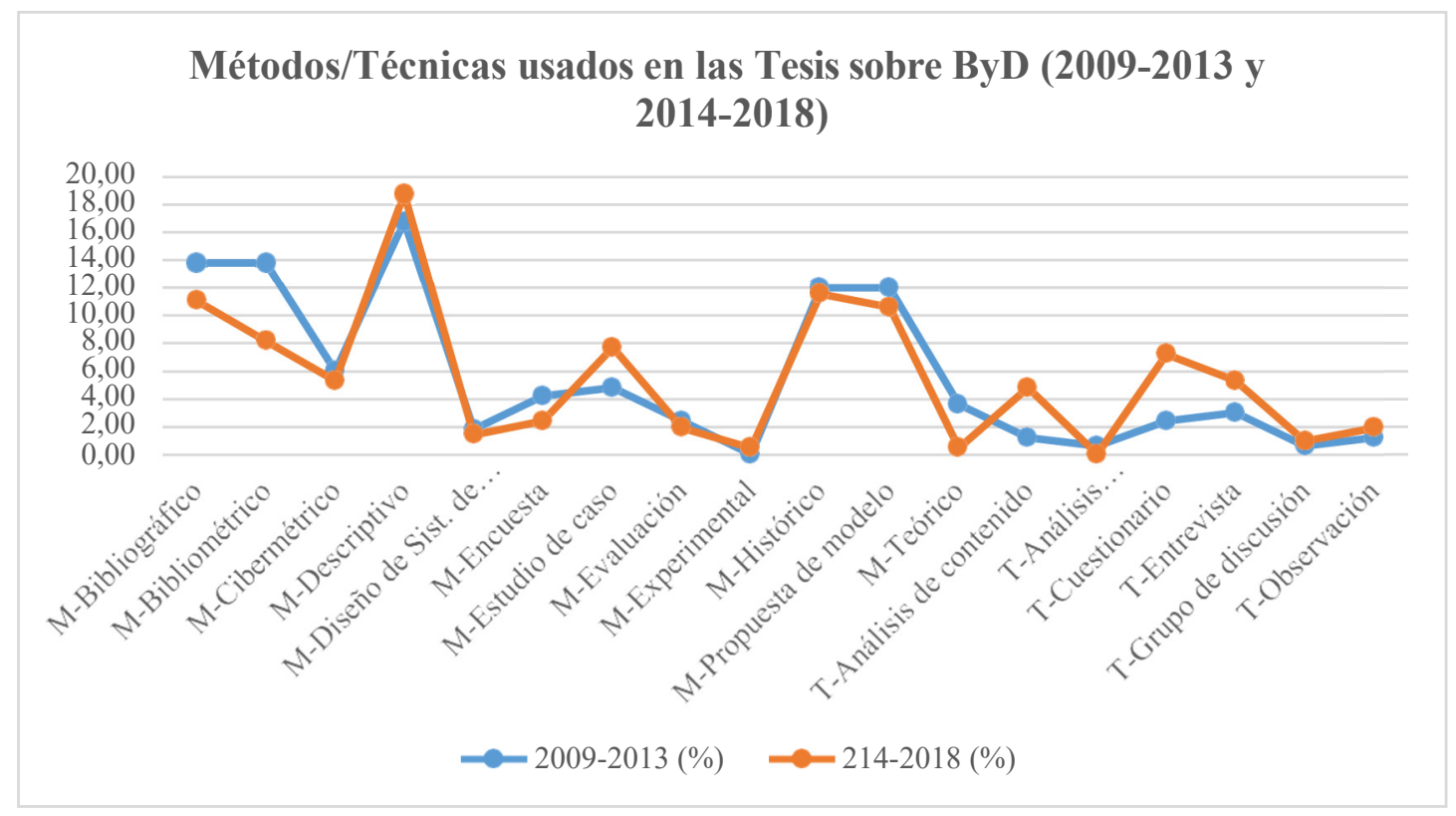

Fuente: elaboración propia.

En cuanto a las técnicas de investigación, en un análisis diferenciado de los métodos de investigación, se puede observar en la tabla 8 , el predominio del cuestionario, la entrevista y el análisis de contenido por 
encima del resto propuesto en el cuadro de categorías. Si se comparan nuestros resultados con los obtenidos por otros autores y en este caso, además, en trabajos realizados sobre revistas científicas (Borrego, 1999, Hider y Pymm, 2008, Chu, 2015, Ferran-Ferrer et al., 2017), se puede apreciar que coinciden plenamente, aunque aparecen otras técnicas, como el análisis transaccional o el uso de documentos personales, que obtienen un porcentaje mínimo o no han sido contemplados en nuestro cuadro de clasificación.

Finalmente, la tabla 8 también muestra, en general, un predominio, en los porcentajes más altos, de los métodos cuantitativos sobre los métodos cualitativos en las tesis doctorales independientemente del periodo de tiempo al que pertenecen, lo que en opinión de Blake (1994) viene ratificado desde los años 60 hasta los 80, junto con el uso de técnicas estadísticas. A partir de estos años 80 , se comienza a considerar el carácter científico de lo cualitativo y se produce un aumento de este tipo de métodos a partir de la década de los 90 (Powell, 1999). El análisis de los resultados para nuestros dos periodos de tiempo bien diferenciados no difiere en cuanto al predominio de una tipología frente a la otra, sin embargo, teniendo en cuenta el resto de los porcentajes en su escala de posición, puede deducirse un equilibrio entre ambas tipologías. En otros estudios sobre revistas científicas (Hider y Pymm, 2008, Ferran-Ferrer, et al. 2017), se advierte igualmente a partir de la década del 2000 un equilibrio entre los métodos cuantitativos y cualitativos de investigación, cuestión que en opinión de Gauchi (2016) es hacia dónde debe dirigirse nuestra disciplina.

\section{Conclusiones}

El objetivo general de este trabajo era averiguar si los métodos y técnicas de investigación en las tesis doctorales en Información y Documentación han sufrido una evolución a lo largo de los últimos diez años, y si puede comprobarse que han cambiado, han desaparecido o han surgido métodos nuevos.

Partimos de un aumento en general del número de tesis doctorales a lo largo de los diferentes periodos históricos de la disciplina, lo cual puede interpretarse como una consolidación de esta como ciencia. Sin embargo, la distribución desigual en el número de tesis doctorales en 
España en los últimos diez años, parece depender de la regulación de los estudios de doctorado que ha marcado los periodos de defensa de estos trabajos de investigación, y por otra parte, de las diferentes áreas de conocimiento existentes en un determinado departamento y el peso del área de IyD en el mismo, así como de la facultad que sostiene estos estudios, o de la universidad a la que pertenecen, evidenciado esto en el ranking donde se sitúan las universidades a escala global.

A pesar de las diferencias que existen entre las clasificaciones elaboradas por los diferentes autores a lo largo del tiempo, los métodos y técnicas de investigación más significativos son similares a los que aparecen en este trabajo. Por otra parte, a lo largo del tiempo han predominado unos métodos y técnicas de investigación sobre otros, y han ido surgiendo otros nuevos, como es el caso del bibliométrico (o cibermétrico), cuestión que aparece reflejada en nuestro estudio y que puede considerarse un signo de la evolución de la disciplina como ciencia. Sin embargo, parece predominar el uso de metodologías descriptivas para solucionar problemas relacionados con la profesión, tal y como ya lo advirtieron autores como Delgado (2002) o Gauchi (2016) lo que, por otra parte, puede impedir el avance hacia su carácter científico.

Finalmente, se constata el carácter multidisciplinar de nuestra disciplina, en la diversidad de métodos y técnicas que son utilizados en la elaboración de las tesis doctorales. No obstante, si bien tradicionalmente los métodos y técnicas de investigación han tenido un carácter cuantitativo, a partir de los años 80 se confirma un auge de los métodos cualitativos, y hoy puede afirmarse que existe un equilibrio en la utilización de las dos tipologías de investigación (cuantitativa y cualitativa) en general y en nuestro país en concreto.

\section{Bibliografía}

Abadal, E. (1999). La documentación en España. Madrid: CINDOC, FESABID. Disponible en http://hdl.handle.net/10261/36885

Blake, V.L.P. (1994). Since Shaughnessy: Research methods in Library and Information Science dissertations, 1975-1989. Collection Management, 19(1/2), 1-42 DOI: 10.1300/j105v19n01_01. 
Blake, V.L.P. (2001). Dissertations in Library/Information Science (1975-1994). A futher analysis. En Encyclopedia of Library and Information Science (pp. 105-26). New York: Marcel Dekker.

Blake, V.L.P. (2003). Research methods in LIS dissertations. En Encyclopedia of Library and Information Science (pp. 2513-2523). New York: Miriam Drake.

Bonal Zazo, J.L. (2000). La investigación universitaria sobre archivos y archivística en España a través de las tesis doctorales. En J. López Yepes (coord.). Teoría, bistoria y metodología de las Ciencias de la Documentación (1975-2000), (pp. 217-224). Madrid: Universidad Complutense.

Borrego Huerta, A. (1999). La investigación cualitativa y sus aplicaciones en Biblioteconomía y Documentación. Revista Española de Documentación Científica, 22(2), 139-156. Disponible en http://www.redc.revistas.csic.es/index.php/redc/article/view/ $\underline{3} \underline{35 / 543}$

Chu, H. (2015). Research Methods in Library and Information Science: a content analysis. Library \& Information Science Research, 37, 36-41. Disponible en http://www.academia.edu/11557368/Research methods in li $\underline{\mathrm{b}} \underline{\text { rary }}$ and information science A content analysis

Delgado López-Cózar, E. (2002). La investigación en biblioteconomía y documentación. Gijón: TREA.

Delgado López-Cózar, E. (2007). La investigación en Biblioteconomía y Documentación en España. Conferencia celebrada en la Facultad de Informática de la Universidad Politécnica de Valencia, 12 de diciembre.

Ferran-Ferrer, N., Guallar, J., Abadal, E. y Server, A. (2017). Research methods and techniques in spanish Library and Information Science journals (2012-2014). Information Research, 22(1), march. Disponible en http://InformationR.net/ir/22-1/paper741.html 
Grotzinger, L. (1981). Methodology of Library ScienceInquiry: past and present. En C. Busha, et al. A library science research reader and bibliographic guide. Littleton, CO: Libraries Unlimited.

Guachi Risso, V. (2015). Métodos de investigación empleados en bibliotecología $y$ ciencia de la información durante los últimos diez años. Universidad de Granada. [Tesis doctoral] Disponible en http://hdl.handle.net/10481/43376

Guachi Risso, V. (2016). Research methods used in Library and Information Science during the 1970-2010. New Library World, 117(1/2), 74-93. DOI: 10.1108/NLW-08-2015-0055

Hider, P. y Pymm, B. (2008). Empirical research methods reporter in high-profile LIS journal literature. Library \& Information Science Research, 30(2), 108-114. DOI: 10.1016/j.lisr.2007.11.007

López, P. (1996). La investigación bibliométrica en España (tesis doctorales). Revista Española de Documentación Científica, 19(1), 84-89.

Powell, R. (1995). Research competence for PhD students in Library and Information Science. Journal of Education for Library and Information Science, 36(4), 319-329.

Powell, R. (1999). Recent trends in research: a methodological essay. Library and Information Science Research, 21(1), 91-119. DOI: 10.1016/S0740-8188(99)80007-3

Román, A. y Sorli, A. (1994). La Documentación en los noventa. ¿Podemos predecir el futuro rastreando el pasado reciente de la investigación documental? En Terceras Jornadas Españolas de Documentación Automatizada (pp. 1171-1185). Palma de Mallorca: Universitat de les Illes Balears.

Schlachter, G. y Thomison, D. (1974). The Library Science Doctorate: a quantitative analysis of dissertations and recipients. Journal of Education for Librarianship, 15(2),95-111. DOI: 10.2307/40322826

Schlachter, G. y Thomison, D. (1982). Library Science dissertation, 1973 1981. Littleton, CO: Libraries Unlimited. 



\title{
Claves metodológicas de la investigación experimental en Comunicación.
}

\section{Aplicaciones prácticas en persuasión narrativa}

\author{
Juan José Igartua Perosanz
}

Catedrático de Universidad de Comunicación Audiovisual y Publicidad, Universidad de Salamanca

\section{Resumen}

En el presente capítulo se describen las principales características del método experimental en Comunicación tomando como paradigma la investigación en persuasión narrativa y situando dicho ámbito de investigación en el estudio de los efectos mediáticos. Los efectos mediáticos son considerados en la actualidad como efectos condicionales, indirectos y transaccionales. Ello implica que cualquier estudio riguroso sobre los efectos mediáticos ( $\mathrm{y}$, en particular, sobre el efecto de los mensajes narrativos en las actitudes, creencias, intención de conducta y comportamiento de las personas), necesariamente precisa del estudio de las variables moderadoras y mediadoras. En este contexto, se muestran ejemplos de instrumentos de medida para evaluar procesos mediadores y variables moderadoras. Finalmente, se plantean los retos que deberá afrontar en el futuro la investigación experimental en persuasión narrativa. 


\section{Introducción}

$\mathrm{E}$

N 2018, se publicaba en la revista Journal of Communication, el trabajo titulado "The ebb and flow of communication research: seven decades of publication trends and research priorities" (el flujo y reflujo de la investigación en comunicación: siete décadas sobre las tendencias de publicación y las prioridades de investigación) (Walter, Cody y Ball-Rokeach, 2018). Dicha revista, se ha convertido en una especie de barómetro para analizar las tendencias de investigación en nuestra disciplina. Por ello, cualquier análisis que se centre en lo que en ella se publica puede servir de referente para valorar las claves teóricas y metodológicas en Comunicación. En el trabajo que nos ocupa, se examinaron 1.574 estudios empíricos publicados en dicha revista entre 1951 y 2016, analizándose (entre otras cuestiones) dos aspectos que aquí queremos destacar: la aproximación metodológica del estudio (cuantitativa, cualitativa o mixta) y el método de investigación (experimento, encuesta, análisis de contenido, análisis del discurso, entrevistas abiertas en profundidad, etc.). Los resultados globales ponían que manifiesto que dominaban los métodos cuantitativos $(79,1 \%)$ y que las técnicas o métodos de investigación más utilizados eran el experimento (29,8\%), el análisis de contenido $(25,8 \%)$ y la encuesta $(23,7 \%)$. Además, se observaba que el experimento había sido la técnica dominante en la década de los años $50(74,3 \%)$ disminuyendo su presencia en las décadas de los $80(11,5 \%)$ y de los $90(12,2 \%)$ pero incrementando desde entonces de nuevo su presencia hasta situarse en la última década analizada (hasta 2016) en el 37,7\% de los trabajos empíricos publicados. El experimento, se puede decir, goza de buena salud en la investigación en Comunicación y así lo atestigua también un análisis sobre los trabajos publicados en la revista Journal of Communication en el año 2015, observándose que el 43,47\% de los trabajos publicados eran experimentos (Igartua, 2017a).

El énfasis en la metodología experimental se explica, en parte, por el foco analítico de los trabajos publicados en la revista Journal of Communication: la gran mayoría se centra en elementos micro (58\%) y domina el análisis de las audiencias (54,9\%, que implica también el estudio de los procesos de recepción) y de los mensajes mediáticos $(29,4 \%$, que no necesariamente tienen que ser estudios de análisis 
de contenido o análisis del discurso). De hecho, uno de los campos de mayor desarrollo en la teoría de la comunicación está relacionado con el estudio de los procesos y efectos mediáticos (media effects), es decir, el análisis de los procesos de influencia de la comunicación en las personas y, en dicho campo, el experimento es una técnica ampliamente utilizada (Bryant y Miron, 2004). Potter y Riddle (2007) realizaron un estudio sobre dicho tema, analizando una muestra de 962 artículos empíricos, publicados entre 1993 y 2005, en 16 revistas académicas, observando que el $28,8 \%$ de los trabajos publicados eran experimentos.

La primera conclusión a la que se llega a partir de los resultados de los estudios previamente mencionados es que el experimento es una técnica de investigación de gran relevancia en los estudios empíricos que se publican en el área de Comunicación a nivel internacional. Y la segunda conclusión es que gran parte de los trabajos que analizan los efectos mediáticos se basan en la metodología experimental. El presente capítulo se centra en la descripción de las claves metodológicas de la investigación experimental mostrando su aplicación a un campo concreto de estudio: la investigación sobre persuasión narrativa (Igartua, 2007). Lo que no se aborda en este capítulo es una descripción pormenorizada sobre el experimento, la cual puede encontrarse en otros trabajos de carácter metodológico (Igartua, 2006; Boyle y Schmierbach, 2015; Thorson, Wicks, y Leshner, 2012; Wimmer y Dominick, 2013).

\section{Una plantilla para analizar los efectos de lacomunicación mediática}

En la película "En la mente del asesino" (Cohen, 2012) el jefe de policía, tras descubrir cómo está actuando el criminal y ante la necesidad de difundir un comunicado de prensa a los medios para calmar a la opinión pública, dice lo siguiente: "está decidido, daremos la versión de un psicópata asesino, con un objetivo concreto; esto apaciguará a los ciudadanos". Este "mensaje" busca provocar un efecto, reducir el miedo, reducir la sensación de peligro o vulnerabilidad personal. Si el mensaje incluye la información "el asesino tiene un objetivo concreto", las personas pensarán que su riesgo es bajo.

La anécdota anterior nos permite ilustrar un hecho fundamental: comunicar es intentar provocar efectos en una determinada audiencia. 
Por ello, no es de extrañar que una gran parte de la investigación en comunicación se ha concentrado en el estudio de los efectos mediáticos, generando hasta la fecha más de 4.000 estudios en los cerca de 100 años de historia de investigación sobre dicho tema (Poter, 2011, 2012). Ello ha supuesto que sea considerado por algunos autores como el "paradigma dominante" en la investigación de la disciplina (Lang, 2013).

Un efecto mediático se define como un cambio en una determinada variable de resultado que se produce dentro de una persona o en una entidad social, y tiene lugar por la influencia de los medios de comunicación después de producirse la exposición a un mensaje ouna serie de mensajes emitidos por dichos medios (Igartua, 2015; Potter, 2011). El estudio de los efectos mediáticos ha generado un número muy elevado de teorías, llegando a identificarse más de 144 teorías diferentes (Potter y Riddle, 2007). Cada una de ellas se centra en un aspecto diferente de los medios de comunicación o se concentra en explicar un determinado tipo de efecto mediático. En un esfuerzo por sintetizar lo que dichas teorías tienen en común, Valkenburg y Peter (2013) propusieron un modelo o plantilla teórica general denominado Differential Susceptibility to Media Effects Model (Modelo de Susceptibilidad Diferencial a los Efectos Mediáticos), la cual permite abordar el estudio de cualquier efecto mediático con un guion o mapa conceptual y metodológico estructurado y, al mismo tiempo, establece los rasgos que caracterizan la investigación actual sobre el estudio de los efectos mediáticos:

1.- Los efectos mediáticos son condicionales. Ello significa que los medios de comunicación o los mensajes que vehiculan no afectan a todas las personas por igual. No todas las personas que se exponen a un determinado mensaje lo experimentan de la misma manera y, por ello, se pueden producir efectos más fuertes o más débiles dependiendo de determinados factores (Valkenburg, Peter y Walther, 2016).

De este modo, se establece que existen tres tipos de variables vinculadas con la susceptibilidad de los individuos a los efectos de los medios de comunicación: diferencias individuales (rasgos de personalidad y otras características psicológicas, como el estado de ánimo previo a la exposición a un mensaje), evolutivas (vinculadas con el desarrollo de las personas) y contexto socio-cultural (desde aspectos 
interpersonales, como estar acompañado o no durante la exposición a un mensaje, hasta aspectos culturales, institucionales o normativos que regulan la vida social) Dichas variables actúan como moderadores, es decir, variables que pueden modificar la dirección o la fuerza de la relación entre dos variables (como el consumo o exposición mediática y un determinado efecto o un proceso de recepción). Es por ello que una de las principales áreas de investigación sobre los efectos mediáticos se focaliza en determinar las condiciones en las que se producen efectos "fuertes" y los contextos o las variables que los debilitan o los anulan. Ahora bien, este tipo de variables de susceptibilidad diferencial también pueden jugar un segundo rol, actuando como predictores del uso mediático.

2.- Los efectos mediáticos son indirectos. Hablar de efectos indirectos es referirse al estudio de las variables mediadoras. Una variable mediadora interviene entre una variable independiente y una dependiente y hace explícito un mecanismo o proceso de influencia de una variable sobre otra (Igartua, 2012). De hecho, para adquirir confianza sobre la relación causal entre dos variables (por ejemplo, la exposición a un mensaje persuasivo y un efecto en las actitudes) es preciso que se explicite un mecanismo o proceso y que éste se derive de una determinada teoría (Yanovitzky y Greene, 2009).

Figura 1. Modelo de Susceptibilidad Diferencial a los Efectos Mediáticos de Valkenburg y Peter (2013).

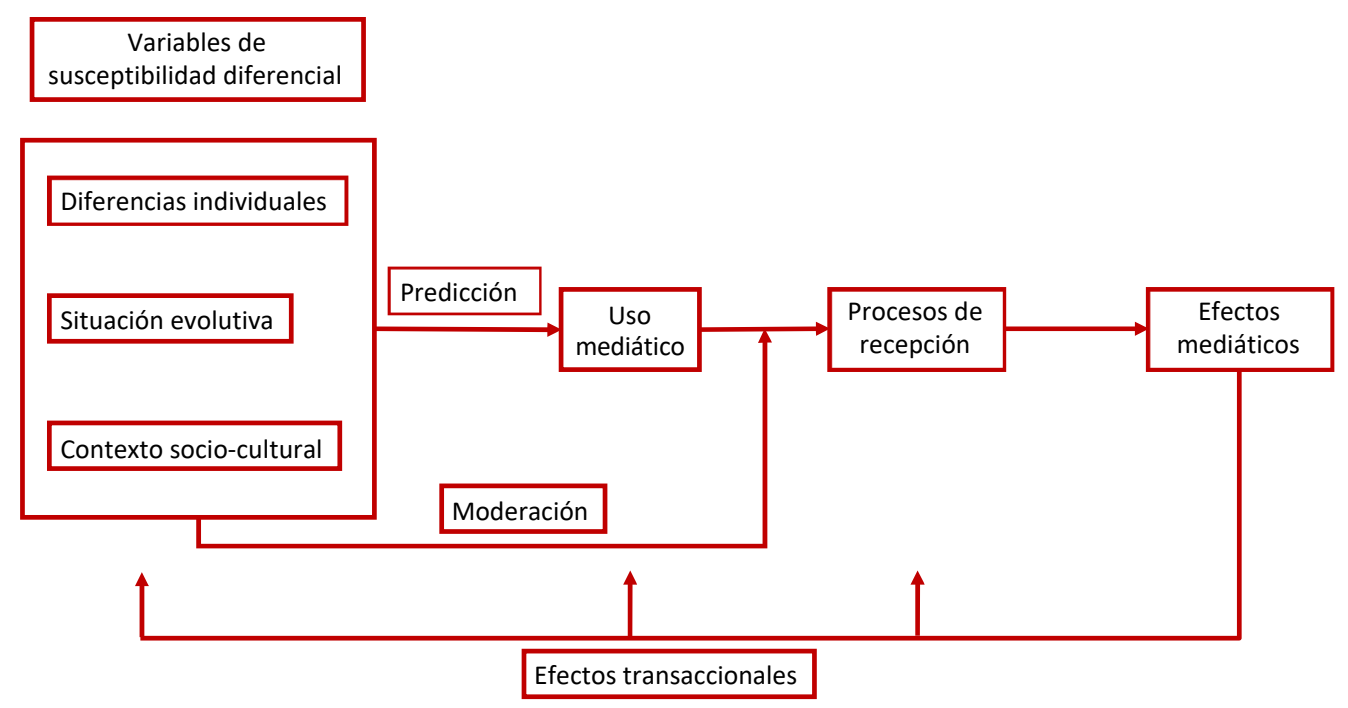

Nota. - Elaborado a partir de Valkenburg y Peter (2013) p. 226. 
Las teorías sobre los efectos de los medios han identificado tres tipos de efectos indirectos. En primer lugar, el uso mediático (exposición) puede actuar como un mecanismo mediador entre una variable de diferencias individuales y un efecto o proceso de recepción. De este modo, se puede observar que determinadas diferencias individuales (como los rasgos o atributos de personalidad) influyen en el uso mediático, lo que a su vez produce determinados efectos en los procesos de recepción. Por ejemplo, la búsqueda de sensaciones puede influir en el consumo de contenidos violentos y ello, a su vez, ejerce un efecto en las emociones experimentadas durante la exposición a dichos mensajes o en la conducta agresiva. En segundo lugar, los procesos psicológicos y fisiológicos (procesos de recepción) que ocurren durante la exposición a un mensaje mediático actúan como mecanismos mediadores entre el uso y los efectos. Por ejemplo, la exposición a noticias impactantes incrementará la activación fisiológica (arousal) y ello, a su vez, puede influir en el recuerdo de la información. Y, en tercer lugar, se puede hablar de los efectos mediáticos como mecanismos mediadores, lo que lleva a conceptualizar un segundo tipo de efecto mediático, los efectos mediáticos de segundo orden que pueden producirse más allá del momento de la exposición al mensaje. Por ejemplo, el consumo de noticias sobre contenidos políticos puede estimular la discusión interpersonal y ello, a su vez, estimular la participación en una contienda electoral. En el contexto de los medios sociales, el uso de este tipo de aplicaciones puede incrementar el despliegue de comentarios íntimos y personales al interactuar con otra persona (por ejemplo, vía WhatsApp) lo que, a su vez, puede mejorar la calidad de la relación interpersonal.

2.- Los efectos mediáticos son transaccionales. Ello significa que se dan relaciones bidireccionales o efectos recíprocos entre el uso mediático y los efectos mediáticos. De este modo, cualquier efecto mediático puede, a su vez, influir en las variables de susceptibilidad diferencial y en los procesos de recepción. Por ejemplo, la exposición continuada a la pornografía puede provocar que se interioricen creencias sobre las mujeres como objetos sexuales, lo que implicará que en futuras oportunidades de consumo de este tipo de materiales sexuales explícitos se incremente la implicación emocional (dado que percibe a las mujeres como objetos sexuales). Volviendo al terreno de los medios sociales, se puede pronosticar que un uso intenso de este 
tipo de aplicaciones puede reducir el rendimiento académico de los adolescentes lo que, a su vez, puede provocar que sus progenitores establezcan normas más rígidas de acceso y uso.

\section{Qué es un experimento}

El experimento es la técnica de investigación mejor preparada para contrastar relaciones causales porque implica manipular directamente una o más variables independientes y observar el efecto en una o diferentes variables dependientes (Boyle y Schmierbach, 2015; Igartua, 2006; Thorson et al., 2012). En este contexto, son relevantes los siguientes conceptos para comprender en qué consiste un experimento:

1.- Manipulación. En un experimento, se produce una manipulación activa por parte del investigador de las variables independientes. Así como en los métodos correlacionales (como la encuesta) el investigador se limita a recopilar datos de determinadas variables mediante un cuestionario (sin modificar el entorno ni el fenómeno donde se recoge la información), en el experimento se provoca un fenómeno en unas condiciones determinadas con el fin de analizar sus efectos y verificar una determinada hipótesis. Sin embargo, la manipulación ejercida debe quedar encubierta para los sujetos que participan en la investigación. En la investigación experimental en Comunicación suelen manipularse diferentes tipos de variables independientes como los aspectos formales o de contenido de los mensajes mediáticos, aspectos contextuales, las condiciones ambientales en las que se recibe el mensaje y la manipulación mediante instrucciones que los participantes reciben antes de exponerse al mensaje.

2.- Medición. Implica la utilización de diferentes instrumentos y procedimientos para evaluar las variables dependientes del estudio. Las medidas más frecuentes se basan en la utilización de escalas de autoinforme (insertas en cuestionarios) y en técnicas basadas en el listado de pensamientos para evaluar procesos cognitivos (thought-listing technique). Aunque son menos frecuentes, también se utilizan como variables dependientes medidas implícitas (como el Test de Asociación Implícita). Cada vez se utilizan con mayor frecuencia las medidas online que permiten la evaluación de procesos y efectos de la 
recepción en tiempo real. En este caso, se recoge información sobre reacciones evaluativas, reacciones conductuales (eyes on screen) o se realiza un registro de reacciones fisiológicas y cerebrales para evaluar procesos cognitivos o emocionales (Bolls, Weber, Lang y Potter, 2019).

3.- Control experimental. En un experimento se manipulan determinadas variables independientes, pero, al mismo tiempo, se mantiene constante el efecto de otras variables relevantes que podrían contaminar los resultados. Para lograr dicho control experimental se deben realizar dos operaciones. En primer lugar, todas las versiones del mensaje que se utilicen en un experimento deben ser iguales en todo menos en el factor que se manipula. Por ejemplo, si se desea manipular la nacionalidad del protagonista de una noticia sobre un suceso delictivo (el protagonista es español versus es extranjero) se crearán dos versiones de dicha noticia, de modo que sean exactamente idénticas en todo menos en dicho elemento (Igartua, 2013). En segundo lugar, el control experimental se refiere a que los individuos que participan en las diferentes condiciones experimentales sean similares antes de comenzar el experimento. En los experimentos esto se logra por medio de la aleatorización de los participantes a las diferentes condiciones o tratamientos experimentales. Es decir, se utilizan procedimientos de sorteo para que los participantes sean asignados por azar a las diferentes condiciones o tratamientos experimentales. Con ello se logra homogeneizar los grupos experimentales de modo que sean equivalentes antes de aplicar el tratamiento. Debido a la aleatorización los diferentes grupos serán tratados como equivalentes y, por tanto, cualquier diferencia entre los grupos en la variable dependiente podrá atribuirse a la acción de la(s) variable(s) independiente(s) y no a la presencia de variables extrañas o contaminadoras. Siguiendo con el ejemplo anterior, por medio de la asignación aleatoria de los participantes a las dos condiciones experimentales (noticia protagonizada por una persona española versus noticia protagonizada por una persona extranjera) se podrá tener seguridad de que, antes de la lectura de la noticia, los participantes son similares en cuestiones relevantes como el nivel de prejuicio hacia los inmigrantes, la edad, el género, el nivel de contacto con inmigrantes o el auto-posicionamiento político. 


\section{Persuasión narrativa: un campo en expansión}

Uno de los pocos rasgos universales de la especie humana es nuestra necesidad de contar y escuchar historias. De hecho, las personas dedican mucho tiempo a consumir mensajes narrativos en forma de series de televisión, películas, videojuegos, novelas, etc. Y los medios sociales también han expandido las oportunidades para exponerse a mensajes narrativos testimoniales, o narraciones personales, en donde las personas comparten sus experiencias o relatan pequeñas historias. En este contexto, se entiende que una narración es una secuencia de acontecimientos conectados causalmente, en los que intervienen uno o varios personajes de cuya experiencia las personas pueden obtener una enseñanza (Hoeken, Kolthoff y Sanders, 2016). A pesar de la centralidad de los mensajes narrativos en la vida de las personas, el estudio científico sobre los efectos de las narraciones (narrative effects; Green, Bilandzic, Fitzgerald y Paravati, 2019) es muy reciente (Green y Brock, 2000; Green, Strange y Brock, 2002) y ha dado lugar a una nuevo campo de investigación en el estudio de los efectos mediáticos que se denomina persuasión narrativa: la investigación sobre persuasión narrativa investiga cómo la exposición a la información que se encuentra dentro de las narraciones produce cambios consistentes con el contenido de la historia en las creencias, actitudes, intención de conducta y comportamiento (Igartua, 2007).

Una de las aplicaciones más relevantes de la investigación sobre persuasión narrativa se está dando en la Comunicación para la Salud, por medio de mensajes narrativos cortos en formato testimonial (por ejemplo, la campaña "Tips from Former Smokers", desarrollada en Estados Unidos por el Centers for Disease Control and Prevention) o mediante narraciones más completas utilizadas en intervenciones de educación-entretenimiento (por ejemplo, la serie "Revelados, desde todas las posiciones" desarrollada en Colombia") (Igartua, 2017b; Igartua y Vega, 2016). En este campo, se ha observado que los mensajes narrativos de salud son capaces de provocar cambios de creencias y actitudes coherentes, así como estimular comportamientos saludables (De Graaf, Sanders y Hoeken, 2016). Otro campo de aplicación es la reducción del prejuicio hacia grupos estigmatizados como los inmigrantes (Igartua, Wojcieszak y Kim, 2019) ya que los formatos narrativos ofrecen un contexto no amenazante en el cual las 
personas pueden experimentar el contacto parasocial vicario con personajes que pertenecen a exogrupos discriminados y que, en situaciones de contacto social directo o interpersonal, provocarían incomodidad o malestar (Chung y Slater, 2013).

El conocimiento académico sobre los procesos de persuasión narrativa permitirá comprender mucho mejor el papel del story-telling en la vida de las personas, pero también mejorará las condiciones en las que se implementen campañas sanitarias (por ejemplo, para la prevención del tabaquismo) o intervenciones narrativas para la reducción del prejuicio y el fomento de la tolerancia hacia grupos estigmatizados.

La investigación sobre persuasión narrativa adopta como metodología dominante el experimento y por ello, en los siguientes epígrafes, se mostrarán las principales características de la investigación en este campo lo que permitirá, a su vez, mostrar las claves metodológicas del experimento en Comunicación.

\section{Variables independientes en la investigación sobre persuasión narrativa}

Los estudios de meta-análisis muestran que las intervenciones narrativas producen efectos significativos, pero también se detecta una variación significativa en estos efectos (Braddock y Dillard, 2016). Ello significa que los mensajes narrativos pueden servir como una herramienta prometedora de comunicación para provocar cambios sociales, pero no todas las narraciones son efectivas. Por lo tanto, un aspecto importante que la comunidad científica se plantea es conocer cuáles son los "ingredientes" (narrative devices) de las narraciones que son más efectivos desde un punto de vista persuasivo. Ello supone indagar acerca de las variables independientes, es decir, qué se manipula en los experimentos sobre persuasión narrativa (para una revisión, véase Tukachinsky, 2014).

Un primer bloque de variables que se manipulan en los experimentos sobre persuasión narrativa se relaciona con las características intrínsecas de los mensajes narrativos (authorial or story-telling techniques). En este tipo de experimentos se modifican las características en la forma de contar la historia, porque ello puede incrementar (o reducir) la implicación o enganche con la misma: a) voz narrativa (primera versus tercera 
persona); b) modalidad (mensaje escrito, sonoro, audiovisual, videojuego); c) estructura del mensaje (alterar el orden cronológico de los acontecimientos); y, d) la perspectiva desde la que se cuenta la historia (protagonista versus antagonista).

Un segundo tipo de manipulación se relaciona con los atributos de los personajes protagonistas de los mensajes narrativos. La variable más analizada en este campo es la similitud: hasta qué punto la audiencia del mensaje comparte ciertos rasgos con el protagonista. La similitud puede basarse en rasgos objetivos (en aspectos demográficos, como el género o la edad) pero también en características psicológicas o subjetivas (como la personalidad, creencias, opiniones, valores o experiencias biográficas). De ahí que en los experimentos sobre persuasión narrativa se manipulen diferentes tipos de similitud: a) similitud demográfica (gender matching); b) similitud en experiencias biográficas o vitales; c) similitud en apariencia física; d) similitud en actitudes, creencias o valores; e) similitud en rasgos de personalidad; f) similitud en términos de identidad social; y e) similitud conductual.

Finalmente, se manipulan variables relacionadas con las condiciones $y$ estados de exposición. Una condición de exposición es un estado psicológico particular en el que las personas reciben el mensaje narrativo. Las condiciones y estados de exposición suelen manipularse mediante procedimientos que: a) buscan provocar distracción (por ejemplo, indicando a los participantes que localicen errores gramaticales o palabras complejas en una narración escrita); b) entregan información meta-narrativa antes de exponerse a la narración (por ejemplo, indicando que la historia que se va a leer, ver o escuchar es ficción versus es una historia basada en hechos reales); c) suministran instrucciones motivacionales a los participantes (por ejemplo, indicando que vean la narración audiovisual para entretenerse versus para analizar su mensaje); d) entrenan la imaginación mediante instrucciones de contacto intergrupal imaginado; y, e) entregan instrucciones para estimular la empatía con el protagonista. 
Tabla 1. Ejemplo de instrucciones para manipular estados o condiciones de exposición.

\begin{tabular}{|c|c|c|}
\hline $\begin{array}{l}\text { Información } \\
\text { meta- narrativa }\end{array}$ & $\begin{array}{l}\text { "Los sucesos narrados en la } \\
\text { historia forman parte de una obra } \\
\text { literaria. El parecido con personas } \\
\text { y lugares reales es, por supuesto, } \\
\text { una coincidencia". }\end{array}$ & $\begin{array}{l}\text { "Los sucesos narrados en la } \\
\text { historia ocurrieron } \\
\text { recientemente y se informó } \\
\text { de ello en un periódico local } \\
\text { hace dos meses". }\end{array}$ \\
\hline $\begin{array}{l}\text { Contacto } \\
\text { intergrupal } \\
\text { imaginado }\end{array}$ & $\begin{array}{l}\text { "Usted va a leer una breve historia, } \\
\text { en la cual una persona comparte } \\
\text { sus experiencias relacionadas con } \\
\text { su vida en España. } \\
\text { Antes de leer la historia, nos } \\
\text { gustaría que pasara los próximos } 2 \\
\text { minutos imaginando que usted } \\
\text { tiene un encuentro con un } \\
\text { inmigrante marroquí por primera } \\
\text { vez. Mientras imagina ese } \\
\text { encuentro piense específicamente } \\
\text { cuándo (por ejemplo, el próximo } \\
\text { jueves) y dónde (por ejemplo, en la } \\
\text { parada de autobús) podría ocurrir } \\
\text { esta conversación. } \\
\text { Imagínese que la interacción es } \\
\text { positiva, relajada y agradable. } \\
\text { Puede servirle de ayuda cerrar los } \\
\text { ojos mientras se imagina la } \\
\text { conversación". }\end{array}$ & $\begin{array}{l}\text { "Usted va a leer una breve } \\
\text { historia, en la cual una } \\
\text { persona comparte sus } \\
\text { experiencias relacionadas } \\
\text { con su vida en España. } \\
\text { Antes de leer la historia, nos } \\
\text { gustaría que pasara los } \\
\text { próximos } 2 \text { minutos } \\
\text { imaginando una escena al } \\
\text { aire libre. } \\
\text { Trate de imaginar diferentes } \\
\text { aspectos de la escena } \\
\text { relevantes para usted (por } \\
\text { ejemplo, que es una playa, } \\
\text { un bosque, hay árboles, } \\
\text { colinas, lo que se ve en el } \\
\text { horizonte). Puede servirle de } \\
\text { ayuda cerrar los ojos } \\
\text { mientras se imagina la } \\
\text { escena al aire libre". }\end{array}$ \\
\hline $\begin{array}{l}\text { Empatía con el } \\
\text { protagonista }\end{array}$ & $\begin{array}{l}\text { "Usted va a leer una breve historia, } \\
\text { en la cual una persona comparte } \\
\text { sus experiencias relacionadas con } \\
\text { su vida en España. Durante la } \\
\text { lectura intente ponerse en el lugar } \\
\text { de esa persona e imagine cómo se } \\
\text { siente por los hechos que describe. } \\
\text { Trate de experimentar el impacto } \\
\text { emocional por las situaciones que } \\
\text { se narran". }\end{array}$ & $\begin{array}{l}\text { "Usted va a leer una breve } \\
\text { historia, en la cual una } \\
\text { persona comparte sus } \\
\text { experiencias relacionadas } \\
\text { con su vida en España. } \\
\text { Durante la lectura intente } \\
\text { mantener una perspectiva } \\
\text { objetiva hacia los hechos } \\
\text { que describe esa persona en } \\
\text { la narración. Trate de no } \\
\text { prestar atención a los } \\
\text { sentimientos } \\
\text { protagonista, manténgase } \\
\text { objetivo y distante". }\end{array}$ \\
\hline
\end{tabular}

Nota. - Las instrucciones de contacto intergrupal imaginado y de empatía con el protagonista fueron utilizadas en el estudio 1 y 2 (respectivamente) del proyecto de investigación "Herramientas narrativas para reducir el prejuicio. Efectos de la similitud, el contacto imaginado, la empatía y la voz narrativa", financiado por el Ministerio de Ciencia, Innovación y Universidades (Agencia Estatal de Investigación. Programa Estatal de Fomento de la Investigación Científica y Técnica de Excelencia) dirigido por Juan José Igartua. 


\section{Variables dependientes en la investigación sobre persuasión narrativa}

Como ya se mencionó en un epígrafe anterior, la investigación sobre persuasión narrativa analiza el efecto de la exposición a la información que se encuentra dentro de mensajes narrativos en las creencias, actitudes, intención de conducta y comportamiento de las personas expuestas a dichos mensajes (Igartua, 2007). Es por ello, que la gran mayoría de los trabajos en este campo utiliza como variables dependientes diferentes medidas relacionadas con las actitudes (las valoraciones o juicios evaluativos sobre objetos sociales), las creencias (los juicios cognitivos acerca de la probabilidad de que un suceso o un objeto estén asociados con mayor o menor fuerza con un determinado atributo), la intención de conducta (la probabilidad subjetiva que un individuo manifiesta en relación a la realización de un determinado comportamiento en el futuro) y los comportamientos (las conductas manifiestas realizadas por una persona).

La revisión de meta-análisis llevada a cabo por Braddock y Dillard (2016) demostró que los menajes narrativos provocan efectos significativos (medidos en coeficientes de correlación $r$ de Pearson) en las actitudes $(r=.19)$, creencias $(r=.17)$, intención de conducta $(r$ $=.17)$, y comportamientos $(r=.23)$. Dichos efectos se pueden considerar entre pequeños y moderados, aunque es preciso tener en cuenta que la mayor parte de la investigación sobre los efectos mediáticos arroja tamaños de efecto entre $r=.10$ y $r=.20$ (Valkenburg, Peter y Walther, 2017). Estos valores en el tamaño del efecto son muy similares a los obtenidos en la investigación en Psicología Social, donde después de analizar la investigación desarrollada durante 105 años (sintetizando 322 estudios de metaanálisis) se concluyó que el tamaño de efecto medio en las investigaciones de dicha disciplina era $r=.21$ (Richard, Bond y StokesZoota, 2003). Además, en el estudio desarrollado por Rains, Levine y Weber (2018), en el que se revisaron 149 estudios de meta-análisis desarrollados en los últimos 60 años en Comunicación, se observó que el tamaño de efecto medio era de $r=.21$ y la mediana en dicho tamaño del efecto era $r=.18$ (es decir, el $50 \%$ de los estudios revisados arrojaba tamaños de efecto iguales o inferiores a $r=.18$ ). Ahora bien, en dicho trabajo también se indicaba el tamaño del efecto en diferentes áreas de investigación, observándose que en persuasión el tamaño de efecto medio era $r=.18$ (mediana del tamaño del efecto $r=.13$ ). 


\section{Tabla 2. Ejemplos de medidas (variables dependientes) en los estudios}

sobre persuasión narrativa.

\begin{tabular}{|c|c|}
\hline $\begin{array}{l}\text { Medida } \\
\text { (fiabilidad de } \\
\text { la escala). }\end{array}$ & Ítems de la escala \\
\hline $\begin{array}{l}\text { Actitud hacia } \\
\text { la inmigración } \\
\left(\alpha_{\text {Cronbach }}=.83\right)\end{array}$ & $\begin{array}{l}\text { Ahora le planteamos algunas preguntas sobre sus opiniones } \\
\text { generales acerca de la inmigración. } \\
\text { Recuerde que no existen respuestas correctas o incorrectas, } \\
\text { simplemente nos interesa su opinión. } \\
\text { Por favor indique en qué medida está a favor o en contra de la } \\
\text { inmigración ( } 1=\text { muy en contra, } 7 \text { = muy a favor). } \\
\text { Por favor indique en qué medida está a favor o en contra de que } \\
\text { el Gobierno español financie campañas de información sobre los } \\
\text { inmigrantes ( } 1 \text { = muy en contra, } 7 \text { = muy a favor). } \\
\text { Por favor indique en qué medida está a favor o en contra de que } \\
\text { el Gobierno endurezca las leyes para impedir la explotación de } \\
\text { los inmigrantes en los lugares de trabajo en España ( } 1 \text { = muy en } \\
\text { contra, } 7=\text { muy a favor). } \\
\text { Como sabe, todos los países desarrollados reciben inmigrantes. } \\
\text { ¿Cree que, en términos generales, la inmigración es más bien } \\
\text { positiva o más bien negativa para España? ( } 1 \text { = muy negativa, } \\
7=\text { muy positiva). }\end{array}$ \\
\hline $\begin{array}{lr}\text { Intención } & \text { de } \\
\text { conducta } & \text { de } \\
\text { contacto intergrupal } \\
\left(\alpha_{\text {Cronbach }}=.87\right)\end{array}$ & $\begin{array}{l}\text { Pensando en la próxima vez que se encuentre en una situación en } \\
\text { la que podría interactuar con un inmigrante marroquí (por } \\
\text { ejemplo, esperando un autobús, con amigos en un café, etc.). } \\
\text { ¿Cuán interesado estaría en iniciar una conversación con } \\
\text { dicha persona? ( } 1 \text { = nada interesado, } 7 \text { = muy interesado) } \\
\text { ¿Cuán importante considera que sería aprender más sobre los } \\
\text { inmigrantes marroquíes y los problemas a los que se enfrentan? (1= } \\
\text { nada importante, } 7=\text { muy importante). } \\
\text { ¿Cuán interesado estaría en participar en un grupo de discusión } \\
\text { que incluyera inmigrantes marroquíes y donde la conversación se } \\
\text { centrara en los temas del prejuicio y la discriminación? ( } 1=\text { nada } \\
\text { interesado, } 7=\text { muy interesado). }\end{array}$ \\
\hline $\begin{array}{l}\text { Intención de } \\
\text { compartir el mensaje } \\
\left(\alpha_{\text {Cronbach }}=.94\right)\end{array}$ & $\begin{array}{l}\text { Piense en el mensaje que acaba de leer. Por favor, indique en qué } \\
\text { medida está de acuerdo o en desacuerdo con las siguientes } \\
\text { afirmaciones ( } 1=\text { muy en desacuerdo, } 7=\text { muy de acuerdo). } \\
\text { Estaría dispuesto a compartir esta información con otras } \\
\text { personas. } \\
\text { Hablaría con otras personas sobre esta información. }\end{array}$ \\
\hline
\end{tabular}




\begin{tabular}{|l|l|}
\hline \multirow{1}{*}{$\begin{array}{l}\text { conducta prosocial } \\
\left(\alpha_{\text {Cronbach }}=.93\right)\end{array}$} & $\begin{array}{l}\text { Orientaría a otras personas para ir a una dirección donde poder } \\
\text { leer esta información. } \\
\text { Le daría "me gusta" a una página en Facebook que tuviera } \\
\text { esta información. } \\
\text { Estaría dispuesto a publicar un enlace a esta información en } \\
\text { Facebook. } \\
\text { Re-tuitearía un enlace con esta información. }\end{array}$ \\
\hline $\begin{array}{l}\text { Gumo usted sabe, en España existen muchas Organizaciones No } \\
\text { contexto, indique en qué medida está de acuerdo o en desacuerdo } \\
\text { con las siguientes afirmaciones (1 = muy en desacuerdo, } 7=\text { muy } \\
\text { de acuerdo). } \\
\text { Me gustaría hacerme socio de una ONG de apoyo a } \\
\text { inmigrantes. }\end{array}$ \\
$\begin{array}{l}\text { Estaría dispuesto a donar dinero a una ONG para financiar } \\
\text { campañas contra el racismo y la xenofobia. } \\
\text { Estoy considerando colaborar activamente como voluntario en una } \\
\text { ONG de apoyo a inmigrantes. } \\
\text { Me gustaría recibir información sobre las actividades desarrolladas } \\
\text { por alguna ONG de apoyo a inmigrantes. }\end{array}$ \\
\hline
\end{tabular}

Nota.- Medidas utilizadas en el proyecto de investigación "Herramientas narrativas para reducir el prejuicio. Efectos de la similitud, el contacto imaginado, la empatía y la voz narrativa", financiado por el Ministerio de Ciencia, Innovación y Universidades (Agencia Estatal de Investigación. Programa Estatal de Fomento de la Investigación Científica y Técnica de Excelencia) dirigido por Juan José Igartua. Los datos de fiabilidad de la medida de actitud e intención de conducta de contacto intergrupal se refieren al Estudio 1, realizado sobre una muestra de 400 personas residentes en España (50\% mujeres, de 18 a 65 años, $M_{\text {edad }}=40,41$ años, $\left.D E_{\text {edad }}=12,16\right)$ Los datos de fiabilidad de las medidas de intención de compartir el mensaje y de intención de conducta prosocial se refieren al Estudio 3, realizado sobre una muestra de 464 personas residentes en España (50\% mujeres, de 18 a 65 años, $M_{\text {edad }}=41,11$ años, $D E_{\text {edad }}=12,51$ )

\section{Variables mediadoras y moderadoras en la investigación sobre persuasión narrativa}

El análisis de los procesos causales se ha vuelto más complejo en la actualidad en la investigación experimental, en general, y también en los estudios sobre persuasión narrativa, en particular. La investigación experimental más reciente y avanzada no solo se preocupa por demostrar efectos principales (o de interacción) de una o más variables independientes sobre una variable dependiente, sino que cada vez son más frecuentes los análisis centrados en los efectos condicionales y en los efectos indirectos (Walter et al., 2018). En este escenario, entran 
en juego los conceptos de variable moderadora (lo que remite al análisis de los efectos condicionales) y variable mediadora (lo que supone analizar los efectos indirectos).

Una variable moderadora es la que modifica la relación entre una variable independiente y una variable dependiente, de modo que el signo y/o la fuerza de la relación entre ambas variables depende de la influencia de dicha variable moderadora (Hayes, 2018). Por tanto, el análisis de la moderación se refiere a cuándo o en qué situaciones se produce un determinado efecto. En el contexto de la investigación sobre persuasión narrativa, el análisis de la moderación permite conocer bajo qué circunstancias se produce un efecto en actitudes, creencias, intención de conducta o comportamientos. Por ejemplo, podría aventurarse que un mensaje narrativo diseñado para estimular la empatía hacia los inmigrantes será más eficaz (mejorará en mayor medida las actitudes hacia la inmigración) que un mensaje que simplemente muestre ejemplos de interacciones positivas entre la población autóctona e inmigrante, pero que dicho efecto solo se produciría en personas que puntuaran bajo o moderado en racismo moderno, de modo que las personas más racistas serían inmunes a un mensaje de tales características (véase Tabla 3, para una descripción de una medida del racismo moderno) (Igartua y Frutos, 2016).

En la investigación sobre persuasión narrativa, las variables moderadoras se pueden clasificar en cuatro grandes grupos. En primer lugar, las variables moderadoras pueden estar vinculadas con medidas de diferencias individuales. Dichas diferencias individuales, a su vez, pueden relacionarse con rasgos de personalidad o características estables de las personas, como la necesidad de cognición, que mide el grado de motivación y preferencia que muestran las personas hacia actividades cognitivas como reflexionar o resolver problemas que requieren esfuerzo (Falces, Briñol, Sierra, Becerra y Alier, 2001). También pueden referirse a medidas relacionadas con percepciones sobre determinados objetos sociales, con características sociodemográficas (como la ideología política o la edad) y con medidas de estado o variables que pueden fluctuar de un momento a otro (como el estado de ánimo). 
Tabla 3. Ejemplo de variable moderadora: racismo moderno.

\begin{tabular}{|l|l|}
\hline $\begin{array}{l}\text { Medida } \\
\text { (fiabilidad de } \\
\text { la escala) }\end{array}$ & \multicolumn{1}{|c|}{ Ítems de la escala } \\
\hline $\begin{array}{l}\text { Escala de } \\
\text { racismo } \\
\text { moderno } \\
\left(\alpha_{\text {Cronbach }=89)}\right.\end{array}$ & $\begin{array}{l}\text { Nos gustaría conocer tus opiniones sobre la inmigración y los } \\
\text { inmigrantes en general que residen en España. Para ello responde } \\
\text { indicando tu grado de acuerdo o desacuerdo con cada afirmación }(1= \\
\text { muy en desacuerdo, 7 muy de acuerdo). } \\
\text { "En los últimos años, los inmigrantes han conseguido } \\
\text { económicamente más de lo que merecen". } \\
\text { "En los últimos años, el gobierno y los medios de comunicación han } \\
\text { mostrado más respeto y consideración por los inmigrantes del que se } \\
\text { merecen". } \\
\text { "Los inmigrantes están siendo demasiado exigentes en su lucha por } \\
\text { la igualdad de derechos". } \\
\text { "Los inmigrantes tienen más influencia sobre las decisiones de los } \\
\text { políticos de la que deberían tener". } \\
\text { "Los inmigrantes están ahora mejor de lo que nunca han estado". } \\
\text { "Los inmigrantes que reciben ayuda social podrían salir adelante sin } \\
\text { ella si lo intentaran de verdad". } \\
\text { "En general, los funcionarios públicos dedican más atención a las } \\
\text { peticiones y quejas de los inmigrantes que a las de un ciudadano } \\
\text { español". } \\
\text { "Todos los españoles deberíamos apoyar a los inmigrantes en su } \\
\text { lucha contra la discriminación" (R). } \\
\text { "Los inmigrantes no deberían estar donde no se les quiere". }\end{array}$ \\
\hline
\end{tabular}

Nota. - Dicha escala se utilizó en el estudio "Procesos de recepción y efectos socio- cognitivos de películas sobre inmigración. El papel moderador del prejuicio hacia inmigrantes", publicado en la revista Migraciones (Igartua y Frutos, 2016).

Un segundo tipo de variable moderadora se relaciona con los aspectos evolutivos, es decir, con las características diferenciales existentes entre las personas que se explican por su desarrollo psico- social. En tercer lugar, existen variables moderadoras de tipo socio- cultural o contextual, que se relacionan con aspectos culturales generales (como el porcentaje de población inmigrante, que puede variar en diferentes países y condicionar el efecto de un mensaje de reducción de la xenofobia en las actitudes hacia la inmigración). Las variables contextuales pueden vincularse también con aspectos interpersonales o referirse a las condiciones en las que se recibe un mensaje narrativo (por ejemplo, visionar un mensaje narrativo audiovisual en compañía de otras personas o hacerlo en solitario; Tal- Or y Tsfati, 2016). 
Finalmente, también se puede hablar de moderación cuando se observa el efecto de interacción entre ciertas características de los mensajes narrativos, es decir, cuando en el diseño experimental se manipulan dos o más variables relacionadas con rasgos intrínsecos del mensaje (por ejemplo, la voz narrativa) y/o alguna característica del protagonista de la narración (por ejemplo, la similitud con la audiencia del mensaje) (Kim, Kim, Wojcieszak, Igartua y Min, 2019, estudio 2).

El análisis de la mediación se centra en tratar de explicar cómo o por qué (procesos, mecanismos) se produce un determinado efecto mediático (es decir, cómo se explica la relación entre una variable independiente y una variable dependiente) (Igartua, 2006, 2012). En este sentido, una variable mediadora puede ser cualquier variable relacionada con un estado psicológico, un proceso cognitivo, afectivo, un cambio biológico o fisiológico relacionado con la variable independiente y la variable dependiente (Hayes, 2018). Este tipo de análisis (de efectos indirectos) es importante porque permite postular y contrastar explicaciones teóricas que ayuden a entender los procesos que operan en la realidad.

En la investigación sobre los procesos de persuasión narrativa se han desarrollado diferentes modelos teóricos para comprender cómo y por qué los mensajes narrativos provocan cambios en actitudes, creencias, intención de conducta y comportamientos. Los principales modelos teóricos de la persuasión narrativa son el Modelo de Transporte Narrativo (Transportation-Imagery Model) de Green y Brock (2002), el Modelo Extendido de Probabilidad de Elaboración (Extended Elaboration Likelibood Model, E-ELM) de Slater y Rouner (2002), y el Modelo de Superación de la Resistencia mediante Mensajes de Entretenimiento (Entertainment Overcoming Resistance Model, EORM) de Moyer-Gusé (2008). En este contexto, los principales procesos mediadores identificados por dichos modelos y estudiados empíricamente son la identificación con el protagonista, el enganche o transporte narrativo, la contra-argumentación y la reactancia (Tukachinsky, 2014; Tukachinsky y Stokunaga, 2013).

La identificación es un proceso imaginativo que implica la pérdida de autoconciencia paulatina y la asunción del punto de vista afectivo y cognitivo del protagonista de una narración (Cohen, 2001; Igartua, 
2010; Igartua y Fiuza, 2018). El transporte narrativo es un proceso psicológico que implica un estado de enganche o inmersión con la historia o el relato que se narra (Busselle y Bilandzic, 2009; Green y Brock, 2000). La contra-argumentación es el proceso de emisión de valoraciones críticas durante la exposición al mensaje (y que supone pensar en negativo sobre la propuesta persuasiva o preventiva). $\mathrm{Ha}$ sido definida de manera operacional como la generación de pensamientos (o respuestas cognitivas) que refutan explícitamente la propuesta persuasiva incorporada en el mensaje (Niederdeppe, Kim, Lundell, Fazili y Frazier, 2012). Finalmente, la reactancia es un segundo proceso vinculado con la resistencia ante el intento persuasivo que se pone en marcha cuando el individuo considera que su libertad de elección está siendo amenazada (Quick, 2012; Reynolds-Tylus, 2019). 
Tabla 4. Ejemplos de variables mediadoras en los estudios sobre persuasión narrativa

\begin{tabular}{|l|l|}
\hline $\begin{array}{l}\text { Medida } \\
\text { (fiabilidad de } \\
\text { la escala) }\end{array}$ & Ítems de la escala \\
\hline $\begin{array}{l}\text { Identificación con } \\
\text { la protagonista } \\
\left(\alpha_{\text {Cronbach }}=.93\right)\end{array}$ & $\begin{array}{l}\text { La historia que acaba de leer cuenta la experiencia personal } \\
\text { de Alina desde que llegó a España. Por favor, indique en } \\
\text { qué medida ha experimentado lo siguiente durante la lectura } \\
\text { de la historia de Alina (1= nada, } 5=\text { mucho). } \\
\text { Me he sentido implicado afectivamente con los } \\
\text { sentimientos de Alina. } \\
\text { Me he sentido como "si yo fuera Alina". } \\
\text { He imaginado cómo actuaría yo si me encontrara en el lugar } \\
\text { de Alina. } \\
\text { Me he sentido preocupado por lo que le sucedía a Alina. } \\
\text { He comprendido la forma de actuar, pensar o sentir de } \\
\text { Alina. } \\
\text { Yo mismo he experimentado las reacciones emocionales de } \\
\text { Alina. } \\
\text { He intentado imaginar los sentimientos, pensamientos y } \\
\text { reacciones de Alina. } \\
\text { He tenido la impresión de vivir realmente yo mismo la } \\
\text { historia de Alina. } \\
\text { He entendido los sentimientos o emociones de Alina. } \\
\text { He intentado ver las cosas desde el punto de vista de Alina. } \\
\text { Me he identificado con Alina. }\end{array}$ \\
\hline $\begin{array}{l}\text { Transporte } \\
\text { narrativo } \\
=.86)\end{array}\left(\alpha_{\text {Cronbach }}\right.$ & $\begin{array}{l}\text { Por favor indique en qué medida está de acuerdo o en } \\
\text { desacuerdo con las siguientes frases relativas al texto que acaba } \\
\text { de leer (1 = muy en desacuerdo, 7 = muy de acuerdo). } \\
\text { Podía imaginarme a mí mismo en las situaciones descritas en } \\
\text { la narración. } \\
\text { Me sentí muy implicado mentalmente durante la lectura del } \\
\text { relato. } \\
\text { Quería saber cómo iba a terminar la historia. El texto me ha } \\
\text { afectado emocionalmente. } \\
\text { Mientras leía la narración me hice una imagen muy vívida y } \\
\text { clara de Alina }\end{array}$ \\
\hline
\end{tabular}




\begin{tabular}{|c|c|}
\hline $\begin{array}{l}\text { Contra- } \\
\text { argumentación } \\
\left(\alpha_{\text {Cronbach }}=.77\right)\end{array}$ & $\begin{array}{l}\text { Ahora responda a las siguientes preguntas teniendo en cuenta lo que } \\
\text { pensaba durante la lectura de la narración }(1=\text { muy en desacuerdo, } 7 \\
\text { = muy de acuerdo). } \\
\text { Mientras leía la narración, he pensado que no estaba de acuerdo con } \\
\text { algunas de las cosas dichas por Alina. } \\
\text { Mientras leía el mensaje, pensaba que la información que daba Alina } \\
\text { era inexacta, engañosa o exagerada. } \\
\text { Durante la lectura del relato, intentaba averiguar si había defectos en } \\
\text { las conclusiones que sacaba Alina sobre algunos temas. }\end{array}$ \\
\hline $\begin{array}{l}\text { Reactancia } \\
\left(\alpha_{\text {Cronbach }}=.89\right)\end{array}$ & $\begin{array}{l}\text { Indique en qué medida está de acuerdo o desacuerdo con las } \\
\text { siguientes afirmaciones relacionadas con el relato que acaba de leer } \\
(1=\text { muy en desacuerdo, } 7 \text { = muy de acuerdo). } \\
\text { El mensaje amenazaba mi libertad de elegir. } \\
\text { El mensaje intentaba tomar una decisión por mí. El mensaje } \\
\text { trataba de manipularme. } \\
\text { El mensaje intentaba presionarme. }\end{array}$ \\
\hline $\begin{array}{l}\text { Elaboración } \\
\text { cognitiva } \\
\left(\alpha_{\text {Cronbach }}=.81\right)\end{array}$ & $\begin{array}{l}\text { Ahora responda a las siguientes preguntas teniendo en cuenta lo que } \\
\text { pensaba durante la lectura de la narración }(1=\text { muy en desacuerdo, } \\
7=\text { muy de acuerdo). } \\
\text { Mientras leía la narración, reflexioné intensamente sobre el tema de la } \\
\text { inmigración. } \\
\text { A medida que avanzaba en la lectura, he intentado sacar } \\
\text { conclusiones para ajustar mis opiniones sobre la inmigración. } \\
\text { La lectura del mensaje me ha hecho pensar profundamente sobre la } \\
\text { vida de los inmigrantes en España. }\end{array}$ \\
\hline
\end{tabular}

Nota. - Medidas de variables mediadoras utilizadas en el proyecto de investigación "Herramientas narrativas para reducir el prejuicio. Efectos de la similitud, el contacto imaginado, la empatía y la voz narrativa", financiado por el Ministerio de Ciencia, Innovación y Universidades (Agencia Estatal de Investigación. Programa Estatal de Fomento de la Investigación Científica y Técnica de Excelencia) dirigido por Juan José Igartua. Los datos de fiabilidad de las diferentes escalas fueron obtenidos en el Estudio 3, realizado sobre una muestra de 464 personas residentes en España (50\% mujeres, de 18 a 65 años, $M_{\text {edad }}=41,11$ años, $\left.D E_{\text {edad }}=12,51\right)$.

Los procesos mediadores se pueden clasificar en dos grupos en función de su rol en la cadena causal. El primer grupo de mecanismos mediadores incluye aquellos que están directamente relacionados con el impacto de las características de los mensajes narrativos y son la identificación con el protagonista y el transporte narrativo. El segundo 
grupo se refiere a los mecanismos mediadores que ayudan a explicar por qué las personas implicadas con las narraciones y sus protagonistas son persuadidas. En este caso, se ha establecido que la identificación y el transporte narrativo tienden a reducir los procesos de contra- argumentación y reactancia: una persona altamente implicada con una narración ve impedida su capacidad para criticar el contenido actitudinal del mensaje (su propuesta persuasiva) y, por ello, puede asimilar más fácilmente las creencias y actitudes vehiculadas en el mismo. Por tanto, en el inicio de la cadena causal, la identificación y el transporte narrativo actúan como procesos mediadores primarios, dado que inician el proceso que va a facilitar el impacto persuasivo, a través de reducir la emisión de contra-argumentos y la reactancia que se consideran mecanismos mediadores secundarios (véase Figura 2).

Figura 2. Mediadores primarios y secundarios en la investigación sobre persuasión narrativa.

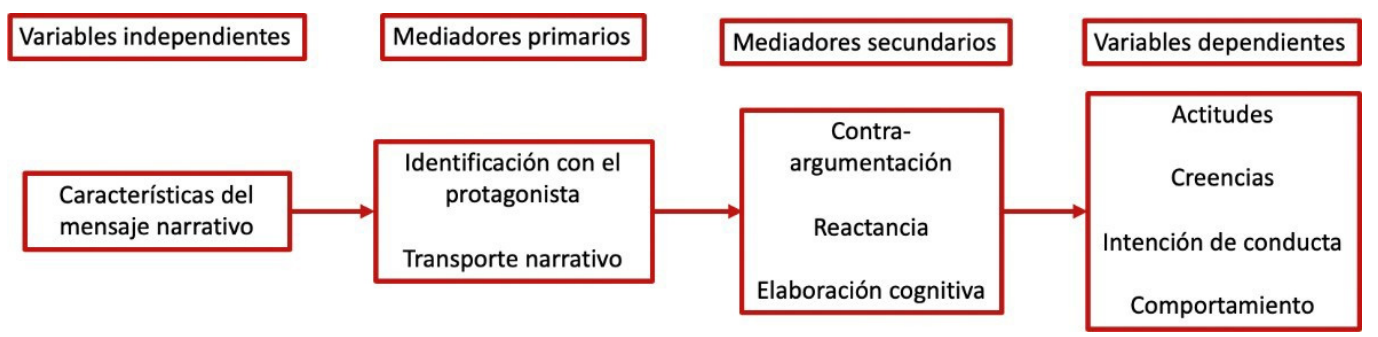

Recientemente también se ha establecido un mecanismo mediador secundario adicional que es la elaboración cognitiva (Igartua y Vega, 2016). La elaboración cognitiva se define como un proceso de reflexión en torno a los contenidos del mensaje persuasivo y constituye una medida de la intensidad con la que se reflexiona sobre el tema abordado en la narración durante el proceso de recepción. Se ha argumentado que la elaboración cognitiva provoca que se generen respuestas cognitivas relevantes con el tema principal del mensaje narrativo, lo que determinará el impacto actitudinal. Por tanto, la elaboración cognitiva se plantea como un mecanismo mediador secundario que compite con los mecanismos de resistencia ante el mensaje narrativo. 


\section{Conclusiones: retos en la investigación sobre persuasión narrativa}

La investigación sobre persuasión narrativa es un campo relativamente nuevo en la investigación en comunicación, ya que el primer trabajo empírico reseñable fue publicado en el año 2000 (Green y Brock, 2000) ${ }^{1}$. Sin embargo, su crecimiento ha sido exponencial, como lo atestigua el análisis desarrollado por Braddock y Dillard (2016):

"En las últimas dos décadas, la investigación relacionada con los efectos de las narraciones en las actitudes y creencias ha crecido a un ritmo dramático. Una búsqueda en la base de datos Communication and Mass Media Complete sobre artículos con el término "narrative" en el título arrojaba 15 citas de artículos publicados en el año 1993. La misma búsqueda en el año 2003 mostró un aumento del 380\% en relación con el número de artículos publicados, y en 2013, un incremento del 700\%. Dicha base de datos indicaba igualmente que habían sido publicados1.346 artículos (en revistas con procesos de revisión por pares) sobre este tema en los últimos 20 años" (Braddock y Dillard, 2016, p. 446).

A pesar de su rápida expansión como área de investigación, cabe plantearse cuáles son los retos que se plantean en este campo y cuáles deberían ser los siguientes hitos para mejorar la comprensión científica sobre cómo influyen los mensajes narrativos en las actitudes, creencias y comportamientos de las personas.

En primer lugar, consideramos que el futuro de este campo deberá ir parejo al desarrollo metodológico que se está produciendo en la investigación experimental en comunicación y en disciplinas afines (como la psicología). El experimento es la técnica dominante en la investigación en persuasión narrativa (Dahlstrom, Niederdeppe, Gao y Zhu, 2017) y en este campo una de las principales innovaciones que se está produciendo es la inclusión de medidas fisiológicas y basadas en técnicas de neuroimagen para analizar los procesos de recepción (Potter y Bolls, 2012; Rodero, Larrea y Mas, 2016). Este es un elemento muy relevante dado que el consumo de un mensaje narrativo es un proceso que tiene lugar en el tiempo (es un proceso on line o dinámico) y ello supone que los procesos mediadores (como la identificación con los personajes o el transporte narrativo) fluctúan y

\footnotetext{
${ }^{1}$ El trabajo de Green y Brock (2000) ha sido citado hasta la fecha (2 de diciembre de 2019) 3.344 veces en Google Scholar.
} 
experimentan cambios. En segundo lugar, también es relevante este cambio hacia un modelo de media neuroscience porque las medidas fisiológicas y las basadas en técnicas de neuroimagen permiten una evaluación de los procesos psicológicos de una manera más completa y global, ya que toda actividad mental existe en el cerebro y se manifiesta a través de determinados patrones de actividad del sistema nerviosos central y periférico, puesto que "the brain is embodied" (Potter y Bolls, 2012, p. 24). En tercer lugar, esta aproximación fisiológica permite ir más allá del recuerdo de un proceso psicológico (“¿cuánto me he sentido enganchado con el mensaje narrativo durante su visionado?") que es lo que permiten las medidas de auto-informe basadas en escalas auto- aplicadas. Ahora bien, afirmar esto no supone considerar que las medidas basadas en el auto-informe de los participantes son poco "válidas", porque el escenario ideal es utilizarlas en combinación con las medidas fisiológicas, llegando a una situación de triangulación metodológica que se apoye en medidas conductuales, medidas de auto- informe y medidas fisiológicas (Bolls et al., 2019). Además, existen procesos relevantes en este campo que se definen como constructos multidimensionales (como sucede con el concepto de identificación con los personajes; Igartua y Barrios, 2012), por lo que resulta extremadamente complicado contar con un solo sistema de medición fisiológica para evaluar dicho proceso o experiencia de recepción (véase, van Krieken, Hoeken y Sanders, 2017).

Un segundo reto en la investigación sobre persuasión narrativa es fundir la investigación sobre big data con las intervenciones de educación-entretenimiento para desarrollar mensajes narrativos altamente personalizados que lleguen en la "dosis" más adecuada a las personas que más lo necesitan. Por ejemplo, en el ámbito de la prevención del racismo y la xenofobia, chasta qué punto es posible personalizar la difusión de "píldoras narrativas" que contengan los "ingredientes" necesarios para persuadir a las personas que muestran un mayor rechazo hacia inmigrantes estigmatizados? Las técnicas de big data podrían ser utilizadas para localizar a las personas con perfiles más problemáticos (por ejemplo, a través de comentarios en las redes sociales y el análisis supervisado de sentimientos) (Arcila, Ortega, Jiménez y Trulleque, 2017). También podrían ser utilizadas para detectar qué elementos narrativos pueden resultar más eficaces para 
persuadir a personas con diferentes perfiles psico-sociales. Este, sin lugar a dudas, será un campo de crecimiento en los próximos años en la investigación sobre persuasión narrativa.

Un tercer reto de la investigación en persuasión narrativa es trabajar en el seno de programas de investigación que permitan encadenar diferentes experimentos para determinar con mayor rigor el rol de los diferentes mecanismos mediadores (primarios y secundarios). Aunque los modelos estadísticos permiten incluir varios mecanismos mediadores "en serie o en paralelo" (Hayes, 2018), la garantía sobre las conclusiones causales es menor cuando el modelo que se pone a prueba mide en el mismo tiempo todos los procesos mediadores, dado que hablar de correlación no significa demostrar una relación causal. Por ello, sería recomendable encadenar unos experimentos con otros, formalizando un programa de investigación. En un primer momento supondría manipular variables del mensaje (narrative devices) que influyen en los procesos mediadores primarios (identificación, transporte narrativo, etc.) e, indirectamente, en las variables dependientes consideradas (actitudes, creencias, intención de conducta o comportamientos). En segundo lugar, se procedería a manipular variables procesuales (por ejemplo, la identificación con los personajes mediante la perspectiva; Hoeken, Kolthoff y Sanders, 2016) para ver su influencia en procesos mediadores secundarios (contra-argumentación, reactancia, elaboración cognitiva). De este modo, los resultados obtenidos permitirían concluir con mayor seguridad sobre la relación causal entre las variables independientes, los procesos o mecanismos mediadores y las variables dependientes, precisamente una de las principales metas de la metodología experimental.

\section{Bibliografía}

Arcila, C., Ortega, F., Jiménez, J. y Trulleque, S. (2017). Análisis supervisado de sentimientos políticos en español: clasificación en tiempo real de tweets basada en aprendizaje automático. El Profesional de la Información, 26(5), 978-987.

Bolls, P. D., Weber, R., Lang, A. y Potter, R. F. (2019). Media psychophysiology and neuroscience: bringing brain science into media processes and effects research. En M. B. Oliver, A. A. 
Raney y.J. Bryant (Eds.) Media Effects. Advances in theory and research (pp. 195-210) Nueva York, NY: Routledge.

Boyle, M. y Schmierbach, M. (2015). Applied communication research methods. Getting started as a researcher. Nueva York, NY: Routledge.

Braddock, K. y Dillard, J. P. (2016). Meta-analytic evidence for the persuasive effect of narratives on beliefs, attitudes, intentions, and behaviors. Communication Monographs, 83(4), 446-467.

Bryant, J. y Miron, D. (2004). Theory and research in mass communication. Journal of Communication, 54(4), 662-704.

Busselle, R. y Bilandzic, H. (2009). Measuring narrative engagement. Media Psychology, 12(4), 321-347.

Cohen, J. (2001). Defining identification: A theoretical look at the identification of audiences with media characters. Mass Communication y Society, 4(3), 245-264.

Cohen, R. (2012). (Director). En la mente del asesino [película]. Estados Unidos: QED International.

Chung, A. H. y Slater, M. D. (2013). Reducing stigma and out-group distinctions through perspective-taking in narratives. Journal of Communication, 63(5), 894-911.

Dahlstrom, M. F., Niederdeppe, J., Gao, L. y Zhu, X. (2017). Operational and conceptual trends in narrative persuasion research: comparing health-and non-health-related contexts. International Journal of Communication, 11,4865-4885.

Falces, C., Briñol, P., Sierra, B., Becerra, A. y Alier, E. (2001). Validación de la escala de necesidad de cognición y su aplicación al estudio del cambio de actitudes. Psicothema, 13(4), 622-628.

Graaf, A. D., Sanders, J. y Hoeken, H. (2016). Characteristics of narrative interventions and health effects: A review of the content, form, and context of narratives in health-related narrative persuasion research. Review of Communication Research, 4, 88-131. 
Green, M., Bilandzic, H., Fitzgerald, K. y Paravati, E. (2019). Narrative effects. En M. B. Oliver, A. A. Raney y J. Bryant (Eds.) Media Effects. Advances in theory and research (pp. 130-145). Nueva York, NY: Routledge.

Green, M. C. y Brock, T. C. (2000). The role of transportation in the persuasiveness of public narratives. Journal of Personality and Social Psychology, 79(5), 701-72.

Strange, J., Green, M. y Brock, T. (2002). Narrative impact. Social and cognitive foundations. Mahwah, NJ: Lawrence Erlbaum Associates.

Hayes, A. F. (2018). Introduction to mediation, moderation, and conditional process analysis second edition. A regression-based approach. Nueva York, NY: The Guilford Press.

Hoeken, H., Kolthoff, M. y Sanders, J. (2016). Story perspective and character similarity as drivers of identification and narrative persuasion. Human Communication Research, 42(2), 292-311.

Igartua, J. J. (2006). Métodos cuantitativos de investigación en comunicación. Barcelona: Bosch.

Igartua, J. J. (2007). Persuasión narrativa. Alicante: Editorial Club Universitario.

Igartua, J. J. (2010). Identification with characters and narrative persuasion through fictional feature films. Communications. The European Journal of Communication Research, 35(4), 347-373.

Igartua, J. J. (2012). Tendencias actuales en los estudios cuantitativos en comunicación. Comunicación y Sociedad, 17(1), 15-40.

Igartua, J. J. (2013). Impacto actitudinal y canalización cognitiva de estereotipos sobre la inmigración a través de las noticias. Revista Latina de Comunicación Social, 68, 599-621.

Igartua, J. J. (2015). Psicología social de los medios de comunicación. En J. M. Sabucedo y J. F. Morales (Eds.) Psicología social, (pp. 371391). Madrid: Editorial Médica Panamericana. 
Igartua, J. J. (2017a). Cuestiones de calidad y metodología en la investigación en Comunicación en España. En B. Díaz Nosty y R. De Frutos (Coords.) Tendencias en la investigación universitaria española en Comunicación, (pp. 269-286). Pamplona: Thomson Reuters-Aranzadi.

Igartua, J. J. (2017b). Comunicación para la salud y eduentretenimiento. En U. Cuesta, C. Peñafiel, J. L. Terrón, E. Bustamante y S. Gaspar (Coords.) Comunicación y salud, (pp. 161181). Madrid: Dextra.

Igartua, J. J. y Barrios, I. M. (2012). Changing real-world beliefs with controversial movies. Processes and mechanisms of narrative persuasion. Journal of Communication, 62(3), 514-531.

Igartua, J. J. y Fiuza, D. (2018). Persuading with narratives against gender violence. Effect of similarity with the protagonist on identification and risk-perception. Palabra Clave, 21(2), 499-523.

Igartua, J. J. y Frutos, F. J. (2016). Procesos de recepción y efectos socio-cognitivos de películas sobre inmigración. El papel moderador del prejuicio hacia inmigrantes. Migraciones, 40, 33-61.

Igartua, J. J. y Vega, J. (2016). Identification with characters, elaboration, and counterarguing in entertainment-education interventions through audiovisual fiction. Journal of Health Communication, 21(3), 293-300.

Igartua, J. J., Wojcieszak, M. y Kim, N. (2019.) How the interplay of imagined contact and first-person narratives improves attitudes toward stigmatized immigrants. A conditional process model. European Journal of Social Psychology, 49 (2), 385-397.

Kim, N., Kim, H. K., Wojcieszak, M., Igartua, J. J. y Min, L. C. (2019). The presence of the protagonist: explaining narrative perspective effects through social presence. Media Psychology. https://doi.org/10.1080/15213269.2019.1665548

Lang, A. (2013). Discipline in crisis? The shifting paradigm of mass communication research. Communication Theory, 23(1), 10-24. 
Moyer-Gusé, E. (2008). Toward a theory of entertainment persuasion: Explaining the persuasive effects of entertainment- education messages. Communication Theory, 18(3), 407-425.

Niederdeppe, J., Kim, H. K., Lundell, H., Fazili, F. y Frazier, B. (2012). Beyond counterarguing: simple elaboration, complex integration, and counter elaboration in response to variations in narrative focus and sidedness. Journal of Communication, 62(5), 758- 777.

Potter, R. F. y Bolls, P. (2012). Psychophysiological measurement and meaning. Cognitive and emotional processing of media. Nueva York, NY: Routledge.

Potter, W. J. (2011). Conceptualizing mass media effect. Journal of Communication, 61(5), 896-915.

Potter, W. J. (2012). Media effects. Thousand Oaks, CA: Sage.

Potter, W. J., y Riddle, K. (2007). A content analysis of the media effects literature. Journalism y Mass Communication Quarterly, 84(1), 90-104.

Quick, B. L. (2012). What is the best measure of psychological reactance? An empirical test of two measures. Health Communication, 27(1), 1-9.

Rains, S. A., Levine, T. R. y Weber, R. (2018). Sixty years of quantitative communication research summarized: lessons from 149 meta-analyses. Annals of the International Communication Association, 42(2), 105-124.

Richard, F. D., Bond, C. F. y Stokes-Zoota, J. J. (2003). One hundred years of social psychology quantitatively described. Review of General Psychology, 7(4), 331-363.

Rodero, E., Larrea, O. y Mas, L. (2016). Media Psychology y su aproximación a la psicofisiología: una nueva disciplina para comprender los procesos mediáticos. Disertaciones. Anuario Electrónico de Estudios en Comunicación Social, 9(2), 163-180. 
Slater, M. D. y Rouner, D. (2002). Entertainment-education and elaboration likelihood: Understanding the processing of narrative persuasion. Communication Theory, 12(2), 173-191.

Tal-Or, N. y Tsfati, Y. (2016). When Arabs and Jews watch TV together: the joint effect of the content and context of communication on reducing prejudice. Journal of Communication, 66(4), 646-668.

Thorson, E., Wicks, R. y Leshner, G. (2012). Experimental methodology in journalism and mass communication research. Journalism y Mass Communication Quarterly, 89(1), 112-124.

Tukachinsky, R. (2014). Experimental manipulation of psychological involvement with media. Communication Methods and Measures, 8(1), 1-33.

Tukachinsky, R. y Stokunaga, R. (2013). The effects of engagement with entertainment. Annals of the International Communication Association, 37(1), 287-322.

Reynolds-Tylus, T. (2019). Psychological reactance and persuasive health communication: a review of the literature. Frontiers in Communication, 4, 56.

Valkenburg, P. M. y Peter, J. (2013). The differential susceptibility to media effects model. Journal of Communication, 63(2), 221-243.

Valkenburg, P. M., Peter, J. y Walther, J. B. (2016). Media effects: theory and research. Annual Review of Psychology, 67, 315-338.

Van Krieken, K., Hoeken, H. y Sanders, J. (2017). Evoking and measuring identification with narrative characters. A linguistic cues framework. Frontiers in Psychology, 8, 1190.

Walter, N., Cody, M. J. y Ball-Rokeach, S. J. (2018). The ebb and flow of communication research: seven decades of publication trends and research priorities. Journal of Communication, 68(2), 424-440.

Wimmer, R. D. y Dominick, J. R. (2013). Mass media research. An introduction. Boston, MA: Wadsworth (10 edición). 
Yanovitzky, I. y Greene, K. (2009). Quantitative methods and causal inference in media effects research. En R. L. Nabi y M. B. Oliver (Eds.) The SAGE handbook of media processes and effects (pp. 35-52) Thousand Oaks, CA: Sage. 



\section{Metodología de estudio de la audiencia social de televisión: análisis por indicadores}

\section{Soledad Ruano López}

Profesora Titular de Comunicación Audiovisual y Publicidad.

Universidad de Extremadura

\section{$\mathbf{M}^{\mathrm{a}}$ del Rosario Fernández-Falero}

Profesora Contratada Doctora de Biblioteconomía y Documentación.

Universidad de Extremadura

\section{Resumen}

El principal objetivo de este trabajo es mostrar la metodología de evaluación por indicadores, en redes sociales, de series de ficción españolas emitidas por canales generalistas. Además, se incluye el estudio de un caso: análisis de un curso televisivo de series, programadas en prime time, de Antena 3, La 1 y Tele 5.

\section{Introducción}

T A TELEVISIÓN vive una paradójica situación ante la crisis de 1 los sistemas tradicionales de medición de audiencia; por un lado, los nuevos servicios de vídeo bajo demanda, las plataformas como Netflix, HBO o Amazon, han hecho una fuerte apuesta por las series, hay un aumento de popularidad de las series. Además, la cantidad de horas que los usuarios pasan viendo una serie en las plataformas hace 
que estas resulten muy rentables, en perjuicio del consumo de las mismas en la televisión lineal, lo que está provocando una grave crisis en esta forma de consumo de la televisión; y por otro, el consumo, sobre todo de ficción, se personaliza y se distancia de la programación lineal de las cadenas.

En este contexto, han emergido con fuerza las redes sociales en las cadenas de televisión de todo el mundo y se están convirtiendo en una herramienta clave para compartir conocimiento y dar a conocer contenidos de los programas en general y de las series en particular. Cualquier programa de televisión se ha visto afectado por este nuevo fenómeno que son las redes sociales. Este fenómeno ha ido creciendo tanto que ha creado un nuevo contexto y, debido a ello, las cadenas crean webs propias para dichos programas, donde los seguidores pueden entrar y hacer comentarios en las redes sociales creadas para tal fin, de manera que satisfacen con inmediatez y eficacia las nuevas necesidades.

Con las redes sociales los espectadores están en contacto directo, los usuarios pueden dejar sus comentarios y opiniones a través de la propia web, de la propia página de Facebook o sus cuentas en Twitter o Instagram. Además, las redes sociales permiten a los telespectadores estar más informados de los contenidos exclusivos que pueden encontrar de sus series y programas favoritos y participar en concursos y juegos e incluso comentar la emisión de algunos de los programas en directo. Se crea así una forma divertida de ver la televisión al mismo tiempo que se interactúa con otros usuarios de Internet.

Junto a las redes sociales tenemos que destacar otro fenómeno que es la audiencia social, como se denomina a la audiencia que hace un seguimiento a tiempo real de lo que sucede en los 30 minutos anteriores a la emisión lineal, durante la emisión lineal y en los 30 minutos posteriores de la finalización del programa. Las cadenas de TV facilitan las palabras claves, invitados, los tertulianos, etiqueta (hashtag). El resto de comentarios que se suceden antes o después del periodo de análisis se considera "ruido social".

Los análisis sobre las audiencias de televisión y las redes sociales muestran la visión del área sobre estas investigaciones, marcada por la necesidad de estudiar las nuevas formas de relación entre la televisión 
y sus audiencias. De hecho, se han realizado investigaciones aplicadas a distintos elementos, como la plataforma digital al Jazeera, donde se muestra la adaptación de la cadena a las redes sociales (Bañón Castellón, 2016). Por tanto, se establecen canales de comunicación bidireccionales y se observa la evolución de la televisión digital a la televisión social, siendo esta la que usa las redes sociales como medio de comunicación con las audiencias (Spina, 2016). Así, la actividad en redes sociales ha originado el concepto de audiencia social y por consiguiente, estudios comparativos de las tres audiencias: lineal, social y en diferido (González Neira, 2016). También se analiza el comportamiento de la audiencia de televisión en redes sociales, indicando que los programas más comentados en las redes sociales son los de ficción (Gómez Aguilar, 2015).

Estas evaluaciones basadas en indicadores forman parte de las diversas metodologías de investigación en diferentes disciplinas, y de igual modo es la base de los estudios Cienciométricos (Repiso, 2018). Aparte de permitir estudiar y comparar distintas realidades, por ello en el ambiente televisivo se están empleado para el análisis de los servicios informativos, específicamente de la radiotelevisión pública (CamposFreire, 2018). Los estudios en redes sociales también consideran a los indicadores sociales en el análisis (Marauri- Castillo, 2018). Igualmente, el uso de las audiencias como indicador se utiliza en el análisis de la confianza de los consumidores (Morales-Blanco-Steger, 2018) y de hecho se observan avances en la medición de la audiencia digital online (Papí-Gálvez, 2018). Por ello el objetivo de este trabajo es evaluar las actividades de las audiencias de series de televisión en redes sociales.

\section{Contextualización teórica del tema}

En el marco teórico del presente trabajo se realiza la conceptualización de las series en estudio que se elabora consultando distintos documentos como fuentes de información de las características y datos evaluados (Wikipedia, 2019), (Noxvo, 2019), (Vertele, 2019), (Atresmedia, 2019), (RTVE, 2019), (Mediaset España, 2019) y (Fórmula TV 2019). 


\subsection{Series de la primera temporada del curso televisivo 2018/2019}

Sabuesos es una serie emitida por La 1. Se estrenó el 31 de julio de 2018 y finalizó el 5 de octubre de 2018. Perteneciente al género comedia de misterio, su discreto rendimiento llevó a los directivos de la cadena a retirarla del prime time de los martes para finalmente relegarla al late night de los viernes; así los ocho primeros capítulos se emitieron los martes a las 22:40 y los dos últimos pasaron a emitirse los viernes alas 23:50. Ha tenido una media como vemos en la tabla 1 un poquito por encima del millón de espectadores y un share promedio de 8,7\%. Todos sus capítulos se habían mantenido por encima de la barrera del millón, pero la emisión del 18 de septiembre con el estreno de Gran Hermano VIP: límite 48 horas, y el estreno de Presunto culpable no pasó de los 961.000 seguidores y un share de 6,6\%. Su hueco fue ocupado por Estoy Vivo.

Tabla 1. Relación de características generales de la serie Sabuesos.

\begin{tabular}{|l|l|l|l|l|l|}
\hline Temporada & Episodios & Estreno & Final & $\begin{array}{l}\text { Media } \\
\text { Espectadores }\end{array}$ & $\begin{array}{l}\text { Media } \\
\text { share }\end{array}$ \\
\hline $\mathbf{1}$ & 10 & $\begin{array}{l}31 \text { de julio de } \\
2018\end{array}$ & $\begin{array}{l}5 \text { de octubre } \\
\text { de } 2018\end{array}$ & 1.086000 & $8,7 \%$ \\
\hline
\end{tabular}

Fuente: elaboración propia con datos de Wikipedia (2019) Noxvo (2019) Vertele (2019) y RTVE (2019).

Estoy vivo es una serie de televisión emitida en La 1 de TVE. Se convirtió en una de las grandes sorpresas del pasado año, y regresó a La 1 con su segunda temporada, tras los buenos datos obtenidos en la primera. Se estrenó el martes 25 de septiembre, y marcó un aceptable $11,5 \%$, sustituyendo a Sabuesos, que había saltado del prime time de los martes al late night de los viernes en parte debido al éxito de Gran Hermano VIP: límite 48 horas, que se mantuvo imbatible, y a la apuesta fuerte del prime time Presunto culpable de Antena 3. La espectacular subida cada semana de Gran Hermano Vip provocó una bajada de audiencia en las ficciones que competían a la misma hora: Estoy vivo y Presunto culpable. La semana del 15 de octubre decide dar el salto a los lunes y mejora sensiblemente su resultado marcando un $13,6 \%$. 
Tabla 2. Relación de características generales de la serie Estoy vivo.

\begin{tabular}{|l|l|l|l|l|l|}
\hline Temporada & Episodios & Estreno & Final & $\begin{array}{l}\text { Media } \\
\text { Espectadores }\end{array}$ & $\begin{array}{l}\text { Media } \\
\text { Share }\end{array}$ \\
\hline $\mathbf{2}$ & \multirow{2}{*}{13} & $\begin{array}{l}25 \mathrm{de} \\
\text { septiembre de } \\
2018\end{array}$ & $\begin{array}{l}17 \mathrm{de} \\
\text { diciembre de } \\
2018\end{array}$ & 1769000 & $11,5 \%$ \\
\hline
\end{tabular}

Fuente: elaboración propia con datos de Wikipedia (2019)Noxvo (2019)Vertele (2019) y RTVE (2019).

Cuéntame, es una serie emitida por La 1 de Televisión Española desde el año 2001. La 19 a etapa, comprende dos periodos: el primero con los episodios 330 a 338, comenzó su emisión el jueves, 25 de enero de 2018 y finalizó el jueves 22 de marzo de 2018, y el segundo, desde el capítulo 339 al 348, comenzó el jueves, 13 de septiembre de 2018 y finalizó el 29 de noviembre de 2018.

La $20^{\mathrm{a}}$ etapa, también comprende dos periodos de 10 episodios cada uno; el primero va de los episodios 349 a 358, desde el jueves, 21 de marzo de 2019 al jueves, 30 de mayo de 2019, y el segundo, que vadel capítulo 359 al 368, previsiblemente se emitirá en el primer trimestre de 2020, a las 22:50. El final de temporada de Cuéntame revolucionó Twitter: los seguidores de Cuéntame cómo pasó quedaron impactados con el cierre de la ficción, especialmente al confirmarse el divorcio de sus protagonistas tras 20 temporadas.

Tabla 3. Relación de características generales de la serie Cuéntame.

\begin{tabular}{|l|l|l|l|l|l|l|}
\hline Temporada & Episodios & Estreno & Final & $\begin{array}{l}\text { Media } \\
\text { Espectadores }\end{array}$ & $\begin{array}{l}\text { Media } \\
\text { Share }\end{array}$ & $\begin{array}{l}\text { Media } \\
\text { Histórica: }\end{array}$ \\
\hline $\mathbf{1 9}$ & 20 & $\begin{array}{l}13 \text { de } \\
\text { septiembre } \\
\text { de } 2018\end{array}$ & $\begin{array}{l}29 \text { de } \\
\text { noviembre } \\
\text { de } 2018\end{array}$ & 2.560 .000 & $16,3 \%$ & $\begin{array}{l}4.710 .000 \\
(30,8 \%)\end{array}$ \\
\hline $\mathbf{2 0}$ & 10 & $\begin{array}{l}21 \text { de } \\
\text { marzo de } \\
2019\end{array}$ & $\begin{array}{l}30 \text { de } \\
\text { mayo de } \\
2019\end{array}$ & 2.202 .000 & $14,1 \%$ & \\
\hline
\end{tabular}

Fuente: elaboración propia con datos de Wikipedia (2019)Noxvo (2019)Vertele (2019) y RTVE (2019).

Presunto culpable es una serie de televisión española de Antena 3, que se estrenó el 18 de septiembre de 2018. Ha sido una de sus principales 
apuestas en el terreno de la ficción para este inicio de temporada televisiva 2018/2019. De género intriga, se estrenó con buen dato de audiencia, pero fue perdiendo fuelle debido a su gran rival en la cadena de Medisaet, Gran Hermano VIP, que hizo que tanto la ficción de Antena 3 como la ficción de La 1 Estoy vivo no consiguieran conectar y fidelizar a su audiencia. Su segundo mejor dato lo marcó en su último episodio: un 14,9\%.

Tabla 4. Relación de características generales de la serie Presunto culpable.

\begin{tabular}{|l|l|l|l|l|l|}
\hline Temporada & Episodios & Estreno & Final & $\begin{array}{l}\text { Media } \\
\text { Espectadores }\end{array}$ & $\begin{array}{l}\text { Media } \\
\text { Share }\end{array}$ \\
\hline $\mathbf{1}$ & 13 & $\begin{array}{l}18 \mathrm{de} \\
\text { septiembre de } \\
2018\end{array}$ & $\begin{array}{l}11 \mathrm{de} \\
\text { diciembre de } \\
2018\end{array}$ & 1898000 & $13,2 \%$ \\
\hline & & 2018 & & \\
\hline
\end{tabular}

Fuente: elaboración propia con datos de Wikipedia (2019)Noxvo (2019)Vertele (2019) y Atresmedia (2019).

Vivir sin permiso. Mediaset España estrenó su gran apuesta de ficción de la primera temporada del curso televisivo 2018/2019 en todos los canales del grupo (menos Boing y Cuatro), anotando un muy buen $22,3 \%$ de share y 3.047.000 espectadores en total. En cuanto a la emisión individual de Telecinco, la serie también triunfó con un 19\% de share y casi 2,6 millones de espectadores, convirtiéndose en lo más visto de la jornada.

Tabla 5. Relación de características generales de la serie Vivir sin permiso.

\begin{tabular}{|l|l|l|l|l|l|}
\hline Temporada & Episodios & Estreno & Final & $\begin{array}{l}\text { Media } \\
\text { Espectadores }\end{array}$ & $\begin{array}{l}\text { Media } \\
\text { Share }\end{array}$ \\
\hline $\mathbf{1}$ & 13 & $\begin{array}{l}\text { 24 de septiembre } \\
\text { de } 2018\end{array}$ & $\begin{array}{l}17 \text { de } \\
\text { diciembre } \\
\text { de } 2018\end{array}$ & 2700000 & $19,0 \%$ \\
\hline
\end{tabular}

Fuente: elaboración propia con datos de Wikipedia (2019)Noxvo (2019)Vertele (2019) y Mediaset España (2019).

Vivir sin permiso repitió cada semana como la emisión preferida de los lunes por la noche. Cosechando buenos datos. No obstante, hay que destacar alguna bajada de puntos en las semanas séptima y octava respecto a las anteriores. Aun así, consiguió liderar las jornadas, 
sacando casi ocho puntos a su principal competidor, Estoy vivo; precisamente los puntos que baja Vivir sin permiso son los puntos que mejora Estoy vivo.

La verdad, serie de televisión producida por Mediaset España. Intriga. La serie fue grabada en 2016, pero su estreno se ha ido posponiendo hasta llegar a 2018. En rueda de prensa de Mediaset España de 2018, se anunció su estreno para febrero y más tarde se concretó que sería el día 14; incluso hicieron una cuenta atrás en redes sociales, pero debido a un movimiento de contraprogramación se canceló tres días antes. Desde entonces, la serie se siguió promocionando tres meses más, hasta que la hermana italiana de Telecinco, Canale 5, la anunció para el día 25 de mayo, y así Mediaset España se vio obligada a emitirla, anunciando pocos días antes el estreno. Finalmente se estrenó el 21 de mayo. La serie en su segunda temporada ha marcado unos resultados de audiencia discretos. La verdad se despidió de la pantalla con un final que parece no haber conquistado demasiado al público.

Tabla 6. Relación de características generales de la serie La verdad.

\begin{tabular}{|l|l|l|l|l|l|}
\hline Temporada & Episodios & Estreno & Final & $\begin{array}{l}\text { Media } \\
\text { Espectadores }\end{array}$ & $\begin{array}{l}\text { Media } \\
\text { Share }\end{array}$ \\
\hline $\mathbf{2}$ & 8 & $\begin{array}{l}7 \text { de noviembre } \\
\text { de } 2018\end{array}$ & $\begin{array}{l}26 \mathrm{de} \\
\text { diciembre } \\
\text { de } 2018\end{array}$ & 1657000 & $11,7 \%$ \\
\hline
\end{tabular}

Fuente: elaboración propia con datos de Wikipedia (2019)Noxvo (2019)Vertele (2019) y Mediaset España (2019).

\subsection{Series de la segunda temporada del curso televisivo 2018/2019}

Hospital Valle Norte es una serie de televisión estrenada el 14 de enero de 2019 en La 1. La serie no comenzó 2019 con buen pie: una serie más de televisión española que se da el batacazo; la cadena estrenó el lunes 14 de enero la que se suponía que iba a ser una de sus grandes apuestas de la temporada, pero el resultado no fue el esperado: marcó un $9,5 \%$ en su estreno.

Matadero, serie de televisión emitida por Antena 3, consiste en una temporada de 10 episodios con un final cerrado. Se estrenó en Antena 3 el 9 de enero de 2019. El 16 de enero fue noche de estrenos de segundas temporadas en La 1 y en Telecinco. La cadena pública 
arrancó la segunda edición de Maestros de la costura ante un 12\% de la audiencia y Tele 5 lanzó Los nuestros 2, su gran apuesta, pero no consiguió los datos esperados, ya que se quedó en un mal 10,2\%. Pese a estos dos importantes estrenos, Matadero consiguió mantenerse líder en su segunda semana con un gran $15,8 \%$, pese a perder $-5,8$ puntos respecto al estreno del miércoles anterior.

Tabla 7. Relación de características generales de la serie Hospital Valle Norte.

\begin{tabular}{|l|l|l|l|l|l|}
\hline Temporada & Episodios & Estreno & Final & $\begin{array}{l}\text { Media } \\
\text { Espectadores }\end{array}$ & $\begin{array}{l}\text { Media } \\
\text { Share }\end{array}$ \\
\hline $\mathbf{1}$ & 10 & $\begin{array}{l}14 \text { de enero de } \\
2019\end{array}$ & $\begin{array}{l}18 \mathrm{de} \\
\text { marzo de } \\
2019\end{array}$ & 1297000 & $8,0 \%$ \\
\hline
\end{tabular}

Fuente: elaboración propia con datos de Wikipedia (2019)Noxvo (2019)Vertele (2019) y RTVE (2019).

El 23 de enero el partido del Barcelona ante el Sevilla en la Copa del Rey protagonizó la noche del miércoles, desplazando a Maestros de la costura al domingo. El partido fue lo más seguido, marcando en La 1 un 15,6\% y ocasionando que las ofertas de ficción de la noche firmaran una bajada. Matadero siguió descendiendo, en esta ocasión a un 12,9\%, mientras que Los nuestros 2 se queda con un 9,4\%. Sigue su tendencia a la baja con su cuarto episodio, aunque, en esta ocasión, frena su caída, marcando un discreto $12,5 \%$.

Tabla 8. Relación de características generales de la serie Matadero.

\begin{tabular}{|l|l|l|l|l|l|}
\hline Temporada & Episodios & Estreno & Final & $\begin{array}{l}\text { Media } \\
\text { Espectadores }\end{array}$ & $\begin{array}{l}\text { Media } \\
\text { Share }\end{array}$ \\
\hline $\mathbf{1}$ & 10 & $\begin{array}{l}9 \text { de enero } \\
\text { de } 2019\end{array}$ & $\begin{array}{l}13 \text { de marzo } \\
\text { de } 2019\end{array}$ & 1770000 & $12,1 \%$ \\
\hline
\end{tabular}

Fuente: elaboración propia con datos de Wikipedia (2019)Noxvo (2019)Vertele (2019) y Atresmedia (2019).

Los nuestros 2, miniserie de acción, suspense y drama española, emitida en Telecinco. La primera entrega se emitió del 2 al 16 de marzo de 2015.

La segunda temporada de la serie se estrenó el 16 de enero de 2019 y acabó el 30 de enero. La serie no ha marcado en ninguna de sus 3 
semanas de emisión de la segunda temporada un dato aceptable de audiencia, a diferencia de lo que pasó en su primera temporada. Esta temporada fue un fracaso de la ficción de Tele 5 en cuanto a datos de audiencia.

Tabla 9. Relación de características generales de la serie Los nuestros.

\begin{tabular}{|l|l|l|l|l|l|}
\hline Temporada & Episodios & Estreno & Final & $\begin{array}{l}\text { Media } \\
\text { Espectadores }\end{array}$ & $\begin{array}{l}\text { Media } \\
\text { Share }\end{array}$ \\
\hline $\mathbf{2}$ & 3 & $\begin{array}{l}16 \text { de enero } \\
\text { de } 2019\end{array}$ & $\begin{array}{l}30 \text { de enero } \\
\text { de 2019 }\end{array}$ & 1329000 & $9,9 \%$ \\
\hline
\end{tabular}

Fuente: elaboración propia con datos de Wikipedia (2019)Noxvo (2019)Vertele (2019) y Mediaset España (2019.)

\subsection{Series de la tercera temporada del curso televisivo 2018/2019}

Secretos de estado, serie de televisión española de suspense, se estrenó en Telecinco el 13 de febrero de 2019. Una semana después de su estreno, se mantenía como líder del prime time de los miércoles. La ficción fue lo más visto de su franja al reunir a 1.805 .000 espectadores y $13,2 \%$ de share. Pese a perder $-2,5$ puntos respecto a su estreno, la ficción se mantuvo fuerte frente a la competencia. De esta forma, Maestros de la costura en La 1 creció $+2,5$ puntos y se quedó como segunda opción de la noche con un 12,5\% (1,4 millones de espectadores) mientras que Matadero, pese a crecer dos décimas, se quedó en un bajo 10\% de cuota y 1.357 .000 espectadores. Las ficciones de la noche bajaron de nuevo. Secretos de Estado siguió descendiendo en su tercera emisión marcando un pobre $11,1 \%$ y en sucesivas emisiones siguió perdiendo puntos hasta un discreto $9 \%$ en su último episodio.

Tabla 10. Relación de características generales de la serie Secretos de estado.

\begin{tabular}{|l|l|l|l|l|l|}
\hline Temporada & Episodios & Estreno & Final & $\begin{array}{l}\text { Media } \\
\text { Espectadores }\end{array}$ & $\begin{array}{l}\text { Media } \\
\text { Share }\end{array}$ \\
\hline $\mathbf{1}$ & 13 & $\begin{array}{l}13 \text { de } \\
\text { febrero de } \\
2019\end{array}$ & $\begin{array}{l}7 \text { de mayo } \\
\text { de } 2019\end{array}$ & 1.500 .000 & $11,5 \%$ \\
\hline
\end{tabular}

Fuente: elaboración propia con datos de Wikipedia (2019) Noxvo (2019) Vertele (2019) y Mediaset España (2019). 
Allí abajo, la serie de Antena 3 que va por su quinta temporada, se estrenó 7 de abril de 2015 y finalizó su primera temporada el 30 de junio del mismo año, con un total de 13 capítulos. Antena 3 estrena la quinta temporada el 10 de marzo de 2019 y finalizó, cerrando la serie, el 11 de junio, con 10 episodios. Avalada por los resultados cosechados desde su estreno, con un promedio de 3,2 millones de espectadores y un 18,8 por ciento de cuota de pantalla.

Tabla 11. Relación de características generales de la serie Allí abajo.

\begin{tabular}{|l|l|l|l|l|l|}
\hline Temporada & Episodios & Estreno & Final & $\begin{array}{l}\text { Media } \\
\text { Espectadores }\end{array}$ & $\begin{array}{l}\text { Media } \\
\text { Share }\end{array}$ \\
\hline $\mathbf{5}$ & 10 & $\begin{array}{l}19 \text { de marzo } \\
\text { de } 20198\end{array}$ & $\begin{array}{l}11 \text { de junio } \\
\text { de } 2019\end{array}$ & 19590009 & $12,5 \%$ \\
\hline
\end{tabular}

Fuente: elaboración propia con datos de Wikipedia (2019) Noxvo (2019) Vertele (2019) y Atresmedia (2019).

45 Revoluciones, una serie de televisión emitida en Antena 3, se estrenó el 18 de marzo de 2019. La serie no obtuvo el éxito esperado en su debut, con un 10,1\% de cuota de pantalla (1.532.000). En esta ocasión, Antena 3 no logró reunir al público en el estreno como en casi todas sus producciones. En su segundo episodio, bajó a un 7,1\% (1.099.000) y con el tercero y sucesivos fue cayendo cada semana: un 5,4\%, con menos de un millón de espectadores (810.000) 4,8\% (725 000) 3,4\% (624 000) hasta su emisión número 11 que alcanzó su cuota más baja (187.000) 2,0\%, para reponerse en unas décimas en los dos últimos capítulos.

Tabla 12. Relación de características generales de la serie Allí abajo.

\begin{tabular}{|l|l|l|l|l|l|}
\hline Temporada & Episodios & Estreno & Final & $\begin{array}{l}\text { Media } \\
\text { Espectadores }\end{array}$ & $\begin{array}{l}\text { Media } \\
\text { Share }\end{array}$ \\
\hline $\mathbf{1}$ & 13 & $\begin{array}{l}18 \text { de marzo } \\
\text { de } 2019\end{array}$ & $\begin{array}{l}30 \text { de mayo } \\
\text { de } 2019\end{array}$ & 630000 & $4,2 \%$ \\
\hline
\end{tabular}

Fuente: elaboración propia con datos de Wikipedia (2019) Noxvo (2019) Vertele (2019) y Atresmedia (2019).

La caza, serie conocida como "La caza. Monteperdido" en su primera temporada y "La caza. Tramuntana" en la segunda. Es una serie de thriller psicológico emitida en La 1 de TVE, cuyo estreno tuvo lugar el 25 de marzo de 2019. El 27 de mayo de 2019, la serie fue renovada 
para una segunda temporada, pese a tener en un principio una única temporada con final cerrado. El 20 de agosto se anunció que la segunda temporada comenzará sus grabaciones en marzo de 2020.

Tabla 13. Relación de características generales de la serie Allí abajo.

\begin{tabular}{|l|l|l|l|l|l|}
\hline Temporada & Episodios & Estreno & Final & $\begin{array}{l}\text { Media } \\
\text { Espectadores }\end{array}$ & $\begin{array}{l}\text { Media } \\
\text { Share }\end{array}$ \\
\hline $\mathbf{1}$ & 8 & $\begin{array}{l}25 \text { de marzo } \\
\text { de } 2019\end{array}$ & $\begin{array}{l}20 \text { de mayo } \\
\text { de } 2019\end{array}$ & 2158000 & $14,0 \%$ \\
\hline
\end{tabular}

Fuente: elaboración propia con datos de Wikipedia (2019) Noxvo (2019) Vertele (2019) y RTVE (2019).

\section{Material y método}

La metodología empleada en este trabajo la ha desarrollado el grupo de investigación Conectar de la Universidad y la Junta de Extremadura (SECTI, 2019).

\subsection{Material}

El objeto de estudio son los perfiles en redes sociales de las series emitidas durante un curso televisivo. Se incluyen en la tabla 14 ordenadas alfabéticamente por cadenas y después por títulos de la serie.

Tabla 14. Relación de series a analizar y las características de las mismas.

\begin{tabular}{|l|l|l|l|l|l|}
\hline $\begin{array}{l}\text { TÍTULO DE } \\
\text { LA SERIE }\end{array}$ & CADENA & $\begin{array}{l}\text { PÁGINA WEB } \\
\text { OFICIAL }\end{array}$ & FACEBOOK & TWITTER & $\begin{array}{l}\text { OTRAS } \\
\text { REDES } \\
\text { SOCIALES }\end{array}$ \\
\hline $\begin{array}{l}\text { 45 REVOLU- } \\
\text { CIONES }\end{array}$ & A3 & $\begin{array}{l}\text { https://www. } \\
\text { antena3.com/serie } \\
\text { s/45revoluciones/ }\end{array}$ & $\begin{array}{l}\text { https://www. } \\
\text { facebook.com/4 } \\
\text { 5revolucion estv/ }\end{array}$ & $\begin{array}{l}\text { Se ha } \\
\text { suspendido } \\
\text { la cuenta }\end{array}$ & \\
\hline ALLí ABAJO & A3 & $\begin{array}{l}\text { https://www. } \\
\text { antena3.com/serie } \\
\text { s/alli- abajo/ }\end{array}$ & $\begin{array}{l}\text { https://www. } \\
\text { facebook.com/all } \\
\text { iabajo/?fr ef=ts }\end{array}$ & $\begin{array}{l}\text { https:// } \\
\text { twitter.com/ } \\
\text { alliabajo }\end{array}$ & \\
\hline $\begin{array}{l}\text { MATADERO: } \\
\text { UN } \\
\text { THRILLER } \\
\text { IBÉRICO }\end{array}$ & A3 & $\begin{array}{l}\text { https://www. } \\
\text { antena3.com/serie } \\
\text { s/matadero/?fbcli } \\
\text { d=IwAR1DhfpjLg } \\
\text { ZokSeuopRj0znBt } \\
\text { HXHIYX5Iks5c_c } \\
\text { hZ7arMVfFXI0S } \\
\text { Hp67rNc }\end{array}$ & $\begin{array}{l}\text { https:// } \\
\text { www.facebook.c } \\
\text { om/MataderoTV }\end{array}$ & $\begin{array}{l}\text { https:// } \\
\text { twitter.com/ } \\
\text { MataderoTV }\end{array}$ & No \\
\hline
\end{tabular}




\begin{tabular}{|c|c|c|c|c|c|}
\hline $\begin{array}{l}\text { TÍTULO DE LA } \\
\text { SERIE }\end{array}$ & CADENA & $\begin{array}{l}\text { PÁGINA } \\
\text { WEB } \\
\text { OFICIAL }\end{array}$ & FACEBOOK & TWITTER & $\begin{array}{l}\text { OTRAS } \\
\text { REDES } \\
\text { SOCIALES }\end{array}$ \\
\hline $\begin{array}{l}\text { PRESUNTO } \\
\text { CULPABLE }\end{array}$ & A3 & $\begin{array}{l}\text { https://ww } \\
\text { w.antena3.c } \\
\text { om/series/ } \\
\text { presunto- } \\
\text { culpable/ }\end{array}$ & $\begin{array}{l}\text { https://www. } \\
\text { facebook.co } \\
\text { m/PresuntoC } \\
\text { ulpableTV/ }\end{array}$ & $\begin{array}{l}\text { https://twitter.co } \\
\text { m/PresuntoCulp } \\
\text { aTV?lang=es }\end{array}$ & No \\
\hline $\begin{array}{l}\text { CUÉNTAME } \\
\text { OTRA VEZ }\end{array}$ & A3 & $\begin{array}{l}\text { https://ww } \\
\text { w.antena3.c } \\
\text { om/series/ } \\
\text { presunto- } \\
\text { culpable/ }\end{array}$ & $\begin{array}{l}\text { https://www. } \\
\text { facebook.co } \\
\text { m/PresuntoC } \\
\text { ulpableTV }\end{array}$ & $\begin{array}{l}\text { https://twitt } \\
\text { er.com/Pres } \\
\text { untoCulpaT } \\
\text { V?la ng=es }\end{array}$ & No \\
\hline ESTOY VIVO & La 1 & $\begin{array}{l}\text { http://ww } \\
\text { w.rtve.es/te } \\
\text { levision/cu } \\
\text { entame }\end{array}$ & $\begin{array}{l}\text { https://www. } \\
\text { facebook.co } \\
\mathrm{m} / \mathrm{pg} / \text { cuenta } \\
\text { mecomopaso } \\
\text { /about/?ref= } \\
\text { page_internal }\end{array}$ & $\begin{array}{l}\text { https://twit } \\
\text { ter.com/cue } \\
\text { nta metve }\end{array}$ & $\begin{array}{l}\text { Spotify: } \\
\text { https://open. } \\
\text { spotify.com/ } \\
\text { playlist/2LT } \\
\text { KuLq6JzQfG } \\
\text { mDfKwomn } \\
\text { W } \\
\text { Instagram: } \\
\text { https://www. } \\
\text { instagram.co } \\
\text { m/cuentamet } \\
\text { ve/ }\end{array}$ \\
\hline $\begin{array}{l}\text { HOSPITAL } \\
\text { VALLE } \\
\text { NORTE* }\end{array}$ & La1 & $\begin{array}{l}\text { http://www. } \\
\text { rtve.es/tele } \\
\text { vision/esto } \\
\text { y-vivo/ }\end{array}$ & $\begin{array}{l}\text { https://www. } \\
\text { facebook.co } \\
\text { m/EstoyVivo } \\
\text { TVE/?ref=br } \\
\text { _rs }\end{array}$ & $\begin{array}{l}\text { https://twitt } \\
\text { er.com/estoy } \\
\text { vi vo_tve }\end{array}$ & $\begin{array}{l}\text { Instagram: } \\
\text { https://www } \\
\text { instagram.co } \\
\mathrm{m} / \text { estoyvivot } \\
\text { ve/?hl=es }\end{array}$ \\
\hline $\begin{array}{l}\text { LA CAZA: } \\
\text { MONTEPERDI } \\
\text { DO* }\end{array}$ & La 1 & $\begin{array}{l}\text { http://ww } \\
\text { w.rtve.es/te } \\
\text { levision/ho } \\
\text { spital-valle- } \\
\text { norte/ }\end{array}$ & $\begin{array}{l}\text { https://www. } \\
\text { facebook.co } \\
\text { m/seriesRTV } \\
\text { E/ }\end{array}$ & $\begin{array}{l}\text { https://twit } \\
\text { ter.com/Ser } \\
\text { iesRTVE }\end{array}$ & $\begin{array}{l}\text { Instagram: } \\
\text { https://ww } \\
\text { w.instagram. } \\
\text { com/seriesrt } \\
\text { ve/ }\end{array}$ \\
\hline \multirow[t]{2}{*}{ SABUESOS } & La 1 & $\begin{array}{l}\text { http://ww } \\
\text { w.rtve.es/te } \\
\text { levision/la- } \\
\text { caza- } \\
\text { monteperdi } \\
\text { do } \\
\text { /seriesRTV } \\
\text { E }\end{array}$ & $\begin{array}{l}\text { https://www. } \\
\text { facebook.co } \\
\text { m/seriesRTV } \\
\text { E/ }\end{array}$ & $\begin{array}{l}\text { La página } \\
\text { no existe }\end{array}$ & $\begin{array}{l}\text { Instagram: } \\
\text { https://www } \\
\text {.instagram.co } \\
\mathrm{m} / \text { monteper } \\
\text { didotve }\end{array}$ \\
\hline & La1 & $\begin{array}{l}\text { http://ww } \\
\text { w.rtve.es/te } \\
\text { levision/sa } \\
\text { buesos/ }\end{array}$ & $\begin{array}{l}\text { https://twitte } \\
\text { r.com/MaxSa } \\
\text { buesos_tve }\end{array}$ & $\begin{array}{l}\text { https://twit } \\
\text { ter.com/Ma } \\
\text { xSabuesos_ } \\
\text { tve }\end{array}$ & $\begin{array}{l}\text { Instagram: } \\
\text { https://ww } \\
\text { w.instagram. } \\
\text { co } \\
\text { m/max_sab } \\
\text { u esos_tve/ }\end{array}$ \\
\hline
\end{tabular}




\begin{tabular}{|c|c|c|c|c|c|}
\hline $\begin{array}{l}\text { TÍTULO DE } \\
\text { LA SERIE }\end{array}$ & CADENA & $\begin{array}{l}\text { PÁGINA } \\
\text { WEB } \\
\text { OFICIAL }\end{array}$ & FACEBOOK & TWITTER & $\begin{array}{l}\text { OTRAS } \\
\text { REDES } \\
\text { SOCIALES }\end{array}$ \\
\hline LA VERDAD & Tele 5 & $\begin{array}{l}\text { https://www. } \\
\text { telecinco.es/l } \\
\text { averdad }\end{array}$ & $\begin{array}{l}\text { https://www.fa } \\
\text { cebook.com/la } \\
\text { verdadserie/ }\end{array}$ & $\begin{array}{l}\text { https://twitter } \\
\text {.com/laverdad } \\
\text { serie }\end{array}$ & $\begin{array}{l}\text { Instagram: } \\
\text { https://ww } \\
\text { w.instagram. } \\
\text { com/laverda } \\
\text { d.serie/ }\end{array}$ \\
\hline $\begin{array}{l}\text { LOS } \\
\text { NUESTROS }\end{array}$ & Tele 5 & $\begin{array}{l}\text { https://www.t } \\
\text { elecinco.es/los } \\
\text { nuestros/ }\end{array}$ & $\begin{array}{l}\text { https://www.fa } \\
\text { cebook.com/lo } \\
\text { snuestrosserie/ }\end{array}$ & $\begin{array}{l}\text { https://twitter } \\
\text {.com/Los_Nu } \\
\text { estros }\end{array}$ & No \\
\hline $\begin{array}{l}\text { SECRETOS } \\
\text { DE ESTADO }\end{array}$ & Tele 5 & $\begin{array}{l}\text { https://www. } \\
\text { telecinco.es/s } \\
\text { ecretosdeesta } \\
\text { do/ }\end{array}$ & $\begin{array}{l}\text { https://www.fa } \\
\text { cebook.com/Se } \\
\text { cretosDeEstado } \\
\text { TV/ }\end{array}$ & $\begin{array}{l}\text { https://twitter.c } \\
\text { om/SecretosEst } \\
\text { ado }\end{array}$ & $\begin{array}{l}\text { Instagram: } \\
\text { https://ww } \\
\text { w.instagram. } \\
\text { com/secreto } \\
\text { sdeestadotv/ }\end{array}$ \\
\hline $\begin{array}{l}\text { VIVIR SIN } \\
\text { PERMISO }\end{array}$ & Tele 5 & $\begin{array}{l}\text { https://www.te } \\
\text { lecinco.es/vivir } \\
\text { sinpermiso/ }\end{array}$ & $\begin{array}{l}\text { https://www.fa } \\
\text { cebook.com/V } \\
\text { SPserie/ }\end{array}$ & $\begin{array}{l}\text { https://twitter.c } \\
\text { om/vspserie }\end{array}$ & $\begin{array}{l}\text { Instagram: } \\
\text { https://ww } \\
\text { w.instagram. } \\
\text { com/vspseri } \\
\text { e/ }\end{array}$ \\
\hline
\end{tabular}

*Perfiles en Facebook y Twitter no son específicos de estas series es el de las series de RTVE.

Fuente: Wikipedia (Wikipedia, 2019), Formula tv (Noxvo, 2019), Vertele (2019), y paginas oficiales de las cadenas de las series (Atresmedia, 2019), (RTVE, 2019) y (Mediaset España, 2019).

Los perfiles oficiales de las series en redes sociales se localizan a través de la página web oficial de las mismas.

\subsection{Metodología}

El método empleado viene avalado por publicaciones del grupo de investigación Conecta (Ruano López, 2018) (Ruano López, 2016) y se analizan series españolas de producción propia emitidas en prime time por cadenas generalistas (La1, A3 y Tele5).

El método de estudio se desarrolla en las etapas siguientes:

1.- Se analizan las tres temporadas del curso televisivo, que comienza en septiembre de 2018 y finaliza en junio de 2019. El día 29 de septiembre de 2019 se realiza la recuperación de la información de los perfiles sociales de las series compiladas. Para ello se escogen series de producción propia y que se emiten por canales generalistas.

2.- Las series seleccionadas deben tener perfiles oficiales en Facebook y Twitter. Por ello en el caso de las series Hospital valle norte y La caza: 
Monteperdido, dado que no tienen perfiles propios, y el community manager gestiona la información desde el perfil oficial de series de RTVE, se eliminan del análisis. Además 45 revoluciones tampoco presentan perfil en Twitter, por tanto, se analizan 10 perfiles en Twitter y 11 en Facebook.

3.- Las variables de estudio son las siguientes (Tabla 15):

a) Datos obtenidos de los perfiles de las redes sociales, concretamente el número de me gusta (likes) y el número de seguidores (followers) de las mismas.

b) Las audiencias totales de las series seleccionadas para el estudio.

Tabla 15. Variables de estudio.

\begin{tabular}{|c|c|c|c|c|}
\hline VARIABLE & REPRESENTACIÓN & $\begin{array}{l}\text { UNIDAD DE } \\
\text { MEDIA }\end{array}$ & OBJETIVO & $\begin{array}{l}\text { MODO DE } \\
\text { INTERPRETA- } \\
\text { CIÓN }\end{array}$ \\
\hline $\begin{array}{l}\text { NÚMERO } \\
\text { DE ME } \\
\text { GUSTA } \\
\text { (LIKES) } \\
\text { TOTAL } \\
\text { DEL } \\
\text { PERFIL }\end{array}$ & 1 & $\begin{array}{l}\text { Me gusta } \\
\text { (likes) }\end{array}$ & $\begin{array}{ll}\text { Determinar } & \text { la } \\
\text { capacidad } & \text { de } \\
\text { generar } & \\
\text { emociones } & \\
\text { positivas } & \end{array}$ & $\begin{array}{l}\text { A mayor número } \\
\text { de likes, más } \\
\text { atractivos son los } \\
\text { contenidos del } \\
\text { perfil y atraerá y/o } \\
\text { fidelizará mayor } \\
\text { número re } \\
\text { seguidores, tanto } \\
\text { del perfil, como de } \\
\text { la serie }\end{array}$ \\
\hline $\begin{array}{l}\text { NÚMERO } \\
\text { DE } \\
\text { SEGUIDO- } \\
\text { RES } \\
\text { (FOLLOW } \\
\text { ERS) } \\
\text { TOTALES } \\
\text { DEL } \\
\text { PERFIL }\end{array}$ & $\mathrm{s}$ & $\begin{array}{l}\text { Seguidores } \\
\text { (followers) }\end{array}$ & $\begin{array}{l}\text { Determinar el } \\
\text { número de fans } \\
\text { de las series en } \\
\text { redes sociales. }\end{array}$ & $\begin{array}{l}\text { Los usuarios de los } \\
\text { perfiles, son los que } \\
\text { ven las series y } \\
\text { realizan } \\
\text { comentarios } \\
\text { solicitan o } \\
\text { información más } \\
\text { community } \\
\text { manager sobre la } \\
\text { misma. A mayor } \\
\text { número } \\
\text { seguidores de } \\
\text { audiencia de la serie }\end{array}$ \\
\hline $\begin{array}{l}\text { MEDIA DE } \\
\text { ESPECTA- } \\
\text { DORES } \\
\text { POR } \\
\text { EPISODIO }\end{array}$ & $\mathrm{a}$ & Espectadores & $\begin{array}{ll}\text { Determinar el } \\
\text { número medio } \\
\text { de espectadores } \\
\text { de todos los } \\
\text { capítulos } & \\
\text { emitidos de las } \\
\text { series r por } \\
\text { televisión } & \text { en } \\
\text { esta } & \\
\text { temporada. }\end{array}$ & $\begin{array}{l}\text { La audiencia media } \\
\text { de las series de } \\
\text { televisión } \\
\text { analizadas. }\end{array}$ \\
\hline
\end{tabular}

Fuente: Ruano López (2018). 
4.- En esta etapa se determinan los indicadores a evaluar para establecer un método de análisis sistematizado; diferenciaremos los indicadores de redes sociales y los de televisión.

a) Indicador de seguidores (followers)iF (Tabla 16).

b) Indicador de me gusta (likes) de los perfiles, iL (Tabla 16).

c) Indicador de Audiencias, iA (Tabla 17).

d) El share (Sh) es una medida de audiencia que estima el porcentaje de hogares o espectadores que están viendo un programa de televisión y con respecto al total que tiene encendido su televisor durante la emisión.

Los indicadores, como se indica en las tablas 16 y 17 , se hallan al calcular el tanto por ciento de las variables. De este modo se puede establecer una comparación entre los indicadores, de manera que, a mayor valor, mayor aceptación en redes sociales, bien por número de followers (seguidores) o de likes (me gusta); en el caso de las audiencias, a mayor tanto por ciento más telespectadores tiene la serie. El Share es un indicador en sí mismo, porque al igual que los tres anteriores, la forma de calcularlo permite situar estos valores en el tiempo televisivo y en el espacio social. Es decir, los tiempos de emisión varían, porque pueden coincidir otros programas de gran audiencia (acontecimientos deportivos y otros) el mismo día de emisión de las series. El espacio social también está sujeto a la presencia o ausencia de otros acontecimientos (deportivos, políticos, sociales y otros) que dirigen las opiniones de los seguidores hacia ellos. 
Tabla 16. Los indicadores de Facebook y Twitter.

\begin{tabular}{|c|c|c|c|c|c|c|}
\hline NOMBRE & OBJETIVO & $\begin{array}{l}\text { DEFINI- } \\
\text { CIÓN }\end{array}$ & $\begin{array}{l}\text { UNIDAD } \\
\text { DE } \\
\text { MEDIDA }\end{array}$ & $\begin{array}{l}\text { FÓRMULA } \\
\text { DE } \\
\text { CÁLCULO }\end{array}$ & MÉTODO & $\begin{array}{l}\text { MODO DE } \\
\text { INTERPRETA- } \\
\text { CIÓN }\end{array}$ \\
\hline $\begin{array}{l}\text { INDICA- } \\
\text { DOR DE ME } \\
\text { GUSTA } \\
\text { (LIKES) DE } \\
\text { LOS } \\
\text { PERFILES }\end{array}$ & $\begin{array}{l}\text { Conocer la } \\
\text { relación de } \\
\text { me gusta } \\
\text { (likes) totales } \\
\text { del perfil, } \\
\text { respecto al } \\
\text { total de me } \\
\text { gusta (likes) } \\
\text { de los } \\
\text { perfiles en } \\
\text { estudio. Con } \\
\text { esta relación } \\
\text { se establece } \\
\text { el ranking de } \\
\text { me gusta } \\
\text { (likes) de las } \\
\text { series. }\end{array}$ & $\begin{array}{l}\text { Relación de } \\
\text { me gusta } \\
\text { (likes) del } \\
\text { perfil } \\
\text { respecto a la } \\
\text { suma del total } \\
\text { de } \\
\text { publicaciones } \\
\text { de los perfiles } \\
\text { en estudio. }\end{array}$ & $\begin{array}{l}\text { Me gusta } \\
\text { (likes) }\end{array}$ & $\begin{array}{l}\text { iL = (1 / L) } \\
* 100 \\
\text { Donde: } \\
-1 \text { es el } \\
\text { número de } \\
\text { me gusta } \\
\text { (likes) de } \\
\text { una serie. } \\
\text {-L es el } \\
\text { número de } \\
\text { me gusta } \\
\text { (likes) total } \\
\text { de todos los } \\
\text { perfiles } \\
\text { objeto de } \\
\text { estudio. } \\
\text { L=Sum } 1_{1} \text {, } \\
\mathrm{l}_{2}, \ldots, \mathrm{l}_{\mathrm{n}}\end{array}$ & $\begin{array}{l}\text { División del } \\
\text { número de } \\
\text { me gusta } \\
\text { (likes) de un } \\
\text { perfil por la } \\
\text { suma del } \\
\text { total de me } \\
\text { gusta (likes) } \\
\text { de los } \\
\text { perfiles en } \\
\text { estudio. }\end{array}$ & $\begin{array}{l}\text { Valores del } \\
\text { porcentaje } \\
\text { próximos a 100, } \\
\text { indican que se } \\
\text { trata de series con } \\
\text { alto número de } \\
\text { me gusta (likes) } \\
\text { Por tanto, son } \\
\text { series con mucha } \\
\text { aceptación en } \\
\text { redes sociales. }\end{array}$ \\
\hline $\begin{array}{l}\text { INDICA- } \\
\text { DOR DE } \\
\text { SEGUIDO- } \\
\text { RES } \\
\text { (FOLLOWE } \\
\text { RS) }\end{array}$ & $\begin{array}{l}\text { Conocer la } \\
\text { relación de } \\
\text { seguidores } \\
\text { (followers) } \\
\text { totales del } \\
\text { perfil, } \\
\text { respecto al } \\
\text { total de } \\
\text { seguidores } \\
\text { (followers) } \\
\text { de los } \\
\text { perfiles en } \\
\text { estudio. Con } \\
\text { esta relación } \\
\text { se establece } \\
\text { el ranking de } \\
\text { seguidores } \\
\text { (followers) } \\
\text { de las series. }\end{array}$ & $\begin{array}{l}\text { Relación de } \\
\text { seguidores } \\
\text { (followers) } \\
\text { del perfil } \\
\text { respecto a la } \\
\text { suma del total } \\
\text { de } \\
\text { publicaciones } \\
\text { s de los } \\
\text { perfiles } \\
\text { estudio. }\end{array}$ & seguidores & $\begin{array}{l}\text { iF }=(\mathrm{f} / \mathrm{F}) \\
* 100 \\
\text { Donde: } \\
\text {-f es el } \\
\text { número de } \\
\text { seguidores } \\
\text { (followers) } \\
\text { de una serie. } \\
\text {-F es el } \\
\text { número de } \\
\text { seguidores } \\
\text { (followers) } \\
\text { total de } \\
\text { todos los } \\
\text { perfiles } \\
\text { objeto de } \\
\text { estudio. } \\
\text { F=Sum } \mathrm{f}_{1} \text {, } \\
\mathrm{f}_{2}, \ldots, \mathrm{f}_{\mathrm{n}}\end{array}$ & $\begin{array}{l}\text { División del } \\
\text { número de } \\
\text { seguidores } \\
\text { (followers) } \\
\text { de un perfil } \\
\text { por la suma } \\
\text { del total de } \\
\text { seguidores } \\
\text { (followers) } \\
\text { de los } \\
\text { perfiles en } \\
\text { estudio. }\end{array}$ & $\begin{array}{l}\text { Valores del } \\
\text { porcentaje } \\
\text { próximos a } 100, \\
\text { indican que se } \\
\text { trata de series con } \\
\text { alto número de } \\
\text { seguidores } \\
\text { (followers) por } \\
\text { tanto, son series } \\
\text { con alta } \\
\text { aceptación en las } \\
\text { redes sociales. }\end{array}$ \\
\hline
\end{tabular}

Fuente: Ruano López (2018). 
Tabla 17. Los indicadores de audiencias de televisión.

\begin{tabular}{|c|c|c|c|c|c|c|}
\hline NOMBRE & OBJTIVO & $\begin{array}{l}\text { DEFINICI- } \\
\text { ON }\end{array}$ & $\begin{array}{l}\text { UNIDAD } \\
\text { DE } \\
\text { MEDIDA }\end{array}$ & $\begin{array}{l}\text { FÓRUMULA } \\
\text { DE } \\
\text { CÁCULCO }\end{array}$ & MÉTODO & $\begin{array}{l}\text { MODO DE } \\
\text { INTERPRETA- } \\
\text { CIÓN }\end{array}$ \\
\hline $\begin{array}{l}\text { INDICA- } \\
\text { DOR DE } \\
\text { AUDIEN- } \\
\text { CIAS }\end{array}$ & $\begin{array}{l}\text { Conocer la } \\
\text { media de } \\
\text { audiencias } \\
\text { de las } \\
\text { series } \\
\text { durante } \\
\text { toda la } \\
\text { temporada } \\
\text {. Con esta } \\
\text { relación se } \\
\text { establece el } \\
\text { ranking de } \\
\text { audiencias } \\
\text { de las } \\
\text { series. }\end{array}$ & $\begin{array}{l}\text { Relación de } \\
\text { audiencia } \\
\text { media de } \\
\text { cada serie } \\
\text { respecto a la } \\
\text { suma del } \\
\text { total de } \\
\text { audiencias } \\
\text { medias de } \\
\text { las series en } \\
\text { estudio. }\end{array}$ & $\begin{array}{l}\text { espectador } \\
\text { es }\end{array}$ & $\begin{array}{l}\text { iA = (a/As) } \\
* 100 \\
\text { Donde: }- \text { a es } \\
\text { la media de } \\
\text { espectador es } \\
\text { de una serie. } \\
\text {-As son las } \\
\text { audiencias } \\
\text { medias } \\
\text { totales de } \\
\text { todas las } \\
\text { series objeto } \\
\text { de estudio. } \\
\text { A=Sum } a_{1}, \\
a_{2}, \ldots, a_{n}\end{array}$ & $\begin{array}{l}\text { División del } \\
\text { número } \\
\text { audiencia } \\
\text { media de } \\
\text { una serie } \\
\text { por la suma } \\
\text { del total } \\
\text { audiencias } \\
\text { medias de } \\
\text { las series en } \\
\text { estudio. }\end{array}$ & $\begin{array}{l}\text { Valores del } \\
\text { porcentaje } \\
\text { próximos a 100, } \\
\text { indican que se } \\
\text { trata de series } \\
\text { con muchos } \\
\text { espectadores. } \\
\text { Por tanto, son } \\
\text { series con } \\
\text { mucha } \\
\text { aceptación en } \\
\text { televisión. }\end{array}$ \\
\hline SHARE & $\begin{array}{l}\text { Conocer el } \\
\text { porcentaje } \\
\text { medio } \\
\text { deaudiencia } \\
\text { de la } \\
\text { temporada } \\
\text { en relación } \\
\text { con la } \\
\text { audiencia } \\
\text { total de } \\
\text { espectadore } \\
\text { s televisivos }\end{array}$ & $\begin{array}{l}\text { Porcentaje } \\
\text { entre la } \\
\text { audiencia } \\
\text { media de } \\
\text { cada serie } \\
\text { respecto al } \\
\text { total de } \\
\text { espectadore } \\
\text { s que tiene } \\
\text { encendido } \\
\text { el televisor } \\
\text { durante la } \\
\text { emisión de } \\
\text { la serie }\end{array}$ & $\begin{array}{l}\text { espectador } \\
\text { es }\end{array}$ & $\begin{array}{l}\text { Sh }=(\mathrm{a} / \mathrm{A}) \\
* 100 \text { Donde: } \\
\text { a es la media } \\
\text { de espectador } \\
\text { es de una } \\
\text { serie. } \\
\text {-A Total de } \\
\text { espectadores } \\
\text { conectados a } \\
\text { la televisión, } \\
\text { durante la } \\
\text { emisión de la } \\
\text { serie }\end{array}$ & $\begin{array}{l}\text { División de la } \\
\text { audiencia } \\
\text { media de una } \\
\text { serie por el } \\
\text { total de } \\
\text { espectadores } \\
\text { que tienen } \\
\text { encendido el } \\
\text { televisor } \\
\text { durante la } \\
\text { emisión de la } \\
\text { serie }\end{array}$ & $\begin{array}{l}\text { Valores del } \\
\text { porcentaje } \\
\text { próximos a 100, } \\
\text { indican que se } \\
\text { trata de series con } \\
\text { Muchos } \\
\text { espectadores. Por } \\
\text { tanto, son series } \\
\text { con mucho éxito. } \\
\text { De hecho, se } \\
\text { llevan la gran } \\
\text { mayoría } \\
\text { espectadores que } \\
\text { están viendo la } \\
\text { televisión durante } \\
\text { le emisión. }\end{array}$ \\
\hline
\end{tabular}

Fuente: Noxvo (2019).

5.- Finalmente se decide comparar todas las series independientemente del número de temporadas emitidas. 


\section{Resultados}

El curso televisivo comprende 13 series españolas emitidas por televisiones generalistas. De ellas, dos, Cuéntame y Secretos de estado, programan dos temporadas a lo largo del intervalo de tiempo analizado.

Tabla 18. Índice de audiencias y Share de las series analizadas.

\begin{tabular}{|l|l|l|}
\hline TÍTULO DE LA SERIE & SHARE & $\begin{array}{l}\text { INDICADOR DE } \\
\text { AUDIENCIAS }\end{array}$ \\
\hline 45 REVOLUCIONES & 4,2 & 2,8 \\
\hline ALLÍ ABAJO & 12,5 & 8,8 \\
\hline MATADERO: UN THRILLER IBÉRICO & 12,1 & 7,9 \\
\hline PRESUNTO CULPABLE & 13,2 & 8,5 \\
\hline *CUÉNTAME OTRA VEZ & 15,2 & 10,7 \\
\hline ESTOY VIVO & 8 & 5,8 \\
\hline HOSPITAL VALLE NORTE & 14 & 9,7 \\
\hline LA CAZA: MONTEPERDIDO & 11,5 & 7,9 \\
\hline SABUESOS & 8,7 & 4,9 \\
\hline *LA VERDAD & 12,8 & 8,3 \\
\hline LOS NUESTROS & 9,9 & 6,0 \\
\hline SECRETOS DE ESTADO & 11,5 & 6,7 \\
\hline VIVIR SIN PERMISO & 19 & 12,1 \\
\hline
\end{tabular}

*Al emitirse dos temporadas en este curso se calcula la media de las dos.

Fuente: elaboración propia con datos de Noxvo (2019) y Vertele (2019).

En dos de las series compiladas no se ha podido realizar la evaluación en redes sociales, por carecer de perfiles en el momento del análisis. Se han considerado al calcular los índices televisivos ya que han competido por la audiencia en el momento de emisión.

Posteriormente, al estudiar los perfiles en redes sociales se observa que Hospital valle norte y La caza: Monteperdido son las series que no presentan perfiles oficiales propios en las redes sociales Facebook y Twitter. Por tanto, se analizan 11 series en Facebook y 10 en Twitter debido a que 45 revolución tiene la cuenta suspendida en esta red social. A continuación, se muestran los resultados del estudio (Tabla18) de las variables de los perfiles en las dos redes sociales. 
Tabla 19. Valores de las variables en redes sociales.

\begin{tabular}{|c|c|c|c|c|}
\hline \multirow{2}{*}{$\begin{array}{l}\text { TÍTULO DE LA } \\
\text { SERIE }\end{array}$} & \multicolumn{2}{|c|}{ VARIABLES FACEBOOK } & \multicolumn{2}{|c|}{ VARIABLES TWITTER } \\
\hline & $\begin{array}{l}\text { Me gusta } \\
\text { (likes) }\end{array}$ & $\begin{array}{l}\text { Seguidores } \\
\text { (followers) }\end{array}$ & $\begin{array}{l}\text { Me gusta } \\
\text { (likes) }\end{array}$ & $\begin{array}{l}\text { Seguidores } \\
\text { (followers) }\end{array}$ \\
\hline 45 REVOLUCIONES* & 604 & 632 & $\mathrm{X}$ & $\mathrm{X}$ \\
\hline ALLÍ ABAJO & 67327 & 66705 & 1133 & 87000000 \\
\hline $\begin{array}{l}\text { MATADERO: UN } \\
\text { THRILLER IBÉRICO }\end{array}$ & 786 & 801 & 299 & 1275 \\
\hline $\begin{array}{l}\text { PRESUNTO } \\
\text { CULPABLE }\end{array}$ & 2705 & 2738 & 476 & 2282 \\
\hline $\begin{array}{l}\text { CUÉNTAME OTRA } \\
\text { VEZ }\end{array}$ & 90956 & 90150 & 24400000 & 139000000 \\
\hline ESTOY VIVO & 10310 & 10751 & 1221 & 8275 \\
\hline SABUESOS & 684 & 694 & 291 & 720 \\
\hline LA VERDAD & 10715 & 10866 & 122 & 4174 \\
\hline LOS NUESTROS & 50029 & 4985 & 0 & 22 \\
\hline $\begin{array}{l}\text { SECRETOS DE } \\
\text { ESTADO }\end{array}$ & 2046 & 2124 & 12 & 915 \\
\hline VIVIR SIN PERMISO & 15134 & 15361 & 497 & 581000000 \\
\hline
\end{tabular}

*Se ha suspendido la cuenta de Twitter

Fuente: elaboración propia con datos de Facebook (2019) y Twitter (2019).

Los resultados del cálculo de los indicadores sociales son los siguientes. 
Tabla 20. Indicadores de las series en las redes sociales compiladas.

\begin{tabular}{|c|c|c|c|c|}
\hline \multirow{2}{*}{$\begin{array}{l}\text { TÍTULO DE LA } \\
\text { SEKIE }\end{array}$} & \multicolumn{2}{|c|}{ INDICADORES FACEBOOK } & \multicolumn{2}{|c|}{ INDICADORES TWITTER } \\
\hline & $\begin{array}{l}\text { Me gusta } \\
\text { (likes) }\end{array}$ & $\begin{array}{l}\text { Seguidores } \\
\text { (followers) }\end{array}$ & $\begin{array}{l}\text { Me gusta } \\
\text { (likes) }\end{array}$ & $\begin{array}{l}\text { Seguidores } \\
\text { (followers) }\end{array}$ \\
\hline 45 REVOLUCIONES* & 0,24 & 0,31 & $\mathrm{X}$ & $\mathrm{X}$ \\
\hline ALLÍ ABAJO & 26,79 & 32,41 & 0,00046 & 10,8 \\
\hline $\begin{array}{l}\text { MATADERO: UN } \\
\text { THRILLER } \\
\text { IBÉRICO }\end{array}$ & 0,31 & 0,39 & 0,0012 & 0,0002 \\
\hline $\begin{array}{l}\text { PRESUNTO } \\
\text { CULPABLE }\end{array}$ & 1,08 & 1,33 & 0,002 & 0,0003 \\
\hline $\begin{array}{l}\text { CUÉNTAME OTRA } \\
\text { VEZ }\end{array}$ & 36,19 & 43,80 & 99,98 & 17,2 \\
\hline ESTOY VIVO & 4,10 & 5,22 & 0,005 & 0,001 \\
\hline SABUESOS & 0,27 & 0,34 & 0,001 & 0,00009 \\
\hline LA VERDAD & 4,26 & 5,28 & 0,0005 & 0,0005 \\
\hline LOS NUESTROS & 19,91 & 2,42 & 0 & 0,000003 \\
\hline $\begin{array}{l}\text { SECRETOS DE } \\
\text { ESTADO }\end{array}$ & 0,81 & 1,03 & 0,00005 & 0,0001 \\
\hline $\begin{array}{l}\text { VIVIR SIN } \\
\text { PERMISO }\end{array}$ & 6,02 & 7,46 & 0,002 & 72 \\
\hline
\end{tabular}

*Se ha suspendido la cuenta de Twitter

Fuente: elaboración propia.

\section{Conclusiones}

Pocas ficciones logran mantener el tipo a lo largo de una temporada completa y cada vez resulta más complicado que los estrenos se asienten y consigan una audiencia fiel como las de Cuéntame cómo pasó.

En la mayoría de las series su trayectoria es descendente y se encuentran otros casos de series que llegan fuertes y acaban totalmente desinfladas, debido a que la audiencia está harta del horario, la duración o las pausas publicitarias. Si bien algunas cadenas están optando por rebajar el tiempo de duración de las series a 50 minutos, entre ellas Antena 3, con su estreno de 45 revoluciones el 18 de marzo de 2019, el prime time español cada vez se aleja más del horario de cualquier 
prime time de las televisiones europeas. TVE ya lo intento en 2015, por indicaciones del gobierno: adelantaron el prime time a las 22.15h., siendo El ministerio del tiempo la serie abanderada del cambio. Una semana después, volvieron a cambiar el horario otra vez, adelantándolo a las $22 \mathrm{~h}$., pero se quedó sola en este mandato. A esto hay que sumar que las series cada vez tienen más seguidores en las plataformas como Netflix, HBO o Amazón.

Esto hace que las cadenas de televisión no tengan una oferta variada en la franja del prime time y opten por emitir más de un día a la semana otro tipo de contenidos que sí tienen más visibilidad en la televisión tradicional y generan más fidelidad en la audiencia, como la tele realidad y los talents. Una muestra de ello es lo que ha sucedido el curso televisivo pasado. Las series no acabaron de conectar con las audiencias y eran incapaces de competir con programas como Gran Hermano o La Voz.

Las conclusiones referidas al análisis de los perfiles sociales muestran que la actividad no es directamente proporcional al número de temporadas, pues si bien Cuéntame lidera los indicadores de Facebook, no ocurre lo mismo con Twitter donde Vivir sin permiso lidera el ranking de seguidores; sin embargo, vuelve a ser Cuéntame el que más me gustas presenta. En cuanto a las cadenas, La 1 lidera Facebook y Tele 5 Twitter, pero al mismo tiempo Sabuesos de La 1 ocupa la última posición en Facebook mientras que en Twitter es Tele 5 con Los nuestros. La audiencia de Vivir sin permiso y por tanto Tele 5 es quien lidera el ranking y en La 1 Sabuesos y Hospital valle norte son las series que se encuentra en último lugar.

Finalmente, el hecho de que 8 de las series tienen perfil en Instagram, lleva a la conclusión de que sería interesante incluir esta red social en futuros estudios de audiencia 2.0.

\section{Bibliografía}

Atresmedia. (2019). Series Antena3. Disponible en https://www.antena3.com/series/

Bañón Castellón, L. (2016). Redes sociales y audiencias en televisión: el caso al Jazeera como referente para nuevos modelos de digitales 
informativas para la construcción de una nueva RTVV. Ad Comunica, 191-194.

Campos-Freire, F., Soengas-Pérez, X. y Rodríguez-Castro, M. (2018). Indicadores de evaluación de los servicios informativos de la radiotelevisión pública. El profesional de la información, 27(2), 267277. doi:doi.org/10.3145/epi.2018.mar.05

Facebook. (2019). Facebook. (Facebook). Disponible en https://www.facebook.com/

Gómez Aguilar, M., Paniagua Rojano, F. y Farias Batle, P. (2015).

Comportamiento de la audiencia de televisión en las redes sociales. Una aproximación al perfil y programas más comentados. Revista Latina de Comunicación Social (70), 539-551. doi:10.4185/RLCS-2015-1058.

González Neira, A. y Quintas Froufe, N. (2016). El comportamiento de la audiencia lineal, social y en diferido de las series de ficción española. Revista de la Asociación Española de Investigación de la Comunicación, 3(6), 27-33. Disponible en http://www.revistaeic.eu/index.php/raeic/article/view/63

Marauri-Castillo, I., Cantalapiedra-González, M. y Álvarez-Fernández,

C. (2018). Blog y Twitter, la combinación perfecta del comunicador digital: los casos de Escolar.net, El comidista y Mi mesa cojea. El profesional de la información, 27(2), 349-358. doi:doi.org/10.3145/epi.2018.mar.13

Mediaset España. (2019). Telecinco: Series. Disponible en https://www.telecinco.es/series/

Morales-Blanco-Steger, B. y Fuente-Cobo, C. (2018). Confianza de las audiencias en las marcas televisivas: propuesta de indicadores de responsabilidad social y reputación corporativa. El profesional de la información, 27(3), 537-547. doi:doi.org/10.3145/epi.2018.may.07

Noxvo. (2019). Formula TV. Disponible en http://www.formulatv.com/ 
Papí-Gálvez, N., y Perlado-Lamo-de-Espinosa, M. (2018). investigación de audiencias en las sociedades digita-les: su medición desde la publicidad. El profesional de la información, 27(2), 383-393. doi:doi.org/10.3145/epi.2018.mar.17

Repiso, R. (20 de junio de 2018). Blog EPI. (EPI, Ed.) Disponible en http://www.elprofesionaldelainformacion.com/notas/tablaperiodica-de-indicadores/

RTVE. (2019). Series TVE. Disponible en http://www.rtve.es/television/series-tve/

Ruano López, S., Garcés Botacio, I. y Fernández Falero, M. (2016). Las series de televisión en las redes sociales: Estudio de caso. Opción, 32(12), 525-540.

Ruano López, S., Trabadela Robles, J. y Fernández Falero, M. R. (2018). Facebook como calibrador de audiencias de las series de televisión. En J. Muñoz Jiménez, S. Martínez Martínez, y B. Peña Acuña. La realidad audiovisual como nuevo vehiculo de comunicación (pp. 427-440) Barcelona: Gedisa.

Ruano López, S., Trabadela Robles, J. y Fernández Falero, M. (2019). Evolución de la audiencia social de las series de las cadenas de TV generalistas españolas. McGraw-Hill.

SECTI. (2019). Catálogo de grupos de investigación. Disponible en Junta de Extremadura: https://secti.gobex.es/SECTI/publico/catalogo/catalogo.jsf

SER. (2019). Cadena Ser. Disponible en cadenaser.com

Spina, P. y Viallon, M. (2016). La pratique des réseaux sociaux par les diffuseurs télé: un nouvel espace de liberté pour le téléspectateur et de gestion des audiences pour l'émetteur. ESSACHESS. Journal for Communication Studies, 2(18), 101-112. Disponible en: https://www.essachess.com/index.php/jcs/article/view/340/38 9

Tele 5. (2019). Tele 5. Disponible en: https://www.telecinco.es/losnuestros/

Twitter. (2019). Twitter. Disponible en https://twitter.com/ 
Vertele. (2019). Vertele. Disponible en http://vertele.eldiario.es/

Wikipedia. (2019). Wikipedia. Disponible en https://es.wikipedia.org/wiki/Wikipedia:Portada 


\title{
La cara "sombría" de los procesos de liderazgo: el papel de la comunicación interpersonal del líder
}

\author{
Sandra Miranda \\ Profesor Asociado - Sección de Ciencias Sociales, Escuela de \\ Comunicación Social (ESCS) - Instituto Politécnico de Lisboa (IPL) \\ Centro de Investigación de Estudios de Sociología (CIES) - Instituto \\ Universitario de Lisboa (IUL)
}

\section{Resumen}

Centrándose en el liderazgo organizacional y en los comportamientos políticos que estos actores manifiestan en los escenarios de trabajo, esta investigación tiene como objetivo comprender en qué medida el estilo de comunicación interpersonal del líder es el hilo conductor de las tácticas y de los comportamientos políticos. Para este propósito, utilizamos una investigación mixta - método cuantitativo y cualitativo con triangulación de técnicas para la recolección de datos cuestionarios, entrevistas semiestructuradas e incidentes críticos. Los resultados muestran que los comportamientos de liderazgo político dependen en gran medida de cómo se gestiona la comunicación y que cuanto más destacadas sean las habilidades comunicativas de los líderes en su asertividad, mayor será la probabilidad de que participen en la práctica política y de que se manifiesten políticamente. 


\section{Introdução e Objetivos}

POLITICA e os comportamentos políticos nas organizações A representam um domínio único e particular das relações em 1 contexto organizacional, sendo considerada um fenômeno complexo, ambíguo e, por vezes, divisivo. Uma perspectiva política das organizações permite explicar muitos comportamentos organizacionais que, doutra forma, pareceriam irracionais (Gandz \& Murray, 1980) e chama a atenção para os interesses e motivações individuais dos actores organizacionais e para a sua necessidade de satisfação.

No seio da trama política organizacional, é inevitável compreender em que medida a liderança e o comportamento dos líderes - enquanto actores e peças centrais do puzzle organizacional, interfere nessa dinâmica, nomeadamente através do modo como os líderes se relacionam com os colaboradores e fazem da comunicação interpessoal uma das pedra de toque dessa relação.

Esse trabalho de investigação visa construir uma reflexão e análise acerca da problemática no cruzamento das questões da política, do comportamento político e da liderança nas organizações, procurando clarificar algumas especificidades acerca da comunicação do líder nas organizações e contribuir para o aprofundamento do estudo do fenómeno de política organizacional (Ferris, Frink, Galang, Zhou, Kacmar, \& Howard (2004).

Assim, e seguindo os reptos de Ferris et al. (2004), propomos-mos fornecer alguma consistência teórica e evidência empírica a um campo de trabalho praticamente inexplorado. Para o efeito, foi construído um modelo teórico de análise que congrega um conjunto de variáveis, praticamente negligenciadas até à data, e que dizem respeito ao estilo de comunicação interpessoal (Morreale, Osborn, e Pearson, 2000) que os líderes utilizam para comunicar com os seus colaboradores e às suas táticas e comportamentos políticos. Parte-se da assunção de que as competências comunicacionais e, em particular, o estilo de comunicação interpessoal, situam-se no topo das competências imprescindíveis e mais determinantes para se ser bem sucedido em contexto organizacional e na trama política. 


\section{Marco teórico}

\subsection{A Política nas Organizações: controvérsias, tabus e trajetos!}

Apesar de a política nas organizações - regra geral, circunscrita à análise dos comportamentos políticos, ser equiparada ao exercício do poder (Miles, 1980), é incontornável a asserção de que a investigação nesta área tem sido atravessada pela controvérsia de ordem epistemológica e metodológica, o que se deve, sobretudo, ao facto de estar a originar um novo olhar sobre as organizações, ter vindo abrir novas perspetivas teóricas, ter motivado diferentes linhas de investigação, ter posto em causa alguns dos conhecimentos adquiridos no contexto das teorias organizacionais, questionado paradigmas e métodos rotineiros e, finalmente, adoptado uma postura de algum distanciamento ou ate afastamento, perante a ciência positivista (Bradshaw-Camball e Murray, 1991). Na verdade, aduzimos uma pluralidade de diferentes vozes que atravessam o campo de estudo. Contudo, essas diferentes vozes não formam um coro afinado, integrado e harmonioso, impondo, como ponto de partida, um esforço de clarificação conceptual e balizamento concetual.

Embora o conceito de Influência não se realize apenas no campo da política, a actividade política processa-se, regra geral, através do exercício da influência (Farrel e Peterson, 1982; Mintzberg, 1983; Deluga, 1988; Drory e Room, 1988 e 1990; Drory e Beaty, 1991; Peterson, 2000). Para Allen et al., (1979): - "o estudo da política é o estudo da influência" (pg. 77) sendo que a influência do poder e as tacitas de influência são manuseadas com o intuito de alterar, modificar ou condicionar, as atitudes, os valores e os comportamentos de quem esta a ser influenciado ou de quem se pretende influenciar. Uma das conceptualizações que mais ênfase da ao papel da influência nas organizações é a de Mintzberg (1983) já que considera a política organizacional, juntamente com a autoridade, ideologia e perícia, como um dos grandes sistemas de influência presentes nas organizações.

De acordo com Farrel e Peterson (1982), o que verdadeiramente distingue a influência política de outros tipos de influência reside na sua intencionalidade, uma vez que a actividade política implica acções pensadas, reflectidas, deliberadas, calculadas na senda de obter benefícios pessoais. Note-se que a este nível colocam-se grandes 
entraves operacionais, já que é extremamente difícil aferir as intenções políticas dos indivíduos pressupondo, muitas vezes, um processo atribucional da parte do observador. Conforme ilustrado por Mayes e Allen (1977), uma prenda oferecida a um chefe tanto pode representar um gesto de amizade e apreço, como pode implicar uma tentativa de suborno, pagamento de favores ou obtenção de regalias pessoais. Para que assim possam ser rotulados precisamos de descortinar os verdadeiros motivos e propósitos que estão por detrás desses comportamentos.

Bacharach e Baratz (1962) referem-se a esta questão ao desenvolverem o conceito de segunda face do poder e da política. Para eles, não obstante sejamos capazes de observar e reconhecer, em determinadas ocasiões, o exercício do poder e da política de um modo directo e visível (primeira face do poder), existem agendas seguras (segunda face do poder) dificilmente observáveis, acusadas unicamente através daquilo que não é discutido abertamente, ou através aquilo que é discutido de um modo indirecto. Estas agendas seguras inserem-se, de acordo com alguns investigadores (Bacharach e Baratz, 1962; Hardy e Clegg, 1999), dentro das chamadas —nondecision making- processo através do qual alguns assuntos são excluídos da tomada de decisão, acometidos ao patamar de top secret, permitindo o alcance de resultados que são manobrados nos bastidores. Nas palavras dos autores (1970):

"Um conjunto de valores, crenças, rituais predominantes e procedimentos institucionalizados ('regras do jogo') que sistemática e consistentemente operam no sentido de beneficiar certas pessoas e grupos às expensas de outros. Aqueles que beneficiam são colocados numa posição favorável no sentido de defenderem e melhor promoverem os seus interesses" (pg. 4344).

Com uma postura bastante critica, Lukes (1974) identifica, ainda, a presença de uma terceira dimensão de poder, muito mais subtil e impercetível (e por vezes, muito mais perturbadora) e que diz respeito à habilidade para gerir sentidos, partilhar perceções, preferências e cognições. Materializa-se na capacidade para definir a realidade dos outros de modo a que seja interpretada e internalizada "como se duma 
ordem divina (benéfica) se tratasse; ou então - para que (os indivíduos) não consigam ver ou imaginar alternativas substitutas àquela realidade" (Lukes, 1974: 24). Na esteira de Marx, Lukes (1974) pretende relembrar-nos que os sistemas não são constituídos apenas por indivíduos que escolhem os seus atos de livre vontade muito pelo contrário, eles são socialmente estruturados, cultural e institucionalmente determinados - "os homens fazem a sua história, mas não a fazem tal como gostariam. Não a fazem perante as circunstâncias por eles escolhidas, mas perante as circunstâncias encontradas, dadas e transmitidas do passado" (Marx in Kearins, 1996: 9).

No entendimento do autor, esta face de poder é razão explicativa daquilo que apelidou de quiescence política e que se consubstância nas seguintes questões: - Porque razão existe poucas greves? Porque razão não surge mais conflitos nas organizações? Porque razão os trabalhadores aceitam passivamente directivas que vão contra os seus interesses? Exposto desta forma, a inação pode ser o resultado de uma forte imposição de poder, logo: - (...) podemos ser enganados, persuadidos, coagidos e manipulados dentro da aparente inactividade políticall (Saunders in Hardy, 1995: XVII). Na esteira de Lukes (1974), Hardy (1995) reconheceu a forte presença do poder e da política nos pressupostos inconscientes dos valores, tradições, culturas e estruturas organizacionais, sumariando da seguinte forma as várias facetas do poder: poder sobre os recursos; poder sobre os processos e poder sobre o significado.

Para além da questão da intencionalidade, a direcção da influência política tem-se mostrado uma área de estudo bastante frutuosa e prometedora. A este nível existem conclusões para todos os gostos. Se é verdade que os primeiros trabalhos que se debruçaram sobre esta temática circunscreveram o estudo da influência a uma análise unidireccional - nomeadamente à influência que é exercida pelos líderes junto dos subordinados (Bass, 1981 e 1985) trabalhos posteriores vieram confirmar que ela pode manifestar-se em várias sentidos: horizontal, vertical e lateral, (Knipis et al, 1980; Farrel e Peterson , 1982; Yukl e Falbe, 1992; Sussman et al., 2002; Yukl, 1998 e 
2006). Esta ratificação não é, de todo, surpreendente dada a importância e visibilidade que o trabalho em equipa tem ganho nas organizações contemporâneas. Ao analisar o tipo de relação existente entre as mensagens políticas, os canais escolhidos e os alvos da influência, Sussman et al., (2002) concluíram que a probabilidade dos indivíduos intensificarem os comportamentos políticos, optarem por utilizar uma comunicação estratégica e adoptarem tacitas menos éticas é maior quando o objecto da influência é os pares. A informalidade subjacente ao relacionamento, faz com que as regras sejam menos explicitas, escapando, por isso, ao controlo organizacional.

A existência de interesses e objectivos divergentes entre os indivíduos e outro dos vectores despoletadores de comportamentos políticos no seio organizacional, pressupondo uma dose de conflitualidade (Pfeffer, 1980 e 1992; Mintzberg, 1983) resistência e oposição entre as partes envolvidas (Barbalet, 1985; Sawicki, 1995).

O conceito de resistência e oposição ocupa aqui um lugar preponderante. Frost e Hayes (1979) consideram ser esta a peça que faltava para completar o puzzle da análise da política nas organizaçõos. Neste quadro, o que caracteriza um comportamento político não e seu conteúdo, mas a resistência e oposição que consegue gerar junto do alvo da influência vislumbrando-se, entre as partes envolvidas, um diferencial no que diz respeito aos meios, fins e circunstâncias (Drory e Room, 1990). Barbalet (1985), na esteira de Frost e Hayes (1979), ao efectuar um exame detalhado acerca da relação entre o poder, a política e a resistência, aduziu que estes conceitos, embora substantivamente distintos, estão profundamente imbricados. No seu entender, todas as relações de poder (mesmo aquelas que são legitimadas) implicam uma dose de aceitabilidade da parte de quem esta a ser alvo desse poder, mas também implicam uma porção de resistência logo, sem a possibilidade de resistência, o exercício do poder e da política tornamse actividades absolutamente estéreis. Clegg (1988b) tem uma formulação semelhante quando afirmam que "onde há poder há resistência e, contudo, ou talvez por isso mesmo, esta nunca está em posição de exterioridade relativamente ao poder; (...) o poder e a resistência raramente existem um sem o outro" (Clegg, 1988b: 208). 
Buchanan (1993; em parceria com Badham, 1999) ao centrar o seu objecto de estudo nos processos de mudança organizacional acrescenta que, em muitas ocasiões, a resistência à mudança poderá ser o único mecanismo que alguns indivíduos têm ao seu dispor para exercer poder, encontrando no cinismo organizacional uma das mais encapotadas formas de lhe dar corpo.

Assim, e tendo em conta o que acabou de ser discutido, aponta-se como um dos principais preditores de comportamento político a percepção de um conflito de interesses. Esses interesses tendem a reflectir um conjunto complexo de objectivos, valores, desejos, expectativas, e áreas de importância que o indivíduo deseja preservar, ampliar, proteger ou atingir e que no terreno da política organizacional andam a volta de, basicamente, três domínios interligados e relativos ao cargo (referentes ao trabalho que se está a desempenhar) à carreira (aspirações e expectativas em relação à sua vida profissional) e à vida pessoal (pressupostos básicos, estilo de vida, vida familiar, interesses fora da organização) (Morgan, 1996). Os diferentes domínios tendem a interagir uns com os outros, o que faz com que a relação com o trabalho, mesmo antes dos actores organizacionais levarem em linha de conta a existência e as acções dos outros membros organizacionais, seja por inerências uma relação política.

O conflito de interesses e o conteúdo político aumenta quando se reconhece a existência de outros actores podendo culminar num conflito efectivo sempre que uma das partes envolvidas actue numa lógica distributiva (também designada de lógica bad guy - good guy) (Lewicki et al., 1999), no sentido de que a consecução dos seus interesses pessoais implica a subjugação e a anulação dos interesses dos outros, ainda mais quando ao longo do processo são aplicadas tacitas e manifestados comportamentos que a parte lesada considera de inaceitáveis.

Talcott Parsons (in Barbalet, 1985) em -O problema de lidar com a resistência esclarece que a relação entre poder, política, resistência e conflito não é tão linear como alguns investigadores apregoam, uma vez que o surgimento do conflito está altamente dependente das estratégias e formas adoptadas pelos interlocutores envolvidos tanto para exercer o poder como para lhe resistir. 
Destaque-se que a abordagem política das organizações, muito embora esteja devidamente documentada acerca do potencial -lado negro do conflito em ambientes organizacionais e providencie estratégias no sentido controlar e amenizar a sua disfuncionalidade, faz do conflito uma das suas principais bandeiras ao colocar a tónica nas diferenças e assimetrias de objectivos e preferências entre os actores/grupos organizacionais e ao concentrar-se no modo como essas diferenças são resolvidas. De acordo com Tushman (1977), o conflito, a desarmonia, e os processos levados a cabo contra a cooperação organizacional outrora negligenciados e tidos como aspectos de somenos importância na análise do comportamento organizacional - são agora maduramente integrados e estudados. A organização política é um todo que congrega e reflecte todos os interesses conflituosos, ao invés de os omitir ou ignorar.

O comportamento político abarca um conjunto de actividades que estão para além do papel atribuído formalmente aos actores organizacionais. Essas acções tendem a desenvolver-se predominantemente no seio da organização informal escapando, por isso, mais facilmente às malhas das sanções organizacionais (Zanzi e O'Neill, 2001). A ideia de que a política é uma actividade exercida off the record, fora do esquema e rede de relações estabelecidas pela estrutura formal da organização tem sido, teórica e empiricamente, atestado pelos diversos estudos que vêm sendo publicados (Farrel e Peterson, 1982). Porém, convém frisar que nem todos os comportamentos e actividades que ocorrem na clandestinidade da informalidade são políticos, se assim fosse correríamos o risco de estar a misturar no mesmo saco positivas manifestações de cidadania organizacional, comportamentos altruístas, prosociais e extra - papel com actividades ilegais, comportamentos maquiavélicos e anti-sociais. Por exemplo, um trabalhador que nutra um elevado envolvimento e empenhamento afectivo para com a organização e que faça esforços extra com o intuito de ajudá-la a melhorar o seu desempenho - esses comportamentos podem não ser de natureza política, pelo contrário podem ser o resultado de um forte vínculo emocional ou gratidão que o indivíduo desenvolveu em relação à mesma. Por seu turno, conforme demonstrado empiricamente por Sussman e Vechio (in Drory e 
Romm, 1990), a motivação no trabalho é uma manifestação de influência social a que os agentes organizacionais recorrem quando necessário.

Resta acrescentar que, de acordo com alguns estudiosos (Allen et al., 1979; Pfeffer, 1981), o facto da política organizacional comportar a ocultação dos verdadeiros motivos que regem a acção, faz com que tenha actuação privilegiada no palco da informalidade.

Embora a esmagadora maioria dos estudos atribuam à organização informal a exclusividade da acção política, é de suma importância frisar que existem decisões e comportamentos que são tomados sobre a égide da formalidade - facto que os torna particularmente eficazes politicamente e, porque mascarados, particularmente perigosos para a organização. Para Cabral - Cardoso (1995), é justamente a aparência técnica, científica e formal dos instrumentos utilizados na tomada de decisão que permitem camuflar a potencial utilização política, logo colocada acima de qualquer suspeita. Pfeffer (1981) argumenta que essa racionalidade é usada quase como uma religião nas organizações formais, facto que serve de apanágio justificativo para a tomada de decisões políticas. Desta forma, parece claro que se o actor político for hábil ao salvaguardar os seus verdadeiros motivos e a sua actuação por detrás do escudo da formalidade, mais eficaz ele será politicamente.

De acordo com Mintzberg (1983), o que realmente força o sistema político - tão egoísta e divisivo - a disfarçadamente alinhar desde o ponto de vista organizacional aquando do processo de tomada de decisão, é a necessidade que ele tem em operar sob a égide da racionalidade. Quer isto dizer que, independentemente do quão egoísta possa ser uma acção ou comportamento, ela deve ser apresentada como algo que vai ao encontro dos objectivos e do bem-estar organizacional. Burns (1961) expõe esta mesma ideia da seguinte forma:

"É impossível neste momento não fazer uma referência às observações feitas por F. M. Cornford no Guia para o jovem político. Existem dois tipos de proposições, as minhas e as tuas. As minhas, são propostas para o bem-estar comum que implicam (muito contra a minha vontade) a ascensão de alguns dos meus amigos, ou então (ainda muito mais contra a minha vontade) a minha ascensão. As tuas propostas são intrigas insidiosas promovendo a tua ascensão 
e a dos teus amigos, que pretendes fazer passar por propostas benéficas para o bem comum" (pg. 260).

Tal como aqui já foi largamente discutido, existe um vasto espectro de investigadores que consideram a disfuncionalidade como um elemento caracterizador do comportamento político, altamente prejudicial para a concretização dos objectivos organizacionais (Pettigrew, 1973), foco de ineficácia e patologias organizacionais situando-se para além dos limites da legitimidade organizacional (Mayes e Allen, 1977; Mintzberg, 1983). Também a este nível somos confrontados com dificuldades no que diz respeito ao balizamento de fronteiras rigorosas entre o que pode ser considerado de legitimo e ilegítimo, já que estamos a lidar com um fenómeno perceptivo altamente subjectivo (Vigoda e Cohen, 2002) que pode reflectir ou não a realidade organizacional. Tal como Gandz e Murray (1980) notaram: -a política organizacional é um estado de espírito (pg. 248) logo a colocação dessa marca está dependente do momento, das circunstâncias e dos indivíduos envolvidos.

Frost e Hayes (1979) e Pfeffer (1981) argumentam que a legitimidade é uma temática organizacionalmente disputada, já que o estabelecimento dos seus limites é parte integrante do jogo político, sendo estipulado pelos detentores do poder organizacional. Acrescente-se os relatos de acções políticas ilegítimas que são intencionalmente levadas a cabo com o intuito de legitimar uma dada política (Elsbach e Sutton, 1992), ou então, o facto dos actores organizacionais manifestarem acções políticas ilegítimas através de -legítimos sistemas de influência (Mintzberg, 1983: 186) - referimo-nos concretamente à autoridade, normas organizacionais e perícias. De resto, a este nível Mintzberg (1983 e 1990) protagoniza uma das abordagens mais acutilantes já que entende todas as situações e condições de visibilidade de comportamentos políticos como sendo perpassadas pela ilegitimidade dos diferentes tipos de jogos políticos: jogo da insubmissão; jogo para parar a insubmissão; jogo do apadrinhamento; jogo da construção de alianças; jogo da construção de impérios; jogo do orçamento; jogo da competência especializada; jogo do autoritarismo; jogo da batalha entre a linha hierárquica, os funcionais e o apoio logístico; jogo da rivalidade entre dois campos; jogo de candidatos a postos estratégicos; jogo de Farrel e Peterson(1982) em Padrões de comportamento político nas organizações propõem uma tipologia que, entre outras coisas, 
—etiqueta os comportamentos políticos em função da díade legitimidade - ilegitimidade. Estes investigadores entendem que a actividade política em cenários de trabalho e uma realidade insofismável, sendo que o que verdadeiramente separa a actuação política comum, rotineira, legítima da ilegítima reside no seu pendor não oficial e não autorizado. Assim sendo, são apelidados de ilegítimos todos os comportamentos políticos extremos que violem as regras do jogo impostas pela organização, inserindo-se neste rótulo: a sabotagem, os protestos simbólicos (por exemplo: comportar-se ou vestir de um modo pouco ortodoxo pode ser um sinal de protesto contra a organização), os distúrbios, os motins, as ameaças, as denúncias (por exemplo: quando determinados indivíduos tornam públicas algumas das práticas ilegais, irresponsáveis e pouco éticas que são praticadas no seio da organização e que prejudicam o interesse público) e a deserção (por exemplo: quando um trabalhador abandona a organização, desvia clientes e monta um negócio semelhante).

Também Porter, Allen e Angle (1983) se interessaram sobre esta questão. Para eles, o comportamento político ilegítimo comporta todas as acções discricionárias de influência social, isto é, todas aquelas que se situam fora das zonas comportamentais prescritas ou proibidas pela organização formal.

Importa sublinhar que embora a vertente disfuncional e ilegítima da política seja prevalecente, podemos encontrar na literatura da especialidade posturas alternativas. De acordo com Hardy (1995), embora a perspectiva funcionalista veja a política como o resultado de acções, ataques ilegítimos e disfuncionais que se jogam fora das estruturas da legitimidade, existem diferentes conceptualizações que podem ser encontradas na tradição crítica Marxista/Weberiana. Os investigadores que se inserem dentro deste último veio de estudo consideram que o poder e a política está imbuída nas estruturas e processos formais da organização originando formas de dominação (herrschaft ${ }^{6}$ - (Weber, [1918] 1968), enquanto que as acções que são levadas a cabo para desafiar a dominação são focos de resistência. Estas ideias contrastam grandemente com a perspectiva funcionalista que vê os arranjos organizacionais não como estruturas de dominação, mas como autoridade formal, legítima e funcional. 
Uma das ideias mais enraizadas na revisão da literatura diz respeito ao facto da actividade política ser auto-interessada (e interesseira) (Allen et al., 1979; Gandz e Murray, 1980; Mintzberg, 1983; Ferris et al., 1989). Subjacente a esta designação está a tentativa de influenciar a distribuição de vantagens e perdas com vista a satisfazer apenas os interesses próprios, comprometendo os objectivos e a eficácia organizacionais. Neste caso, descrevemos indivíduos com uma actuação eminentemente calculista, egoísta e interessada, fazendo da satisfação dos seus interesses pessoais o centro das suas preocupações, excluindo e ignorando o beneficio dos outros indivíduos ou então, provocando o seu prejuízo. Tal como Porter et al., (1980) afiançaram, o comportamento político é, por definição, um excessivo conjunto de actividades competitivas que ameaçam os interesses dos outros. Note-se, porém, que apesar da faceta sombria ser claramente predominante, a última década, tem assistido ao surgimento de estudos que colocam a descoberto o lado solar da política, identificando consequências positivas da política (Elbanna, 2018; Ellen, Ferris, \& Buckley, 2016; Hochwater, 2012; Landells \& Albrecht, 2017; Maslyn, Farmer \& Bettenhausen, 2017; Miranda \& Antunes, 2019; Vigoda-Gadot \& Drory, 2006) em aspetos tão diversos quanto a tomada de decisão estratégica (Elbanna, 2018), o desempenho das equipas (Yang \& Zhang, 2014) ou a eficácia organizacional e os processos de mudança (Buchanan, 2008).

\subsection{Líder Político nas Organizações: o papel da comunicação do líder}

Dentro do tópico da política nas organizações, uma das dimensões que tem suscitado mais curiosidade prende-se com a compreensão de como - através do exercício da comunicação, o líder se manifesta politicamente (Ferris et al., 2005, Bennister, 2016, Miranda, 2009, 2017).

Embora a literatura seja escassa e pouco conclusiva, o estilo interpessoal de comunicação reveste-se de grande protagonismo quando o associamos ao estudo dos que têm poder e dos que são politicamente hábeis (Pfeffer, 1981 e 1992; Alessandra e Hunsaker, 1993; Ferris et al., 2000 e 2004; Mumford et al., 2000a). A relevância deste tema está plasmada na maioria dos manuais de comunicação o organizacional que nos dão conta da sua inevitabilidade e importância, constituindo a chave para o (in)sucesso gestionário e resolução de muitos problemas organizacionais. 
O modo (e o estilo) como os membros organizacionais comunicam em termos interpessoais não é alheio a esse facto, já que (por exemplo) para além de existirem estilos pessoais de comunicação o que podem erigir verdadeiras barreiras comunicação, as palavras escolhidas, os canais seleccionados, as competências de escuta, os componentes cinéticos, proxémicos e paralinguisticos (entre outros) são elementos de somenos importância no processo e eficácia comunicacional.

Ao dedicar-se a estudar esta temática, Pfeffer (1992) refere que é fundamental que o líder seja sensível aos outros, transformando-se num bom intérprete de indivíduos, estando atento aos outros, compreendendo quem são, o que pretendem, quais são os seus interesses, trilhando o melhor caminho para os influenciar. Trata-se de saber avaliar com precisão, a disponibilidade e a resistência dos elementos organizacionais, tirando o máximo partido das suas motivações e sensibilidades.

Para ser bem sucedido nesta tarefa, cabe ao agente influenciador aperfeiçoar a sua habilidade para comunicar (especialmente a nível interpessoal), desenvolvendo consideravelmente as competências de assertividade, afinando a fluência verbal (Mumford et al., 2000a); sendo empático (Cegela, 1981), aperfeiçoando a sua capacidade de escuta (Alessandra e Hunsaker, 1993), estando atento aos sinais não verbais daqueles que pretende influenciar (Pfeffer, 1981 e 1992), demonstrando interesse pela conversa dos outros e adaptando o seu discurso consonante as singularidades do contexto e dos ouvintes Mumford et al., 2000a e 2000b).

A certificar estas afirmações estão um conjunto de estudos empíricos recentes: por exemplo, para Sussman et al., (2002), baseados na teoria da riqueza dos meios, - "não restam dúvidas para afirmar que os comportamentos e as tacitas políticas assentam num conjunto de pistas persuasivas verbais e não verbais. A inflexão verbal, o contacto visual, a insinuação, os gestos, todos eles servem para estabelecer, aumentar ou reforçar as mensagens verbais" (pg. 326). Essas pistas persuasivas são bastante mais eficazes na interacção face-a-face do que noutro qualquer canal comunicacional como é o caso do telefone, memorandos, ou correio eletrónico. 
Maes, Weldy e Icenogle (1997) e Morreale, Osborn e Pearson (2000) concluíram que as competências comunicacionais se situam no topo das áreas a melhorar e desenvolver junto dos membros organizacionais e estudantes de pós-graduação. Mais recentemente, os Gestores de Recursos Humanos das empresas mais salientes da Fortune 500 distinguiram a comunicação de informação, o estilo interpessoal de comunicação e a capacidade de escuta como as competências imprescindíveis e a incluir nos programas das disciplinas das escolas de gestão do século XXI. Fazendo parte do grupo restrito e limitado de investigadores que, ate à data, testaram o conceito de competência comunicacional nas organizações, Penley et al., (1991) verificaram que os gestores que manifestavam elevados níveis de desempenho eram descritos pelos seus subordinados como detentores de ótimas apetências e capacidades interpessoais para comunicar e escutar.

Moore e Rudd (2004) ao procurarem aferir, em ambientes organizacionais, quais os traços e as competências essenciais dos líderes políticos concluíram que, contrariamente às expectativas iniciais e às orientações da literatura, a esmagadora maioria dos entrevistados apontava a área comunicacional como uma das mais determinantes, materializando-se nas habilidades e competências comunicacionais que seguidamente apresentamos: 
Tabela 1. Competências comunicacionais da liderança política, construído a partir de Moore e Rudd (2004).

\section{COMPETÊNCIAS}

\begin{tabular}{|c|c|c|}
\hline \multirow[t]{11}{*}{$\begin{array}{l}\text { Habilidade } \\
\text { comunicacional }\end{array}$} & Escutar & $\begin{array}{l}\text { Escutar activamente as pessoas. } \\
\text { Identificar barreiras que } \\
\text { prejudicam a escuta. Eliminar as } \\
\text { barreiras que prejudicam a escuta. }\end{array}$ \\
\hline & Falar & $\begin{array}{l}\text { Comunicar oralmente com uma } \\
\text { pessoa ou grupos de diferentes } \\
\text { dimensões. }\end{array}$ \\
\hline & & Levar a cabo apresentações orais. \\
\hline & & $\begin{array}{l}\text { Comunicar oralmente com } \\
\text { grupos de várias valências e } \\
\text { backgrounds. }\end{array}$ \\
\hline & & $\begin{array}{l}\text { Interagir e comunicar com } \\
\text { indivíduos possuidores de vários } \\
\text { e diferentes graus de } \\
\text { conhecimento e capacidades. }\end{array}$ \\
\hline & & $\begin{array}{lcr}\text { Interagir e comunicar } & \text { com } \\
\text { indivíduos } & \text { possuidores } & \text { de } \\
\text { diferentes pontos de vista. } & \end{array}$ \\
\hline & & $\begin{array}{l}\text { Reconhecer e utilizar } \\
\text { eficazmente os comportamentos } \\
\text { não verbais. }\end{array}$ \\
\hline & Ler & $\begin{array}{l}\text { Ler e compreender um grande } \\
\text { conjunto de publicações }\end{array}$ \\
\hline & $\begin{array}{l}\text { Comunicar por via } \\
\text { eletrónica }\end{array}$ & $\begin{array}{l}\text { Comunicar eficazmente com os } \\
\text { outros através dos meios } \\
\text { eletrónicos. }\end{array}$ \\
\hline & Interagir com media & Interagir com themedia. \\
\hline & Escrever & $\begin{array}{lcr}\text { Escrever } & \text { acerca } & \text { vários } \\
\text { propósitos. } & \text { Escrever } & \text { para } \\
\text { diferentes audiências. } & \end{array}$ \\
\hline
\end{tabular}

Não obstante a literatura nos forneça várias tipologias de estilos pessoais de comunicação uma das mais referenciadas e testadas numa pletora de amostras e contextos é a que distingue os estilos assertivo, agressivo, manipulador e passivo (Waters, 1981), encontrando-se no 
primeiro a fórmula mais eficaz (principalmente em situações de conflito) para comunicar e conquistar aquilo que se pretende obter dos outros. Na realidade, e tal como defendido por Pfeffer (1992), o usufruto do poder político associa- se fortemente com a assertividade na comunicação, significando que o interlocutor, para além de ser autoconfiante e auto-afirmativo - defendendo construtivamente a sua esfera individual - integra e reconhece o ponto de vista e a perspectiva dos outros. Sublinhe-se que a este nível, alguns estudos apontam que embora determinados actores políticos se escudem por detrás da égide da assertividade - metaforicamente gizada do seguinte modo: "é mais fácil atrair abelhas com mel do que com vinagre" (Cunha et al., 2003: 380), esta acaba por ser uma estratégia eficaz e uma forma encapotada para gerir impressões e interacções ocultando estilos interpessoais mais agressivos e manipuladores, materializando-se (entre outras coisas) na arte da dissimulação, do fingimento, da insinuação, da sedução, do baralhar das cartas lançando a confusão. O propósito central não é, por exemplo, negociar acordos favoráveis para o grupo de trabalho, obter apoios favoráveis para as decisões do todo ou desenvolver e melhorar as condições dos colaboradores e alcançar objectivos organizacionais, trata-se de influenciar os outros procurando manipulá-los, alcançando o engrandecimento pessoal e a satisfação egoísta dos objectivos pessoais.

Uma outra tipologia comunicacional que tem acolhido diversos estudiosos e se afigura assaz prometedora na análise do comportamento político em cenários de trabalho diz respeito ao tetramodelo SARA proposto por Alessandra e Hunsaker (1993). O modelo apresenta duas dimensões básicas: o binómio directo-indirecto e o binómio auto-contido-apoiante/aberto, possuidores das seguintes idiossincrasias:

- A pessoa directa é extremamente franca, expressa facilmente a sua opinião, é assertiva, é opinativa e combativa, aparenta autoconfiança, toma iniciativa social, orienta-se para a acção, gosta de assumir riscos, prefere decisões rápidas, gosta de resultados, mostra-se impaciente. Varia o tom de voz e denota gestos que realçam os pontos-chave daquilo que deseja expor. 
- Contrariamente ao estilo anterior, o actor indirecto é reservado nas suas opiniões e na partilha e manifestação dos seus sentimentos, ouve mais do que fala, é parco nos gestos, é paciente, socialmente pouco competitivo, escusa situações que envolvam grandes mudanças, medita bastante antes de tomar uma decisão, atende aos detalhes, analisa os processos e os dossiers passo-a-passo, é diplomático, evita o conflito e confrontações de ideias e pontos de vista.

- Tal como o nome sugere, a pessoa auto-contida auto-limita-se na expressão de sentimentos e emoções, é extremamente formal e fria no trato, gosta de manter uma grande distância (física e psicológica) com os outros, gesticula pouco com o corpo e mãos, inflecte pouco a voz, propende para os factos e para os detalhes.

- O agente aberto/social é emocionalmente aberto, partilha sentimentos pessoais, não tem qualquer pejo em manifestar as suas alegrias e tristezas, expressa opiniões com facilidade, gosta de conversar, tem bom humor, tem expressões faciais animadas, gesticula com o corpo e mãos, tem um discurso muito informal, mantém uma grande proximidade física com os outros, gosta do tacto e valoriza os sentimentos dos outros.

Da secância destas duas dimensões emergem quatro tipos - ideais de estilos interpessoais de comunicação, cujas iniciais suportam a designação atribuída ao modelo SARA: Social, Afiliativo, Reflexivo e Administrador. Pela caracterização das diferentes tipologias e analisando de perto as peculiaridades das arenas políticas urge extrair duas importantes ilações:

Por um lado, facilmente podemos aludir que os actores organizacionais que se enquadram no perfil social/expansivo donde se diferencia: a valorização do envolvimento social - determinante para a criação de contactos, redes, parcerias e coligações; os motivos de poder (McClelland, 1987); o espírito criativo; as óptimas competências persuasivas; a busca do êxito e admiração; são os que melhor se enquadram na objectiva do retrato: politicamente eficaz. 
Por outro lado, os estilos afiliativo/relacional e o social/ expansivo ao demonstrarem possuir uma grande apetência e predisposição para se relacionarem socialmente são variáveis explicativas, de acordo com as orientações da literatura da especialidade (nomeadamente ao nível da liderança organizacional), dum conjunto bastante diversificado e rico de atitudes e comportamentos organizacionalmente pertinentes, designadamente: eficácia; motivação; satisfação; empenhamento; confiança na organização e nos gestores; comportamentos pro-sociais e de cidadania organizacional; percepções de justiça; comportamentos retaliatórios; reacção às tentativas de influência; absentismo; turnover; produtividade, entre outros (Bass, 1985 e 1999; McClelland, 1987; Conger e Kanungo, 1988; Bryman, 1992 Waldman et al., 1995; Lowe, Kroeck e Sivasubramaniam, 1996; Yukl, 1998; Miranda, 2003; Tredway et al., 2004). Da pletora de estudos justificativos veja-se, por exemplo, os apresentados por de Yukl (1998) que revela que os comportamentos de consideração tendem a relacionar-se positivamente com a satisfação. Likert (1967) aduziu que a eficácia (produtividade e satisfação do pessoal) progredia à medida que as organizações passavam de relacionamentos interpessoais autoritárias para sistemas mais participativos. House (1977) Bass (1985 e 1999), Conger e Kanungo (1988 e 1998) Treadway (2004) e seus colaboradores demonstraram numa volumosa multiplicidade de amostras que os líderes que pautam a sua actuação de acordo com os princípios da consideração elevam (por vezes, de uma forma impressionantemente) os níveis de satisfação, empenhamento e confiança na organização e reduzem as percepções e exteriorização de formas de cinismo organizacional.

Com o intuito de testar e adaptar o tetra-modelo comunicacional de Alessandra e Hunsaker (1993) à realidade organizacional portuguesa, Rego (2001) verificou o forte pendor afiliativo e a fraca propensão assertiva dos gestores portugueses. Quando os inquiridos eram solicitados a descrever os comportamentos comunicacionais de uma pessoa à sua escolha, uma significativa maioria indicava a tipologia Afiliativo e estabeleciam correspondência com o estilo mais eficaz. Os resultados postos em evidencia não primam pela novidade já que surgem no trilho de outras investigações aferidas em território nacional (McClelland, 1987; Hofstede, 1980; Rego e Jesuíno, 2002), todas elas 
acentuando o forte carácter feminino da cultura portuguesa. Hofstede em entrevista explica esta característica do seguinte modo:

"Portugal e um país tipicamente latino, pertencendo, por isso, ao grupo mais feminino. No entanto, reconheci imediatamente que os portugueses diferem dos outros países latinos e, ao contrário dos espanhóis, não matam os seus touros. Os portugueses tendem a ser mais simpáticos para as pessoas e são bons negociadores, tentando sempre encontrar uma via pacífica. Por isso, resolvem muitos problemas negociando e não guerreando. Existe também uma tendência para o colectivismo. (...) Por outro lado, a sua tendência latina manifesta-se na tendência para evitar a incerteza. São por isso, cuidadosos com as pessoas que não conhecem - é o sentido de que o diferente é perigoso (Hofstede in Sakellarides, 1997: 40).

Pese embora a fraca notoriedade patente na literatura parece-nos que, tendo em conta as características e peculiaridades das organizações pós-modernas (e respectivas envolventes), seria naïve da nossa parte reduzir a eficácia do estilo interpessoal de comunicação do indivíduo com poder político ao identificado anteriormente. $\mathrm{Na}$ verdade, e de acordo com as orientações da literatura da especialidade (GalWillner, 1984; Conger, 1985; House, Woycke e Fedor, 1988; Howell e Frost, 1989; House e Shamir, 1993; Gardner e Avolio, 1998; Awamleh e Gardner; 1999), a habilidade para comunicar emoções ocupa aqui um papel preponderante, daí o constante recurso aos apelos emocionais, aos símbolos, às metáforas, às analogias, entre outros.

Particularmente no uso da retórica, diversos investigadores (como é o caso de Cheney et al., 2004) são unânimes ao afirmar que embora o conteúdo das mensagens seja importante, o fascínio que provocam advém não da lógica ou da qualidade das ideias mas dos estímulos emocionais que transmite e das emoções e sentimentos que desperta nos ouvintes. Trata-se, de acordo com a explicação de Aristóteles, da - arte de usar símbolos para persuadir os outros a alterarem as suas atitudes, crenças, valores ou acções (Aristóteles in Cheney et al., 2004: 79) encerrando, não raras vezes, uma dimensão estratégica na senda de alcançar fins previamente especificados, e corroborando da convicção de Hardy e Clegg (1999) de que o discurso é inseparável do poder. 
Esta comunicação criativa (Casse, 1994) é uma das principais armas à qual os indivíduos, emocionalmente inteligentes (Goleman, 2000) e habilmente políticos, recorrem quando pretendem activar os mecanismos de identidade e sentido colectivo de trabalho; quando querem instilar, gerar e manter a excitação, o entusiasmo, a confiança, o optimismo e a cooperação; quando desejam estabelecer e/ou manter uma identidade organizacional significativa para os membros organizacionais.

Por exemplo Wilner (1984), ao levar cabo uma série de estudos de caso, concluiu que as imagens bíblicas, as metáforas, as historias populares, as rimas e as repetições são elementos frequentes nos discursos dos actores organizacionais imbuídos de poder. Semelhantes ilações foram retiradas por Shamir, Arthur e House (1994), sendo que o apelo à história colectiva, às tradições, aos valores partilhados e justificações morais são a pedra de toque. De acordo com Pondy (1983), o exercício da liderança política esta fortemente dependente do jogo da linguagem, ou seja, do modo como o líder escolhe palavras que expliquem a importância das experiências e comunhão colectivas. O tipo de linguagem utilizada é, por natureza, extremamente inclusiva e polissémica - contemplando múltiplas interpretações - tendo por isso, de acordo Fiol, Harris e House (1999), um fito extremamente agregador, mobilizador e persuasivo junto dos indivíduos que se pretende influenciar.

Para Martindale (1986), e Emrich et al. (2001) a eficácia da linguagem utilizada advém do apelo que faz ao imaginário, isto é, em que medida e com que rapidez as palavras conseguem despertar uma experiência sensorial, uma imagem mental ou um som junto dos receptores. Por exemplo, se considerarmos o seguinte conjunto de palavras: sonho vs ideia; suor vs esforço; coração vs compromisso; auxílio vs ajuda; verificamos que embora tenham o mesmo significado não provocam o mesmo impacto. Para isso basta aduzir o quão diferente teria sido se Martin Luther King tivesse proferido: - "eu tive uma ideia"; ou então, porque razão, no mundialmente famoso discurso de Churchill em que ele frisa a importância do —sangue, esforço, lágrimas e suor, a palavra esforço tem sido ignorada ao longo dos tempos sendo hoje citado e recordado como o discurso do —-sangue, suor e lágrimas. 
Desta forma, entendem os investigadores que a utilização de palavras que evoquem imagens, sons, cheiros, gosto e outras sensações, para além de provocarem um efeito mais imediato, directo, real e identificativo do que a utilização de palavras que apenas apelam ao intelecto e às dimensões racionais da audiência, facilitam uma maior e mais completa memorização da mensagem: -uma mensagem que apele a imagens será armazenada em muitos mais locais e com um detalhe muito mais rico do que uma mensagem que apele a conceitos. Assim, na hora de agir, os seguidores serão melhor sucedidos na consecução da mensagem e terão em mão um guia de acção muito mais completo e potencialmente mais instrutivo (Emrich et al., 2001: 5).

Vejamos, a título de exemplo, alguns dos conjuntos de palavras retiradas dos inúmeros estudos levados a cabo por Martindale (in Emrich et al., 2001: 27) e que são agrupadas em duas categorias: as que apelam a experiências sensoriais e pictóricas e as que invocam interpretações racionais e lógicas tendo o primeiro grupo um efeito muito mais profundo e persuasivo junto dos alvos:

Tabela 2. Palavras que apelam a imagens e palavras que apelam a conceitos, construído a partir de Martindale (in Emrich et al., 2001).

\begin{tabular}{|l|l|}
\hline PALAVRAS APELAM & $\begin{array}{l}\text { PALAVRAS APELAM } \\
\text { IMAGENS }\end{array}$ \\
\hline Suor (sweat) & Trabalho/esforço (work) \\
\hline Dar a m o (hand) & Ajuda (help) \\
\hline Vê(see) & Compreende (understand) \\
\hline Amor (heart) & Empenhamento (commitment) \\
\hline Explora (explore) & Pergunta (inquiry) \\
\hline Cresce (grow) & Produz (produce) \\
\hline Imagina (imagine) & Pensa (think) \\
\hline
\end{tabular}

$\mathrm{Na}$ esteira do anteriormente discutido, Kay, Jimenez e Jost (2002) ao efectuarem uma análise de conteúdo comparativa aos discursos de Bush e Gore concluíram que, embora o candidato democrata estivesse 
estivesse melhor preparado e fosse mais conhecedor da realidade política interna e externa do seu país, o facto de recorrer a respostas com uma grande carga e complexidade cognitiva não o beneficiou junto do eleitorado. Por seu turno, Bush acabou por beneficiar da leveza, imprecisão, e redundância que imprimiu aos seus discursos.

Mas não se trata apenas duma questão de retórica ou da forma como verbalmente a mensagem é construída, o modo como tais indivíduos comunicam a sua própria motivação para liderar é também um elemento determinante. Ao usarem modos de acção expressivos, verbais e não verbais, eles manifestam as suas convicções, autoconfiança e dedicação para materializar o que defendem. Estas mesmas qualidades podem igualmente ser expressas pela forma de vestir, aparências pessoal e linguagem corporal (Willner, 1984; Conger, 1991; Conger e Kanungo, 1988 e 1998; House, Woycke e Fodor, 1988; Howell e Frost, 1989; Shamir, Arthur e House 1994; Den Hartog e Verburg, 1997). O agente político pode apresentar-se animado, ou falar em tons fortes e decididos. Todos estes diversos modos de expressão são instrumentos que eles têm ao seu dispor para comunicar o seu entusiasmo, empenhamento, motivação que, por sua vez, se tornam contagiantes para os demais. Um exemplo paradigmático do que acabou de ser gizado pode encontrar-se no modo como Bill Clinton comunica com os seus públicos. Uma análise exaustiva ao estilo comportamental que imprimia aquando dos discursos e debates televisivos, entrevistas e conferências de imprensa revelou o uso estratégico de pausas para o efeito e o controlo calculado de emoções, representadas pelo actor William Hurt no filme Broadcast News (Ferris et al., 2000). Nos interstícios do que foi dito, poder-se-á afirmar que a eficácia da liderança política passara por um processo que envolve uma porção considerável de gestão e manipulação das emoções dos alvos, beneficiando do portolio de atributos pessoais trazidos a lume pela moda da Inteligência e Liderança Emocional (Goleman, 1999 e 2000) - autoconsciência; autogestão; consciência social; competências sociais - e que de certa forma, vão ao encontro de algumas das idiossincrasias identificadas e discutidas anteriormente. A este nível, pese embora a apologia dos argumentos de Goleman, introduz-se aqui uma nota de cautela, das quais se destacam as apontadas por Hunt (2001) alertandonos para os possíveis malefícios da gestão instrumental dos estados 
emocionais e dos sentimentos das pessoas. Entende Hunt (2001) que a possibilidade dos líderes poderem de uma forma consciente lidar com as suas emoções e com as das outras pessoas e geri-las de um modo funcional quer em termos pessoais quer organizacionais faz com se possa estar a evoluir para uma forma de controlo burocrático da emocionalidade, transformando os indivíduos "escravos" organizacionais sem que disso tenham consciência.

Aliás, floresce na literatura como pistas para investigação futura a necessidade de se efectuar um maior investimento e dedicar maior atenção às ligações emocionais como fortes determinantes e preditores de relações de dependência e poder, nomeadamente no que diz respeito às estratégias de poder negocial baseadas na manipulação das emoções e dos alvos; no modo como o líder emocionalmente inteligente consegue exercer poder sobre os seguidores e organização; e, no grau em que uma hábil gestão das emoções dos outros e do próprio pode constituir uma base de poder de elevada eficácia (George, 2000; Hunt, 2001).

\subsection{Investigar política e comportamentos políticos nas organizações: inquietações e dificuldades metodológicas}

Tal como realçado ao longo do marco teórico devido à sua enorme sensibilidade, complexa conceptualização e operacionalização, a política e o comportamento político é uma das mais difíceis áreas de investigação da teoria e comportamento organizacional. É certo que as razões deste facto se podem espartilhar e detalhar num conjunto alargado de explicações, porém, há alguns aspectos que urge evidenciar.

Em primeiro lugar porque - não obstante alguns avanços já efectuados - subjacente ao estudo da política nas organizações está (e estará?) associada e enraizada a crença e o tabu moral (Crozier, 1973; Kanter, 1979) de que a sua manifestação se resume a um conjunto de comportamentos socialmente reprováveis, ilegítimos, manobras e acordos efectuados na penumbrall dos bastidores que servem apenas para colmatar os interesses de uma pequena minoria e de que o seu impacto, a existir, só poderá ser negativo e altamente pernicioso para os indivíduos e para a organização. Em boa verdade, a prevalência desta faceta maculada, indecorosa e suja da política faz com que sempre que 
se pretende discutir a actividade política interna da organização, os actores demonstrem alguma dificuldade em se rever na figura de um político ou agindo como tal - com excepção das decisões e acções que são, devidamente, justificadas em prol do pretenso bem comum.

Tal como Pfeffer aventou (1992), à guisa do avançado por Burns (1961), "quando fazemos política em nosso proveito, vemo-la como uma força positiva (...) mas quando são os outros a fazê-lo, principalmente quando cerceiam os nossos objectivos ou ambições, encaramo-la como se do demónio se tratasse" (Pfeffer, 1992: 35). O exposto ajuda-nos, de imediato, a perceber as dificuldades inerentes ao estudo do fenómeno e a interrogar a sinceridade atinente às respostas obtidas por inquérito por questionário (um dos métodos - por vezes, o único - mais utilizados na abordagem desta temática) (Pfeffer e Salancick, 1974; Bacharach e Lawler, 1980; Bradshaw-Camball e Murray, 1991; Hardy, 1995; Hardy e Clegg, 1999), e a exigir técnicas mais refinadas e técnicos deveras experimentados caso, porventura, se opte por uma abordagem de cariz mais qualitativo, como, por exemplo, as entrevistas. De resto, são frequentes os testemunhos de investigadores que foram obrigados a recorrer a diligências várias para aceder e abordar o tema, a "pesarem cada palavra" que empregavam ou a proferirem e a recorrerem a eufemismos - por exemplo: nível de informalidade (Prasad e Rubeinstein, 1992); propensão para se comportar politicamente (Mayes e Anderson, 1984) ou a utilizarem conceitos aproximados (como é o caso da influência e tacitas de influência) (Yukl, 1998) que amenizassem a conotação dura e negativa adstrita aos termos e "embrulhassem a verdadeira questão numa capa mais neutra para o respondente ou entrevistado" (Cabral-Cardoso, 1996: 411.

Em segundo lugar, porque a natureza altamente perceptiva da actividade política desapodera-a, à partida, da possibilidade da sua medição ser feita de um modo absoluto e objectivo (Gandz e Murray, 1980; Ferris, Russ e Fandt, 1989; Valle e Perrewe, 2000; Davis e Gardner, 2004) Os actores organizacionais constroem, vivem, dão sentido e atribuem significado à sua realidade em prol daquilo que vêem e interpretam e não, necessariamente, em função daquilo que a realidade objectivamente é, logo, apresenta-se extremamente difícil e 
penosa a tarefa de demarcar quais são os domínios, as faces e as fronteiras da política organizacional. Conforme Gandz e Murray (1980) ilustraram, da mesma forma que uma situação pautada por conflitos, negociações e jogos de poder pode ser, sentida e percepcionada, por alguns cidadãos organizacionais, como um processo transparente, imbuído dentro dos trâmites e do curso normal da rotina diária e na senda do bem-estar da comunidade organizacional, outros, podem perspectivá-la como um tenebroso processo altamente politizado. Acresce que o que verdadeiramente distingue a influência política de outros tipos de influência reside na sua intencionalidade, uma vez que a actividade política implica acções estrategicamente pensadas, planeadas, reflectidas e deliberadas. Também a este nível colocam-se grandes entraves operacionais, já que é extremamente difícil aferir as reais intenções políticas dos indivíduos, descortinar as suas agendas seguras (Bacharach e Baratz, 1962) pressupondo, muitas vezes, um processo atribucional da parte do observador, porém, a fiabilidade deste procedimento é bastante discutível! Assim, um favor pessoal efectuado a um colaborador tanto pode representar um gesto de altruísmo, amizade e apreço da parte da chefia, como pode implicar uma tentativa futura de pagamento de favores, suborno ou obtenção de regalias pessoais (Mayes e Allen, 1977; Allen et al., 1979).

Em terceiro lugar, porque à actividade política agrada-lhe, extraordinariamente, o conforto, a informalidade e o anonimato do trabalho de bastidores obrigando a um esforço acrescido e esmiuçado de profundidade de análise e interpretação dos níveis menos visíveis (porém, mais ricos e reveladores) do comportamento e da dinâmica organizacionais que, entendemos, estarem dificilmente acessíveis às abordagens frias, musculadas e superficiais das propostas funcionalistas e do seu atinente positivismo metodológico. É certo que em algumas ocasiões conseguimos a vista desarmada identificar e reconhecer o exercício da actividade política outrossim, sabemos que a política encerra em si mesma uma multiplicidade de faces (Bacharach e Baratz, 1962; Lukes, 1974), algumas delas muito menos percetíveis, mas muito mais delatoras das regras do jogo, unicamente obtidas através da -malhall fina das análises de cariz interpretativo (Pettigrew, 1973; Bradshaw-Camball \& Murray, 1991). 
Em quarto lugar, porque apesar dos esforços encetados e das tipologias avançadas (Farrel e Peterson, 1982; Porter, Allen e Angle, 1983; Zanzi e O'Neill, 2001) com o intuito de balizar as fronteiras e as divisas da legitimidade das tacitas e dos comportamentos empregues na actividade política, esta, para além de estar, sobremaneira, confiscada às específicas características situacionais e às amarras culturais (Fu e Yukl, 2000) está, igualmente, dependente da avaliação dos fins a que se destina. A este nível faz sentido trazer, novamente, para o debate a ideia tenazmente comungada por Frost e Hayes (1979), Gandz e Murray (1980) ou Pfeffer (1981) para quem a legitimidade da política organizacional é tão volátil como um estado de espírito logo, a colocação dessa marca esta dependente do momento, das circunstâncias e dos indivíduos envolvidos. Afinal, e dando vida à analogia ilustrativa de Barbuto Jr. (2000), olhar para o comportamento de um líder sem levar em linha de conta o comportamento dos alvos será a mesma coisa que olhar para o comportamento do condutor de um camião que se depara com um veado na estrada e tem de prevenir $\mathrm{o}$ acidente sem nunca considerar aquilo que o animal pode fazer.

Em quinto lugar, porque a literatura não e consensual quanto ao nível de análise que deve ser considerado quando estamos a estudar o fenómeno em questão. Na verdade, se revisitarmos o caleidoscópio dos estudos mais salientes dentro desta área de trabalho verificamos que o subgrupo (Bacharach e Lawler, 1980) e o grupo são, sem dúvida, a unidade de análise de eleição (Pfeffer e Salancick, 1974; Tushman, 1977; Yukl, 2006). Nele enquadram-se, por exemplo, o estudo da formação e da dinâmica das coligações; da negociação política; da formação de estabelecimento de normas e consensos ao nível do grupo; dos interesses de grupo e, obviamente, da liderança. É certo que, como defende Farrel e Peterson (1982), a política organizacional também advém da actividade individual e está largamente dependente de factores disposicionais e das competências pessoais dos agentes políticos e que, como refere Cobb (1986), o nível de análise individual é significativo e não deve ser desconsiderado, porém o poder e as dinâmicas grupais são assaz distintas da desgarrada acção individual. De igual modo, há actividades organizacionais (como por exemplo, a constituição de redes; o envolvimento em processos eleitorais) que só se encaixam no nível de análise macro. 
Tal como Drory e Room (1990) gizaram, e em função das leituras e da reflexão teórica efectuada, e nossa convicção que o estudo da política em cenários de trabalho só tem a ganhar se, para além do individual e do grupal também for capaz de pensar o organizacional, ou seja, ela deve trespassar os três níveis de análise, ainda mais quando nos aproximamos ao domínio da liderança política e sabemos que os líderes operam em três níveis de acção política e adequam os seus comportamentos e as tacitas de influência política às particularidades de cada estrato (Cobb, 1986; Ammeter et al., 2002).

Finalmente, porque, no que se prende especificamente com o fenómeno da liderança política, apesar de recentemente, esta temática tenha vindo a granjear alguma notoriedade no âmbito dos estudos organizacionais (Ferris et al., 2000; Perrewé et al., 2000; Ammeter et al., 2002; Treadway et al., 2004; Miranda, 2017; Miranda \& Antunes, 2019), ela carece de um grande desenvolvimento e amadurecimento teórico, o que se materializa na pouca abundância de estudos empíricos e na inexistência de instrumentos próprios. De resto, a ausência de instrumentos de análise quantitativos fidedignos e consistentes é uma das maiores dificuldades que, na generalidade, atravessa o estudo da política nas organizações tendo, por essa razão, ficado, demasiadas vezes, confinado a mensuração parcial das tacitas e dos comportamentos políticos de influência dos seus actores (BradshawCamball, 1991) - facto atestado pela parafernália e alegoria de propostas e tipologias copy cat que emergiram para esse fim (Allen et al., 1979 ; Kipnis, Schmidt e Wilkinson, 1980; Farrel e Peterson, 1982; Kipnis e Schmidt, 1982; Brass, 1984). Assim, com o fito de ultrapassar algumas dessas limitações, têm surgido novas e promissoras abordagens ao estudo da política nas organizações passando pela análise do clima político na organização (Drory, 1993; Ferris et al., 1996) e pela aferição da habilidade política (Ferris et al., 1999). Irremediavelmente, o aduzido tem repercussões e implicações metodológicas. $\mathrm{Na}$ verdade, a ideia de que a investigação sobre política deve recorrer a uma combinação de vários métodos e não se cingir à utilização única e exclusiva de apenas um deles, recolhe bastante apoio e parece representar um dos tópicos em que a maioria dos estudiosos converge (Bradshaw-Camball e Murray, 1991; Bacharach e Lawler, 1998; Ammeter et al., 2002; Yukl, 2006). Uma abordagem multimetodológica, triangulada (Denzin, 1989) ou seja, o recurso a um mix 
de métodos quantitativos e qualitativos, nele incluindo os inquéritos por questionário, as entrevistas, os incidentes críticos, a construção de cenários, as narrativas, o estudo de casos, a observação participante ..., representariam um alargamento e enriquecimento do leque de técnicas e instrumentos de diagnóstico considerados legítimos e aceitáveis, bem como um distanciamento critico perante o positivismo metodológico dominante (Stevenson, Pearce e Porter, 1985; Redding, 1994) e o seu kit de métodos prontos a usar. Por se tratar de um fenómeno sujeito a um grande melindre, pretende-se, por um lado, cruzar, refinar e peneirar o mais possível a informação obtida pelas diferentes técnicas; por outro lado, e por contraste a uma abordagem metodológica mais tradicional - descontextualizada, desespacializada destemporalizada e, de acordo com Clegg (1989), ate imaginada, a abordagem multimetodológica tem a vantagem de reforçar a validade externa e a utilidade dos resultados (Bradshaw-Camball e Murray, 1991).

Em boa verdade, apesar dos ecos patentes na literatura mostrando ser redutor, insuficiente e ate inadequado cingir o estudo da política (e da liderança política) ao espartilho dos inquéritos por questionário, verifica-se que na prática os mesmos continuam a ser isolada e insistentemente utilizados, da mesma maneira que os métodos mais refinados como é o caso dos longitudinais e dos etnográficos (Vigoda e Cohen, 2002) - muito mais ricos, mas também muito mais onerosos em termos de tempo e dinheiro - continuam a ser preteridos. É importante não olvidarmos que, muitas vezes, são os imperativos e os critérios de ordem económica e/ou temporal, que não científicos, a determinar as opções metodológicas. Neste contexto, não parece descabido o observado por Triandis (1992) no - Handbook of, Industrial and Organizational Psychology - o que importa não é escolher um método específico, mas antes uma combinação de métodos! 


\section{Metodologia}

\subsection{Método e Instrumentos de Recolha dos dados}

Com o intuito de compreender em que medida o estilo interpessoal de comunicação dos lideres é preditor dos comportamentos políticos optou-se por levar a cabo uma investigação do tipo quantitativa e qualitativa com triangulação de técnicas (Denzin, 1989), operacionalizada, por um lado, por via da aplicação de inquéritos por questionário a uma amostra não probabilística composta por 1780 sujeitos inseridos em cenários de trabalho (colaboradores) e, por outro lado, entrevistas semi-estruturadas acopladas de listagem de incidentes críticos a 20 líderes (chefias diretas) (Flick, 2002).

O inquérito por questionário é composto por duas escalas centrais. Para aferir a habilidade comunicacional dos lideres utilizou-se a escala de Waters (1981) que postula a divisão entre os estilos agressivo, manipulador, passivo e assertivo (alfas de Cronbach $=0,79 ; 0,70 ; 0,79$; 0,86 , respetivamente); por seu turno, para avaliar os comportamentos políticos manifestados pelos sujeitos recorreu-se à escala de tacitas e comportamentos políticos: suaves e duros (Yukl e Falbe, 1990) (alfa de Cronbach $=0,88 ; 0,73$, respetivamente). Para responder a estas questões, foi solicitado aos colaboradores que se reportassem à sua chefia directa, utilizando uma escala de Likert de 5 pontos (1. Discordo totalmente; 5. Concordo totalmente).

Para a elaboração do guião das entrevistas, para além de tomarmos como ponto de partida um conjunto de reflexões, ilações e pistas que surgiram no decurso do amadurecimento teórico que foi efectuado aquando da revisão da literatura tivemos, sobremaneira, em atenção os resultados oriundos da análise dos dados dos inquéritos por questionário efectuados aos colaboradores - o que equivale a dizer que as entrevistas só foram elaboradas e levadas a efeito após termos efectuado a análise quantitativa dos dados.

Tendo em conta o seu pendor essencialmente convergente e confirmatório, acima de tudo, com isto pretendeu-se suscitar nos entrevistados (chefias directas) comentários, opiniões, interpretações e reacções que pudessem revelar luz sobre alguns dos aspectos menos claros, óbvios e percetíveis do fenómeno estudado trazidos a lume pelos dados resultantes dos inquéritos por questionário, tal como obter 
a versão dos factos de quem se encontra do outro lado da barricada. De resto, esta é, para o mentor da técnica (Flanagan, 1954), uma das grandes vantagens dos incidentes críticos e que consiste em evidenciar factos significativos e acima de tudo, captar as observações para áreas onde os comportamentos não podem ser facilmente observados e avaliados por outras técnicas. Apresenta-se de seguida, alguns dos aspectos e vectores centrais que foram abordados nas entrevistas:

- Definição e avaliação das características, motivações, competências e comportamentos comunicacionais que, actualmente, consideram mais relevantes enquanto chefias;

- Definição e avaliação das actividades, situações e relações que, actualmente, consideram mais relevantes enquanto chefias;

- Descrição das relações que mantêm com os outros, a importância que estas revertem aos seus olhos e aos olhos dos outros;

- Relevância e opinião atribuída aos mecanismos de influência política e actividades de bastidores;

- Avaliação e descrição do ambiente vivido na organização de pertença;

Para além disso, foi pedido aos entrevistados que face a uma lista de tacitas e comportamentos políticos, escolhessem 3 comportamentos que manifestavam com mais frequência sempre que pretendiam mobilizar os seus colaboradores.

No que diz especificamente respeito aos incidentes críticos, na fase final da entrevista foi solicitado aos sujeitos inquiridos que descrevessem uma ou várias situações concretas em que, directa ou indirectamente, tivessem vivificado ou presenciado jogos de poder ou acções políticas na sua organização. Este pedido generativo (Riemann e Schutze, 1987) foi, sempre que necessário, complementado e pontuado com pequenas e curtas intervenções do entrevistador onde se procurou explorar e recuperar fragmentos dos incidentes que não tinham sido devidamente aflorados, tal como foi pedido aos entrevistados que indicassem com que frequência (nunca; raramente; frequentemente, sempre) (Flanagan, 1954) esses ou incidentes similares ocorreriam nas suas organizações de pertença. 


\subsection{Procedimentos}

Os inquéritos por questionário foram aplicados entre Janeiro e Maio de 2018. Para testar e analisar o modelo teórico, recorreu-se à aplicação do modelo de equações estruturais (Structural Equation Model - SEM).

As entrevistas foram realizadas entre Janeiro e Abril de 2018, tiveram uma duração entre 15-20 minutos, cada. Para analisar o material recolhido recorreu-se à análise de conteúdo (Vala, 1986). A frase foi eleita a unidade de registo.

\subsection{População e Amostra}

De uma forma sistemática, o procedimento adoptado para a escolha da amostra foi antecedido pela delimitação da população de pesquisa: sujeitos (homens e mulheres), activos, inseridos em ambientes organizacionais nacionais.

No que diz respeito ao estudo quantitativo, a amostra é constituída por 1780 sujeitos, $65 \%$ homens e $35 \%$ mulheres. Para a idade, embora a fatia mais representativa da população (33\%) estudada se situe no intervalo dos 31 e 40 anos de idade há, igualmente, uma percentagem bastante significativa $(27,9 \%)$ de sujeitos com idades compreendidas entre os 41 e os 50 anos e com idades iguais ou inferiores a 30 anos $(19,4 \%)$. Finalmente, o grupo etário dos 51 e 60 anos é o que menor peso detém na amostra (18\%).

Em relação ao nível de escolaridade, se atentarmos para a percentagem de indivíduos que possuem o ensino secundário $(43,8 \%)$ e o ensino superior $(26 \%)$ podemos concluir que estamos perante uma população relativamente bem instruída e alfabetizada. Apenas $29 \%$ dos inquiridos afirmaram ter estudos até ao 9o ano.

A amostra do estudo qualitativo é composta por 15 homens e 5 mulheres, com idades compreendidas entre os 33 e os 53 anos, detentores de uma escolaridade que oscila entre a posse da escolaridade obrigatória e a licenciatura. Todos os entrevistados exercem cargos de chefia direta. 


\section{Resultados}

\subsection{Resultados da Análise Quantitativa: As equações estruturais}

Uma primeira leitura aos dados dá-nos conta que todos os caminhos postulados no modelo de análise apresentam pesos de regressão significativos (todos com um $\mathrm{p}<0,001$ ). No que diz respeito ao estudo dos caminhos previstos no modelo teórico de análise, verifica-se que os antecedentes relacionados com as capacidades comunicacionais dos líderes em termos interpessoais estabelecem com os comportamentos políticos uma relação positiva embora dissemelhante nos seus pesos e níveis de importância. Os dados indicam-nos que os níveis de associação mais baixos estabelecem-se entre o estilo passivo e os comportamentos políticos dos líderes, ao passo que à medida que nos vamos afastando do estilo agressivo e nos aproximamos do estilo manipulador e assertivo coligimos valores mais elevados $(0,09 ; \mathrm{z}=8,48$ $\mathrm{p}<0,001 ; 0,17 ; \mathrm{z}=5,57 \mathrm{p}<0,001 ; 0,38 ; \mathrm{z}=8,21 \mathrm{p}<0,001 ; 0,60 ; \mathrm{z}=8,11$ $\mathrm{p}<0,001$, respetivamente). Assim, conclui-se que quanto mais salientes forem as habilidades comunicacionais dos líderes no que diz respeito à sua assertividade, maior será a possibilidade de enveredarem na prática politica e de se manifestarem politicamente. No que diz respeito ao ajustamento do modelo, todos os índices de ajustamento atendem às recomendações necessárias para que aceitemos a hipótese nula de que a matriz de covariância implicada pelo modelo não é diferente da matriz de covariância observada: $2(8,22038)=256,38, \mathrm{p}<0,001$; CFI $=1,00 ; \mathrm{GFI}=1,00 ; \mathrm{AGFI}=0,99 ; \mathrm{RMSEA}=0,03 ; \mathrm{AIC}=302,38$.

\subsection{Resultados da Análise Qualitativa: As entrevistas}

\subsubsection{Comportamentos de liderança}

Para estudar a presente categoria de análise optámos por enveredar por dois caminhos distintos, porém complementares. Assim, por um lado, e de uma forma livre, procuramos aferir e indagar quais os comportamentos que os entrevistados consideravam estarem mais comprometidos com o sucesso e eficácia do líder, e por outro lado, muito mais focalizado para as tacitas e comportamentos políticos de liderança, foi solicitado aos sujeitos que, face a uma lista de acções, elegessem as três que manifestavam com mais frequência sempre que pretendiam mobilizar os seus colaboradores face a uma nova proposta ou desafio. 
Em relação à primeira parte da análise, vislumbrou-se um considerável número de respostas coincidentes entre os sujeitos entrevistados. Os comportamentos que mais sobressaíram relacionam-se com a criação, a elaboração e a implementação de uma visão de longo prazo para a empresa (12), coadjuvada de um acompanhamento próximo, atento, constante ao grupo de trabalho (7), conforme patente na tabela 3 . O exposto leva-nos a concluir que os líderes analisados partilham a ideia de que as peculiaridades das actuais paisagens competitivas não se compaginam com acções de cariz reactivo, sublinhando a preferência pelo estabelecimento e implementação de uma visão apelativa e estratégica de futuro e de que essa visão será mais facilmente alcançada com envolvimento e participação de todo o grupo de trabalho.

Tabela 3. Comportamentos de liderança: extractos ilustrativos e análise da frequência.

\begin{tabular}{|c|c|}
\hline COMPORTAMENTOS DE LIDERANÇ̧A & FREQUÊNCIA \\
\hline "Ter uma visão distante para definição de objectivos e estratégia"; & 12 \\
\hline $\begin{array}{l}\text { "Acompanhar a realização das mesmas (tarefas) em reuniões } \\
\text { com periodicidade certa"; }\end{array}$ & 7 \\
\hline "Envolver as pessoas na definição dos objectivos"; & 6 \\
\hline "Ser exemplo"; & 5 \\
\hline "Atrever-se a inovar"; & 4 \\
\hline "Serproactivo"; & 3 \\
\hline $\begin{array}{l}\text { "Estar próximo da organização de todos os públicos afectos à } \\
\text { organização, digo trabalhadores, clientes”; }\end{array}$ & 2 \\
\hline trabalhadores, clientes"; & \\
\hline "Procurar ser justo"; & \\
\hline
\end{tabular}


No que diz respeito à análise dos comportamentos que os líderes indicaram mais vezes exteriorizar quando pretendem mobilizar os colaboradores. Como podemos ver pela leitura da tabela 4, há uma grande uniformidade de respostas, sendo que a esmagadora maioria se enquadra no âmbito das tacitas e comportamentos políticos suaves e dizem respeito à consulta das opiniões e envolvimento do grupo de trabalho ao longo de todo o processo (13); aos apelos hermeticamente técnicos, racionais, lógicos e factuais (9) e, finalmente, à colaboração onde se vislumbra um esforço contínuo e conjunto no sentido de alcançar o mesmo objectivo colocando-se, o líder, ao dispor dos colaboradores oferecendo e providenciando os recursos e a assistência necessária para a concretização da proposta ou desafio enunciado (7).

Tabela 4. Tácticas e comportamentos políticos que as chefias recorrem com mais frequência: análise da frequência.

\begin{tabular}{|l|l|}
\hline COMPORTAMENTOS POLÍTICOS & FREQUÊNCIA \\
\hline Consulta & 13 \\
\hline Persuasão racional & 9 \\
\hline Colaboração & 7 \\
\hline Legitimação & 1 \\
\hline Coligações & 1 \\
\hline
\end{tabular}

\subsubsection{Habilidade política dos líderes:}

Da leitura do quadro seguidamente apresentado podemos verificar que, embora verbalizem justificações distintas, a maioria dos entrevistados (16) posiciona-se favoravelmente e faz a apologia da habilidade política no exercício da liderança, senão vejamos: todos eles são da opinião que esta é uma perícia determinante para o sucesso da liderança, reconhecendo mesmo que, quando ausente, poderá transformar-se no grande "calcanhar de Aquiles" de muitas chefias. Consoante dois entrevistados afirmaram: - "conheço tantos bons profissionais que estão encostados à prateleira"; "provavelmente o meu grande calcanhar de Aquiles". Quer isto dizer que, não obstante a maioria dos entrevistados faça uma interpretação positiva da habilidade política, desprovida de juízos de valor e desconectada com a faceta feia e suja da política, encarando-a como uma dimensão inevitável do comportamento e dinâmica organizacional e presente em quase todas 
as actividades desenvolvidas pelos líderes: - "nas relações com subordinados, colegas e superiores hierárquicos, na negociação que estabelece com cada um destes interlocutores; na prossecução de objectivos, na negociação que estabelece com clientes; na forma como procura superar obstáculos entre partes divergentes, cedendo em determinados aspectos da negociação para depois ganhar noutros", algumas ressalvas são apontadas: por um lado, um entrevistado afirmou que esta perícia tende a assumir diferentes graus de importância nos diferentes níveis organizacionais, implicando que mais liderança de topo exige mais habilidade política sendo, neste patamar, a característica mais importante da sua acção: - "a importância de ser um bom político, e diplomata, é proporcional à altura hierárquica dentro da organização - um presidente terá de ser sempre um bom político/diplomata (interno e externo) pois será a característica mais importante na sua capacidade de liderança". Por outro lado, um outro entrevistado opinou que a habilidade política é, efetivamente, muito relevante quando o agente está a exercer cargos políticos, perdendo bastante vigor e importância fora desse contexto. Finalmente, uma das chefias que se posicionou favoravelmente em relação à posse e domínio da habilidade política advogou da sua premência conquanto, adstrita a comportamentos de bajulação dos superiores hierárquicos: "considero quase fundamental actualmente ser-se politicamente habilidoso, ou seja, quem mais bajular os superiores mais hipóteses tem de ter sucesso".

Tabela 5. A habilidade política dos líderes: extractos ilustrativos e análise valorativa.

\begin{tabular}{|l|l|l|l|}
\hline HABILIDADE POLÍTICA & FAVORÁVEL & NEUTRO & DESFAVORÁVEL \\
\hline "É importante que um líder/chefia & 18 & & \\
seja politicamente habilidoso... & & & \\
Materializa-se nas relações com & & \\
subordinados, colegas e superiores & & \\
bierárquicos, na negociação que & & \\
estabelece com cada um destes & & \\
interlocutores; na prossecução de & & \\
objectivos, na negociação que estabelece & & \\
com clientes; na forma como procura & & \\
superar obstáculos entre partes & & \\
divergentes, cedendo em determinados & & \\
aspectos da negociação para depois & & \\
ganhar noutros"; & & & \\
\end{tabular}




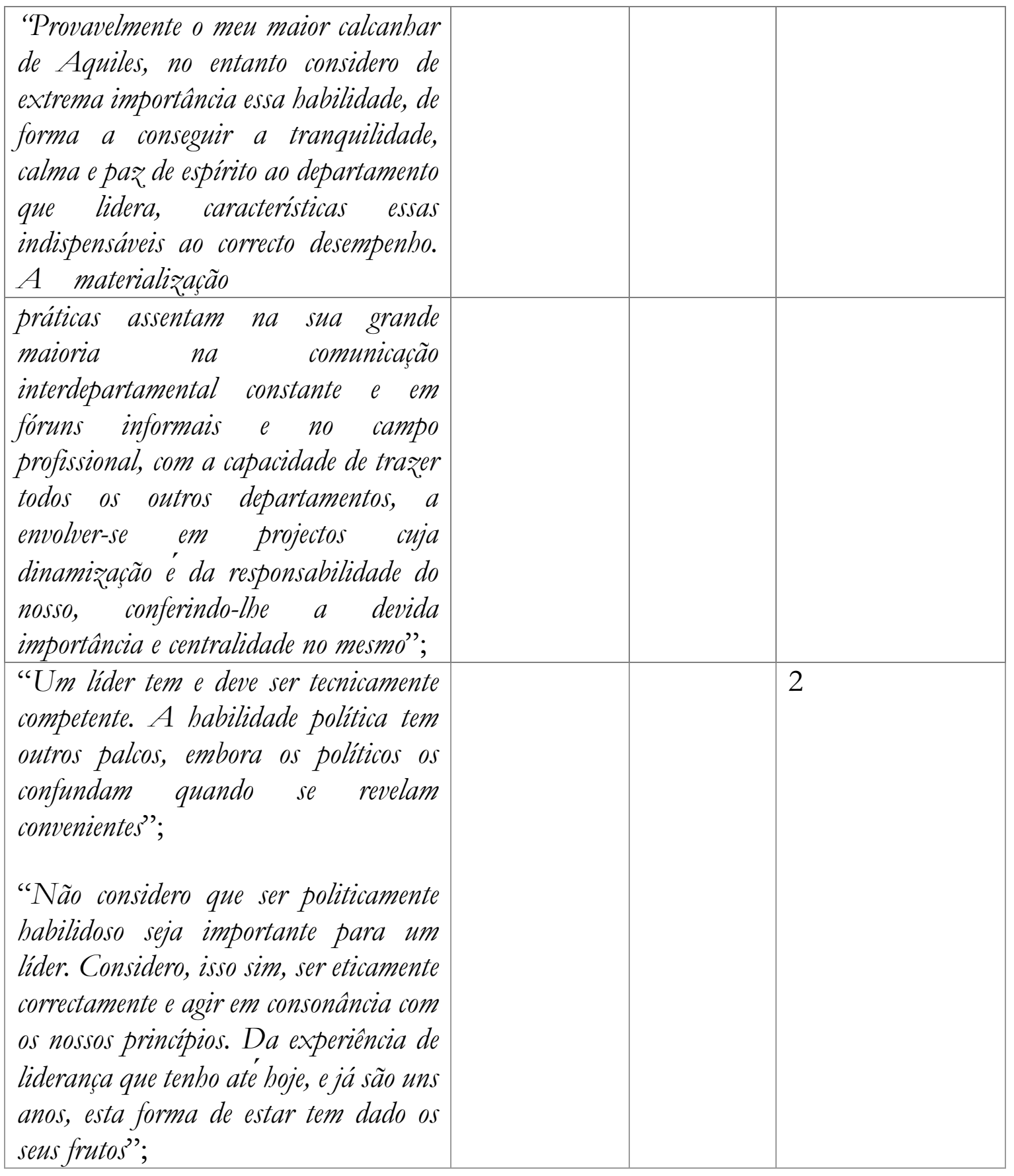

Apenas dois sujeitos discriminaram desfavoravelmente a sua posição, gizando que a actuação dos líderes deve estar apenas conectada com comportamentos de estruturação, concentrando-se, sobretudo nos aspectos na tarefa real e orientado para a organização do trabalho: - "a única coisa que se espera de um líder é que ela seja tecnicamente competente", conotando a habilidade política a práticas e palcos organizacionalmente irrelevantes e eticamente questionáveis. 
Tabela 6. Outras competências de liderança: extractos ilustrativos e análise da frequência.

\begin{tabular}{|l|l|}
\hline COMPETÊNCIAS DE LIDERANÇA & FREQUENCIA \\
\hline "Capacidade de orientação e de supervisão de equipas"; & 2 \\
"Capacidade de comunicação" & 8 \\
"Ser comunicativamente hábil"; & 6 \\
\hline
\end{tabular}

Quisemos igualmente saber de um modo genérico quais as competências de liderança que os sujeitos entrevistados consideravam granjear um maior destaque em cenários de trabalho contemporâneos. Também neste caso, não se verificou uma particular concentração de respostas entre os entrevistados pelo que, conforme patente na tabela 6 , apenas a capacidade de orientação e supervisão de equipas foram referenciadas em duas entrevistas, tendo a capacidade de comunicação obtido uma elevada notação. Neste caso, os entrevistados referiram que a habilidade e os comportamentos políticos de liderança estão extremamente dependentes do modo como se gere a comunicação e do modo como se comunica com os colaboradores, dando enfoque à capacidade de ser assertivo no processo de comunicação, defendendo os seus pontos de vista mas, ao mesmo tempo, incorporando o ponto de vista do outro interlocutor.

\subsection{Os incidentes críticos políticos}

$\mathrm{Na}$ tabela seguidamente apresentados estão ilustrados a totalidade dos incidentes proferidos pelas chefias entrevistadas. Da sua leitura podemos tirar algumas ilações, senão vejamos: em primeiro lugar, e com excepção de um único entrevistado que afirmou perentoriamente nunca ter manifestado, assistido ou presenciado um episódio semelhante no seu local de trabalho, todos os outros foram receptivos e discriminaram alguns exemplos passíveis de se ajustarem ao pedido formulado. Porém, da análise dos onze relatos, verifica-se apenas duas situações (incidente 5 e 6 ) em que os narradores assumem claramente a premência e a necessidade de, por vezes, serem agentes e participantes activos no jogo político, justificando as suas acções a luz daquilo que 
consideram ser uma inevitabilidade da dinâmica organizacional e esgrimindo da absoluta necessidade de saberem interpretar e, em disso, se posicionarem devidamente no terreno: - "o que acontece é que se não entrares nesse jogo acabas por ter muitos entraves para realizar as tuas tarefas do dia-a-dia ate mesmo as mais corriqueiras". "Se assim não for a feitura de um simples telefonema pode tornar-se numa tarefa complicada"; "os jogos políticos fazem parte do nosso quotidiano e temos de saber lidar com isso - é um pressuposto do próprio negócio”.

Tabela 7. Descrição dos incidentes políticos e sua frequência.

\section{INCIDENTE 1}

FREQUÊNCIA

"Todos os dias. Nas reuniões com chefias de diferentes departamentos, existe sempre a tentativa de cada uma das chefias "chamar a si" os "sucessos" de determinada situação, ainda que tenham sido conseguidos com esforço de uma equipa, interdisciplinar, ou seja, com elementos de diferentes departamentos; no tipo de decisões que são tomadas como uma tentativa de mostrar que "aquele" detém o poder e que por essa razão merece ser quase que "venerado" ou "temido".

\section{INCIDENTE 2}

"Como estamos em fase de implantação da empresa em Portugal, uma Frequentemente das pessoas das cúpulas telefonou-me para casa a dizer que a partir daquele dia era eu quem tinha que assinar os documentos e não ele, e que não queria que na correspondência fosse referido o seu nome completo, preferia que ficasse apenas o primeiro e o último nome. Esse mesmo senhor, quando o relembro que são precisas efectuar algumas diligências e tratar de assuntos cruciais com a segurança social, diz-me que não é preciso e que como sou pouco obediente, insinua que qualquer dia vai ter que me "substituir". Situaģões como estas repetem-se frequentemente".

\section{INCIDENTE 3}

"Posso dar também o exemplo de um engenheiro que foi falar com esse senhor dizendo que legalmente havia um conjunto de procedimentos que tinham que ser cumpridos. Passados dois dias quando chegon a casa tinha a carta de despedimento que, por sinal, tinha que ter sido en a tratar. O pessoal dos recursos bumanos só teve conhecimento do ocorrido quando foi contactado pelo engenheiro em causa e que nos informou que tinha sido despedido". 


\section{INCIDENTE 4}

"Presenciei uma situação de jogo de poder propriamente dita quando um elemento de um jüri de um concurso interno para promoção na carreira utilizou a posição que ocupava na organização para impor aos restantes elementos do juiri o "resultado" do concurso".

\section{INCIDENTE 5}

"Embora sem querer especificar denoto diariamente um clima, que não condeno, de troca de favores - eu faço-te isto, tu fazes-me aquilo, entre os diferentes técnicos dos diferentes departamentos. $O$ que acontece é que se não entrares nesse jogo acabas por ter muitos entraves para realizar as tuas tarefas do dia-a-dia ate mesmo as mais corriqueiras. Se assim não for a feitura de um simples telefonema pode tornar-se numa tarefa complicada".

\section{INCIDENTE 6}

"Os jogos políticos fazem parte do nosso quotidiano e temos de saber lidar com isso - é um pressuposto do próprio negócio. É o poder político autárquico que nomeia a Administração. Mau, é quando o poder partidário se faz sentir e influencia negativamente as decisões políticas elou de gestão: isso sim é perverso e contraproducente. Resumindo, cabe-nos implementar e executar decisões políticas municipais".

\section{INCIDENTE 7}

"Estive envolvido numa reestruturação geográfica em que o lider (Director Geral) conduqiu de forma muito hábil todo o processo. Faseadamente, foi concentrando os departamentos mais estratégicos do negócio na cidade do qual era natural. De forma a captar os interesse e apoios necessários da casa mãe (Multinacional) colocou os objectivos da empresa numa fasquia considerável, tendo ele próprio uma intervenção fundamental, essa estratégia, permitiu-lhe durante todo oprocesso eliminar qualquer tipo de resistência ao nivel do accionista, facilitando-lhe toda a operação local. Assim, conseguiu consumar a transferência de uma empresa de Lisboa para o Porto, situação essa que também é uma espécie de contra-corrente. Não obstante ter-me afectado de forma negativa, reconbeço o mérito na gestão política do projecto"

\section{INCIDENTE 8}

"Comigo em concreto nada se passou, mas tenho exemplos de colegas Frequentemente que dão graxa às chefias, prestam favores, silenciam situações algo obscuras para serem promovidos ou ascenderem na carreira”. 


\section{INCIDENTE 9}

"Há também aqui duas situações de colegas que têm progredido na empresa de um modo absurdamente inexplicável. Embora tenham habilitaçoes e competências profissionais bastante inferiores a algumas colegas de trabalho, são sempre quem obtém as melhores avaliações de desempenho e quem recebe os melhores prémios de promoşão, pelos vistos as suas boas performances parecem tratar-se noutros dominios que não o profissional".

\section{INCIDENTE 10}

"Há aqui um caso de uma recente promoção, em que a pessoa Frequentemente promovida e genro da pessoa responsável pela promoção, os critérios que o conduziram a tal nunca foram conhecidos. Aliás já sabiamos quem ia ficar com o lugar. Por sinal, a filha e o neto também cá trabalham".

\section{INCIDENTE 11}

"Temos também um caso muito engrasado de uma chefia muito Frequentemente popular na empresa que apesar de, regra geral, ser muito distante e antipático, quando quer pedir alguma coisa extra aos seus colaboradores directos muda completamente de atitude, torna-se muito simpático e começa a elogiá-los por toda a empresa, já circulam anedotas por causa disso".

No que diz, especificamente, respeito aos comportamentos e acções descritas, o incidente 2 e 3 é, em nosso entender e fazendo a ressalva de que carecem de uma maior contextualização e podem estar enviesados pela perspectiva do próprio narrador, o exemplo mais ilustrativo da versão hard (e, em nosso entender, possivelmente mais disfuncional) da política e também mais próximo do debate encetado por Dalton (1959) e Punch (1996) quando se referiram às colorações que o "dirty business" pode assumir em cenários de trabalho. Os relatos descrevem situações recorrentes de incumprimento legal: "Como estamos em fase de implantação da empresa em Portugal, uma das pessoas das cúpulas telefonou-me para casa a dizer que a partir daquele dia era eu quem tinha que assinar os documentos e não ele, e que não queria que na correspondência fosse referido o seu nome completo, preferia que ficasse apenas o primeiro e o último nome"; acompanhados de pressões e ameaças veladas: - "esse mesmo senhor, quando o relembro que são precisas efectuar algumas diligências e 
tratar de assuntos cruciais com a segurança social, diz-me que não é preciso e que como sou pouco obediente, insinua que qualquer dia vai ter que me substituir"; e de silenciamento dos colaboradores: - "posso dar também o exemplo de um engenheiro que foi falar com esse senhor dizendo que legalmente havia um conjunto de procedimentos que tinham que ser cumpridos. Passados dois dias quando chegou a casa tinha a carta de despedimento que, por sinal, tinha que ter sido eu a tratar". Naturalmente que, a ser verdade, e embora já tenhamos oportunidade de frisar que este não é, de todo, o modelo que costuramos para o líder político contemporâneo, o exposto serve para mostrar as diferentes facetas e variações que a actividade política nas organizações pode assumir, e de que há, de facto, quem siga à risca o lema - vale tudo!

De igual modo, no incidente 4, é descrito uma situação onde se vislumbra, claramente, a tentativa de legitimação de um pedido para benefícios pessoais, assente numa tentativa indevida e inapropriada para vingar a autoridade formal do agente da acção. Neste caso, o sujeito em causa, aproveitou-se da posição e do capital de autoridade de que granjeava na organização para impor aos outros o resultado de um concurso interno:- - "Presenciei uma situação de jogo de poder propriamente dita quando um elemento de um júri de um concurso interno para promoção na carreira utilizou a posição que ocupava na organização para impor aos restantes elementos do júri o resultado do concurso".

Dentro de um patamar mais funcional e suave, o recurso à norma da reciprocidade, seja através da lisonja e/ou da sedução do alvo parece ser uma prática corrente nas organizações estudadas. Os sujeitos entrevistados têm a clara noção que, de um modo estratégico, isto é, premeditadamente, os agentes de influência levam a cabo um conjunto de comportamentos com o fito de aumentarem a sua quota de atractividade junto dos outros, levá-los a agir em conformidade com as suas acções e auferirem das recompensas desejadas. Para o efeito, embora de um modo aparentemente desinteressado, mostram-se prestáveis e disponíveis para ajudar e levar a cabo todos os pedidos 
formulados, induzindo nos alvos um forte sentimento de dívida e de reciprocidade no trato: - "tenho exemplos de colegas que (...) prestam favores (...) para serem promovidos ou ascenderem na carreira"; ou então, optam por enaltecer, elogiar ou realçar algumas das qualidades e competências técnicas do receptor, senão vejamos: -"temos também um caso muito engraçado de uma chefia muito popular na empresa que apesar de, regra geral, ser muito distante e antipático quando quer pedir alguma coisa extra aos seus colaboradores directos muda completamente de atitude, torna-se muito simpático e começa a elogiálos por toda a empresa". Por fim, o recursos à sedução como forma de cair nas boas graças do alvo e garantir a progressão na carreira foi igualmente apontada como uma eficaz estratégia de influência: -"Há também aqui duas situações de colegas que têm progredido na empresa de um modo absurdamente inexplicável. Embora tenham habilitações e competências profissionais bastante inferiores a algumas colegas de trabalho, são sempre quem obtém as melhores avaliações de desempenho e quem recebe os melhores prémios de promoção, pelos vistos as suas boas performances parecem tratar-se noutros domínios que não o profissional”.

Uma última nota para darmos conta da periodicidade com que os incidentes políticos descritos e analisados ocorreram. Instados a escolherem ao longo de uma escala de frequência que comportava os itens: nunca; raramente; frequentemente; sempre, a esmagadora maioria dos entrevistados referiu, de um modo absolutamente perentório, que aqueles e/ou incidentes semelhantes pautavam frequentemente, o dia-a-dia da dinâmica e do comportamento organizacional. Este facto, para além de comprovar, uma vez mais, que as organizações são espaços de acção política atravessados por uma delicada teia de interesses, objectivos e interacções entre os seus diversos elementos constituintes mostra, e dadas as referencias de teor negativo e o pendor disfuncional feitas a estas práticas, ser uma espécie de patologia organizacional com o qual, amiúde, os cidadãos organizacionais têm que conviver. 


\section{Conclusões}

Apesar de ser líquida a asserção de que a política é um facto incontornável e revelador da dinâmica organizacional e da actividade dos líderes, a literatura apresenta-a, no âmbito dos estudos organizacionais, como um dos tópicos sub-investigado. Ao longo desta investigação, ao procurarmos trilhar o caminho da liderança política nas organizações, foi nossa determinação e convicção, comprovada posteriormente pela natureza dos dados postos em evidencia, de que urge ultrapassar e reconhecer sem preconceitos e sem puritanismo intelectual, a esfera política das organizações, de que ela é uma das pecas mais reveladoras do puzzle organizacional e dos processos de liderança, podendo encerrar um enorme potencial funcional e positivo. Para além disso, ficou plasmado que o estilo de comunicação interpessoal do líder para além de ser um fio condutor importante no estabelecimento de relações interpessoais necessárias ao bom andamento do trabalho, sendo que quanto mais conhecimento e consciência do processo comunicativo os líderes e os liderados possuírem, maiores são as perspetivas de eficácia organizacional sendo apontado como pistas para futura investigação a importância de se contextualizar o clima comunicacional (enquanto dimensão meso) vigente nas organizações em estudo.

\section{Referencias Bibliográfícas}

Alessandra, T., y Hunsaker, P. (1993). Communication at work. Nueva York: Simon e Schuster.

Allen, N. J., y Meyer, J. P. (1990). The measurement and antecedents of effective, continuance and normative commitment to the organization. Journal of Occupational Psychology, 63, 1-18.

Alvesson, M. (1984). Questioning rationality and ideology: On critical organisation theory. International Studies of Management and Organizations, 14, 61-79.

Ammeter, A. P., Douglas, C., Gardner, W. L., Hochwarter, W. A., y Ferris, G. R. (2002). Toward a political theory of leadership. Leadership Quarterly, 13, 751-796. 
Awamleh, R., y Gardner, W., (1999). Perceptions of leader charisma and effectiveness: The effects of vision content, delivery, and organizational performance. Leadership Quarterly, 10(3), 345-373.

Bacharach, P., y Baratz, M. S. (1962). The two faces of power. American Political Social Science Review, 56, 947-952.

Bacharach, S. B., y Lawler, E. J. (1980). Power and politics in organizations: The social psychology of conflict, coalitions, and bargaining. SF: Jossey-Bass.

Barbalet, J. M. (1985). Power and resistance. British Journal of Sociology, 36, 531-548.

Barber, B. (1983.) The logic and limits of trust. New Brunswick, NJ: Rutgers University Press.

Barbuto Jr., J. E. (2000). Influence triggers: A Framework for understanding follower compliance. Leadership Quarterly, 11(3), 365-388.

Bass, M. B. (1985). Leadership and Performance Beyond Expectations. London: Free Press.

Bass, M. B. (1999). Two decades of research and development in transformational leadership. European Journal of Work and Organizational Psychology, 8(1), 9-32.

Bennister, M., 't Hart, P., y Worthy, B. (2018). As-sessing the authority of political office-holders: The leadership capital index. West European Politics, 38(3), 417-440.

Bradshaw-Camball, P., y Murray, V. V. (1991) Illusions and Other Games: A Trifocal View of Organizational Politics. Organization Science 4(2), 379-398.

Brass, D. J. (1984a). Being in the right place: a structural analysis of individual influence in organizations. Administrative Science Quarterly, 29, 518-539.

Bryman, A. (1992). Charisma e Leadership in Organizations. London: Sage. 
Buchanan, D. (2008). You stab my back, I'll stab yours: Management experience and perceptions of organization political behavior. British Journal of Management, 19, 49-64

Burns, T. (1961). Micropolitics: Mechanisms of institutional change. Administrative Science Quarterly, 6(3), 257 - 281.

Cabral-Cardoso, C. (1995). A utilização simbólica e política de informação técnica: estudo de processos de decisão em I\&D. Comportamento Organizacional e Gestão, 1(1), 77-90.

Casse, P. (1994). Revisiting communication: A new way to manage it. European Management Journal, 12(3), 253-258.

Cheney, G. (2004). The rhetoric of identification and the study of organizational communication. Journal Quarterly of Speech, 11(2), 234-254.

Clegg, S. R. (1988). Frameworks of power. London: Sage. Cobb, A. T. (1986) Political diagnosis: applications in organizational development. Academy of Management Review, 11, 482- 496.

Conger, J. (1985). Charismatic Leadership in Business: An Exploratory Study. School of Business Administration: Harvard University.

Conger, J. (1991). Líder Carismático. São Paulo: McGraw-Hill.

Conger, J. (1998a). Charismatic Leadership in Organizations. California: Sage.

Conger, J. (1998b). Qualitative research in the understanding leadership. Leadership Quarterly, 9(1), 107-121.

Crozier, M. (1973). The problem of power. Social Research, 40, 211-218.

Cunha, M. P., Rego, A., y Campos e Cunha, R. (2002). Organizações positivas. Lisboa: D. Quixote.

Dalton, R. A. (1959). Man who manage. NY: Wiley.

Deluga, R. J. (1998). The politics of leadership: The relationship between task-people leadership and subordinate influence. Journal of Organizational Behaviour, 9(4), 359-366. 
Den Hartog, D., y Verburg, R. M. (1997). Charisma and rhetoric: Communicative techniques of international business leaders. Leadership Quarterly, 8(1), 355-392.

Denzin, N. K. (1989). The research act. (3ºd.). NJ: Prentice Hall.

Drory, A. (1993). Perceived political climate and job attitudes. Organization Studies, 14, 59-71.

Drory, A. e Beaty, D. (1991). Gender differences in the perception of organizational influence tactics. Journal of Organizational Behavior, 12, 249-254.

Drory, A. e Romm, T. (1988). Politics in organization and its perception within the organization. Organization Studies, 9, 165-179.

Drory, A. e Romm, T. (1990). The definition of organizational politics: A review. Human Relations, 43(11), 1133-1154.

Elbanna, S. (2018). The constructive aspect of political behavior in strategic decision-making: The role of diversity. European Management Journal, 36(5), 616-626.

Ellen, B. P. III, Ferris, G. R., y Buckley, M. R. (2016). Political is the new prosocial: leaders' support of followers through political behavior. En E. Vigoda-Gadot y A. Drory (Eds.), Handbook of organizational politics: Looking back and to the future $\left(2^{\mathrm{a}} \mathrm{Ed}\right.$.), (pp. 95-112). Cheltenham, UK: Edward Elgar.

Emrich, C. G., Brower, H., Feldman, J., y Garland, H. (2001). Images in words: Presidential rhetoric, charisma, and greatness. Administrative Science Quarterly, 3, 3-46.

Farrel, D. e Peterson, J. C. (1982). Patterns of political behaviour in organizations. Academy of Management Review, 7(3), 403-412.

Ferris, G. L., Perrewé, P., Anthony, W. y Gilmore, D. (2000). Political skill at work. Organizational Dynamics, 28(4), 25-37.

Ferris, G. R., Russ, G. y Fandt, P. (1989). Politics in organizations. En Giacalone, R. A. y Rosenfeld, P. (Eds.). Impression Management in Organizations (pp. 143-170) Hillsdale, NJ: Lawrence. Erlbaum. 
Ferris, G.R., Davidson, S. L. y Perrewé, P.L. (2005). Political skill at work: Impact on work effectiveness. CA: Davis-Blake.

Ferris, G.R., Frink, D. D., Galang, M. C., Zhou, J., Kacmar, K. M., y Howard, J. L. (2004). Perceptions of organizational politics: Prediction, stress-related implications, and outcomes. Human Relations, 49(2), 233-268.

Fiol, M., Harris, D., y House, R., (1999). Charismatic leadership: Strategies for effecting social change. Leadership Quarterly, 10(3), 449-480.

Flanagan, J. (1954). The critical incident technique. Psychological Bulletin, $51(4)$

Flick, U. (2002). Métodos qualitativos na investigação científica. Lisboa: Monitor.

Frost, P. J. y Hayes, D. C. (1979). An Exploration in two cultures of a model of political behavior in organizations. En England, G.W., Negandhi, A.R., y Wilbert, B. (Eds.). Organizational Functioning in a Cross-Cultural Perspective (pp. 251-272). Kent: University Press.

Fu, P. F. y Yukl, G. (2000). Perceived effectiveness of influence tactics in the United States and China. Leadership Quarterly, 11, 251-266.

Gandz, J. y Murray, V. V. (1980). The experience of workplace politics. Academy of Management of Journal, 23, 237-251.

Gardner, W. y Avolio, B. (1998). The charismatic relationship: A dramaturgical perspective. Academy of Management Review, 23, 32-58.

Goleman, D. (2000). Leadership that gets results. Harvard Business Review, 2, 78-90.

Hardy, C. (1995). Power and politics in organizations. Cambridge: University Press.

Hardy, C. y Clegg, S. (1999). Some dare call it power. En Clegg S., y Hardy, C. (Eds.), Studying organization (pp. 368-387), California: Sage. 
Hochwarter, W. A. (2012). The positive side of organizational politics. En Ferris, G. R., y Treadway, D. C. (Eds.) Politics in organizations: Theory and research considerations (pp. 27-66). NY: Routledge.

Hofstede, G. (1980). Motivation, leadership, and organization: Do American theories apply abroad? Organization Dynamics, 9(1), 4263.

House, R. J. (1977). A 1976 theory of charismatic leadership. En Hunt. J. G., y Larson, L.L. (Eds.) Leadership: The Cutting Edge (pp. 189-207), Southern Illinois: University Press.

House, R. J., y Shamir, B. (1993). Toward the integration of transformational, charismatic and visionary theories. En Chemers, M. M., y Ayman, R. (Eds.) Leadership Theory and Research: Perspectives and Directions (pp. 81-107). San Diego: Academic Press.

House, R. J., Woyke, J., y Fodor, E. M. (1988). Charismatic and non charismatic leaders: Differences in behavior and effectiveness. En Conger, J. y Kanungo, R. (Eds.), Charismatic Leadership (pp. 98121). San Francisco: Jossey Bass.

Howell, J. M., y Frost, P. (1989). A laboratory study of charismatic leadership. Organizational Behavior and Human Decision Processes, 43, 243-269.

Kanter, R. M. (1979). Power failures in management circuits. Harvard Business Review, 57(4), 65-75.

Kay, A., Jimenez, M., y Jost, J. (2002). Sour grapes, sweet lemons, and the anticipatory racionalization of the status quo. Personality and Social Psychology Bulletin, 28(9), 1300-1312.

Kearins, K. (1996). Power in organizational analysis: Delineating and contrasting a Foucaultdian www.mngt.waikato.ac.nz/depts/sml/journal/vol_ _3/, (Consultado el 12 de enero 2019). 
Kipnis, D. y Schmidt, S. M. (1982). Profile of organizacional influence stategies. San Diego, CA: University Associates.

Kipnis, D., Schmidt, S. M. y Wilkinson, I. (1980). Intra-organizational influence tactics: Explorations in getting one's way. Journal of Apllied Psychology, 65, 440- 452.

Landells, E. M., y Albrecht, S. L. (2017). The positives and negatives of organizational politics: A qualitative study. Journal of Business and Psychology, 32(1), 41-58.

Lewicki, Rot J., McAllister, Daniel J. y Bies, Robert J. (1999). Trust and distrust: New relationships and realities. Academy of Management Review, 23(3), 438-458.

Lowe, K. B., Kroeck, K. G., y Sivasubramaniam, N. (1996). Effectiveness correlates of transformational and transactional leadership: A meta analytic review of the MLQ literature. Leadership Quarterly, 7(2), 385-425.

Lukes, S. (1974). Power: A radical view. London: McMillan.

Maes, J. D., Weldy, T. G. y Icenogle, M. L. (1997). A managerial perspective: Oral communication competency is most important for business students in workplace. Journal of Business Comunication, 34, 67-80.

Martindale, C. (1986). Primary process cognition and hemispheric asymmetry. Journal of Genetic Psychology, 147, 79-87.

Maslyn, J. M., Farmer, S. M., y Bettenhausen, K. L. (2017). When organizational politics matters: The effects of the perceived frequency and distance of experienced politics. Human Relations, 70(12), 1486-1513.

Mayes, B. T. y Allen, R. W. (1977). Toward a definition of organizational politics. Academy of Management Review, 2, 672-678.

McClelland, D. (1987). Human motivation. Glenview: Foresman.

Miles, R. H. (1980). Macro organizational behaviour. California, Goodyear. 
Mintzberg, H. (1983). Power in and around organizations. Englewood Cliffs, NJ: Prentice Hall.

Miranda, S. (2003). Lideranças Transformacionais e Transacional nas organizações: Impacto no empenhamento organizacional (Trabajo Fin de Máster no publicado). Universidade do Minho, Braga, Portugal.

Miranda, S. (2008). Liderazgo político en las organizaciones: En busca de la teoría (Tesis doctoral no publicada). Universidad Complutense de Madrid y Escola Superior de Comunicação Social, Madrid/Lisboa.

Miranda, S. (2017). Diz-me como como comunicas, eu te direi quem és: o líder enquanto ator político nas organizações. Proceedings in XV Assibercom. Lisboa: Universidade Católica Portuguesa.

Miranda, S. y Antunes, A. C. (2019). Dark, Smoke-Filled Room: Política nas Organizações, revisitar o passado e perspetivar o futuro. Análise Psicológica, forthcoming.

Miranda, S., Vicente, A., Antunes, A.C., Rodrigues, B., y D’Oliveira, T. (2013). Workplace aggression in organizational changing processes: The mediation role of political (soft and hard) behavior. Proceedings of the 15th IAMB Conference. Varsow, Poland,

Miranda, S., Vicente, A., Antunes, A.C., Rodrigues, B., y D’Oliveira, T. (2012). The dark side of organizational change: The moderating role of political behavior and organizational cynicism. Proceedings of the 12th IAMB Conference. LIsbon, Portugal.

Miranda, S., Vicente, A., Antunes, A.C., Rodrigues, B., y D’Oliveira, T. (2012). Agressão no trabalho em processos de mudança organizacional: O papel mediador do cinismo organizacional e do comportamento político. Comunicação apresentada no I Congresso Internacional de Psicologia do Trabalho e das Organizações, Braga.

Moore, L. L., y Rudd, R. D. (2004). Leadership skills and competencies for Extension state directors and administrators. Journal of Agricultural Education, 45(3), 22-33. 
Morgan, G. (1996). Imagens da organização. São Paulo: Atlas.

Morreale, A. P., Osborn, M. M. y Pearson, J. C. (2000). Why communication is important: A rationale for the centrally of communication. Journal of Business Comunication, 29, 1-25.

Mumford. M. D., Marks, M. A., Connelly, M.S., Zaccaro, S. J., y ReiterPalmon, R. (2000). Development of leadership skills: Experience and timing. Leadership Quarterly, 11(1), 87-114.

Penley, L. E., Alexander, E. R., Jernigan, I.E. y Henwood, C. I. (1991). Communication habilities for managers: The relationship to performance. Journal of Management, 17, 57-76.

Perrewé, P., Ferris, G. L., Frink, D. y Anthony, W. (2000). Political skill: An antidote for workplace stressors. Academy of Management Executive, 14(3), 115-124.

Pettigrew, A. M. (1973). The politics of organizational decisionmaking. London: Tavistock.

Pfeffer, J. (1981). Power in organizations. NY: Harper.

Pfeffer, J. (1992). Understanding power in organizations. California Management Review. 34(2), 29-50.

Pfeffer, J. y Salancik, G. R. (1974). Organizational decision making as political process: The case of university budget. Administrative Science Quarterly, 19, 135-151.

Pondy, L. (1983). The role of metaphors and myths in organization and in the facilitation of change. En Pondy, L., Frost, P., Morgan, G.,y Dandridge, T. (Eds.), Organizational symbolism (pp. 157-166). Greenwich, CT: JAI: Press.

Porter, L., Allen, R. W. y Angle, H. L. (1981). The politics of upward influence. En Cummings, L. L., y Staw, B. M. (Eds.) Research in organizational behavior, vol. 3, (pp. 109-149), Greenwich, CT: JAI.

Prasad, L. y Rubenstein, A. H. (1992). Conceptualizing organizational politics as a multidimensional phenomenon: empirical evidence from a study of technological innovations. IEEE. Transactions of Engineering Management, 39(1), 4-12. 
Punch, M. (1996). Dirty business. Exploring corporate misconduct, analysis and cases. London: Sage. Rego, A. (2001). Development and validation of an instrument for mensuring the SARA model communication styles. 2nd International Conference of the Iberoamerican Academy of Management, Mexico City.

Rego, A. y Jesuino, C. (2002). Estilos de gestão do conflito e padrões motivacionais - um estudo exploratório. Comportamento Organizacional e Gestão, 8, 9-23.

Shamir, B., Arthur, M. B., y House, R. J. (1994). The rhetoric of charismatic leadership: A theoretical extension, a case study, and implications for research. The Leadership Quarterly, 5(1), 25-42.

Sussman, L, Adams, A, Kuzmits, L., y Rago, L. (2002). Organizational politics: Tactics, channels and hierarchical roles. Journal of Business Ethics, 40, 313-340.

Treadway, D. C., Hochwater, W. A., Ferris, G. R., Kacmar, C. L., Douglas, A., Ammeter, A. y Bucley, R. (2004). Leader skill and employee reactions. Leadership Quarterly, 15(4), 493-514.

Triandis, H. S. (1992). Cross cultural industrial and organizational psychology. En Dunette, M. D. (Ed.). Handbook of Industrial and organizational psychology (pp. 103- 172), CA: Consulting Psychologist Press.

Tushman, M. L. (1977). A political approach to organizations: a review and rational. Academy of Management Review, 2(2), 131-152.

Vala, J. (1986). Análise de conteúdo. En Silva, A., y Pinto, J. (Ed.). Metodologia das ciências sociais (pp. 101-128). Lisboa: Afrontamento. Vigoda, E. y Cohen, A. (2002). Influence tactics and perceptions of organizational politics: a longitudinal study. Journal of Business Research, 55, 311-324.

Vigoda, E. y Drory, A. (2006). Handbook of organizational politics. NY: EEE.

Waldman, D. A., Bass, B. M., y Einstein, W. O. (1995). Effort, performance, and transformational leadership in industrial and military service. Comunicação apresentada na University of New Binghamton, Binghamton. 
Waters, J. A. (1982). Managerial assertiveness. Business Horizons, September-October, 24-29.

Willner, A. R. (1984). The spellbinders: Charismatic political leadership. New Haven, CT: Yale University Press.

Yang, F., y Zhang, L. (2014). Leader political skill and team performance. Asian Journal of Social Psychology, 17, 286-295.

Yukl, G. (1998). Leadership in organizations ( $4^{\mathrm{a}}$ ed.) New Jersey: Prentice-Hall.

Yukl, G. (2006.) Leadership in organizations ( $6^{\mathrm{a}}$ ed.) New Jersey: Prentice-Hall.

Yukl, G. y Falbe, C.M. (1991). Importance of difference power sources in downward and lateral relations. Journal of Applied Psychology, 76, 416-423.

Yukl, G. y Falbe, C.M. (1992). Influence tactics and objectives in upward, downward and lateral influence attempts. Journal of Applied Psychology, 75, 2, 132-140.

Yukl, G., Kim, H. y Falbe, C. M. (1996). Antecedents of influence outcomes. Journal of Applied Psychology, 81, 309-317.

Zanzi, A., y O`Neill, R. M. (2001). Sanctioned versus non-sanctioned political tactics. Journal of Managerial Issues, 13, 245-262. 



\title{
Propuestas de metodología de investigación sobre estereotipos de género en los medios de comunicación. Casos prácticos
}

\author{
Ana González Delgado \\ Profesora Asociada a Tiempo Parcial de Comunicación Audiovisual y \\ Publicidad - Universidad de Extremadura
}

\section{Resumen}

Este trabajo trata de recopilar las líneas de investigación que se han realizado en torno a los estereotipos de género en España, categorizarlos y mostrar otras líneas posibles de investigación para abordar futuros proyectos donde indagar en la brecha existente entre hombres y mujeres desde el ámbito de las Ciencias de la Comunicación. Desde el punto de vista académico, es necesario progresar en la investigación y la indagación de cómo surgen, cómo se perpetúan y de qué manera atajarlos para frenar su influencia en una sociedad desigual.

Respetando las indicaciones de académicos que nos señalan el camino de cómo se debe abordar la metodología de investigación social se proponen varias líneas que profundizan en la obtención de resultados objetivos más allá de consideraciones cualitativas o cuantitativas. Se trata de encontrar aspectos epistemológicos que concluyan en trabajos útiles para la investigación, para quienes realizan dicho análisis. Para ello se plantea analizar de forma minuciosa y concienzuda el camino ya iniciado por otras universidades con una producción científica que ha aumentado en las dos últimas décadas, pero que se considera todavía 
insuficiente para elaborar una categorización de los mismos. De esta forma, se propone un mayor conocimiento de una realidad que necesita de una revisión a través de resultados objetivos que puedan ser útiles para la sociedad a la hora de conformar acciones reales y/o útiles. Para ello se plantean preguntas que nos harán dudar pero que en un trabajo concienzudo de fondo nos llevará por el camino adecuado para conseguir aportar estudios serios y minuciosos para favorecer colaborar en el conocimiento de la desigualdad, aspecto que ya está calando en los medios y en políticas de igualdad impulsadas principalmente desde los Institutos de la Mujer, también desde instituciones universitarias para ampliar la percepción social que se obtiene sobre las mujeres en los medios y en definitiva más ajustada a la realidad comunicativa actual.

\section{Introducción}

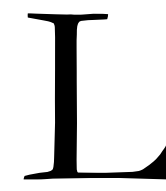

A SOCIEDAD del siglo XXI está compuesta por una estructura patriarcal, donde se encuentran inmersos una serie de estereotipos de género, los cuales determinan la concepción de lo que significa ser hombre y mujer. Ideas que se asimilan mediante un proceso de socialización y aprendizaje durante la infancia. Parte de ese aprendizaje se adquiere a través de los medios de comunicación que conforman la mentalidad de la población, así como el papel que juega cada sexo en la misma. Por ello, la forma en la que se representa tanto el hombre y la mujer determina la imagen y los estereotipos que van a calar en la mentalidad de gran parte de los miembros de una sociedad. Los medios de comunicación no solo son espacios de información, son agentes sociales con potentes mecanismos para influir en nuestro pensamiento que otorgan una dimensión especial cuando se trata de asignar un papel a ambo sexos. La Universidad impulsa líneas de investigación que determinan donde se inician o qué incitan a mantener dichos estereotipos ya sea a través de contenidos informativos, personajes de ficción en series de televisión, la propia publicidad o películas cuyo efecto está fuera de toda duda. De esta forma, para abordar cómo estudiar su representación se plantean en este trabajo distintas líneas metodológicas de investigación que nos acerquen de forma fidedigna a las representaciones que tanto medios de comunicación como las potentes y emergentes redes sociales hacen 
para distinguir los géneros masculino y femenino y los patrones que se han establecido para otorgar roles. Este trabajo trata de dar cabida a los distintos enfoques que podemos dar a futuros trabajos y que conforman la investigación universitaria. Un espacio proclive a dotar de herramientas a estudiosos de este fenómeno ante la necesidad de que desde un punto de vista y determinación ética se realice un acercamiento a una realidad y preocupación de nuestro entorno. Con ello se trata de evitar que dichos estereotipos socioculturales sigan lastrando la igualdad entre ambos sexos y se perpetúan formas de discriminación comunicativas por motivos de género.

Aunque esos estereotipos tradicionales se están transformando hacia una realidad diferente, impulsados por la sociedad que ha alcanzado nuevos niveles de conciencia sobre ello en el siglo XXI, sin embargo, los medios de comunicación tradicionales y la publicidad, suelen insistir en rancios estereotipos que siguen afectando a las mujeres.

La invisibilidad de las mujeres y la estigmatización de las mismas en los medios de comunicación son dos realidades que conviene abordar desde el ámbito académico por la aportación científica que arrojan estudios pormenorizados desde una perspectiva de género. A pesar de que encuentros académicos impulsados desde universidades como la de Sevilla a través del Congreso Internacional sobre Comunicación y Género; el Congreso Internacional de Jóvenes Investigadores con Perspectiva de Género organizado por la Universidad Carlos III de Madrid; el Congreso Internacional Comunicación y Pensamiento o el Seminario Interuniversitario Permanente de Investigación "Género, Estética y Cultura Audiovisual (GECA)" de la Universidad Complutense de Madrid han aportado un extenso trabajo académico desde el que se pueden extraer conclusiones en un análisis en profundidad, las primeras impresiones arrojan que ya existe un foro común donde analizar y comprender los discursos de género en los medios de comunicación.

\section{Objetivos}

Este trabajo pretende establecer metodologías de investigación para alcanzar estudios en los que se analicen aspectos concretos sobre los estereotipos con perspectiva de género. 
-Ofrecer herramientas útiles de investigación.

-Estudiar y analizar dichas herramientas.

-Aportar aspectos metodológicos de interés para la comunidad científica.

-Plantear casos prácticos.

\section{Marco teórico}

\subsection{Estado de los estudios de género en España}

Para poder realizar dicho trabajo ha sido necesario recurrir a una amplia literatura científica y académica, pero sobre todo indagar en las últimas corrientes de investigación en Ciencias Sociales que nos indican un cambio de rumbo en una universidad que peca de burocrática, hecho que la limita la constriñe y la encorseta. La reciente creación de la revista Comunicación y Métodos advierte de la necesidad de abordar con seriedad y sobre todo con profundidad trabajos de este tipo. Pero también nos marca un itinerario para explorar en el entorno digital y utilizar estos medios como herramientas que nos faciliten un aprendizaje hacia un conocimiento real sobre la situación actual de esta materia. Se abren nuevas perspectivas en torno a la comunicación y en la actualidad se pone especial énfasis en el emergente peso de las redes sociales en la población. Es cierto que los estudios de género han aumentado a lo largo de los últimos años auspiciados por distintas cátedras, congresos y algunos enfoques de investigación propiciadas y subvencionadas por organismos vinculados a los diferentes Institutos de la Mujer en las Comunidades Autónomas de España. También distintos estudios nos señalan que se han logrado institucionalizar hasta el punto de colarse en planes de estudio y preferentemente en las facultades de formación del profesorado. En ella se establecen verdaderas líneas cooperativas interdepartamentales para incrementar su número y sobre todo su profundidad. Preocupación que ha ido paralela a otras universidades sudamericanas con fuertes vínculos de trabajo con las españolas y con una realidad común: la desigualdad entre hombres y mujeres (Rovetto, 2013).

En otros trabajos se comprueba que se han realizado en la última década estudios que analizan la presencia de cada sexo en las informaciones difundidas en los medios, tratando de dirimir, desde el 
punto de vista cuantitativo, que interés tienen esos datos en la transmisión de la imagen estereotipada de las mujeres. O valorar, desde una perspectiva cualitativa, cómo se construyen, desde perspectivas patriarcales, el valor de uno y otro género. Pero también existen otras investigaciones que apuntan a un descenso en la aparición de esos estereotipos sobre las mujeres tanto en medios de comunicación o en la ficción televisiva, preocupados por la presión que sectores feministas han conseguido instaurar de forma permanente en los medios en las últimas décadas. Fenómeno que no se circunscribe solo y exclusivamente a la preocupación por la representación que de la imagen de la mujer hacen los medios, igualmente encontramos esa evolución en sectores sociales vinculados a colectivos LGTBI o la discapacidad que aparecen ya de forma permanente en informativos, representados como personajes en series de ficción y con potentes y poderosos perfiles en Facebook, Twitter o en Instagram.

El espectacular crecimiento de la producción científica sobre comunicación que se ha producido en España en las dos últimas décadas (Martínez et al., 2019) contrasta con la escasez de estudios dedicados a conocer realidades puntuales en materia de género. Esto no significa que la Universidad española en su totalidad haya pecado de inacción, pero si se le culpa de una insuficiente investigación en este campo frente a la abundancia de otras materias como son el Periodismo o la Publicidad.

Los Estudios de Género y Feministas han comenzado a ser ofertados actualmente en diferentes universidades del mundo.

"Constituyen un campo académico interdisciplinar que está indiscutiblemente ligado a la Segunda Ola del movimiento feminista de los años 60 y 70 del siglo pasado. En el caso de las universidades públicas españolas, comienzan a institucionalizarse a partir de los años 90, gracias al desarrollo previo de seminarios y asociaciones como la conocida Asociación de Mujeres Universitarias o el Seminario de Estudios Sociológicos de la Mujer, fundados en 1953 y en 1960, respectivamente. Comenzaron a desarrollarse de una manera voluntarista, gracias a las alianzas y los esfuerzos de las académicas. Los seminarios de los entonces llamados "Estudios de las Mujeres", comenzaron a surgir en las universidades de 
Barcelona, la Autónoma de Madrid y la Complutense. De manera muy costosa, fueron consiguiendo el reconocimiento oficial de los Institutos Universitarios de Investigación, que los aprobaron de manera oficial pero no los dotaron de recursos económicos" (Vizcaya, E. 2019).

Esa escasa producción de trabajos científicos contrasta con la existencia de un marco normativo y estructuras que velan por el cumplimiento de la ley en cuestiones de igualdad, pero sí que se detecta que el profesorado no posee formación en estas cuestiones. Los Estudios de Género y Feministas no están reconocidos como área específica del conocimiento por el Ministerio de Educación. Por esta razón, los diferentes Institutos y Centros especializados, se unieron en la Plataforma Universitaria de Estudios Feministas y de Género (EUFEM) en el año 2016 con la intención de trabajar para la creación de un área de conocimiento específica.

Desde la Universidad deben impulsarse estudios que su publicación pongan en evidencia las desigualdades que generan dichos estereotipos de género entre lo masculino y lo femenino. Este problema se ha convertido en una preocupación en instituciones como el Ministerio Superior de Deportes ya que traslada la problemática al medio social para poder hacerle frente:

"Se recomienda a los medios de comunicación aumentar cuantitativamente la representación del deporte practicado por las mujeres, tanto en los informativos y en los programas deportivos como en las retransmisiones" y "Se debe evitar la utilización del cuerpo de las deportistas como reclamo informativo. La noticia debe centrarse en los logros o eventos deportivos, sin desviar la atención hacia el físico de las participantes. Se evitará utilizar referencias sexistas al físico, el uso de estereotipos degradantes y las frases condescendientes. Las fotos de mujeres deportistas que ilustren las informaciones corresponderán a su participación en el evento y al texto de la noticia. Se aconseja el uso de imágenes de las deportistas en acción propia de su disciplina deportiva y la no utilización de poses que refuercen estereotipos. Del mismo modo, se evitarán referencias a su apariencia o cuidado personal (...)". 


\subsection{Estereotipos. Definición y clasificación}

Para acercarnos lo mejor posible al concepto de estereotipo, debemos analizar cómo se ha definido a lo largo de las últimas décadas y razonar cómo ha evolucionado el concepto o idea que moldea y transforma la visión sobre una realidad. Walter Lippman en su libro 'La opinión pública' ya definía estereotipo en las primeras ediciones de esta publicación como un concepto que nace en un contexto de sociedad de masas y que son representaciones colectivas, impersonales, de carácter anónimo "que se transmiten fundamentalmente a través de la familia, la educación, los medios verbales, del arte y de los medios de comunicación de masas; entre ellos, la televisión". Igualmente, se atreve a precisar que los estereotipos también pueden convertirse en mecanismos de defensa y constituyen "una imagen ordenada y más o menos coherente del mundo, a la que nuestros hábitos, gustos, capacidades, consuelos y esperanzas se han adaptado por sí mismos. Puede que no formen una imagen completa, pero son la imagen de un mundo posible al que nos hemos adaptado" (Lippman, 2004: 93).

Los estereotipos de género se definen también como construcciones mentales de imágenes, y modelos aceptados por un grupo o sociedad. Los cuales, determinan los pensamientos, modos de estar, prácticas, sentimientos y acciones, en función del género al que se pertenezca. De forma que, son asignaciones culturales que llevan a la construcción de la personalidad (García, Ayaso y Ramírez, 2008; López- Francés, 2011). Por otro lado, los roles de género son un "conjunto de creencias estructuradas acerca de los comportamientos y características que se creen apropiadas para hombres y mujeres" (González y Cabrera 2013: 5). Constituyendo normas de conducta, que las personas de un determinado grupo, las cuales se encuentran inmersas en un contexto social y cultural, asumen y expresan en su vida cotidiana. Los estereotipos y los roles de género no son estáticos, sino que van sufriendo transformaciones con la edad y con el contexto histórico, siendo influenciados por el nivel de comprensión y apropiación de los mismos (González y Cabrera, 2013).

Según Colás y Villaciervos (2007) los estereotipos conforman herramientas socioculturales sobre las que se asientan las normas de funcionamiento social de una determinada cultura y a su vez constituyen un referente para estructurar la identidad de los sujetos. 
Este sistema de creencias y representaciones son interiorizadas por los sujetos que forman parte de cada cultura, estructurando y definiendo formas de interpretar, actuar y pensar sobre la realidad según, en este caso el sexo de pertenencia. Definen lo que es ser mujer y hombre.

En cuanto a su clasificación, se considera que los estereotipos de género son un subtipo de los estereotipos sociales en general. Podemos definirlos como «creencias consensuadas sobre las diferentes características de los hombres y mujeres en nuestra sociedad» (González, 1999: 83, en Hagag, 2019). Este conjunto de creencias que atañen a las categorías hombre y mujer, que llamamos género, tiene una gran influencia en el individuo, en su percepción del mundo y de sí mismo y en su conducta.

\subsection{Estudios de género}

Según el profesor Juan Carlos Suárez, la investigación sobre la mujer en los medios surge en la década de los 70, marcando fuertemente con un tinte reivindicativo y crítico las imágenes estereotipadas de la mujer tanto en revistas como en los programas televisivos, y el abuso de la exhibición del cuerpo femenino en los mensajes publicitarios. Los esfuerzos por razonar y detallar cómo y dónde se generan esos estereotipos, analizados en congresos bajo el título de Comunicación y Género como el organizado por la Universidad de Sevilla durante años, no han sido suficientes para acabar con encasillamiento tan arraigados, aunque desde dichos encuentros académicos se ha determinado que realizan una representación arbitraria ya que muestran una imagen repetida que se aleja de la realidad social de las mujeres en el siglo XXI. Han tratado de analizar y comprender los discursos de género para transferir los resultados de investigadores en la materia y compartir informaciones y aprendizajes con profesionales de distintos ámbitos que se interesan por cuestiones de género y por la imagen que de este asunto ofrecen los medios de comunicación. Esos esfuerzos siguen estando presentes en algunas unidades de investigación de las universidades españolas y las sudamericanas, con las que la cultura española tiene una mayor facilidad de conjugar el mismo verbo y precisamente por compartir una misma cultura de desigualdades entre hombres y mujeres. Si ese prototipo ha servido como un molde para reproducir o encasillar a las mujeres, cuantos más estudios y mejores 
análisis se realicen más sentido tendrán investigaciones surgidas desde la universidad.

Otra de las cuestiones que en estudios de género también requiere planteare es cómo los estereotipos son una forma de categorización de los personajes que permite al ser humano distinguir, diferenciar y abstraer de la realidad los datos más importantes para poder clasificarlos en su proceso de percepción (Galán, 2006). Precisamente esa categorización, tan importante e imprescindible de hallar en la ficción y mostrar debido a que los espectadores apenas si disponen de tiempo para encontrar ciertos rasgos de personalidad. Por otro lado, encontramos que esa supuesta desventaja se encuentra amplificada cuando dichos personajes se repiten con rasgos similares en las mismas series o películas los que permite obtener de ellos rasgos que habitualmente se generalizan. Suelen transmitir modelos de conducta, prejuicios o valores. Pero, por otro lado, también contribuyen a simplificar cualidades psicológicas restando rasgos complejos que nos ofrecerían una visión más objetiva de los personajes y en concreto de las mujeres.

Conclusiones similares también extrae el académico Roberto Aparici en su libro La construcción de la realidad en los medios de comunicación, el cual afirma que los personajes femeninos "[...] están subordinados a los masculinos y definen su poder y sus deseos casi exclusivamente en términos de la narrativa del macho dominante" (Aparici, 2010: 65). En cuanto a la representación que han hecho de lo femenino y masculino los archiconocidos filmes de Disney, aspecto que requeriría de concienzudos y más numerosos análisis, además de los ya realizados de forma extensa en trabajos académicos, se concluye que princesas o personajes de películas infantiles muestran siempre a la mujer como sujeto pasivo, aunque en la última década esos papeles han comenzado a evolucionar en los casos de Mulan, Frozen, Brave o Mohana mostrándolas ya como luchadora e incluso como heroínas. Pero en muchos casos el perfil que se dibuja en esos filmes refuerza la actitud pasiva (Míguez, 2015: 41-58) de las princesas en películas de animación infantil frente a sentimientos como son el amor o el miedo, manteniendo el estereotipo de que las mujeres son inferiores, muestran sus sentimientos y debilidades. 


\section{Metodología}

\subsection{El planteamiento de las investigaciones sobre género}

Partimos de la idea de que los medios de comunicación son una fuente socializadora que cimientan las representaciones sociales, visiones estereotipadas que generan prejuicios o preferencias hacia grupos humanos. Debido a la naturaleza propia de la televisión, sus características más evidentes de inmediatez, espontaneidad, actualidad encontramos que este medio es una fuente de información poderosa, quizás la más importantes para dar a conocer cualquier realidad, no menos importante es el análisis que puede realizarse en la difusión de esos estereotipos si nos referimos a la ficción televisiva. Miller y Reeves consideran que este medio puede alterar la percepción sobre la vida real, pero este y otros resultados nos sugieren que los medios de comunicación son fuertes socializadores pero que no se puede aislar su influencia del papel que también juega en nuestra conformación sobre hombres y mujeres desde la escuela o la familia. Lo que si arrojan dichos estudios es que persiste la permanencia de los roles tradicionales de género, la especialización temática de las revistas en función del género, la cosmovisión masculina o la presencia de la mujer objeto (Pérez et al. 2012).

Para poder abordar este estudio y la dimensión de su necesidad debemos partir de la base de que la invisibilidad de las mujeres y la estigmatización de las mismas en los medios de comunicación son dos realidades que conviene abordar desde el ámbito académico. Los estudios que han profundizado sobre el reflejo de hombres y mujeres en medios de comunicación impresos realizan exhaustivos análisis del enfoque interpretativo de la realidad, en la que la desigualdad en el tratamiento informativo es una tónica general. La representación de las mujeres en los medios no solamente es escasa, tal y como demuestran las pesquisas desarrolladas hasta el momento, sino que también su papel en el marco académico es igualmente poco notorio, y ello repercute de forma directa en la formación que reciben los futuros profesionales de la Comunicación (Soria, 2018). 


\subsection{Supuestos de investigación}

El catedrático Raúl Eguizábal Maza, director de la Revista Comunicación y Métodos plantea en el volumen 1, número 1 de esta publicación de reciente creación asevera que aunque ya existen publicaciones destinadas a la reflexión teórica en la Comunicación, la deriva hacia trabajos más repetitivos, artificiosos menos autónomos, alejados del trabajo burocrático que cada vez más exige la universidad justifican la creación de una revista que plantea recursos metodológicos más amplios, menos encorsetados y que caminen hacia la innovación. Precisamente ese planteamiento sirve de base para esbozar líneas que puedan asentarse en corrientes metodológicas difundidas por los investigadores de la materia con un amplio currículo investigador como el profesor Zurian.

Los supuestos de investigación que se pretenden abordar en este trabajo se enuncian a continuación. Se indican cuáles son las líneas de investigación que pueden iniciarse, así como la forma en la que deben abordarse. Merece la pena pararse también en las redes sociales que se han convertido en ponentes difusores de la imagen de la mujer, utilizadas por colectivos feministas para la difusión de sus ideas, pero también por una nueva generación de comunicadores que bajo el sobrenombre de influencers, acaparan perfiles de moda, cultura, sociedad. Fenómeno éste escasamente investigado pero cuyos resultados podrían reeditar y modernizar las actuales corrientes de investigación en cuanto a la presencia de estos nuevos modelos de comunicación en la esfera pública.

\subsection{Líneas de investigación}

Este trabajo va a tener como objeto de estudio estudiar roles de género que se han perpetuado a lo largo de las últimas décadas y encontrar algunas de esas líneas de investigación que exploren en la obtención de nuevos datos y elementos que pueden conducir a formular con mayor precisión preguntas de investigación.

Por eso, a continuación, se pretende, en primer término, categorizar dichos estudios en función del papel que juega la mujer en la sociedad, por su contribución con un diseño de investigación en el que se han elaborado varias fichas de análisis con el que se pretende extraer 
distintas categorías que posteriormente se pueden extender a otras dimensiones más específicas.

Por ello, partiendo de que varios enfoques pueden ayudar a iniciar una investigación se proponen a continuación una elaboración de partida que segmente el estudio desde espacios profesionales-laborales. Así también podemos acotar lo que son los escenarios socio-profesionales, ámbitos donde también otros estudios detectan que se produce una ínfima representación de la mujer, o bien, que se limita el perfil al no extender a otros sectores el estudio de las mujeres.

Partimos de la idea de que el análisis de género puede elaborarse desde la perspectiva de los medios audiovisuales con diferentes miradas y ámbitos teóricos, pero que puede extenderse a la ficción, las revistas denominadas femeninas o las emergentes RRSS. Fragmentamos este primer análisis con la idea de que para abordarlo podemos partir desde distintas perspectivas generales para confluir en una particular. En la primera idea se plantea un análisis desde una perspectiva general ya sea para realizar un estudio de informativos en televisión o de contenidos de series ficción y la representación que de ella se hace en función de su profesión o rol en la sociedad. En este tipo de análisis es imprescindible hacer una acotación temporal para otorgar al estudio de parámetros cronológicos que tengan un principio o fin determinado en el espacio-tiempo. De esta forma se dota al estudio de una transversalidad, ya que por un lado intentamos acotar qué profesiones o tareas aparecen en determinados programas con una perspectiva cuantitativa, para seguir en siguientes análisis desentrañando aspectos cualitativos, sociológicos e incluso más teóricos para realizar un análisis audiovisual o formal sobre contenidos. Con estas propuestas, a modo de ejemplos, se defienden unos itinerarios, sin desechar otros. Planteados como paradigmas que permitan partir de una reflexión sobre las identidades y las representaciones de género, capaces de hacerse preguntas complejas sobre los seres humanos, su identidad, sus relaciones, el universo de los sentimientos o incluso la sexualidad.

De esta forma se plantean varias ideas que son solo un camino de partida y en el que se cruzan aspectos cuantitativos, cualitativos, descriptivos, teóricos, analíticos o reflexivos. Por un lado, para conocer de cerca la representación que de las mujeres se hace en distintos medios, así como los roles asignados a diferentes profesiones se 
propone analizar tanto el género en los informativos, la mujer en la ficción televisiva, la mujer en el cine, la mujer y publicidad y las redes sociales. Este estudio se cruza con ciertas profesiones en las que es necesario incidir por su presencia en los medios y se proponen: periodistas, políticas, actrices, modelos, científicas, escritoras, directoras de cine, madres, amas de casa, inmigrantes, influyentes (influencers) economistas, académicas, etc. Se incluye también el papel de las activistas del feminismo por su papel destacado en la reivindicación de los derechos de las mujeres.

Por otro lado, otro de los aspectos a estudiar sería el sociolaboral, al igual que se planteaba en el caso anterior la intención es cruzar datos de la situación laboral y analizarlo en programas cuyos contenidos se han estudiado previamente para estimar si es oportuno o no. $\mathrm{O}$, al menos, que los posibles resultados que se extraigan puedan servirpara la investigación.

Aunque ya se ha tratado en otras investigaciones consultadas, no es menos importante incidir en cómo los informativos siguen presentando a las mujeres no solo en su ámbito profesional sino como meros objetos de representación de la moda. En este apartado, se plantea valorar por un lado el tiempo y por otro el contenido de dichos programas. Examinar con lupa cómo se representa a la mujer cuando aparecen en los informativos y extraer conclusiones reales.

Estas líneas pueden mostrar itinerarios de investigación para aplicar a cada uno de ellos distintos métodos/técnicas/procesos ya que la influencia de los nuevos formatos televisivos de ficción en la que las grandes cadenas utilizan estrategias cruzadas de promoción a través de sus propias pantallas y las redes sociales. De esta forma, pueden ser también objeto de estudio ya que la medición del éxito de las mismas ya no se realiza solo a través de sus medidores tradicionales de audiencia, ahora es fácil hacerlo creando perfiles propios para esas series en redes sociales donde los espectadores pueden comentar en directo sus opiniones sobre un determinado episodio.

Por ello, se propone en este caso realizar una minuciosa indagación en las redes sociales. Verdaderos medios donde tanto los medios de comunicación como perfiles de usuarios conocidos y anónimos lanzan un ingente número de mensajes que tienen una repercusión en sus 
seguidores. Se propone en este caso seguir los perfiles de las tres RRSS que cuentan con un mayor número de seguidores: Facebook, Twitter e Instagram. Dentro de ellas analizar número de personas, comentarios, las palabras que se utilizan que se realizan en las publicaciones que deseemos analizar desde el punto de vista semántico y si existen comentarios sexistas.

También podemos plantear estudios cuyo esquema esté en el protagonismo que la mujer desempeña principalmente por su imagen. Este análisis está enfocado a series de animación donde los diseños de vestuario forman parte de la atracción de estos formatos destinados a llamar la atención de la población infantil. De esta forma, se trata de obtener datos de cómo aparecen representados los distintos protagonistas, así como las actitudes que presentan.

Apartado especial merecen las revistas dedicadas solo a mujeres, en algunos sectores denominadas prensa para féminas donde se les otorga una forma de comportarse de forma exclusiva. Es habitual encontrar en los contenidos de estas publicaciones puntos de interés concretos asignamos de antemano a las mujeres como es la moda, la cosmética y el cuidado del hogar y de los hijos. Además, éstas establecen códigos concretos cuando se trata de revistas para jóvenes adolescentes de forma muy marcada. Para ello se establecen una serie de líneas o incluso una ampliación de las mismas en función del contenido de cada revista. Dichas publicaciones construyen un universo de significados en torno a la mujer en el que se pone el acento en la intimidad, su aspecto físico y las relaciones con su entorno. Se incluye en este apartado también un análisis de sus perfiles en redes sociales porque se han convertido en un atractivo importante para los jóvenes que las consumen en sus ediciones digitales.

En esta ficha de análisis se plantea que la incursión del tema de estudio contenga varias subcategorías de análisis en el que encontremos variables como pueden ser la dimensión física, psicológica o sociológica. Dependiendo si dicho análisis se va a abordar en medios de comunicación o series de ficción, cine o RRSS, las categorías deben ir construyendo un perfil más completo en fichas más específicas. De esta forma, nos permite elaborar análisis cuantitativos y cualitativos más completos y complejos para determinar qué estereotipos aparecen 
en determinados programas para ir amoldando a las características del estudio diseñado.

Según un nuevo informe publicado por We Are Social y Hootsuite, el uso de las Redes Sociales ha crecido notablemente en los últimos años, llegando a una media de más de $\mathbf{3 . 0 0 0}$ millones de personas que ya las utilizan en el mundo mensualmente cada mes. Según el estudio, las más usadas son Facebook, YouTube, WhatsApp y Facebook Messenger. Por la transcendencia que estas redes han tomado en la sociedad actual demanda un análisis en profundidad que requeriría de por sí recorridos concretos de investigación debido al cariz que han alcanzado, aunque su planteamiento en estas páginas es tan solo un punto de partida. Si los resultados de la investigación que aquí se plantean son concluyentes se aconseja realizar una clasificación de los comentarios. Además de las RRSS analizadas anteriormente se añade en este caso YouTube. Aunque es un portal de internet que propicia a sus usuarios la subida de videos, se ha detectado que cada vez cobra más protagonismo la interactividad, sin olvidar que su tráfico móvil supera en ocasiones al de cualquier canal de televisión.

\section{Conclusiones}

En el planteamiento de este trabajo, además de identificar de una forma más teórica los estereotipos de género promovidos desde diferentes medios de comunicación, más allá de análisis cuantitativos y cualitativos, se propone una mirada más teórica y profunda del conocimiento de los estudios de género. Se entiende así que la base teórica de género sea la línea transversal de lo que se ha venido a denominar en las últimas décadas Gender studies. Líneas iniciadas en países anglosajones que comenzaron a llegar a España hace poco más de dos décadas.

Cuando proponemos una perspectiva nueva en la investigación intelectual no desdeñamos la perspectiva cuantitativa, que tantos resultados han ofrecido a lo largo de los últimos años, más bien se utiliza como punto de partida. O desde la cualitativa, que nos acerca aún más al fenómeno de la desigualdad con certidumbres palpables en una exploración no académica. Pero lejos de fijarnos solo en los medios tradicionales, no por ello menos importantes, se ha puesto el foco en las emergentes redes sociales, a las que ya están enganchadas más de 3.000 
millones de personas en todo el mundo y su poder de difusión de imágenes para perpetuar estereotipos es alarmante, pero también pueden ser utilizadas para evitarlos.

La influencia de los nuevos formatos y tecnologías, los debates que en algún momento se han podido generar en torno a ellos y su predominio entre las opciones de comunicación entre la población más joven deben tenerse en cuenta a la hora de elaborar nuevas líneas de trabajo. En torno a las redes sociales, insuficientemente analizadas hasta el momento por el corto recorrido de las mismas, se alerta ya en estudios de universidades españolas y extranjeras la necesidad de abordar estudios transversales.

Así mismo se propone extraer de estos análisis argumentos más significativos, obtener trabajos más profundos que puedan contribuir a la mejora de la sociedad; conseguir una descripción más profunda del tema que queremos conocer, considerando diferentes variables que están relacionadas y con ello obtener más datos y significados a través de diferentes caminos usando la triangulación de teorías, de métodos y de técnicas (Gómez-Diago, 2010).

Algunos de los departamentos universitarios que han situado el foco en los gender studies comienzan a plantearse que la preocupación social que atraviesa ese punto de interés trata de evitar que se estigmatice a las mujeres y que puede mejorar la enseñanza de los futuros estudiantes de Periodismo y Comunicación Audiovisual puesto que supone abrir novedosos itinerarios de indagación que inciden en las desigualdades, así como debates y discusiones sobre la materia.

De esta forma, se promueve el paradigma de mejorar el reencuadre de la comunicación al poner el acento en la necesaria revisión de la investigación sobre género. En definitiva, buscar un conocimiento más profundo y exploratorio de una realidad aplicando un método científico. Presentamos con varias opciones metodológicas ofrecer una herramienta de trabajo para el estudio de la interrelación entre los estereotipos y los influyentes medios de comunicación.

Se plantean varias perspectivas metodológicas para poder avanzar en la investigación. Por un lado, se propone realizar un estudio en profundidad sobre personajes de ficción, para este caso se han 
elaborado varias propuestas que abarquen distintos caminos y de los que se podrá obtener un resultado objetivo, más allá de otras consideraciones. Por ello se proponen modelos de análisis de perfil psicológico de personajes de ficción en series o películas de animación.

En definitiva, promover estudios que produzcan cambios y futuras líneas de investigación que plasmen una producción sólida y crítica sobre la forma en la que el género femenino sigue apareciendo en medios para variar el discurso informativo y enfocar de formas diferentes el tratamiento que se difunde en los medios ya sea informativo o de ficción. Pero sobre todo que sea un motor de cambio social en unos emergentes medios como son las redes sociales en muchos casos utilizadas para banalizar aún más la construcción de identidades. Pautas y estrategias para formar una audiencia crítica que generen propuestas sobre los discursos de género acordes con la realidad.

\section{Bibliografía}

Aparici, R. (2010). La construcción de la realidad en los medios de comunicación. Madrid: Universidad de Educación a Distancia (UNED).

Colás, P. y Villaciervos, P. (2007). La interiorización de los estereotipos de género en jóvenes y adolescentes. Revista de Investigación Educativa. 25, 35-38.

Eguizábal, R. (2019). ¿Por qué una (otra) revista de comunicación? Revista Comunicación y Métodos, 1(1).

Galán, E. (2006). Personajes, estereotipos y representaciones sociales. Una propuesta de estudio y análisis de la ficción televisiva. ECOPÓS- 1 (9), 58-81 Disponible en $\underline{\text { https://e- }}$ archivo.uc3m.es/bitstream/handle/10016/9475/galan personaj es ECOPOS 2006.pdf? sequence $=5$

García, V. (2014). Influencia de la televisión en la creación de estereotipos de género y en la percepción social del liderazgo femenino. La importancia de la táctica de reencuadre para el cambio social Televisión. Colombia. Ciencia Política, (9) 18, 20. 
Disponible

https://revistas.unal.edu.co/index.php/cienciapol/article/view/ $52305 / 52048$

García, C., Ayaso, M. y Ramírez, M. (2008). El patio de recreo en el preescolar: un espacio de socialización diferencial de niñas y niños. Revista venezolana de estudios de la mujer, 31(13), 169-192 Disponible en https://dialnet.unirioja.es/servlet/articulo?codigo $=4136652$

González, B. (1999). Los estereotipos como factor de socialización en el género. Comunica (12), 79-88.

Gómez-Diago, G. (2010). Triangulación metodológica: paradigma para investigar desde la ciencia de la comunicación. Revista Razón y palabra (72)

González M. y Cabrera, C. (2013). Actitudes hacia los roles sexuales y de género en niños, niñas y adolescentes (NNA)Plumilla Educativa, 2(12), 339-360 Disponible en https://dialnet.unirioja.es/servlet/articulo?codigo $=4757437$

Hagag, A. (2019). La evolución de los estereotipos de género en las series de animación infantil. [Trabajo Fin de Estudios]. Universidad de Extremadura. Badajoz. España.

Lippman, W. (1992). La opinión pública. Madrid: Cuadros de Langre.

Martínez, M. Saperas, E. y Carrasco, A. (2019). La investigación sobre comunicación en España en los últimos 25 años (1990-2014) Objetos de estudio y métodos aplicados en los trabajos publicados en revistas españolas especializadas. Empiria: Revista de metodología de ciencias sociales (42), 37-69.

Míguez, M. (2015). De Blancanieves, Cenicienta y Aurora a Tiana, Rapuzel y Elsa: ¿Qué imagen transmite Disney? Revista Internacional de Comunicación y Desarrollo (RICD) 1(2), 41-58.

Disponible

en

http://www.usc.es/revistas/index.php/ricd/article/view/2666/ $\underline{2829}$

Otero, M. (2018). La imagen de la mujer en los deportes. Estudio comparativo de dos cadenas de Televisión: La 1 y Cuatro [Trabajo Fin de Estudios]. Universidad de Extremadura. Badajoz. España. 
Pérez, R., Rodríguez, J. y González, C. (2012). El género en los medios de comunicación: La imagen de mujeres y bombres en la prensa y en los informativos de televisión. Planteamiento de la investigación. 972-987. I Congreso Internacional de Comunicación y Género. Libro de Actas, Sevilla.

Rovetto, F. (2013). Estudios feministas y medios de comunicación: Avances teóricos y periodísticos en España y Argentina. Revista F@ro. 16(1), 14-27.

Soria, M. y Gómez, B. (2017). Análisis del rol profesional de mujeres $\mathrm{y}$ hombres en las agencias de publicidad españolas. Percepciones e integración de igualdad de oportunidades. Sphera Publica, 2(17), 167-193.

Soria, M. (2018). El tratamiento informativo de mujeres y hombres en las revistas españolas: El hombre de éxito y la mujer en el espacio privado. En J. C. Suárez, S. Marín, y P. Panarese, (Eds.) Comunicación, género y Educación. Representaciones y (De) construcciones, (pp. 97-109) Madrid: Editorial Dykinson.

Vilches, L. (coord.) (2011). La investigación en comunicación. Métodos y técnicas en la era digital. Barcelona. Gedisa editorial.

Vizcaya, E. (2019). Los estudios de género ¿Una asignatura pendiente en la Universidad? Disponible en https://perifericas.es/genero- universidad-espanola/.

Zurian, F., y Caballero, A. (2013). ¿'Tiene la imagen género? una propuesta metodológica desde los Gender Studies y la estética audiovisual. En M. V. Mariño, T. González, y M. Pacheco(coord.) Investigar la Comunicación hoy. Revisión de políticas científicas y aportaciones metodológicas: Simposio Internacional sobre Política Científica en Comunicación. Vol. 2 (pp. 475-488).

Zurian, F. y Herrero, B. (2014). Los estudios de género y la teoría fílmica feminista como marco teórico y metodológico para la investigación en Cultura Audiovisual. Área Abierta, 14(3), 5-21. https://doi.org/10.5209/rev_ARAB.2014.v14.n3.46357 



\title{
La revisión sistemática de la literatura como método de investigación
}

\author{
Javier Trabadela Robles \\ Profesor Contratado Doctor de la \\ Universidad de Extremadura \\ María García García \\ Profesora Contratada Doctora de la \\ Universidad de Extremadura
}

\section{Resumen}

En este trabajo se describe la metodología de la revisión sistemática o sistematizada. Se define en qué consiste, sus características principales y cómo proceder al utilizarla. Se complementa con el análisis del proceso seguido en dos ejemplos reales de artículos que siguen este método. Se concluye que, aunque no existe mucha tradición de su uso en Ciencias Sociales, es una metodología en auge en este campo, ya sea como género de investigación en sí mismo, o como establecimiento del estado de la cuestión en trabajos académicos (entre otros).

\section{Introducción}

T A REVISIÓN sistemática o sistematizada de la literatura se ha convertido en una cuestión relevante en el terreno de la dinvestigación (Almeida, 2018; Cooper et al, 2018). Si bien su uso en el ámbito de la salud está muy extendido (García Peñalvo, 2017; Mallett et al., 2012; Moher, Liberati, Tetzlaff, Altman, y The PRISMA group, 2009) su aplicación en las Ciencias Sociales es todavía limitada (Littelly Maynard, 2014; Kelly, 2012; Victor, 2008a). 
El hecho de elaborar un mapa concienzudo de la literatura relevante para la cuestión de estudio ya es en sí misma una herramienta útil tanto para el propio investigador como para futuras investigaciones, ya que permite resaltar aquellas áreas donde existen carencias (Victor, 2008a) aunque Cooper et al. (2018) apuestan porque esta búsqueda sea siempre rigurosa y sistemática para que los hallazgos de los estudios sean considerados relevantes.

Como metodología emergente, se antoja pertinente sentar las bases y definir las cuestiones más relevantes ya que su correcta aplicación y uso determinarán la calidad del conocimiento producido al aplicar dicho método.

Este trabajo pretende ser una aproximación al método para su aplicación al terreno de las Ciencias de la Comunicación e Información. No constituye en sí mismo una revisión sistemática, sino una visión global de los puntos más importantes a tener en cuenta para que pueda ser aplicado a futuros trabajos en el ámbito referido.

\subsection{Definición de la metodología}

En Ciencias Sociales, muchos trabajos de investigación contextualizan los hallazgos encontrados basándose en las publicaciones previas sobre el tema. En este sentido, una revisión de la literatura puede ser una búsqueda rápida en revistas relevantes para determinar la información "nueva" que se incorporará al cuerpo de conocimiento existente de los investigadores (Kelly, 2012). Es decir, puede tratarse de un trabajo riguroso pero que no necesariamente aplica un método y que correspondería con lo que algunos autores denominan revisión narrativa. De manera global puede decirse que una SLR (Systematic Literature Review) es proporcionar un resumen exhaustivo de la literatura disponible en relación a una pregunta de investigación (García-Peñalvo, 2017).

En este sentido para Almeida (2018), García Peñalvo (2017), o Martín Rodero (2014), existen dos tipos de revisiones de la literatura: revisiones narrativas y revisiones sistemáticas. Las revisiones narrativas $(\mathrm{RN})$ son un tipo de revisión que se caracteriza por ser de una forma "más o menos exhaustiva"; son realizadas por "expertos en un tema", el/los autor/es no declaran los métodos que utilizaron para obtener, seleccionar la información mientras que las revisiones sistemáticas son 
una forma de investigación que recopila y proporciona un resumen sobre un tema específico (orientado a responder a una pregunta de investigación); se deben realizar de acuerdo a un diseño preestablecido (Aguilera Eguía, 2014).

Una revisión de la literatura sistemática es algo más que una suma de abstracts, es una revisión planificada que pretende responder a una cuestión. Debe contribuir al debate académico, fomentar una discusión crítica sobre el problema y ayuda a elegir la metodología más apropiada para el trabajo de campo (Almeida, 2018) García- Peñalvo (2017: 9) define el método como aquel que "recopila y analiza críticamente múltiples estudios o trabajos de investigación a través de un proceso sistemático".

Al definir una revisión de la literatura como sistemática se está otorgando al trabajo las cualidades de transparencia (Mallett et al. 2012) rigurosidad (Almeida, 2018; Mallett et al. 2012) y replicabilidad (Mallett et al. 2012) ya que los criterios de elección de los trabajos revisados son claros y podrían ser utilizados en sucesivos trabajos.

La definición del método invita a una planificación metódica del trabajo donde se indicará qué criterios deben tener aquellos documentos que se revisarán y se incluirán en el nuevo estudio a realizar. Las revisiones sistemáticas ayudarán al investigador a centrar la atención en la calidad (o falta de calidad) de la investigación existente; ayudar a prevenir la duplicidad de esfuerzos de investigación; y proporcionar información adicional a través de la comparación y/o combinación de trabajos de investigación individuales (Oakley et al, 2005). Este trabajo de sistematización de la revisión literaria será especialmente pertinente cuando la investigación en curso pretende:

- Revelar tendencias significativas e implicaciones prácticas a través de la síntesis de todas las investigaciones disponibles en un área determinada, así como la identificación de áreas que necesitan investigación adicional (Kelly, 2012).

- Aumentar la amplitud, mejorar la transparencia y enfatizar la importancia de la evidencia empírica sobre el conocimiento preconcebido (Mallett et al. 2012). 
- Detectar ausencia de investigación y señalar debilidades e inconsistencias metodológicas (García-Peñalvo, 2017; Baker, 2016; Mallett et al. 2012).

- Ofrecer un marco teórico al tema objeto de estudio (Baker, 2016).

- Destacar los elementos que caracterizan un área de conocimiento dado (Baker, 2016).

- Evitar el sesgo, aunque no protege contra el sesgo de publicación en los estudios primarios (García-Peñalvo, 2017).

Sin embargo, también es necesario entender que esta metodología plantea dificultades como:

- Requiere una inversión importante, tanto de recursos humanos (puesto que lo ideal es que la búsqueda de los documentos la hagan diversos investigadores) como económicos (puesto que el acceso a las bases de datos no es siempre gratuito).

- Al hacer la selección de criterios de los trabajos a incluir, se corre el riesgo de acotar el área de estudio de manera que se pierda la transversalidad del saber. Las Ciencias de la Comunicación e Información difícilmente pueden desmembrarse de áreas afines como la sociología o la psicología.

- Si el trabajo se demora en el tiempo, será necesario hacer revisiones de la literatura cada cierto tiempo para evitar que quede obsoleta.

Algunos autores como Codina (2017) siguiendo los trabajos de Grant y Booth (2009) y Booth et al. (2012) prefieren utilizar el término "revisión sistematizada" mejor que "sistemática", ya que este último término se ha venido utilizando recurrentemente en las disciplinas de Ciencias de la Salud y se caracteriza porque el marco de aplicación es el de estudios centrados en muestreos aleatorios y métodos cuantitativos. Sin embargo, Codina (2017) explica que en Ciencias Sociales resulta más apropiado utilizar el término "sistematizada", ya que se suele aplicar en investigaciones cualitativas y como parte de trabajos de investigación académicos amplios, por ejemplo, en trabajos de fin de máster o de doctorado. 
En este trabajo la metodología se referirá como "sistemática" puesto que es la forma habitual y más global de describir esta forma de trabajo.

\section{Aplicación de la revisión sistemática como metodología}

A continuación, se exponen dos cuestiones de especial trascendencia en una revisión sistemática de la literatura: ¿qué documentos se pueden incluir en la revisión? ¿Qué pasos dar para hacer una revisión?

\subsection{Documentos a revisar}

En el momento actual, donde la proliferación y el acceso a la información ofrece numerosas oportunidades y materiales a los que recurrir, es necesario tener claro qué recursos pueden considerarse de calidad científica como para ser incluidos en una búsqueda sistemática de literatura y cuáles no.

No se trata de hacer un listado de recursos válidos puesto que esto dependerá del objetivo de la investigación y de las decisiones que los investigadores tomen (reflejadas en el protocolo de la misma) pero sí de tener claro que se debe recurrir a fuentes científicas.

Los tipos de evidencia que podrían incluirse en una revisión sistemática de la literatura incluyen: investigación publicada y no publicada; literatura "gris", por ejemplo, informes del gobierno; tesis informes de conferencias; y la investigación en curso (Victor, 2008b) GarcíaPeñalvo (2017) concreta un poco más estos recursos señalando aquellos documentos de los que una SLR podría valerse e indica que se puede recurrir a:

- Tesis doctorales.

- Artículos de investigación.

- Artículos de datos (data paper - publicación académica de documento etiquetado con metadatos que describe un conjunto particular de datos accesibles, o un grupo de ellos, publicados de acuerdo a las prácticas académicas).

- Artículos de revisión sistemática de literatura.

- Artículos metodológicos. 
- Meta-análisis (proceso de combinar los resultados de diversos estudios relacionados con el propósito de llegar a una conclusión).

- Ensayos (texto escrito, en general por un solo autor, en el cual se exponen de manera argumentativa, el punto de vista, opiniones o posiciones del escritor ante un tema determinado).

- Artículos de divulgación científica.

- Informes técnicos.

- Posts.

- Presentaciones científicas.

Los métodos para identificar evidencias incluyen: búsquedas en bases de datos y registros de investigación; seguimiento de citas; y contacto con académicos y otros especialistas en el campo (Victor, 2008b). Si bien lo más habitual es recurrir a las bases de datos más conocidas o de mayor impacto (WoS, Scopus, Google Scholar, IEEEXplore, ACM, Springer...) no conviene descartar aquellas no tan conocidas.

\subsection{Pasos a seguir}

Los intentos por identificar y señalar los pasos a seguir en una revisión sistemática de la literatura son numerosos. Del ámbito de la clínica y la salud el grupo Cochrane propone unos de los estándares relacionados con la revisión sistemática de la literatura más conocidos: la declaración PRISMA (Moher, Liberati, Tetzlaff, Altman, y The PRISMA group, 2009). En esta propuesta se apunta a 4 fases que determinarán las decisiones a tomar en el proceso de planificación y que marcarán el rumbo de la revisión. La figura 1 recoge el flujo de la información según lo propuesto por el grupo. Además, en el contexto de este grupo se propone una ficha de análisis de los artículos que pude ser usada en las revisiones a modo de checklist. ${ }^{1}$

1.

Disponible

en:

https://es.cochrane.org/sites/es.cochrane.org/files/public/uploads/PRISMA Spanish.pdf 
Figura 1. flujo de información a través de las diferentes fases de una revisión sistemática.

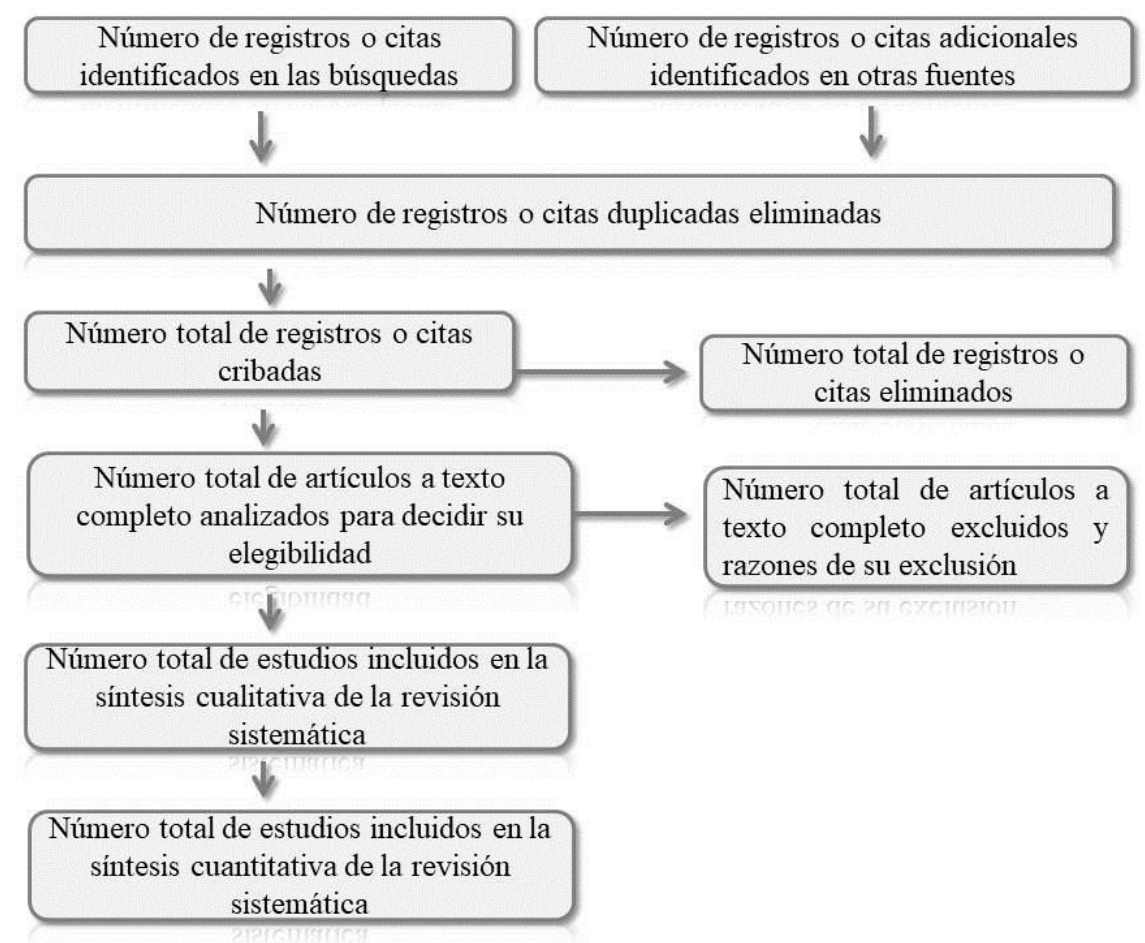

Fuente: Moher, Liberati, Tetzlaff, Altman, y The PRISMA group (2009).

Del ámbito de la medicina, pero con un enfoque más transversal, se encuentra la propuesta de Cooper et al., (2018) quienes intentaron definir un modelo teórico que fuese replicable independientemente del ámbito en el que se realizase la revisión de la literatura y apuntan a los siguientes pasos básicos que comparten las investigaciones que aplican esta metodología:

1. Decidir quien hará la revisión de la literatura. Deberá ser alguien con conocimiento del proceso de búsqueda.

2. Establecer los objetivos y el propósito de la búsqueda bibliográfica. No se trata de revisar toda la literatura sobre la cuestión de estudio sino de identificar aquellos documentos relevantes para conseguir el objetivo marcado en la investigación.

3. Preparación a la búsqueda. Es necesario determinar si existen ya trabajos que aborden el objeto de estudio o si existe la necesidad de hacer una nueva búsqueda y determinar una estrategia de búsqueda inicial para hacer una estimación de la posible literatura relevante. 
4. Diseñar una estrategia de búsqueda indicando los términos que se utilizarán, así como posibles límites (de idioma, geográficos...).

5. Determinar el proceso de búsqueda y dónde buscar: elegir las bases de datos que se consultarán. La cuestión no es elegir un número de bases de datos, sino seleccionar aquellas relevantes para la cuestión de estudio.

6. Determinar el proceso de búsqueda y dónde buscar: materiales adicionales. Más allá de las bases de datos se pueden consultar otros documentos que es necesario valorar.

7. Gestionar la bibliografía. Se puede hacer de manera manual o con algún software de gestión bibliográfica.

8. Justificar la búsqueda, explicitando las bases de datos buscadas (y el host buscado) las estrategias de búsqueda utilizada, y cualquier uso de límites (por ejemplo, fecha, idioma, filtros de búsqueda).

Los esfuerzos por establecer un marco global y no asociado a ninguna disciplina en concreto fueron sistematizados por Victor (2008b) que indica que el investigador debe:

* Determinar los objetivos, el alcance y el protocolo.

* Buscar y seleccionar las evidencias. Desarrollar una estrategia de búsqueda para localizar los recursos más relevantes tratando de evitar cualquier tipo de sesgo.

* Valorar la calidad de los trabajos encontrados. Es frecuente que dos investigadores valoren los hallazgos para asegurar la calidad de los mismos.

* Extracción y síntesis de los datos, dependiendo del enfoque de la revisión, hay que valorar tanto la información cualitativa (como conceptos, por ejemplo) de los trabajos seleccionados en la revisión como cuantitativa.

* Informar y divulgar. Hacer llegar los resultados a todo el público posible. 
Codina (2017) plantea una estructuración en fases algo distinta pero que, en esencia, incluye los mismos procesos a ejecutar, que son los procesos habituales en la búsqueda sistemática y que sería "frameworkSALSA" (Grant y Booth, 2009):

- Search (búsqueda). Afirma que los trabajos de este tipo deben basarse en una búsqueda exhaustiva y perfectamente planificada.

- AppraisaL(evaluación). Los resultados de las búsquedas deben ser evaluados, para lo que se debe establecer unos criterios bien definidos de inclusión y exclusión de registros que formarán parte o no de la revisión.

- Synthesis (síntesis). En este proceso se realizará una síntesis o resumen de cada trabajo seleccionado, con el fin de poder llevar a cabo la siguiente fase.

- Analysis (análisis). Una vez se tienen los resultados numerados y cuantificados (en el caso de investigaciones cuantitativas) o en tablas/fichas de análisis (más utilizadas en investigaciones cualitativas) se procede al análisis y valoración de esa información (de esos resultados).

Codina (2018) hace una representación de estas fases (figura 2) dándole gran importancia a la presentación final de resultados (el "informar y divulgar" de Victor, 2008b).

Figura 2. Diagrama del "Framework ReSiste-SHC".

["Las dos primeras fases aparecen enmarcadas porque son las que admiten un mayor grado de homogeneización. Las fases siguientes

también están enmarcadas por una línea de puntos porque los criterios y procedimientos están vinculados al proyecto concreto”].

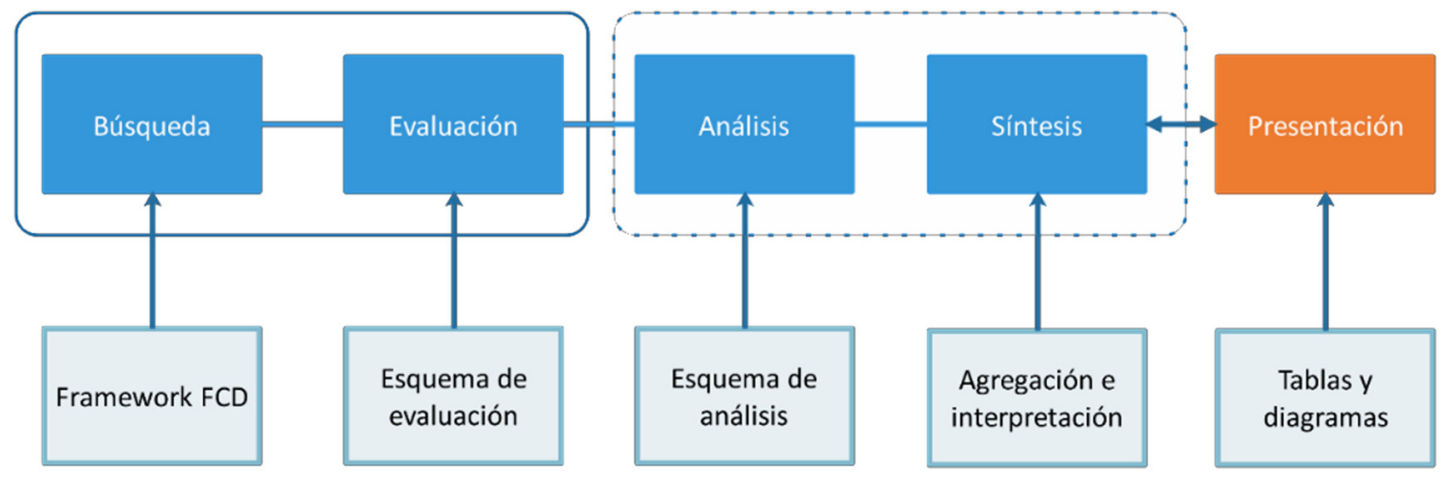

Fuente: Codina (2018). 
Mallett et al. (2012) se preocuparon de conocer los beneficios y desafíos de las revisiones sistemáticas de la literatura para el desarrollo de la investigación internacional al proponer los siguientes pasos:

- Formular una pregunta de investigación teniendo en cuenta la población, los resultados deseados y el tipo de intervención que se va a hacer.

- Definir el protocolo donde se indique la estrategia de búsqueda con todas las decisiones tomadas.

- Búsqueda sistemática en las bases de datos y webs institucionales.

- Selección de los estudios encontrados según su relevancia. En esta etapa pueden intervenir diferentes investigadores.

- Extracción y síntesis de los datos.

Independientemente de las pautas que se sigan, las revisiones sistemáticas de la literatura siguen un proceso marcado de antemano. Las pautas dadas por Mallett et al. (2012) vienen a sintetizar las anteriormente mencionadas y se antoja apropiada para el terreno de la Comunicación, disciplina emergente en la que la dispersión de estudios, las múltiples líneas de investigación posibles y la necesaria relación con otras materias requieren de pasos claros y concisos en los que basar las investigaciones.

En cualquier caso, el hecho de enumerar una serie de pasos a seguir no debe ser interpretado como una forma de encasillar la metodología, sino como una forma de hacer replicable la investigación.

\section{Análisis de ejemplos}

Una forma de que resulte más clara la metodología explicada es el análisis de trabajos de investigación que han utilizado este método de investigación. Con ese fin se analizan a continuación dos ejemplos.

Para ello, se podrían analizar exhaustivamente todos los componentes de los trabajos elegidos, por ejemplo, mediante la lista de comprobación referida con anterioridad de la declaración PRISMA (2009) la cual contiene 27 elementos de análisis. Sin embargo, el análisis se centrará en los aspectos más importantes de una revisión sistemática: 
- Si existe o no una pregunta de investigación.

- Si se define con exactitud el protocolo de búsqueda con todas las decisiones tomadas, de modo que el proceso sea transparente y replicable en el futuro.

- Si se selecciona de entre los documentos encontrados los relevantes para el estudio.

- Si se da una extracción, síntesis y presentación final de resultados.

\subsection{Ejemplo 1: Martínez-Nicolás y Saperas-Lapiedra (2016)}

En este trabajo, titulado "Objetos de estudio y orientación metodológica de la reciente investigación sobre comunicación en España (2008-2014)", los autores, aunque no dicen expresamente que realizan una revisión sistemática, sí que se puede afirmar que la hacen al seguir los pasos que definen dicho método.

Realizan un estudio de lo publicado sobre comunicación en España entre 2008 y 2014. Se trata de un segundo trabajo tras otro que analizaba un periodo anterior, por lo que se entiende que los autores tienen ya ese bagaje previo en este tipo de análisis y en el objeto de estudio.

La pregunta de investigación está claramente presente al cuestionarse los autores sobre qué tipo investigación (concretamente, objetos de estudio y orientaciones metodológicas) en comunicación se ha hecho en España en el periodo señalado. Además, se plantean los objetivos a alcanzar.

Para la búsqueda se definen claramente los criterios, de modo que se podría reproducir en investigaciones futuras. Exponen que se ha examinado artículos científicos (unidad de búsqueda y análisis) en cinco revistas especializadas en comunicación editadas en España: Análisis, Comunicación y Sociedad, Estudios sobre el Mensaje Periodístico, Revista Latina de Comunicación Social y Zer, ya que estas revistas "están incluidas entre las revistas fuente de Comunicación a partir de las que se elaboraron las sucesivas ediciones del índice In-RECS, de la Universidad de Granada" y cuatro de ellas "están situadas entre las cinco primeras según el prestigio otorgado por expertos del área" en la clasificación de 
revistas científicas españolas de Comunicación elaborada en 2009 por el índice RESH del CSIC. De modo que se entiende que los artículos buscados son representativos de la investigación de calidad hecha sobre Comunicación en España en el periodo elegido.

Explican cómo se realizó la selección de entre los documentos encontrados de los relevantes para el estudio: "A partir de esta población de revistas, para el diseño muestral se optó por una cata de años alternos en el periodo estudiado (2008, 2010, 2012 y 2014) que conformó un corpus total de 598 artículos científicos, según la distribución por revista y año recogida en la tabla 1".

Tabla 1. Corpus para el análisis de contenido.

\begin{tabular}{|c|c|c|c|c|c|c|c|}
\hline & Año & Análisis & $\begin{array}{c}\text { Comunicación } \\
\text { y Sociedad }\end{array}$ & $\begin{array}{c}\text { Estudios } \\
\text { Mensaje } \\
\text { Periodístico }\end{array}$ & $\begin{array}{l}\text { Revista } \\
\text { Latina } \\
\text { deC.S. }\end{array}$ & Zer & $\begin{array}{l}\text { Artículos } \\
\text { por año }\end{array}$ \\
\hline 2008 & $\begin{array}{l}\text { Volumen } \\
\text { Artículos }\end{array}$ & $\begin{array}{c}36 \text { y } 37 \\
24\end{array}$ & $\begin{array}{c}21(1-2) \\
12\end{array}$ & $\begin{array}{l}14 \\
35\end{array}$ & $\begin{array}{l}63 \\
42\end{array}$ & $\begin{array}{c}24 \text { y } 25 \\
31\end{array}$ & 144 \\
\hline 2010 & $\begin{array}{l}\text { Volumen } \\
\text { Artículos }\end{array}$ & $\begin{array}{l}40 \\
10\end{array}$ & $\begin{array}{c}23(1-2) \\
23\end{array}$ & $\begin{array}{l}16 \\
26\end{array}$ & $\begin{array}{l}65 \\
43\end{array}$ & $\begin{array}{c}28 \text { y } 29 \\
25\end{array}$ & 127 \\
\hline 2012 & $\begin{array}{l}\text { Volumen } \\
\text { Artículos }\end{array}$ & $\begin{array}{c}45,46 \text { y } 47 \\
17\end{array}$ & $\begin{array}{c}25(1-2) \\
\quad 30\end{array}$ & $\begin{array}{c}18(1-2) \\
\mathbf{5 6}\end{array}$ & $\begin{array}{l}67 \\
22\end{array}$ & $\begin{array}{c}32 \text { y } 33 \\
24\end{array}$ & 149 \\
\hline 2014 & $\begin{array}{l}\text { Volumen } \\
\text { Artículos }\end{array}$ & $\begin{array}{c}50 \\
9\end{array}$ & $\begin{array}{c}27(1-4) \\
39\end{array}$ & $\begin{array}{c}20(1-2) \\
73\end{array}$ & $\begin{array}{l}69 \\
33\end{array}$ & $\begin{array}{c}36 \text { y } 37 \\
24\end{array}$ & 178 \\
\hline Art & $\begin{array}{l}\text { culos por } \\
\text { cevista }\end{array}$ & 60 & 104 & 190 & 140 & 104 & 598 \\
\hline
\end{tabular}

Fuente: Martínez-Nicolás y Saperas-Lapiedra (2016).

Entre todos los artículos encontrados, se seleccionan a su vez sólo aquellos cuyos autores están "adscritos a universidades o centros de investigación radicados en España”, de modo que finalmente trabajan con 529 textos (cerca del 90\% del total).

Para el análisis de contenido de los documentos, los autores utilizaron "una ficha de codificación para la recogida de datos sobre 36 variables 
referidas a distintos aspectos del contenido de los artículos analizados (número y características de los autores, adscripciones institucionales, objetos de estudio, cuestiones metodológicas, etc.)". Definieron los criterios de codificación de las variables, de modo que finalmente obtuvieron los resultados oportunos entre los que se produce una extracción y síntesis en la tabla 2.

Tabla 2. Ámbito mediático o profesional objeto de estudio (20082014). (agrupación de las 61 categorías temáticas codificadas).

\begin{tabular}{|c|c|c|c|}
\hline & $\begin{array}{c}\text { Número }(T= \\
529)\end{array}$ & $\%$ \\
\hline \multirow{8}{*}{$\begin{array}{l}\text { Periodismo o información } \\
\text { periodística }\end{array}$} & $\begin{array}{l}\text { Periodismo (en } \\
\text { general) }\end{array}$ & 49 & 9,3 \\
\hline & Prensa diaria & 74 & 14,0 \\
\hline & Televisión & 29 & 5,5 \\
\hline & Radio & 3 & 0,6 \\
\hline & Medios digitales & 49 & 9,3 \\
\hline & $\begin{array}{l}\text { Docencia / } \\
\text { investigación }\end{array}$ & 15 & 2,8 \\
\hline & Otros & 26 & 4,8 \\
\hline & Total & 245 & 46,3 \\
\hline \multicolumn{2}{|c|}{ Comunicación audiovisual } & 123 & 23,3 \\
\hline \multicolumn{2}{|c|}{$\begin{array}{c}\text { Relaciones públicas y comunicación corporativa } \\
\qquad / \text { institucional }\end{array}$} & 47 & 8,9 \\
\hline \multicolumn{2}{|c|}{ Internet, medios digitales y NTIC } & 37 & 7,0 \\
\hline \multicolumn{2}{|c|}{$\begin{array}{c}\text { Comunicación o comunicación mediática (en } \\
\text { general) }\end{array}$} & 34 & 6,4 \\
\hline \multicolumn{2}{|c|}{ Publicidad y marketing } & 25 & 4,7 \\
\hline \multicolumn{2}{|c|}{ Propaganda } & 8 & 1,5 \\
\hline \multicolumn{2}{|l|}{ Otro } & 10 & 1,9 \\
\hline
\end{tabular}

Fuente: Martínez-Nicolás y Saperas-Lapiedra, 2016. 
Finalmente, los autores analizan los resultados en función de los objetivos planteados al inicio, mostrando los resultados específicos en forma de gráficos sobre 1) evolución de los ámbitos periodísticos objeto de estudio en el periodo indicado; 2) los objetos de estudio específicos; 3) la evolución bienal de los objetos de estudio específicos; 4) evolución de los tipos de investigación; 5) evolución de la investigación empírica; 6) evolución de la investigación empírica con técnicas sistemáticas y 7) técnicas de investigación empírica. Por tanto, los autores consiguen presentar y difundir los resultados relevantes obtenidos.

En definitiva, por todo lo indicado en este breve análisis, el ejemplo seleccionado de Martínez-Nicolás y Saperas-Lapiedra (2016) resulta ser un trabajo de investigación que incluye las características propias de una revisión sistemática.

\subsection{Ejemplo 2: López-García et al. (2019)}

En esta investigación, que lleva por título "Periodismo móvil: Revisión sistemática de la producción científica", los autores realizan expresamente una revisión sistemática preguntándose acerca de la producción científica sobre un tema determinado: el periodismo móvil.

Al considerar que es a partir de 2007 cuando el objeto de estudio adquiere más relevancia, establecen el periodo de análisis entre 2008 y 2018.

A diferencia del ejemplo anterior y al ser un tema muy específico, lo que utilizan para realizar la búsqueda es una serie de descriptores textuales o palabras clave publicados en inglés (tabla 3). Explican que "se ha trabajado con criterios de inclusión conformados por palabras clave definidas" (las referidas antes) y "[...] Se han excluido aquellos en los que el objetivo primario no tenía relación con el periodismo móvil como, por ejemplo, los relacionados con aspectos técnicos de los dispositivos o aquellos que incidían en los procesos de alfabetización mediática". Por tanto, quedan perfectamente definidos los documentos relevantes para el estudio. 
Tabla 3. Descriptores seleccionados para la búsqueda en Web of Science.

\begin{tabular}{|l|c|}
\hline \multicolumn{1}{|c|}{ Descriptor } & $\mathbf{N}^{\mathbf{0}}$ de artículos \\
\hline TS=mobilejournalism & 5 \\
\hline TS=mojo & 5 \\
\hline TS=mobilenews & 18 \\
\hline TS=journalism AND mobile & 53 \\
\hline TS=locative AND mobile & 40 \\
\hline TS=mobile and social media & 6 \\
\hline TS=mobile media & 132 \\
\hline TOTAL & 259 \\
\hline Coincidencias & 60 \\
\hline Total sin coincidencias & 199 \\
\hline
\end{tabular}

Fuente: López-García et al. (2019).

En cuanto a dónde buscaron, "la revisión consistió en la selección de estudios del área de Ciencias Sociales a través de la base de datos Web of Science a partir de las diversas categorías". Se seleccionó esta base de datos para lograr el objetivo principal, que era "estudiar los artículos publicados en las revistas de mayor impacto a nivel internacional".

En cuanto a la extracción de datos y síntesis de resultados, los autores utilizan una ficha de análisis que incluye las siguientes variables: "datos descriptivos (año de publicación, nombre de la revista, título del artículo, palabras clave, tema y número de autores); tipo de estudio (metodología cuantitativa, cualitativa, descriptiva, explicativa, transversal o no especificada); técnicas (observación, cuestionario, entrevistas, análisis de contenido, estudio de caso, experimental o no especificadas); principal aportación; DOI y, por último, institución de origen".

Por tanto, el proceso metodológico se podría replicar con exactitud en investigaciones sucesivas (clave en las revisiones sistemáticas) consistiendo en los siguientes pasos:

1) Identificación del campo de estudio y período a analizar: mobilejournalism (2008-2018). 
2) Selección de las fuentes: artículos de investigación del área de «Social Sciencies Citation Index» (SSCI).

3) Realización de la búsqueda automática en WoS con el listado de descriptores finales.

4) Gestión y depuración de los resultados.

5) Identificación de las variables a estudiar.

Tras la búsqueda y eliminación de coincidencias, los documentos encontrados relevantes para ser objeto de análisis fueron un total de 199.

En la extracción y síntesis de datos entre los resultados "se desgranaron las principales tendencias de la investigación en la materia atendiendo a diversos puntos de vista: publicación -cantidad de artículos publicados y cabeceras-, número de firmantes y temática de los textos revisados".

Tabla 4. Publicaciones analizadas con cinco o más artículos sobre comunicación y periodismo móvil.

\begin{tabular}{|l|c|}
\hline \multicolumn{1}{|c|}{ Revista } & $\mathbf{N}^{\mathbf{o}}$ de artículos \\
\hline Mobile Media y Communication & 55 \\
\hline New Media y Society & 21 \\
\hline Convergence & 12 \\
\hline Journalism Studies & 11 \\
\hline International Journal of Communication & 9 \\
\hline Media International Australia & 9 \\
\hline Continuum & 8 \\
\hline Journalism & 8 \\
\hline Journalism Practice & 7 \\
\hline Information, Communicationy Society & 6 \\
\hline Media Culture y Society & 6 \\
\hline \hline African Journalism Studies & 5 \\
\hline Comunicar & 5 \\
\hline International Journal of Mobile Communication & 5 \\
\hline
\end{tabular}

Fuente: López-García et al. (2019) 
Para la presentación final de los resultados, además de la explicación textual, se eligieron una figura en la que se mostraba el número de artículos anuales, de modo que se analiza la distribución temporal de los trabajos obtenidos; y una tabla (tabla 4) en la que se exponían las revistas que más publican artículos sobre comunicación y periodismo móvil, siempre y cuando hubieran publicado un mínimo de cinco trabajos de los seleccionados.

Por todo lo expuesto, se puede considerar a esta segunda investigación como otro buen ejemplo de revisión sistemática, ya que cumple con los requisitos ya explicados de este tipo de trabajo.

\section{Conclusiones}

Esta metodología se está utilizando cada vez más en Ciencias Sociales en todo tipo de trabajos, como bien resume Codina (2018) en la Figura 3.

Figura 3. Diagrama de las relaciones entre diferentes conceptos vinculados con las revisiones bibliográficas.

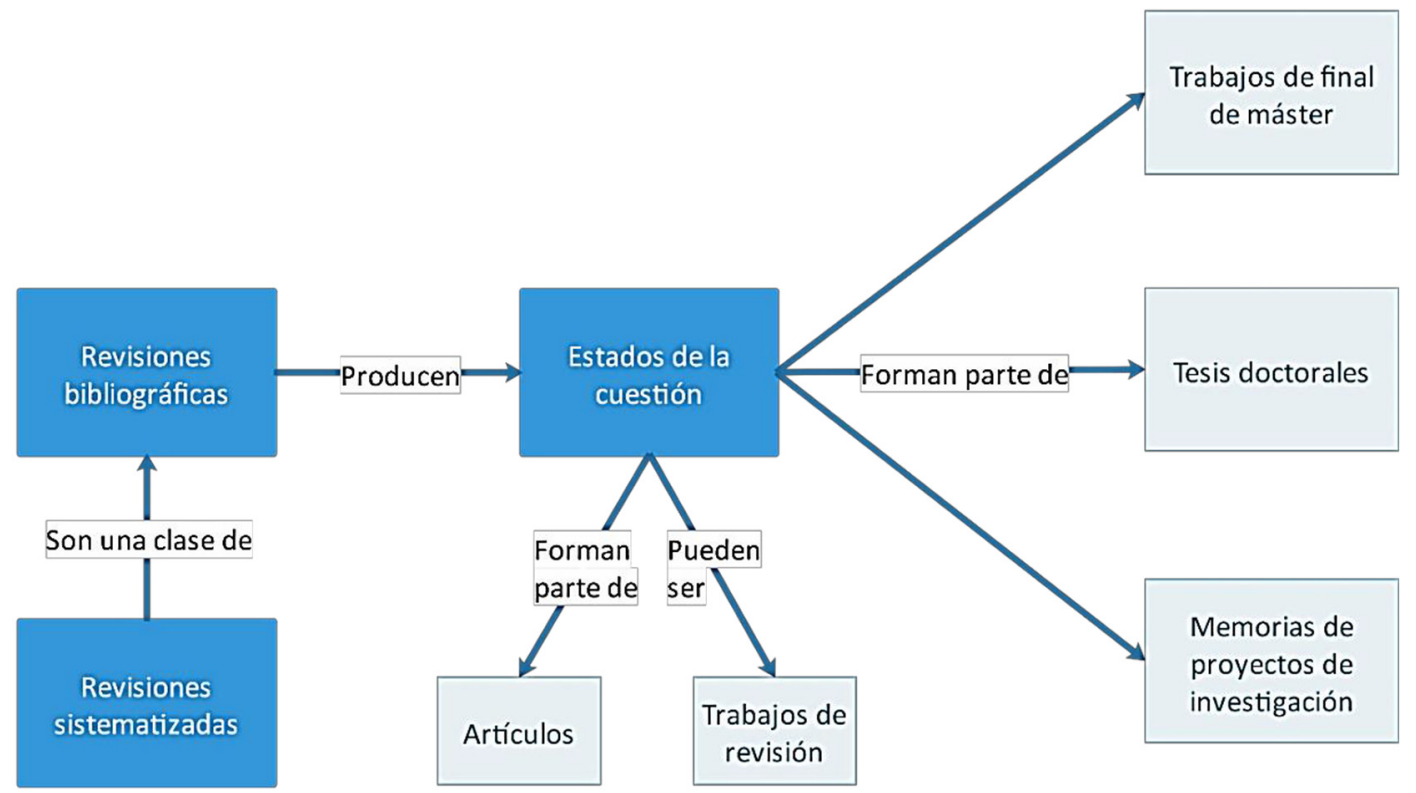

Fuente: Codina (2018).

Desde artículos de investigación, en los que la revisión sistemática se ha convertido ya en un género, hasta los propios trabajos de revisión y establecimiento del estado de la cuestión para trabajos académicos (trabajos fin de máster o tesis doctorales) o incluso para las memorias a presentar en las solicitudes de proyectos de investigación. 
Independientemente del trabajo que se vaya a enfrentar, la atención a la búsqueda, la evaluación y la síntesis, junto con la preocupación por la replicabilidad, ofrecen beneficios transferibles a todos los autores que realizan cualquier tipo de revisión (Kelly, 2012).

Al ser un método basado en la capacidad del investigador para seleccionar, evaluar y sintetizar trabajos de investigación, sería pertinente la participación de más de un investigador. De esta manera, se pretende evitar sesgos.

Es una metodología de investigación muy precisa, lo que implica seguir paso a paso las pautas establecidas en la misma. No obstante, las revisiones sistemáticas de la literatura son un método de investigación maleable. Mallett et al. (2012) apuestan por una aproximación flexible de la metodología donde se sea riguroso en su aplicación, pero flexible para obtener la máxima utilidad de los resultados obtenidos.

Una revisión sistemática de la literatura no debe incluir todos los estudios encontrados y relacionados con el objeto de estudio, sino que se debe saber evaluar y seleccionar aquellos realmente relevantes.

Para finalizar, hay que tener claro que una revisión sistemática implica también algunos condicionantes y algunas limitaciones como, por ejemplo:

- En primer lugar, asumir que una investigación de este tipo es difícil y costosa, tanto en términos de esfuerzo personal (poreso se recomienda que sean varios los autores) como incluso económicos (ya que se debe disponer de presupuesto para el acceso a los recursos bibliográficos necesarios).

- En términos científicos, es conveniente recordar que, puesto que se determinarán una serie de criterios de inclusión y exclusión, no se va a acceder a la totalidad de la producción científica sobre el tema en cuestión, por lo que es probable que producciones científicas de interés queden fuera del objeto de estudio analizado. Por ejemplo, el idioma o las bases de datos elegidas, determinarán apriorísticamente lo incluido y lo excluido.

- El hecho de que todo el procedimiento de búsqueda esté perfectamente descrito $y$, en principio sea replicable, no va a 
implicar que siempre se pueda reproducir del mismo modo exacto la búsqueda de documentos. El motivo es el propio sistema de búsqueda de información de las bases de datos, que puede provocar determinadas diferencias, por ejemplo, al proceder a búsquedas hechas en intervalos de tiempo muy grandes. De hecho, una de las recomendaciones de este tipo de metodologías es que, si pasa mucho tiempo entre un proceso de búsqueda y otro sin haber finalizado el análisis, se proceda a una actualización de los documentos buscados, es decir, se vuelva a proceder a la búsqueda con los criterios iniciales (porque es probable que haya habido cambios, aunque sean menores).

A pesar de estas limitaciones, la búsqueda sistemática tiene muchas características positivas, entre las que se puede destacar que constituyen un magnífico resumen de la producción científica sobre un tema concreto, en un momento determinado y en unas bases de datos seleccionadas. Son perfectas para investigadores que inician sus pesquisas en un determinado ámbito, pero también para aquellos especialistas en una materia que quizás desconozcan alguna publicación en su campo de estudio. Son éstas algunas de las razones por las que esta metodología se utiliza cada vez más en Ciencias Sociales.

\section{Bibliografía}

Aguilera, R. (2014). ¿Revisión sistemática, revisión narrativa o metaanálisis? Revista de la Sociedad Española del Dolor, 21(6), 359$360 . \quad$ DOI: $\quad$ https://dx.doi.org/10.4321/S1134$\underline{80462014000600010}$

Baker, J. D. (2016). The Purpose, Process, and Methods of Writing a Literature Review. AORN Journal, 103(3), 265-269. DOI: https://dx.doi.org/10.1016/j.aorn.2016.01.016.

Booth, A., Papaioannou D. y Sutton A. (2012). Systematic Approaches to a Successful Literature Review. London: Sage.

Codina, L. (2017). Revisiones sistematizadas y cómo llevarlas a cabo con garantías: systematic reviews y SALSA Framework. [artículo online] Disponible en https://www.lluiscodina.com/revisionsistematica-salsa-framework 
Codina, L. (2018). Revisiones bibliográficas sistematizadas: Procedimientosgenerales yFramework, para Ciencias Humanas y Sociales. Barcelona: Máster Universitario en Comunicación Social. Departamento de Comunicación. Universitat Pompeu Fabra. Disponible en https://repositori.upf.edu/handle/10230/34497

Cooper C., Booth A., Varley-Campbell J., Britten N. y Garside R. (2018). Defining the process to literature searching in systematic reviews: a literature review of guidance and supporting studies. BMC Med Research Methodology, 18(1), 1-14. DOI: https://dx.doi.org/10.1186/s12874-018-0545-3.

García-Peñalvo, F. J. (2017). Revisión sistemática de literatura en los Trabajos de Final de Máster y en las Tesis Doctorales. Disponible en https://biblioteca.unirioja.es/tfe e/TFE004581.pdf

Grant, M. J. y Booth, A. (2009). A typology of reviews: an analysis of 14 review types and associated methodologies. Health Information and Libraries Journal, 26, 91-108. DOI: https://dx.doi.org/10.1111/j.1471-1842.2009.00848.x.

Kelly, E. (2012). Systematic and just: The use of a systematic review methodology in social work research. Social Work and Social Sciences Review, 15(3), 72-85. DOI: 10.1921/095352212X657544.

Littell, J. H. y Maynard, B. R., (2014). Review of Systematic Review Methods: The Science of Research Synthesis. Graduate School of Social Work and Social Research Faculty Research and Scholarship, 57. Disponible en http://repository.brynmawr.edu/gsswsr pubs/57

López García, X., Silva Rodríguez, A., Vizoso García, A. A., Westlund, O. y Canavilhas, J. (2019). Periodismo móvil: Revisión sistemática de la producción científica. Comunicar: Revista cientifica iberoamericana de comunicación y educación, (59), 9-18. DOI: https://dx.doi.org/10.3916/C59-2019-01

Mallett, R., Hagen-Zanker, J., Slater R. y Duvendack, M. (2012). The benefits and challenges of using systematic reviews in international development research, Journal of Development Effectiveness, 4(3), 445455, DOI: https://dx.doi.org/10.1080/19439342.2012.711342 
Martín Rodero, H. (2014). La búsqueda bibliográfica, pilar fundamental de la medicina basada en la evidencia: evaluación multivariante de las enfermedades nutricionales y metabólicas. [Tesis doctoral] Universidad Miguel Hernández: Alicante. Disponible en http://dspace.umh.es//handle/11000/1639

Martínez-Nicolás, M. y Saperas-Lapiedra, E. (2016). Objetos de estudio y orientación metodológica de la reciente investigación sobre comunicación en España (2008-2014). Revista Latina de Comunicación Social, 71, 1.365-1.384. Disponible en http://www.revistalatinacs.org/071/paper/1150/70es.html DOI:https://dx.doi.org/10.4185/RLCS-2016-1150es

Moher, D., Liberati, A., Tetzlaff, J., Altman, D.G. y The PRISMA Group (2009). Preferred reporting items for systematic reviews and meta-analyses: The PRISMA Statement. BMJ, 339 b2535. https://doi.org/10.1136/bmj.b2535

Oakley, A., Gough, D., Oliver, S. y Thomas, J. (2005). The politics of evidence and methodology. Evidence y Policy, 1(1), 5-31.

Rutter, D., Francis, J., Coren, E. y Fisher, M. (2011). SCIE systematic Research Reviews: Guidelines (2a ed.) London: SCIE.

Victor, L. (2008a). Systematic reviewing in the social sciences: outcomes and explanation. Enquire, 132-46.

Victor, L. (2008b). Systematic reviewing. Social research update, 54, 1-4. 



\title{
Propuestas metodológicas sobre la investigación de fondos antiguos
}

\author{
José Luis Herrera Morillas \\ Profesor Titular de Biblioteconomía y Documentación \\ Universidad de Extremadura
}

\section{Resumen}

Se plantean varias propuestas para realizar trabajos de investigación sobre colecciones de fondos antiguos, centradas en dos aspectos: la gestión de la conservación; y el análisis de elementos artísticos de los libros antiguos. De cada propuesta se sintetizan los aspectos metodológicos y se muestran ejemplos para ilustrar los planteamientos descritos.

\section{Introducción}

T AS PROPUESTAS de investigación sobre colecciones de fondos antiguos que presentamos se enmarcan dentro de los procedimientos y mecanismos para facilitar la conservación, el conocimiento y difusión a este tipo de colecciones. En concreto nos centramos en:

- El estudio de la gestión de la conservación en colecciones de fondos antiguos.

- El estudio de aspectos artísticos en colecciones de fondos antiguos: encuadernaciones e ilustraciones.

Entendemos por libro antiguo:

“el manuscrito o el libro impreso cuya confección técnica se ha realizado íntegramente de forma manual. Su ámbito cronológico, por 
tanto, se extiende hasta los primeros años del siglo XIX” (Marsá, 1999, p. 15).

También, tenemos en cuenta que para algunos autores se amplía la cobertura cronológica, adentrándose más en el siglo XIX, para poder incluir obras de este siglo que son de gran valor y de las que el número de ejemplares es escaso.

\section{Metodologías}

Las metodologías relacionadas con esta propuesta de investigación la sintetizamos en estos aspectos, que desarrollamos a continuación:

- Metodología para estudios sobre conservación en colecciones de fondos antiguos.

- Metodología para estudios de aspectos artísticos en colecciones de fondos antiguos.

\subsection{Metodología para estudios sobre conservación en colecciones de fondos antiguos.}

La tarea de conservación es fundamental dentro de las tareas de gestión de los fondos bibliográficos, pues se debe "conservar la información para su difusión, que previamente ha reunido y ordenado", pero en el caso de las colecciones de fondos antiguos es todavía más esencial, pues "no sólo la información, sino el propio objeto al margen de esta información es testigo y registro de la evolución de las técnicas históricas de la creación del libro y de su proceso bibliotecario" (Tacón, 2004).

Los trabajos de investigación sobre la conservación de colecciones de fondos antiguos deben centrarse en el estudio de cómo se incluye la tarea de conservación dentro de la política de gestión de la colección y para ello se debe partir del conocimiento de los principales aspectos relacionados con la conservación de este tipo de colecciones, que implica conocer desde un punto de vista teórico todo lo relacionado con ella.

El concepto de conservación ha sido objeto de diferentes planteamientos a la hora de definirlo. Se trata de un concepto abordado con asiduidad por la bibliografía especializada, sobre todo desde del 
ámbito de la Teoría de la Conservación y la Restauración (Macarrón, 2008). Así lo expresa Sánchez (1999) en su pormenorizado estudio:

"Estamos ante un término múltiple y complejo que abarca todas aquellas operaciones encaminadas a retener, en óptimas condiciones, las colecciones documentales y sus contenidos intelectuales, con el fin de asegurar su permanencia y facilitar el acceso de la sociedad a la información".

La conservación está muy relacionada con la preservación y la restauración:

"Conservación y preservación son nociones inseparables, lo mismo que la restauración va ligada a la conservación y precedida por ella" (Macarrón, 2008).

Para guiar el trabajo de conservación de colecciones bibliográficas patrimoniales se han elaborado por parte de las asociaciones y organismos vinculados a las bibliotecas diferentes principios, pautas, estándares, etc. El conocimiento y estudio de estos documentos es una parte esencial para fundamentar investigaciones sobre conservación de fondos antiguos. A continuación, se presentan los documentos más representativos:

La IFLA publicó en 1979 los Principies for the Preservation and Conservation of Library Materials, considerados en su momento como las directrices más completas para la conservación de las colecciones de las bibliotecas. En 1986fueron revisados y como indica Sánchez (1999) estos principios fueron:

"El primer intento por fijar la terminología en un ámbito internacional... verdadero código deontológico de conservación... una serie de normas que sirvan de referencia para establecer, en colaboración con técnicos y científicos, una política para el futuro de los materiales".

En 1998 se edita un documento más reducido destinado al cuidado de las colecciones de las bibliotecas: Principles for the Care and Handling of Library Material (IFLA, 1998).

Otra destacada aportación son las Guidelineson Preservation and Conservation Policies in the Archives and Libraries Heritage elaboradas por 
Patrice Chapman (1990) y editadas por la UNESCO dentro del Programa UNISIT. Concebidas como una guía para establecer paso a paso una política de preservación.

Tres años después se edita Preservation Planning Program Resource Guides de la Association of Research Libraries (1993) que engloba 7 guías elaboradas por expertos en la gestión de la preservación en bibliotecas académicas, para guiar y medir su labor de preservación.

La ACRL (The Asociation of College and Research Libraries) también se ha interesado por la conservación. Destacan las Guidelines for the security of Rare Books, Manuscripts, and other Special Collections, $2009^{1}$, que abordan cuestiones a tener en cuenta por los responsables de las colecciones para evitar robos.

El estándar de ámbito internacional más específico para nuestro objeto de estudio puede ser la norma ISO 11799 (2003) revisada en 2015 (https://www.iso.org/standard/63810.html) destinada a fijar los requisitos para el almacenamiento de documentos de archivos y materiales de bibliotecas.

En el ámbito de las bibliotecas universitarias españolas el texto esencial se denomina Patrimonio bibliográfico histórico universitario normas y directrices para su tratamiento publicado como anexo a la $2^{\text {a }}$ edición (1999) de las Normas y directrices para bibliotecas universitarias y cientificas elaborado por REBIUN. Desarrolla en cinco apartados diversos aspectos sobre el Patrimonio histórico universitario.

Partiendo de estos textos normativos, nuestra propuesta metodológica para el estudio de la conservación de colecciones de fondos antiguos se concreta en la evaluación de su situación mediante un cuestionario que abarca 7 apartados, cada uno de los cuales incluye cuestiones concretas que deben responder los responsables de la gestión de las colecciones objeto de estudio (ver Tabla 1):

Para la elaboración del cuestionario se ha tomado como base las Guidelines de la UNESCO (1994) la Normativa de REBIUN (1999) y los textos de algunas bibliotecas universitarias, sobre todo el Reglamento

1 Existe la traducción al castellano, realizada por el Grupo de trabajo de Patrimonio Bibliográfico de REBIUN: Directrices sobre seguridad y robos en colecciones especiales (2009) 
para uso y conservación de los fondos antiguos y valiosos de la Universidad Complutense de Madrid (1992) y la Normas para uso y conservación de los fondos antiguos y valiosos de la Biblioteca de la Universidad de Sevilla (2009). En su confección se ha pretendido recoger los aspectos esenciales relacionados con la conservación y formularlos de manera sintética, intentando que las cuestiones sean fáciles de identificar y responder.

Tabla 1. Propuesta de cuestionario sobre conservación.

\section{NORMATIVAS}

1. ¿Cuenta con normativas propias que guie la conservación del fondo antiguo?

2. ¿Se siguen normativas y/o estándares ajenos que guíen la conservación del fondo antiguo?

3. ¿Cuenta con plan de conservación preventiva?

\section{LOCALIZACIÓN Y CARACTERÍSTICAS DEL DEPÓSITO}

4. ¿La biblioteca cuenta únicamente con fondo antiguo?

5. Si cuenta con fondo moderno ¿está separado del antiguo?

6. ¿Cuántos depósitos específicos hay para el fondo antiguo?

7. ¿La colección de fondo antiguo es de libre acceso a los usuarios?

8. Además de libros antiguos chay otro tipo de material especial?

9. ¿De qué material son las estanterías? (metal/madera/otros)

10. ¿Hay estanterías adosadas a la pared?

11. ¿Hay otro tipo de mobiliario para el fondo? ¿Cuál?

12. En caso de contar con folletos u otro tipo de material de pequeño formato ¿se guardan en cajas de material no ácido?

\section{MEDIDAS MEDIOAMBIENTALES EN EL DEPÓSITO}

13. ¿Hay ventanas con luz natural directa? (indique si se evita la incidencia sobre los fondos y cómo)

14. ¿Se siguen medidas de control de la iluminación artificial? ¿Cuáles?

15. ¿Se siguen medidas de control de humedad? ¿Cuáles?

16. ¿Hay tuberías o conducciones de agua cercanas a los fondos? 


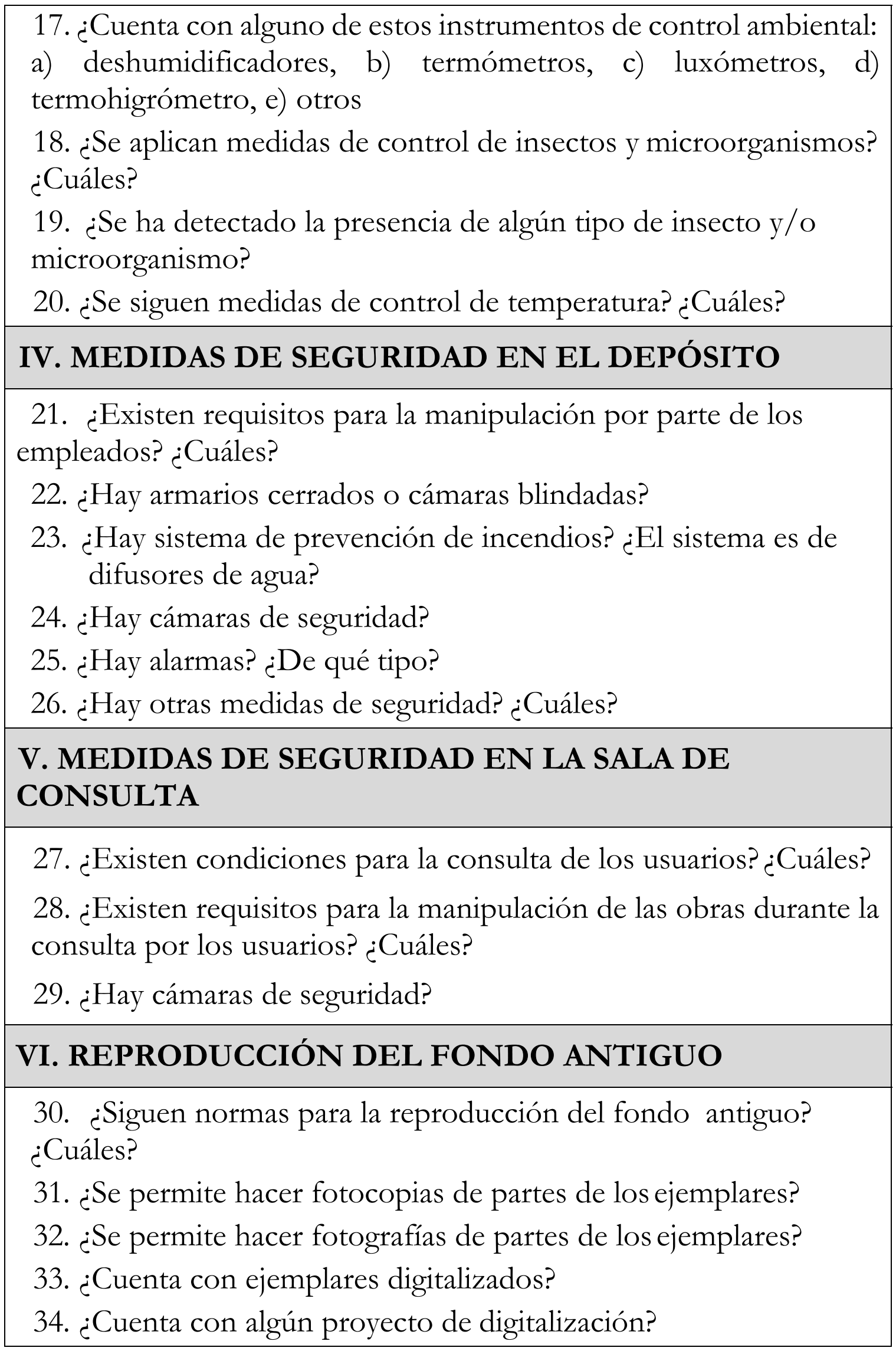




\section{DETERIORO Y RESTAURACIÓN DEL FONDO ANTIGUO}

35. ¿La colección ha sido objeto de algún siniestro?

36. ¿La biblioteca cuenta o ha contado con algún plan de restauración?

37. ¿Ejemplares de la colección han sido objeto de restauración? Si puede, indique el número aproximado de obas restauradas en los últimos 3 años.

38. El porcentaje de documentos con necesidad de restauración es:

Muy elevado ( + del 80\%)

Elevado (70\%)

Considerable (40-50\%)

Escaso (hasta 30\%)

39. De las siguientes patologías puntúe de 1 al 6 (1 la inferior y 6 la superior) las que tienen mayor incidencia en la colección

Efectos de humedad

Encuadernación en mal estado

Cuadernillos descosidos

Ataque y/o efecto de insectos

Ataque y/o efecto de microrganismos

Otras (indíquese)

Fuente: elaboración propia.

Otro aspecto que se puede abarcar en este tipo de investigación es comparar de manera exhaustiva los datos sobre la gestión de la conservación de la colección que se pretende estudiar con las indicaciones de alguna de las normativas señaladas, que se tomarán como referencia de comparación, obteniendo como resultado el grado de cumplimiento de la normativa seleccionada. Para ello, habría que partir de un trabajo de síntesis de la normativa elegida. Nuestra propuesta consiste en reducir los textos de la normativa a una serie de ítems que facilite el trabajo de comparación. A continuación, bastaría con ir indicando si cada uno de estos elementos está reflejado o no en la información observada en la colección objeto de estudio. Tras la 
comparación, se calcularía el número de coincidencias y se harían los cálculos pertinentes.

Seguidamente, reproducimos la síntesis propuesta para las Guidelines de la UNESCO (1994) (ver Tabla 2) y para la Normas de REBIUN (1999) (ver Tabla 3).

Tabla 2. Propuesta de síntesis de las Guidelines de la UNESCO (1994).

\begin{tabular}{|l|}
\hline Preventive Measures \\
\hline Temperatura $16-21^{\circ} \mathrm{C}$ \\
\hline Humedad relativa $40-60 \%$ \\
\hline Termómetros \\
\hline Higrómetros \\
\hline Training Programmes \\
\hline 1. Manipulación no negligente por empleados: \\
\hline a) Formación y concienciación \\
\hline b) Pautas simples a seguir \\
\hline c) Condiciones de trabajo adecuadas \\
\hline 2. Formar a los usuarios sobre la vulnerabilidad de los materiales \\
\hline a) Disponer de unas reglas o pautas simples \\
\hline b) Entorno de trabajo para utilizar los materiales de forma segura \\
\hline Security \\
\hline Plan de contingencia (incendio, agua, etc.) \\
\hline Precisar el nivel de seguridad (robos, incendios...) \\
\hline $\begin{array}{l}\text { Especificar que material requieren condiciones especiales de } \\
\text { seguridad }\end{array}$ \\
\hline Protection \\
\hline Cajas, carpetas, etc. \\
\hline Conservation \\
\hline $\begin{array}{l}\text { Si no hay departamento de restauración, dar indicaciones precisas } \\
\text { a las empresas externas }\end{array}$ \\
\hline Reprography \\
\hline $\begin{array}{l}\text { Especificar los límites o exclusiones para las copias de elementos } \\
\text { específicos }\end{array}$ \\
\hline
\end{tabular}

Fuente: elaboración propia. 
Tabla 3. Propuesta de síntesis de las Normas de REBIUN (1999).

\begin{tabular}{|l|}
\hline Instalación. Depósito \\
\hline Evitar zonas de desagües, tuberías, etc. \\
\hline Temperatura $15-20^{\circ} \mathrm{C}$ \\
\hline Humedad $45-65 \%$ \\
\hline Instrumentos de control \\
\hline -Termohigrógrafos \\
\hline -Psicrómetros \\
\hline Luz fría (filtros ultravioletas) \\
\hline Intensidad inferior 300 lux \\
\hline Focos alejados de los libros \\
\hline La seguridad de los depósitos \\
\hline -Cierres blindados \\
\hline -Sistemas de alarma \\
\hline -Sistema de detección de incendios \\
\hline -Sistema de extinción \\
\hline Instalación. Mobiliario \\
\hline Cajas sin acidez (folletos) \\
\hline Estanterías metálicas \\
\hline Estanterías sin adosar a la pared \\
\hline Archivadores apropiados (grabados, etc.) \\
\hline Tratamiento. Manejo \\
\hline Indicaciones para el manejo \\
\hline -Especial cuidado... \\
\hline -Manos bien limpias... \\
\hline -Guantes en algunos casos... \\
\hline Preservación y restauración \\
\hline Copias de seguridad \\
\hline Promover y participar en planes cooperativos de digitalización \\
\hline Utilización de los fondos. Consulta en la sala \\
\hline Petición con papeleta (formulario) \\
\hline Autorización expresa para obras valiosas \\
\hline Identificación (DNI, pasaporte, carné, etc.) \\
\hline Limites para el no de obras a consultar \\
\hline Solo uso de lápiz... \\
\hline Otras restricciones para proteger las obras (objetos encima, etc.) \\
\hline Prohibición de introducir aparatos de reproducción \\
\hline
\end{tabular}




\begin{tabular}{|l|}
\hline Reproducción \\
\hline Medios reproducción de copias para usuarios \\
\hline Fotocopia directa prohibida (hay excepciones) \\
\hline Las fotografías serán realizadas en la biblioteca por un profesional \\
\hline
\end{tabular}

Fuente: elaboración propia.

\subsection{Metodología para estudios de aspectos artísticos en colecciones de fondos antiguos}

El libro antiguo desde sus inicios ha sido apreciado como un objeto valioso, con el paso del tiempo -y mucho más en nuestros días- se ha revalorizado como objeto de arte: se observa el libro bajo la actitud del bibliófilo (tipografía, composición, ilustración, etc.). Esta apreciación artística se fundamenta en gran medida en la ilustración y en la encuadernación, que han permitido que el libro destaque por su estética y diseño, convirtiéndose en un objeto artístico. Por ello, esta propuesta de investigación se refiere al estudio de dos aspectos del libro antiguo: las encuadernaciones artísticas y las ilustraciones.

\subsubsection{Ilustración del libro antiguo}

Respecto a la ilustración del libro antiguo la metodología se centra en el estudio de las diferentes partes del libro que están ilustradas y/u ornamentadas (portadas, iniciales, orlas, tipografía, ilustraciones de los preliminares, ilustraciones y láminas interiores, tacos, marcas de impresor, viñetas, etc.) según las distintas técnicas del grabado y también, en la identificación y análisis de la iconografía.

El primer asunto abarca el análisis de las portadas que incluyen diversos tipos de ilustraciones como viñetas, marcas tipográficas, retratos, blasones, compartimentos y marcos, frisos y molduras y que a veces se combinan dando lugar a ilustraciones muy complejas. Uno de los modelos más característicos de las portadas ilustradas son los llamados "frontispicios" o "frontis", formados por elementos decorativos arquitectónicos y/o alegorías, que enmarcan la información fundamental de identificación de la obra (autor, título y pie de imprenta). Surgen especialmente en el siglo XVII, se confeccionan mediante sistemas calcográficos que reproducen con frecuencia formas arquitectónicas de puertas: representan el acceso al conocimiento que 
se encuentra recogido en la obra.

Las portadas como primer elemento que el lector ve del libro, tienen importancia para el lector-comprador, se cuidaba mucho, es la tarjeta de presentación de la obra y del taller.

Las iniciales o letras capitales aportan una doble función:

1) Decorativa: se remontan a las capitales miniadas de los manuscritos.

2) Informativa: reproducen una letra que inicia la primera palabra de un parágrafo.

Nos podemos encontrar con capitales simplemente decoradas, o con capitales con ilustraciones que se relacionan con la información textual del documento. Cuantitativamente son el tipo de ilustración más frecuente. En los primeros momentos de la imprenta se dejaba el espacio en blanco y se hacían a mano.

Las orlas, también llamada cenefas, son una banda decorativa que acompaña al texto en uno de sus lados. Recuadro o recuadramiento es la denominación para aludir al conjunto de cuatro cenefas dispuestas a lo largo de los cuatro lados del texto. Cuando sólo aparece el margen superior de la página, se denomina ilustración de cabeza, cabecera u oral de cabeza.

La tipografía puede tener una intencionalidad estética y decorativa, fundamentada en la disposición de la escritura y del texto buscando esta intencionalidad, jugando, por ejemplo, con los cambios de color y/o tamaños de los tipos.

Las ilustraciones de los preliminares suelen estar constituidas, fundamentalmente, por retratos idealizados, a veces, el autor leyendo (como maestro en la cátedra) con el libro en la mano, etc.; y por motivos heráldicos, relacionados con los autores, los personajes a que se dedica la obra, los mecenas, los personajes objeto de la obra (biografiados, homenajeados...) autoridades, órdenes religiosas, escudos académicos, etc. 
Las ilustraciones y láminas interiores se disponen a lo largo del texto de la obra. Pueden tener objetivo informativo o puramente ornamental, y tener o no relación con el contenido de la obra. Las relacionadas con el contenido presentan función informativa, son las ilustraciones propiamente dichas. Las que no tienen relación con el contenido, rellenan espacios en blanco.

Los tacos son adornos ornamentales para rellenar espacios vacíos, por ejemplo, el final de un capítulo, el final del texto, etc. Son muy característicos los de forma de triángulo invertido.

Las marcas de impresor identifican al impresor o a la imprenta, tienen un objetivo inicial identificativo y publicitario, más tarde se transforman en marca de calidad de un producto. En su origen eran una simple sigla, luego abundan las que reproducen una esfera y una cruz. En el siglo XV se difunde el uso de iniciales y monogramas. También, podemos encontrar escudos heráldicos del impresor, de la ciudad, de instituciones, etc. En el siglo XVI se ponen de moda las representaciones alegóricas o figuradas relativas a la ciudad en la que vivió o nació el impresor, a aspectos de su vida, a su nombre o apellidos, a su actividad, etc. Abundan las marcas que reproducen las prensas y otros materiales relativos a la profesión de la imprenta.

Las viñetas son cuadros con ilustraciones, que se intercalan en la superficie que ocupa el texto. Con posterioridad también se sitúan en los inicios de capítulos o partes superiores del texto.

Los caligramas o composiciones figurativas son ilustraciones obtenidas mediante la disposición del texto. Por el ejemplo, los que tienen forma de "Base o pie de lámpara" en forma de triángulo invertido. Se utilizaban para los colofones.

Los monogramas están constituidos por un conjunto de letras combinadas de tal manera que forman un dibujo continuo.

Los ornamentos tipográficos hacen referencia a conjuntos de caracteres tipográficos que reproducen serie de objetos ornamentales. Con ellos se componen las llamadas orlas y marcos de combinación, mediante repetición del mismo tipo hasta formar la orla. Se utilizan series de signos como los paréntesis o letras como la "o". También, mediante 
elementos tipográficos se realizan filetes (líneas de distinta forma y grosor) que adquieren cierto carácter ornamental. Destacan elementos decorativos vegetales: hojas de hiedra, de parra, bellotas, flores...; con otros motivos: estrellas, corazones, cruces, manecillas...; y otros adornos tipográficos indeterminados.

Respecto a las técnicas empleadas para plasmar las ilustraciones en los libros impresos, en los primeros tiempos de la imprenta, el procedimiento era muy semejante a la ilustración del manuscrito: se reservaban los espacios para que los iluminadores los decorasen en ilustrasen, utilizando las mismas técnicas de los copistas en los manuscritos. Pero, pronto se usaron los grabados como forma de introducir la información gráfica en los libros. Los procedimientos más utilizados fueron el grabado en madera (xilografía) y el grabado en cobre (calcografía). Según sea el material en el que se fabrica la plancha o "matriz".

La xilografía se basa en el empleo de un taco o matriz de madera "taco xilográfico" con el dibujo grabado. El grabado se realizaba mediante la presión manual de un rodillo que se pasaba por el reverso del papel en contacto con el taco xilográfico entintado. Posteriormente se utilizaron prensas como en la imprenta. Los tacos los realizaban materialmente profesionales especializados en el trabajo de la madera. Ellos u otros artistas dibujaban la ilustración.

El grabado en cobre, llamado también calcografía o grabado en hueco, tiene su origen en las técnicas utilizadas por los orfebres y fabricantes de armaduras. Entre sus principales peculiaridades están el empleo de la matriz de metal; los trazos plasmados en relieve sobre el papel; o la evidencia de la impronta de la plancha alrededor de la composición grabada (cubeta, huella, testigo, pisada, canalón o mancha). De las principales ventajas de la calcografía sobresalen su mayor duración y el aumento de las posibilidades técnicas (perfección en el resultado).

Respecto a la identificación y análisis de la iconografía es fundamental conocer las fuentes de más influencia en la iconografía, que caracteriza a los libros antiguos españoles: por un lado, la literatura emblemática y la iconografía cristiana; por otro $-y$ en menor medida- la mitología clásica. 
La emblemática española se define por su carácter moral, fruto de un proceso de cristianización, y también, por su carácter ético-político. Destacan obras como las Empresas molares de Juan de Borja; los Emblemas morales de Juan de Horozco; los Emblemas morales de Sebastián de Covarrubias; o las Emblemas moralizadas de Hernando de Soto. Muy relacionada con esta literatura, y fuente fundamental para todo el arte de la época, es la Iconología de Cesare Ripa. Constituye un repertorio alfabético de todos los símbolos y alegorías de la religión cristiana y de las culturas griega, romana y del Renacimiento.

Además de estas obras, para descifrar las alegorías y demás imágenes simbólicas que abundan en nuestros libros antiguos es importante conocer la Biblia, y la vida y atributos que definen a la Virgen María, Jesucristo y los santos. Por último, no podemos olvidar otra ayuda imprescindible como es la Heráldica.

Como ejemplo de una investigación centrada en el estudio de portadas ilustradas se podría utilizar el siguiente esquema de análisis, que nos llevaría a fijarnos en los siguientes aspectos de la portada:

- Tipo de portada.

- Tipo de ilustración.

- Ubicación de la ilustración.

- Técnica del grabado (xilografía, calcografía).

- Iconografía.

- Otras ilustraciones o elementos ornamentales.

En el Tipo de portada se diferenciará, por ejemplo, entre las portadas tipográficas, portadas con ilustraciones, incluso las portadas grabadas calcográficas. Las primeras son las que están compuestas por el texto elaborado con los tipos de la imprenta; las segundas las que incluyen algún tipo de ilustración; y las terceras responden al modelo de portada calcográfica o también llamada frontispicio que goza de cierto auge en el siglo XVII y que técnicamente se elabora en una plancha donde se 
graban las ilustraciones y el texto con la información propia de la portada.

La Ubicación de la ilustración hace referencia al lugar en el que se sitúa la ilustración dentro de la portada. Por ejemplo:

- Parte superior.

- Parte inferior.

- Centro.

- Elemento dentro del grabado.

- Grabado que ocupa toda la portada.

Las tres primeras hacen referencia a las portadas tipográficas, en las que la ilustración es una viñeta que se coloca en una de esas tres posiciones. Las dos últimas, se dan solo en las portadas grabadas; y en este caso se diferencia entre las portadas en las que la iconografía objeto de estudio es un elemento más de una composición con otros elementos iconográficos, y entre las que la iconografía estudiada es un único motivo del grabado que ocupa toda la portada.

En la Técnica del grabado se distingue entre la xilografía (o grabado que utiliza planchas de madera) y la calcografía (que utiliza planchas de metal). La técnica de grabado más propia del siglo XVII es la calcografía, pero todavía se mantiene la xilografía y especialmente en la portada, pues es más apropiada para las viñetas que se insertan en hojas donde abunda el texto, como es el caso de las portadas. Las características estéticas de ambas técnicas son fáciles de apreciar. La xilografía produce unos grabados más primitivos, de efecto plano por la dificultad de conseguir la gradación de los tonos grises. Esto no es problema en la calcografía donde la gradación es posible y por tanto se consiguen representaciones más pictóricas, con mejores efectos de volumen.

En el apartado de Iconografía se le precisaría el tipo de iconografía que reproducen las ilustraciones. 
En Otras ilustraciones o elementos ornamentales se hace referencia a:

- Orlas tipográficas

- Adornos tipográficos

- Otras viñetas

- Letras capitales

\subsubsection{Encuadernación artística del libro antiguo}

Respecto a la encuadernación, su estudio desde el punto de vista artístico está vinculado al concepto de estilo de encuadernación, que comprende tanto el estilo técnico como el estilo artístico (Checa, 2003).

El estilo técnico alude al conjunto de materiales y procedimientos de trabajo que en encuadernación sirven para producir lo que los bibliógrafos llaman el libro material, concretamente la encuadernación entendida como realidad física resultado de un proceso de manufactura de producción industrial. Su objeto de estudio es la constitución estructural del objeto librario mediante una serie compleja de operaciones tales como el cosido de los cuadernos que integran el bloque del libro, la agregación y unión de cubiertas y el recubrimiento de éstas con pieles, telas u otros materiales.

El estilo artístico estudia la decoración de las encuadernaciones, compara esta decoración con los motivos dominantes en las demás artes, principalmente en las artes decorativas, también en la arquitectura y algo menos en la pintura. El estilo artístico estudia además el sistema de formas cuya cualidad y expresión significante hacen visible la intervención personal de un encuadernador.

El nacimiento de los estilos históricos de la encuadernación se debe en gran medida al papel jugado por la bibliofilia, la edición y la biblioteca, que marcan los primeros pasos de la historia de la encuadernación ligada a la labor desarrollada por los coleccionistas de encuadernaciones, los bibliotecarios y los libreros. A los que hay que sumar las descripciones detalladas de los catálogos de las casas de subastas o los catálogos de venta de las bibliotecas. 
El tipo de investigación que proponemos consiste en realizar un análisis documental completo de las encuadernaciones artísticas de un conjunto de libros, que serán seleccionados previamente, describiendo los materiales utilizados, las técnicas de construcción empleadas, las técnicas y motivos decorativos y el estado de conservación. Obteniendo también imágenes de las diferentes partes de las mimas como tapas, lomo, cabezadas, cortes y guardas, con su digitalización y posterior tratamiento de las imágenes.

Por lo tanto, la primera tarea consistiría en delimitar el objeto de estudio, es decir el conjunto de encuadernaciones que se van a estudiar, seguidamente se procedería a la catalogación y descripción de cada encuadernación. Para ello se propone seguir el siguiente modelo de registro, basado en los trabajos de Antonio Carpallo (1999 y 2002) y en nuestra experiencia docente e investigadora en la materia:

1. Referencia bibliográfica.

2. Signatura topográfica.

3. Dimensiones de la encuadernación.

4. Aspectos técnicos.

5. Descripción del estilo artístico y/o ornamentación de la encuadernación.

6. Estado de conservación.

7. Imagen.

Para elaborar las referencias bibliográficas (autor, título, lugar de publicación, impresor y año de publicación) se utilizará la norma ISBD (A).

En los aspectos técnicos se recogerán todos aquellos que se puedan identificar a simple vista: material de la cubierta (piel, pergamino, tela, papel y orfebrería) de las tapas (madera o cartón) características del lomo (forma, nervios, tejuelo) cosido de los cuadernillos, cabezadas, guardas, cierres. Las dimensiones de la encuadernación: largo x ancho x profundo en cms. La descripción de la ornamentación se basará en la estructura decorativa, las técnicas y utensilios, y en la decoración de los cortes, cantos y guardas. 
En el estado de conservación se recogerán las deficiencias detectadas. En caso de que no sea necesario se indicará que el estado de conservación es bueno.

Respecto al proceso de fotografiado se obtendrán imágenes de las cubiertas, cabezadas, guardas, cortes, lomo, cantos y cualquier otro detalle significativo. Para este proceso se aconseja una cámara digital. Al tratarse de material encuadernado, es más oportuno que un escáner de sobremesa, propio para documentos no encuadernados. También se utilizará un soporte para colocar el material que va a ser fotografiado y un trípode para la cámara.

Con la finalidad de conseguir una calidad fotográfica idónea se aplicarán los estándares más adecuados para el fondo antiguo, por ejemplo, los de la Biblioteca del Congreso, institución con gran experiencia en los procesos de digitalización retrospectiva, tanto por el volumen como por la investigación técnica que se está llevando a término. Estos estándares son los que se han empleado en el proyecto American Memory, que reúne una gran cantidad de documentos digitalizados procedentes de unas 90 colecciones históricas, proyecto vinculado a un completo programa de investigación sobre la metodología de la digitalización.

Un importante aspecto a tener en consideración en la actualidad respecto al estudio y difusión de las encuadernaciones artísticas se refiere a las implicaciones que las Nuevas Tecnologías tienen en relación con el libro antiguo. De este modo, elementos como las encuadernaciones constituyen uno de los contenidos más preciados para formar parte de recursos digitales, como catálogos o exposiciones virtuales. En este sentido resulta especialmente interesante y prometedora la línea de investigación que está impulsando el profesor Carpallo en torno a las herramientas para facilitar el estudio y la divulgación de las encuadernaciones. Fruto de ello es su participación en el Catálogo Colectivo de Encuadernaciones Artísticas (CCEA) proyecto que tiene con objetivo último recoger descripciones e imágenes de encuadernaciones artísticas custodiadas en diferentes bibliotecas y archivos de España, planteado como una herramienta de gestión de contenidos, tanto textuales como gráficos, capaz de aglutinar descripciones de encuadernaciones artísticas de diferentes 
instituciones, siguiendo un mismo formato descriptivo para todas ellas. Finalmente, respecto a la normalización para la descripción de las encuadernaciones no existe una uniformidad. Las primeras descripciones más sistematizadas se remontan a 1926, con Johannes Hofmann que promueve realizar una descripción normalizada. También, más tarde, la Verein Deutscher Bibliothekare elabora unas normas para la catalogación de encuadernaciones en bibliotecas. En 1971 el Library Binding Institute de USA publica sus Standard for library binding (revisadas en 1981).

En España se publican en 1964 la $3^{a}$ edición reformada de las Instrucciones para la redacción del Catálogo alfabético de autores y obras anónimas en las Bibliotecas Públicas del Estado. En estas normas se ponen en marcha acuerdos tomados en la Conferencia de París de 1961 organizada por la IFLA. Recogen algunos datos acerca de la descripción de las encuadernaciones. En la III parte, artículo 206, página 138 se refleja lo siguiente:

"Cuando la encuadernación carece de importancia histórica o artística y se juzgue conveniente consignarla, se expresará, mediante las indicaciones usuales, la clase a la que pertenece: Rúst. (rústica)Cart. (cartón)Cartul. (cartulina)Hol. (holandesa)Hol. en tela (holandesa en tela) Pta. (pasta) Pta. en tabla (pasta en tabla) P. de Rusia (piel de Rusia) Zapa, Med. Zapa (media zapa) Bcllo. (becerrillo) Vit. (vitela)Perg. (pergamino)Perg. en cart. (pergamino en cartón) Bad. (badana)Taf. (tafilete)Terciop. (terciopelo) Seda, Tela, Plást. (plástico).

Se consignarán las encuadernaciones notables por su antigüedad o mérito artístico, se dará noticia de sus adornos, del estilo y la época a que corresponden y de los nombres de los encuadernadores si pueden averiguarse. Este último dato deberá ser materia de una nota.

Taf. verde orl., cant. y cort. dor.

Enc. de Pascual Carsí y Vidal.

Bcllo. con arm. de los Reyes de España. 
Se expresará, por tanto, si lleva escudo de armas, iniciales, monograma o algún signo que indique la procedencia del libro, si tiene cantoneras, bollos o cadena; si los cortes son dorados y los cantos labrados, etc.

\section{Perg.}

${ }^{1}$ Esc. de arm. del Príncipe de la Paz.".

En 1974 aparece las normas ISBD (M) y en 1985 las normas ISBD (A) que recogen algunas indicaciones para las encuadernaciones.

Ante esta ausencia de normalización detallada los propios autores e investigadores, relacionados con el estudio de las encuadernaciones, han elaborado sus propios modelos de fichas descriptivas. Así, Hueso Rolland en 1934 utiliza una descripción abreviada con 8 datos (de la obra, de la decoración, las dimensiones, procedencia y signatura). Isabel Ruiz de Elvira en 1992 redacta una ficha descriptiva más completa: datos sobre el material de recubrimiento, soporte, técnica decorativa, dimensiones (alto y ancho, ya en $\mathrm{mm}$.) autor y título de la obra encuadernada, procedencia, signatura y dos grandes apartados, uno para el estado de conservación y otro para la descripción de la decoración y su estructura decorativa. Antonio Carpallo (1999 y 2002) expone unas recomendaciones para la redacción de asientos descriptivos de encuadernaciones, divididos en áreas, secciones y campos, con unas pautas para la normalización de elementos como el nombre de los encuadernadores u otros responsables de la encuadernación, las fechas, las procedencias, etc. La ficha se divide en tres áreas:

- Área de responsabilidad y procedencia de la encuadernación, con el nombre del encuadernador, la fecha, dimensiones (alto, ancho, grosor - mm.) y procedencia.

- Área de descripción de la encuadernación, dividida en cuatro secciones: materiales utilizados, técnicas de encuadernación, decoración (estructura decorativa, utensilios y técnicas decorativas) y estado de conservación.

- Área de descripción del cuerpo de libro. 
Otras fuentes donde se pueden encontrar modelos de descripción son los catálogos de encuadernaciones y las realizadas en los talleres de restauración.

\section{Bibliografía}

Carpallo Bautista, A. (2002). Análisis documental de la encuadernación española: repertorio bibliográfico, tesauro y ficha descriptiva. Madrid: AFEDA, 2002.

Carpallo Bautista, A. (1999). La encuadernación y su descripción. Boletin de la $A N A B A D, 1,227-236$

Chapman, P. (1990). Guidelines on preservation and conservation policies in the archives and libraries heritage. París: UNESCO. Disponible en http://unesdoc.unesco.org/images/0008/000863/086345Eo.pd $\underline{\mathrm{f}}$

Checa Cremades, J.L. (2003). Los estilos de la encuadernación. Madrid: Ollero y Ramos.

Checa Cremades, J.L. (1999). El libro antiguo. Madrid: Acento Editorial. Enciclopedia de la encuadernación (1998). Madrid: Ollero/Ramos.

Escolar Sobrino, H. (dir.) (1993). Historia ilustrada del libro español. De los incunables al siglo XVIII. Madrid: Fundación Germán Sánchez Ruipérez, Pirámide.

IFLA: Principios para el cuidado y manejo del material de bibliotecas (2000). compilado y editado por Edward P. Adcock; con la asistencia técnica de Marie-Thérèse Varlamoff y Virginie Kremp. Santiago de Chile: Centro Nacional De Conservación y Restauración, DIBAM.

Disponible

en https://www.ifla.org/files/assets/pac/ipi/ipi1-es.pdf

IFLA: Principles for the Care and Handling of Library Material (1998). compilado y editado por Edward P. Adcock; con la asistencia técnica de Marie-Thérèse Varlamoff y Virginie Kremp. Paris: IFLA PAC, Washington DR: CLIR. Disponible en https://www.ifla.org/files/assets/pac/ipi/ipi1-en.pdf

ISO 11799: Information and Documentation: Document Storage Requirements for Archive and Library Material (2003). Geneva: ISO. Disponible en https://www.iso.org/obp/ui/\#iso:std:iso:11799:ed-2:v1:fr 
Macarrón, A. (2008). Conservación del patrimonio cultural: criterios y normativas. Madrid: Síntesis.

Marsá Vila, M. (1999). El fondo antiguo en la biblioteca. Gijón: Trea. Martín Abad, J. (2004). Los libros impresos antiguos. Valladolid: Universidad de Valladolid, Secretariado de Publicaciones e Intercambio Editorial.

Normas de conducta ética para bibliotecarios de fondos especiales (2003). Madrid: Ministerio de Educación, Cultura y Deporte, Subdirección General de Información y Publicaciones.

Normas para uso y conservación de los fondos antiguos y valiosos de la Biblioteca de la Universidad de Sevilla (2009). Disponible en https://bib.us.es/conocenos/estrategia/normativa/fondo

Patrimonio bibliográfico bistórico universitario normas y directrices para su tratamiento (1999). Anexo de: Normas y directrices para bibliotecas universitarias y cientificas $2^{\mathrm{a}}$ ed. (documento elaborado por la Red de Bibliotecas Universitarias, REBIUN). Madrid: Ministerio de Educación y Cultura, Dirección General del Libro, Archivos y Bibliotecas.

Pedraza, M.J., Clemente, Y. y Reyes, F. de los (2003). El libro antiguo. Madrid: Síntesis.

Reglamento para uso y conservación de los fondos antiguos y valiosos de la Universidad Complutense de Madrid (1992). Disponible en https://biblioteca.ucm.es/data/cont/docs/60-2014-03-25reglamento280.pdf

Vives Piqué, R (2003). Guia para la identificación de grabados. Madrid: Arco/Libros. 


\title{
Análisis de la información en páginas Web de Portugal, España, Reino Unido y Francia. El caso del comercio electrónico de libros
}

\author{
Ana Isabel Caldes \\ Profesora de Informática \\ Agrupamento de Escolas No3 de Elvas
}

\section{Resumen}

El presente trabajo se basa en el estudio de información presente en los sitios Web que hacen la venta electrónica de libros en Portugal, España, Reino Unido y Francia. El estudio se realiza sobre direcciones Web recuperadas a través del motor de búsqueda Google, con el objetivo de conocer lo que encuentra el usuario cuando navega en la Red. Se estudia el comportamiento del usuario ante la información a través de un instrumento de análisis que nos permite evaluar de forma cuantitativa y cualitativa la información disponible en el sitio Web. Los resultados demuestran que la presencia de las empresas portuguesas, españolas, británicas y francesas tienen que seguir desarrollándose, para mejorar la calidad de los sitios Web con presencia en internet.

\section{Introducción}

TNTERNET ha sido una de las más populares y recientes innovaciones ocurridas en sociedad, que viene proporcionando una serie de transformaciones, en especial, la comunicación y la comercialización de bienes y servicios (Periotto, 2001). Cuando se comenzó a utilizar Internet para fines comerciales se produjeron cambios muy importantes en la economía mundial. Surgió entonces el comercio electrónico (CE) una nueva alternativa para comercializar 
productos, servicios, información y entretenimiento. Cualquier tipo de operación en la que las partes interactúan electrónicamente, es decir, la venta se realiza sin contacto físico directo, se denomina comercio electrónico (Periotto, 2001). Según Heng (2000) el CE se define como "una actividad empresarial directamente relacionada con el comercio de bienes y servicios, y otras actividades relacionadas con el negocio virtual, como medio de transmisión de los activos de información, administración de pagos y de marketing financiero". El comercio electrónico surge como una ampliación de los mercados, siendo una alternativa valiosa; el crecimiento rápido de las aplicaciones y tecnologías para Internet a mediados de la década de los noventa abrió nuevas fronteras para la interacción entre consumidores y empresas (Albuquerque, 2001). La creación de sitios Web es un extra al marketing y al comercio electrónico, pues complementa la actividad de venta directa, proporciona información básica para el usuario/cliente, divulga la imagen de la organización y presenta información complementaria a los consumidores (Loiacono, 2002). El sitio Web es donde se realiza el contacto directo entre la empresa y el usuario/cliente, que posibilita una oportunidad de venta de los productos (Palmer, 1998). La interacción virtual entre el usuario/cliente y la interface del sitio Web, o sea, el facto de que no exista una interacción visual entre el usuario/cliente y el vendedor provoca alteración al comportamiento del usuario/cliente cuando este interactúa con su interfaz. El usuario/cliente no puede comportarse mediante el interfaz del sitio Web de la misma manera como cuando se dirige a la tienda física. Para entender el comportamiento del usuario/ cliente ante la información se torna importante estudiar las características de los sitios Web de comercio electrónico (Zhang, 2007).

\section{Objetivos}

Este trabajo pretende analizar la presencia en la Web de las empresas portuguesas, españolas, británicas y francesas, con especial atención al comercio electrónico de libros. Para ello, estudiaremos diversos aspectos relativos al comercio electrónico por parte de las empresas.

Los objetivos particulares se pueden concretar en los siguientes: 
Elaborar un directorio de Web comerciales de venta de libros de las empresas de Portugal, España, Reino Unido y Francia.

Diseñar y validar un instrumento de análisis de los sitios Web de empresas.

Evaluar cuantitativamente y cualitativamente, el comercio electrónico business-to-consumer (B2C) de libros que las empresas portuguesas, españolas, británicas y francesas hacen en la Web, empleando el instrumento de análisis desarrollado.

Analizar el desarrollo de la venta directa de productos, a través de la World Wide Web, en las empresas.

Analizar los sitios Web de Portugal, España, Reino Unido y Francia, con una metodología basada en el comportamiento humano ante la información (Human Information Behavior - HIB).

Comparar los resultados del análisis por fases de los sitios Web de Portugal, España, Reino Unido y Francia.

Hipótesis

La hipótesis de partida de nuestra investigación es que el diseño delos sitios Web debe centrarse en el usuario/cliente y por tanto el análisis de la recuperación de la información debe estar basado en el comportamiento humano ante la información.

\section{Marco teórico}

\subsection{Comercio Electrónico}

Según Silva (2012) "el comercio electrónico se puede definir como la compra y venta de productos y servicios a través de Internet". Identificamos dos actividades distintas dentro del comercio electrónico: una directa, otra indirecta (Anacom, 2006). El segmento Business-to-Consumer se caracteriza por el establecimiento de relaciones comerciales electrónicas entre empresas y el cliente final. Este tipo de comercio se ha desarrollado con la llegada de la Web, existiendo muchas tiendas y centros comerciales en Internet que comercializan todo tipo de bienes de consumo. 


\subsection{Comercio electrónico y la Industria del Libro}

La actividad editorial es uno de los sectores productivos más valiosos de la actualidad, representa una de las principales actividades, económicas, políticas y culturales de la época contemporánea; desde el punto de vista económico su importancia en el mundo occidental varía dependiendo del país (García, 2011). Para los autores, la implementación de las librerías en Internet para la comercialización de productos fue la principal estrategia adoptada por este sector, para tratar de combatir la crisis. De esta forma existe un contacto más directo entre lectores y autores y se permiten conocer mejor. Según los autores fue de esta manera que comenzaron a surgir las librerías en Internet (Pacheco, 2005; Ferreira, 2010). Los sitios Web de librerías pueden ser de dos tipos, de carácter informativo o pueden ser sitios de comercio electrónico, donde las librerías además de la exposición también venden sus productos. Esta nueva forma de comercio proporciona a los clientes comodidad, pues no tienen que viajar a una librería física a comprar un producto, ya que pueden hacerlo a través del sitio Web de la librería (Costa, 2003).

\subsection{Usuarios}

Los usuarios son una parte importante de las operaciones económicas realizadas en Internet. La oferta de servicios e información en Internet tiene como principal objetivo llegar al usuario y satisfacer sus necesidades (Hernández, 2001).

\section{Comportamiento Humano ante la Información}

El comportamiento de búsqueda de información, es caracterizado por los modelos de búsqueda de información, que es la búsqueda intencionada de información como resultado de la necesidad de alcanzar una meta. Wilson (2000) establece los siguientes tipos de comportamiento humano ante la información: Comportamiento ante la Información, Comportamiento de la Localización de la Información, Comportamiento de la Búsqueda de Información y Comportamiento del Uso de la Información. 


\section{Metodología \\ 4.1 Supuestos de investigación}

Los supuestos de investigación que se pretenden abordar en este trabajo se enuncian a continuación. Para realizar este estudio hemos elegido cuatro países. El criterio utilizado para la selección de los países, Portugal, España, Reino Unido y Francia es que tenían que pertenecer a la Unión Europea. Elegimos Portugal por ser el país de origen del investigador. España fue seleccionada por ser el país donde fue realizada la tesis de doctorado. La situación económica de cada país también tuvo algún peso en la selección de Portugal y España, pues son países que pertenecían en el momento del estudio al grupo PIGS (Portugal, Italia, Grecia y España) por ser considerados países económicamente vulnerables en razón del elevado o creciente endeudamiento y del elevado déficit público con relación al Producto Interno Bruto. Seleccionamos los países Portugal, España y Francia por su proximidad geográfica y el país Reino Unido por la facilidad en el dominio del idioma en que las páginas se presentan.

Seleccionamos para este trabajo la industria del libro, por ser una industria que se ha adaptado bien a Internet, los productos de esta industria están entre los más buscados y adquiridos a través de Internet (CE, 2012).

Para realizar este estudio tomamos la decisión de buscar en la Web para recuperar las páginas de las librerías. El motivo que nos llevó a buscar en la Web es que pretendemos saber lo que encuentra el usuario común cuando navega en la Web, que tipo de páginas están disponibles y que venden. El criterio de selección utilizado para recuperar páginas Web fue: que vendan libros en línea. Utilizamos motores de búsqueda para localizar las páginas en línea porque es el método más usado por los usuarios para localizar páginas de venta en línea (Díaz, 2006; Purcell, 2012).

Una vez seleccionado el material de estudio se procedió al análisis cuantitativo y cualitativo de las páginas Web recuperadas. La selección de las características para realizar el análisis cuantitativo y cualitativo de las páginas Web, sigue la literatura existente sobre el tema. No seguimos las características de un único estudio, hemos elegido seleccionar las características más objetivas, o sea, aquellas que no generan dudas, de 
cada uno de los estudios presentados. La tabla de características fue realizada según el ciclo de compras de Vander Merwe y James Bekker (2003) que divide el proceso de la compra en cuatro fases que corresponden con las definiciones sobre el comportamiento humano ante la información a que se refiere Wilson (2000).

FASE 1. RECONOCIMIENTO DE NECESIDADES: Visita a los sitios Comportamiento ante la información, Information behaviour. En la primera fase se analizan aspectos que llevan al cliente a reconocer el sitio Web como lo que va a satisfacer sus necesidades de compra en línea. Así son analizados aspectos relacionados con la presentación de la información en la Web, evaluando la primera impresión que el sitio Web ha producido en el usuario.

FASE 2. NAVEGAR: UsABILIDAD. Reunir información sobre el producto a comprar, Information Seeking Behaviour. Esta fase representa la búsqueda consciente de información como consecuencia de una necesidad. El usuario accede a la Red y navega por el sitio Web. En esta fase son valorados aspectos de usabilidad del sitio Web.

\section{FASE 3. REUNIR Y EVALUAR LA INFORMACIÓN: CONTENIDOS}

COMERCIALES. Analizar el contenido del sitio, Information Searching Behaviour. Esta fase representa el análisis del contenido del sitio Web donde se produce una interacción del usuario/cliente a través de la navegación por el sitio para encontrar información. El usuario busca información consciente del producto que desea comprar. Si leinteresa el producto buscará información sobre la empresa principalmente para conocer datos concretos y saber si el sitio Web demuestra confianza. Por lo tanto, la información que se estudia es aquella que genera confianza al usuario/cliente.

\section{FASE 3. REUNIR Y EVALUAR LA INFORMACIÓN: CONTENIDOS} CORPORATIVOS. Analizar el contenido del sitio, Information Searching Behaviour. En esta fase es importante conocer la información sobre la empresa para que el usuario/cliente conozca quien vende y a su vez generar confianza en el sitio Web. 
FASE 4. REALIZAR LA COMPRA: FIABILIDAD - REALIZAR LA COMPRA, INFORMATION USE BEHAVIOUR.

En esta fase el cliente realiza la compra y llegado a este punto el usuario/cliente ya incorpora la información al conocimiento. Mentalmente la nueva información es comparada a la información más antigua y el usuario/cliente decide Qué, Dónde y Cómo comprar. Los parámetros estudiados son aquellos que generan fiabilidad y ayudan el usuario/cliente a decidir si compra el producto.

\subsection{Obtención de la muestra}

Para nuestro estudio consideramos cuatro poblaciones: la primera es constituida por empresas portuguesas con presencia en la Web y que practican el CE de libros -B2C, la segunda es constituida por las empresas españolas con presencia en la Web y que practican el CE de libros-B2C, la tercera es constituida por las empresas británicas con presencia en la Web y que practican el CE de libros-B2C y la cuarta es constituida por empresas francesas con presencia en la Web y que practican el CE de libros-B2C. Decidimos trabajar con cuatro poblaciones para analizar la presencia en la Web de las empresas de Portugal, España, Reino Unido y Francia con especial atención al comercio electrónico de libros. En nuestro estudio no existe una base de la muestra, pues no existe una lista única que identifique para cada país del estudio las empresas con sitios Web de librerías que hacen comercio electrónico-B2C de libros. Esto ocurre debido a la facilidad que las empresas tienen en crear un sitio Web en Internet, dificultando así su control. Para nuestro estudio elegimos un muestreo no probabilístico por conveniencia. Este tipo de muestreo integra elementos en la muestra seleccionados por conveniencia, los elementos constituyentes son seleccionados en función de su disponibilidad o por su accesibilidad (Zikmund, 1997). Ha sido seleccionado un muestreo de 100 direcciones de sitios Web de páginas comerciales de venta de libros para cada país, de un total de 1323 direcciones. El tamaño de la muestra seleccionado se justifica con la economía de tiempo y recursos. Las direcciones Web recuperadas del motor de búsqueda Google han sido ordenadas por orden de búsqueda, seguidamente se atribuyó a cada dirección un número. Los elementos de la muestra han sido seleccionados a través de un script de programación que genera números al azar. 
El script de programación recibe un número mínimo (1) y un número máximo (número de direcciones recuperadas por país).

\subsection{El estudio}

Después de seleccionar los elementos de la muestra aplicamos la tabla de características a cada dirección Web de la muestra y recopilamos los datos analizando los sitios Web y guardando los datos en una hoja de cálculo del software Microsoft Excel. Para recopilar los datos del estudio se ha utilizado una tabla de características. La tabla ha sido elaborada teniendo por base estudios de otros autores (Merwe, 2003; Quaresma, 2005; Openheim, 2006; Fernández-Falero, 2011; Hurtado, 2013). Los parámetros considerados en la tabla de características son los más objetivos, no generan dudas. La tabla de características se divide en cuatro fases representando el comportamiento humano ante la información (Wilson, 2000). La recopilación de los datos se ha hecho para una hoja de cálculo del software Microsoft Excel. Las direcciones de los sitios Web han sido analizadas observando cada parámetro de la tabla de características, la presencia del parámetro en el sitio Web fue asignada en la hoja de cálculo del software Microsoft Excel con el valor 1 y la no existencia del parámetro ha sido asignada con el valor 0 .

\section{Resultados}

\subsection{Resultados del análisis cuantitativo y cualitativo}

Las direcciones de los sitios Web han sido analizadas observando cada parámetro de la tabla de características, la presencia del parámetro en el sitio Web fue asignada en la hoja de cálculo del software Microsoft Excel con el valor 1 y la no existencia del parámetro ha sido asignada con el valor 0 .

En cuanto al análisis de las fases, se demuestra que las fases dos y tres (Tabla 1) son las fases más cuidadas por los sitios Web analizados de los cuatro países, entre 50\% y 70\% (Tabla 1) Con relación al total por fases, la tercera fase relacionada con los contenidos comerciales es la más cuidada, con $70 \%$, de modo que la imagen del producto es el aspecto más valorado por todos los sitios Web de todos los países, seguido de la segunda fase, con 56\% (Tabla 1) mostrando que la navegación por el sitio Web es valorada por las empresas de los sitios Web evaluados. Seguido de la información corporativa, con 53\% (Tabla 1) de manera que los sitios Web analizados están muy preocupados por la imagen que pasan al usuario/cliente. 
La fase cuatro, es donde se hace la venta del producto, teniendo en cuenta su importancia en la finalización de la compra, es una fase poco cuidada, con 39\% (Tabla 1). Por último, la primera fase con $20 \%$ (Tabla 1) demuestra que los sitios Web analizados no valoran los aspectos que hacen que el comprador permanezca en la página en el primer contacto.

Tabla 1. Resumen de los resultados obtenidos para cada país por fases.

\begin{tabular}{|c|c|c|c|c|c|c|c|c|c|c|c|c|}
\hline \multirow{2}{*}{ ESCENARIO } & \multicolumn{2}{|c|}{ FASE $1-R$} & \multicolumn{2}{|c|}{ FASE 2 - $R$} & \multicolumn{2}{|c|}{ FASE $3-1-R$} & \multicolumn{2}{|c|}{ FASE $3-2-R$} & \multicolumn{2}{|c|}{ FASE 4- $R$} & \multirow{2}{*}{$\begin{array}{c}\text { TOTAL POR } \\
\text { PAÍS }\end{array}$} & \multirow{2}{*}{$\begin{array}{l}\text { PORCENTAUE } \\
\text { POR PAÍS }\end{array}$} \\
\hline & Observado & Máximo & Observado & Máximo & Observado & Máximo & Observado & Máximo & Observado & Máximo & & \\
\hline \multirow{2}{*}{ PORTUGAL } & 130 & 800 & 551 & 1000 & 672 & 1000 & 735 & 1500 & 522 & 1400 & 2610 & 5700 \\
\hline & $16 \%$ & $100 \%$ & $55 \%$ & $100 \%$ & $67 \%$ & $100 \%$ & $49 \%$ & $100 \%$ & $37 \%$ & $100 \%$ & $46 \%$ & $100 \%$ \\
\hline \multirow{2}{*}{ ESPAÑA } & 148 & 800 & 566 & 1000 & 679 & 1000 & 801 & 1500 & 617 & 1400 & 2811 & 5700 \\
\hline & $19 \%$ & $100 \%$ & $57 \%$ & $100 \%$ & $68 \%$ & $100 \%$ & $53 \%$ & $100 \%$ & $44 \%$ & $100 \%$ & $49 \%$ & $100 \%$ \\
\hline \multirow{2}{*}{ REINO UNIDO } & 171 & 800 & 556 & 1000 & 716 & 1000 & 815 & 1500 & 518 & 1400 & 2776 & 5700 \\
\hline & $21 \%$ & $100 \%$ & $56 \%$ & $100 \%$ & $72 \%$ & $100 \%$ & $54 \%$ & $100 \%$ & $37 \%$ & $100 \%$ & $49 \%$ & $100 \%$ \\
\hline \multirow{2}{*}{ FRANCIA } & 201 & 800 & 566 & 1000 & 715 & 1000 & 845 & 1500 & 549 & 1400 & 2876 & 5700 \\
\hline & $25 \%$ & $100 \%$ & $57 \%$ & $100 \%$ & $72 \%$ & $100 \%$ & $56 \%$ & $100 \%$ & $39 \%$ & $100 \%$ & $50 \%$ & $100 \%$ \\
\hline \multirow{2}{*}{$\begin{array}{l}\text { TOTAL POR FASE } \\
\text { PORCENTAUE POR } \\
\text { FASE }\end{array}$} & 650 & 3200 & 2239 & 4000 & 2782 & 4000 & 3196 & 6000 & 2206 & 5600 & & \\
\hline & $20 \%$ & $100 \%$ & $56 \%$ & $100 \%$ & $70 \%$ & $100 \%$ & $53 \%$ & $100 \%$ & $39 \%$ & $100 \%$ & & \\
\hline
\end{tabular}

Fuente: elaboración propia.

Los países que mejor cuidan la fase unos son, Francia y Reino Unido con 25\% y 21\% (Tabla 1). Los países que mejor cuidan la fase dos son, Francia y España con 57\% (Tabla 1). Los países que mejor cuidan la fase tres, con relación a los contenidos comerciales son, Francia y Reino Unido con $72 \%$ (Tabla 1) y con relación a los contenidos corporativos son, Francia con 56\% (Tabla 1) seguido del Reino Unido con 54\% (Tabla 1). Los países que mejor cuidan la fase cuatro son, España y Francia con 44\% y 39\% (Tabla 1).

\section{Conclusiones}

Los resultados obtenidos en este trabajo permiten responder a los supuestos de investigación planteados más arriba.

Con relación al $1^{\circ}$ objetivo - El directorio de empresas de los sitios Web comerciales, que hacen la venta de libros, representa la situación de las librerías de los cuatro países estudiados, en un determinado período y es también un repositorio de información. 
Con relación al $2^{\circ}$ objetivo - Para mejorar la presencia de las empresas en Internet, utilizamos un instrumento de análisis para la evaluación de los sitios Web. El instrumento se caracteriza por su objetividad, lo que simplifica su aplicación como tal, se eliminaron los aspectos subjetivos del análisis. La validación de nuestro instrumento de análisis se traduce en los resultados y conclusiones que se presentan. Se muestra que la metodología es válida.

Con relación al $3^{\circ}$ objetivo - Las empresas estudiadas que hacen comercio electrónico de libros muestran que existe preocupación con los aspectos informacionales del sitio en línea, sin embargo, en algunos casos se podría mejorar. Esta preocupación refleja la característica principal del comercio electrónico, que es la comodidad. El comprador, desde su casa, visita cualquier sitio, en cualquier parte del mundo y en cualquier momento.

La falta de información durante las cuatro fases estudiadas puede comprometer el proceso de compra a través de Internet, en el sitio Web seleccionado por el usuario/cliente. Un usuario/cliente que no encuentra la información necesaria y/o deseada, puede no ser capaz de hacer la compra. Por lo tanto, su insatisfacción no permitirá, sin duda, que vuelva al sitio Web.

Con relación al $4^{\circ}$ objetivo - Se puede concluir, que la venta directa, en la industria del libro, se está expandiendo, permitiendo al usuario/cliente, la adquisición cómoda del producto. Revela una adaptación a los nuevos mercados, potencia nuevos autores y se puede revelar muy beneficioso para el desarrollo de la actividad empresarial.

Con relación, al $5^{\circ}$ objetivo $-1^{a}$ Fase del comportamiento ante la información $\rightarrow$ Concluimos que Francia, seguida de Reino Unido, España y Portugal, valoran la importancia de que la información llegue al comprador, de una manera pasiva, como la publicidad; no hay búsqueda activa por parte del usuario/cliente, generando una sensación de que este sitio Web, se adapta a sus necesidades de compra y como tal no se irá del mismo. 
Con relación al $5^{\circ}$ objetivo $-2^{a}$ Fase del comportamiento de localización de información $\rightarrow$ Concluimos que España y Francia, seguido por el Reino Unido y Portugal, valoran los parámetros que facilitan la localización de información en los sitios Web, mediante una navegación fácil, a través del sitio, de forma que la información disponible genera al usuario/cliente, que este sitio Web satisface sus necesidades.

Con relación al $5^{\circ}$ objetivo - $3^{a}$ Fase del comportamiento de búsqueda de información $\rightarrow$ En relación con los contenidos comerciales, se destaca Francia y Reino Unido, seguido de España y Portugal. En comparación con los contenidos corporativos, tenemos Francia seguido por el Reino Unido, España y Portugal. Concluimos que, para ambos, los contenidos, la demanda consciente del usuario/cliente es un aspecto muy valorado por Francia y Reino Unido. Estos países consideran que es importante que el usuario/cliente encuentre el producto que desea y con las características que desea. Con relación a la información corporativa, el sitio Web, al proporcionar su información, presenta una imagen seria al usuario/cliente.

Con relación al $5^{\circ}$ objetivo - $4^{a}$ Fase del comportamiento de uso de la información $\rightarrow$ Se concluye que España, seguida de Francia, Portugal y Reino Unido, valoran los parámetros que faciliten la compra en los sitios Web, cuidando mucho los aspectos de la información que generan, seguridad y fidelidad al usuario/cliente, lo que permite realizar la compra y ofrecer un servicio post-venta.

Con relación al $6^{\circ}$ objetivo - Concluimos que Francia es el país que cuida mejor todas las fases, seguido de España y Reino Unido y por último, Portugal.

Con relación al objetivo general - Concluimos que la presencia de las empresas de los cuatro países estudiados tiene que seguir desarrollándose, para mejorar la calidad de los sitios Web, con presencia en la Web. 
La hipótesis de partida de nuestra investigación es que el diseño de los sitios Web debe centrarse en el usuario/cliente y por tanto el análisis de la recuperación de la información debe estar basado en el humano ante la información. Validamos a través de la revisión bibliográfica, que el diseño de los sitios Web basados en el comportamiento humano ante la información es adecuado para realizar ventas a través de Internet, ya que se centra en el usuario/cliente.

\section{Bibliografía}

Albuquerque, A. (2001). Qualidade de Websites de comercio electrónico [en línea]. [Tesis de Máster] Universidad de Fortaleza, Brasil. Disponible en http://www.livrosgratis.com.br/arquivos livros/cp0045 79.pdf.

ANACOM (2006). Serviço de acesso à Internet - $4^{\circ}$ semestre [en línea]. Disponible

en http://www.anacom.pt/streaming/manual_comercio_elec.pdf?c ontentId=178219yfield=AT'TACHED_FILE.

Caldes, Ana Isabel P. (2014). Análisis de la información en páginas web de Portugal, España, Reino Unido y Francia. El caso del comercio electrónico de libros [Tesis doctoral] Universidad de Extremadura, Departamento de Información y Comunicación.

CE (2004). European Union public opinion on issues relating to business to consumer E-Commerce [en línea]. European Commission. Disponible en: Http:/ / europa.eu.int/comm/consumers/topics/ecommerce_2004_en.pdf.

Costa, A., Palheta, A., Mendes, A. y Loureiro, A. (2003). Industria cultural: revisando Adorno e Horkheimer. Movendo Idéias, 8(13), 13-22. Disponible http://www.cristhianlima.com.br/wpcontent/uploads/2011/11 $/$ IND $\%$ C3\%9ASTRIA-CULTURAL-REVISANDO$\mathrm{C} \% \mathrm{C} 3 \% \mathrm{~B} 3$ pia.pdf. 
Díaz, P., Guevara P, A. J. y Clavé, A. S. (2006). La presencia en Internet de los municipios turísticos de sol y playa: Mediterráneo y Canarias. En Turitec: VI Congreso nacional turismo y tecnologías de la información y las comunicaciones. Escuela Universitaria de Turismo. Disponible en: http://www.turitec.com/actas/2006/L29lapresenciaeninternetde stinoscanarias.pdf.

Fernández-Falero, M. R. y Peral, D. (2001). Comportamiento humano de la información comercial: teleformación en España. Information research, 16(1), Disponible en http:/ / www.informationr.net/ir/161/paper459.html.

Ferreira, P. (2010). Mercado livreiro em mutação [en línea]. [consulta: 21 de diciembre de 2010]. Disponible en Http://www.expressodasnove.pt/noticia.php?id=846.

García, J., Díaz, R. y Arévalo, J. (2011). Gutenberg 2.0, la revolución de los livros electrónicos. España: Ediciones Trea.

Heng, M. S. H. (2000). Understanding electronic commerce from a historical perspective. Research Memorandum, 38. Disponible en Http://netec.mcc.ac.uk/WoPEc/data/Papers/ dgrvuarem200038.html.

Hernández, P. (2001). La producción del conocimiento científico como base para determinar perfiles de usuarios. Investigación Bibliotecológica: archivonomía, bibliotecología e información, 5(30), 30-64. Disponible en http://www.revistas.unam.mx/index.php/ibi/article/view/39 $69 / 3521$.

Hurtado, M. A. (2013). Comercio electrónico extremeño: estudio cualitativo (2006) y cuantitativo de websites empresariales (20032007 y 2011). [Tesis Doctoral]. Departamento de Información y Comunicación, Universidad de Extremadura. Disponible en: http://dehesa.unex.es:8080/xmlui/bitstream/handle/10662/578 /TDUEX_2013_Hurtado_Guapo.pdf?sequence=1. 
Loiacono, E., Watson, R. y Goodhue, D. (2002). WebQual(tm): A Web site quality instrument. En: Conference, American Marketing Association: Winter Marketing Educators. Austin, Texas. USA, [consulta: 01 de September de 2013]. Disponible en: http:/ / books?id=c7cLBAAAQBAJypg=PA48ylpg=PA48ydq=W ebQual $(\mathrm{tm}):+\mathrm{A}+\mathrm{Web}+$ site+quality + instrument.+En:+Conferen ce,+American + Marketing + Association:+Winter+Marketing + Ed ucatorsysource $=$ blyots $=$ cy $13 \mathrm{~A} \% 20 \mathrm{C}$ onference $\% 0$ Educators.

Merwe, R. y Bekker, J. A (2003). framework and methodology for evaluating e-commerce web sites. Internet Research: electronic Networking Applications and Policy 13(5), 330-341. Disponible en: http://www.emeraldinsight.com/journals.htm?articleid=863787.

Openheim, C. y Ward, L. (2006). Evaluation of web sites for B2C ecommerce. Aslib Proceedings New Information Perspectives, 58(3), 237260.

Disponible

en:

Http:/ /www.mendeley.com/catalog/evaluation-web-sitesb2c-ecommerce.

Pacheco, A. y Alves, C. (2005). Indústria da edição de livro em Portugal [en línea]. Bibvirtual. Disponible en http://bibvirtual.blogs. sapo.pt/48121.html.

Palmer, J. y Griffith, D. (1998). An emerging model of Web site design for marketing. Communications of the ACM 41(3), 44-51. Disponible en http://dl.acm.org/citation.cfm?id=272296.

Periotto, A. J. et al. (2001). Comércio electrónico: características e barreiras. Caderno de Administração 9(2), 77-96. Disponible en: http://www.scielo.br/pdf/rac/v3n1/v3n1a05.pdf.

Purcell, K., Brenner, J. y Rainie, L. (2012). Search Engine Use [en línea]. Un projeto de Pew Research Center's Internet y American Life Project. Disponible en: http://www.pewinternet.org/2012/03/09/search-engine-use2012/. 
Quaresma, R. F. C. (2005). Presencia de las empresas españolas y portuguesas en Internet. Especial atención al comercio electrónico. [Tesis Doctoral]. Departamento de Economía Financiera y Dirección de Operaciones, Universidad de Sevilla. Disponible en http://dspace .uevora.pt/rdpc/requestitem?handle $=10174 / 2335$ ybitstream $-i d=3493$.

Silva, K., Almeida, R. y Rolim, V. (2012). Consumo na era digital: comportamento do consumidor [en línea]. [consulta: 04 de Agosto de 2013]. Disponible en: Http://vanessagomesrolim.files.wordpress.com/2012/10/comp ortamento-do consumidor-consumo-na-era-digital3.pdf.

Wilson, T. D. (2000). Human information behavior. Informing Science, 3(2), 49-56. Disponible en: http://inform.nu/Articles/Vol3/v3n2p49-56.pdf.

Zhang, X., Prybutok, V.R. y Strutton, D. (2007). Modeling influences on impulse purchasing behaviors during online marketing transactions. Journal of Marketing Theory and Practice, 15(1), 79-89. Disponible en: http://connection.ebscohost.com/c/articles/23756234/modelli ng-influences-impulse-purchasing-behaviors-during-onlinemarketing -transactions.

Zikmund, W. G. (1997). Exploring marketing research. USA: The Dryden Press. 



\title{
Lectura, género, penitenciaría: apuntes sobre metodología de una investigación cualitativa
}

\author{
Paula Sequeiros \\ Investigadora del Centros de Estudios Sociales - CES \\ Universidad de Coímbra
}

\section{Resumen}

El propósito de este texto es tanto compartir dudas y comentarios, como traer a debate algunas soluciones que se presentaron durante mi investigación en una cárcel femenina. Este proyecto fue conducido por medio de un trabajo de campo en el Estabelecimento Prisional Especial de Santa Cruz do Bispo, durante cuatro meses en el 2012.

Las editoras de este libro me propusieron desarrollar un texto que se dirigiera a las y los investigadores y profesionales que se enfrentan con la literatura publicada y con el diseño de investigación. Lo haré a partir del cruce interdisciplinario de algunas áreas: lectura, bibliotecas penitenciarias, sociología de la cultura y de la vida penitenciaria. Mi reciente participación en un seminario en la Facultad de Ciencias de la Documentación y la Comunicación, de la Universidad de Extremadura, Badajoz y el debate entre colegas que allí tuvo lugar, crearon el momento propicio para que yo retome este tema. Para evitar redundancias en relación a lo que ya he dicho, apunto para mis trabajos publicados donde algunos de los problemas que plantearé ya fueron abordados en detalle. Paralelamente me referiré a alguna literatura que considero es una buena base para un estudio profundo de temas más polémicos o menos divulgados. 


\section{Introducción}

- UÉ USO le dan a la biblioteca penitenciaria las mujeres detenidas en Santa Cruz do Bispo? ¿Qué leen? ¿Qué prácticas de lectura desarrollan? ¿Cuándo y dónde leen? ¿Por qué leen? Este fue un conjunto de preguntas de partida que motivaron la investigación cualitativa que realicé en esta prisión femenina, orientada a comprender procesos y agentes. Más tarde agregué otros interrogantes: ¿Cuáles son sus preferencias? ¿Siguen alguna orientación en la lectura y de quién? ¿Cómo cambian los significados de la lectura en el contexto penitenciario?

Atendiendo al contexto penitenciario, las preguntas siguieron siendo afinadas y también comenzaron a indagar en los significados atribuidos tanto por las lectoras, como por el personal de la cárcel con quienes más se contactaban y también por los responsables de la biblioteca. La administración y operación de la prisión se hacía, en aquel momento, por funcionarios del Ministerio de Justicia. Bajo una alianza públicoprivada, el área educativa, donde se incluía la biblioteca, era administrada por una institución religiosa caritativa y de asistencia social.

El análisis deseado buscó conjugar estos temas con dimensiones sociales tales como: clase social, género, etnia o raza, edad, ocupación y educación de las mujeres privadas de libertad que participaron en esta investigación con sus interacciones, cuestionamientos y respuestas.

Para la comprensión de los procesos de lectura enclaustrada y de la intervención de diversos agentes sociales (lectoras, guardias, servicio educativo penitenciario) se requirió de un enfoque integral y una indagación profunda de las realidades aludidas (lecturas de mujeres, prisiones femeninas) que, siendo complejas, son terreno de debates científicos y disputas políticas. En trabajos anteriores ya abordé la caracterización social de esta población penitenciaria (Sequeiros 2016; 2018).

Antes y durante las visitas que realicé a la prisión, recurrí a literatura científica sobre la lectura femenina en prisión. Tomé como base teórica algunos textos que adoptaron una perspectiva crítica (Cunha 2002) con enfoque de género (Fonseca 2010; Myers 1996) no únicamente sobre 
el sistema penitenciario sino también en relación a las prácticas de lectura de mujeres dentro de la prisión. Este proceso investigativo implicó, por lo tanto, que los interrogantes planteados en campo mismo se alimentaron de más teoría, pasando con frecuencia, por una validación y ajuste del diseño de este proyecto según los acontecimientos inesperados o intrincados que fueron apareciendo, hasta llegar a la redacción de las conclusiones. Las secciones From Theory to the Research Questions y The Research Process (Sequeiros 2018) fueron dedicadas a la relación entre teoría, problemáticas iniciales y el desarrollo del proyecto alrededor de este caso. El enfoque de género fue una vez más relevante en el momento de escuchar e interpretar los modos de lectura en la prisión femenina (McRobbie 2009).

En las secciones siguientes destaco cuestiones que frecuentemente generan preguntas sobre las opciones de diseño de un proyecto investigativo, resaltando algunos temas de carácter epistemológico y metodológico.

\section{Problemáticas epistemológicas}

¿Qué tenía de particular esta área de estudio? ¿En qué se distingue, bajo el enfoque que me interesó, de otras investigaciones? ¿Existían vacíos o saltos explicativos que despertasen mi atención o curiosidad? A partir de esta perspectiva, ¿Cómo se planteaba la producción de conocimiento sobre aquella población, sobre sus prácticas y significados? Iniciando, realmente yendo y viniendo a lo largo de todo el trabajo, entre lo empírico y la teoría ¿Qué es lo que pretendía cuestionar, comparar, completar, rehacer?

Una perspectiva que entendí era fructífera y fundamental, fue la que trazó el camino para la comprensión del sistema penitenciario actual: los aportes feministas ganaron relevancia, tanto por tomar a las mujeres como centro de análisis, dentro de un sistema particular de dominación, como principalmente, por las relaciones históricas de género presentes en el sistema penitenciario (Bosworth 2000).

Entre los estudios sobre prisiones me fue posible también encontrar literatura, principalmente de orientación feminista, que debatía aspectos teórico-prácticos. Algunas de esas cuestiones, planteadas por la ética que pretendí imprimir a la investigación, encontraron pistas y 
soluciones que adopté y recreé (Zaitzow y Thomas 2003) frente a las situaciones concretas en las que me involucré. A continuación, repaso algunas de mis preocupaciones:

- Tratar respetuosamente a las mujeres detenidas, evitar la condescendencia de la investigadora "de afuera", evitar los juicios moralistas en relación a sus condenas o sus conductas en prisión;

- Orientar esta investigación de la manera menos intrusiva posible, proteger la identidad de las detenidas;

- Considerar que se habían hecho recientemente reportajes periodísticos sobre este centro y que la condición de reclusa puede ser vergonzosa si es conocida en ciertos casos. Con estos antecedentes, les propuse que escogieran un seudónimo de su agrado, lo que también permitiría a cada participante identificarse en los textos que se publicarían;

- Diseñar el proyecto de investigación de forma tal que refleje estos posicionamientos y luego operar tanto en el trabajo de campo como en la producción de comunicación científica;

- Comprender que el análisis de mi experiencia sobre la vida penitenciaria, partiendo de prácticas "micro", a escala individual o en pequeños grupos y basada en una parte de su experiencia en la cárcel, podría ser propuesta como una contribución para una visión "macro", o amplia, del mundo penitenciario femenino, buscando agregar densidad a partir de un caso situado en un contexto y momento concreto.

\section{Enfoque cualitativo}

La biblioteca del Estabelecimento Prisional Especial (EPE) de Santa Cruz do Bispo mostró ser un lugar interesante, desde el punto de vista social, para investigar la lectura en bibliotecas.

Inclusive, esta biblioteca tenía como lectoras, en buena medida, a mujeres de clases populares, lo que no es frecuente en Portugal. Como pude constatar, poquísimas de las mujeres que contacté habían alguna vez entrado a una biblioteca.

Cabe señalar que no existían programas institucionales para la lectura en prisiones, ni a nivel nacional ni en el municipio correspondiente. 
Dadas las características del terreno investigado, la singularidad de las situaciones que pretendí resaltar, la reflexividad que busqué, especialmente para una reconstrucción adecuada de la teoría, adopté el Método de Estudio de Caso Extendido de Michael Burawoy (1998). Sobre este método escribió también Silva (2018). Donmoyer (2000) analiza en detalle las ventajas de los casos singulares, proporcionando argumentos teóricos para su uso. Adelanta, en particular, respuestas sobre cómo los resultados y conclusiones de los estudios de caso se dirigen a lo particular, en lugar de a la generalización en contextos diferentes.

De esta manera, recurrí a un enfoque cualitativo e integrado, en lugar de seleccionar un conjunto de métodos y técnicas derivadas de sus rasgos intrínsecos. Este enfoque fue moldeado por las problemáticas epistemológicas antes referidas y estas, a su vez, enmarcaron la opción metodológica.

\section{Metodología y herramientas de investigación}

¿Por qué cualitativa? Porque lo que pretendí fue centrarme en un conjunto de principios a lo largo del proceso de investigación:

- Comprensión profunda de fenómenos y procesos, para evitar una lista de hechos o datos aisladamente considerados y, por lo tanto, con poca capacidad de proporcionar esa comprensión integral y profunda procurada;

- Integración de la realidad estudiada en el contexto histórico y social, especialmente relevante dada la historia de la prisión (Bosworth 2000) como institución (Sweeney 2008; 2010; Zaitzow y Thomas 2003) y la caracterización social de las detenidas que eran predominantemente madres de clase trabajadora, con baja inversión de capital escolar. Las detenidas racializadas, principalmente gitanas y negras, conformaron un grupo con una representación muy superior a la estimada para esta población en el país en general (Sequeiros 2018, 114-115);

- Superación de jerarquías (investigadora/detenidas) y de juicios moralistas; la investigación se dirigió principalmente a las mujeres en tanto que lectoras, o no lectoras; su clasificación dentro del sistema penal o las razones de su detención o condena no fueron 
cuestionadas en las entrevistas individuales o colectivas, a pesar de que fueron frecuentemente señaladas por ellas mismas;

- Valorización social y política de escuchar, transcribir, entender y sentir para restituir la voz a esas mujeres. El análisis e interpretación de conversaciones y de narrativas, en el transcurso de la observación de las prácticas de uso de la biblioteca o de las entrevistas conducidas, fue uno de los aspectos más complejos de esta investigación - que pretendió evitar un posicionamiento condescendiente o intrusivo -, en un espacio donde las detenidas eran particularmente sensibles a procesos de control yvigilancia, despersonalización, desempoderamiento y dependencia al sistema penitenciario.

Tómese en cuenta la declaración de un prisionero en los Estados Unidos cuestionando a Bosworth $(2005,252)$ :

Sólo porque escribiste ese libro, porque eres una editora, una profesora en una universidad, tan entendida... ¡Nada eso significa una maldita cosa! ¡No significa que sepas una maldita cosa! ¿Cuánto tiempo has hecho? ¿Cuántos cacheos al desnudo? ¿Cuántas horas encadenadas? ¿Cuántas palizas? ¿Cuántas brutalidades? ¡Tú no sabes nada! ¡Todo lo que sabes (de la verdad) es lo que nosotros te decimos! ¿Estás escuchando? ¿Estás realmente escuchando?

- Atención especial a los significados construidos por ellas mismas para sus lecturas y preferencias; véase Representationand significance of Reading (Sequeiros 2018, 119-120):

Cada caso es un caso, somos todas iguales y todas diferentes, es decir, somos todas iguales porque estamos todas en la misma situación, somos todas diferentes porque cada una de nosotras tenemos su propio tipo de lectura.

Declaración de Celeste, bibliotecaria en Santa Cruz do Bispo: (Sequeiros 2018, 114-115);

El análisis de estos significados dio relevancia al modo de lectura en contextos carcelarios, tal como lo señalaron Kathleen J. Ferraro y Angela M. Moe (2003) que no se explica por una simple 
lectura pasiva de identificación especular con el texto, que fue particularmente importante en el análisis de la lectura de géneros literarios y títulos preferidos. Este modo incluía las posibilidades emocionales y cognitivas de que la lectura representara escape, consolación, exaltación, autoconocimiento, revisión del pasado y pensamiento prospectivo sobre la vida después de la detención y de desarrollo de competencias de alfabetización.

- Apertura a lo inesperado, a lo contradictorio y complejo. La investigación se movió de los usos de la biblioteca para centrarse en un tema que me pareció importante para la comprensión de las preferencias de lectura: la incidencia en un pequeño espectro de géneros literarios clasificables como literatura industrial. La colección, casi en su totalidad, no les generaba interés alguno y consideraban que no respondía a sus capacidades de lectura o su capital cultural; las representaciones sobre la lectura de los bestsellers, los propósitos y significados atribuidos a esta lectura en un contexto penitenciario eran variados y no estaban sobre determinados por los orígenes sociales de las lectoras, pero sí asociados a sus competencias y hábitos de lectura adquiridos en el transcurso de sus vidas (Sequeiros 2016, 170-176);

- Interpretación de la realidad investigada: involucramiento con las mujeres detenidas y algunos miembros del personal penitenciario con quienes fueron debatidos los resultados y conclusiones preliminares, antes de la comunicación pública;

- Preocupación con las opresiones interconectadas de género, raza, y clase social, experimentadas por las mujeres detenidas. Dado el compromiso social que expresé en la investigación, tienesentido que lo escriba y comunique en primera persona, reflejando no solo una participación científica no-neutral con la realidad social investigada, sino también, la responsabilidad autoral por el trabajo de interpretación de esa realidad; adicionalmente, entiendo que así puede evitarse la impersonalidad de una escritura distante y desconectada de problemas sociales fuertes.

En los siguientes párrafos adelantaré algunos detalles sobre los caminos que tomé durante el proceso y que moldearon el proyecto de investigación. A diferencia de la investigación estadística, la 
cualitativa recurre a métodos de recolección y análisis de datos escogidos por su adecuación a las preocupaciones antes referidas.

Con este propósito, partí de los datos estadísticos registrados en la prisión que visité, para reunir insumos previos que me permitiesen establecer una muestra significativa de la población detenida en este centro y que incluyera diversas dimensiones - edad, educación, raza, ocupación - conteniendo simultáneamente, mujeres que frecuentan la biblioteca de la prisión. En relación al tema del muestreo cualitativo, el artículo sampling, qualitative (purposive) en Ritzer y Ryan (2011) proporciona una comprensión integral.

Durante la investigación se planteó también la importancia de incluir diferentes edades - muchas mujeres de la tercera edad habían sido encarceladas en ese momento -, incluir interlocutoras de diferentes lenguas y nacionalidades, así como asegurar la representación de diversos grados de escolaridad y alfabetización. En realidad, la diversidad que encontré, en relación a todas estas dimensiones sociales, fue muy superior a mis expectativas iniciales. En un grupo de cerca de veinte lectoras que acompañé de cerca, fue posible ver cómo esas dimensiones se sobreponían. Buena parte de la información recopilada en las entrevistas individuales podría ser comparada y ampliada con la desprendida de la organización de un grupo focal y un grupo de lectura en torno a un cuento, mismo que había sido escogido por usar una forma de escritura muy diferente a la habitualmente leída por medio de la biblioteca (Sequeiros 2018, 124).

En esta fase del proyecto, volver a la teoría, a lo ya publicado, fue nuevamente una práctica recurrente y fructífera. Para dilucidar las opciones con respecto a la siguiente sección y a otras cuestiones de orden terminológico o conceptual y sus articulaciones epistemológicas o metodológicas, sugiero dos obras de referencia (Seale 2004; Ritzer y Ryan 2011) la primera ya reeditada.

Dadas las finalidades de la investigación y los principios metodológicos adoptados, opté por utilizar un conjunto de herramientas de investigación para escuchar y observar a las lectoras seleccionadas, de acuerdo con los criterios referidos, y que se convirtieron en las principales interlocutoras en el proceso. 
En un inicio hablé con la principal responsable del área educativa del establecimiento (escuela interna y biblioteca) y, con frecuencia, recurrí a la persona con jerarquía intermedia, directamente encargada de la operatividad de estas actividades, la cual me facilitó el contacto con las detenidas.

Utilicé la biblioteca de la prisión como lo hacían otras mujeres, sentada leyendo y eventualmente interactuando con las lectoras, sobre todo haciendo observaciones de lo que buscaban, qué espacios usaban más (qué tipo de monografías, periódicos) intentando especialmente crear familiaridad con mi presencia y establecer cierta confianza para iniciar posteriormente las entrevistas. Una de las detenidas, responsable de la organización de la biblioteca, proporcionó mucha información útil y facilitó de manera decisiva mi contacto con las lectoras, así como el conocimiento sobre las prácticas más frecuentes de lectura. Me referiré a ella como la bibliotecaria. Una guardia penitenciaria encargada de esa área física, fue también fuente de información sobre los intereses de lectura, ella misma era una lectora intensiva y hacía de intermediaria en la recepción de libros, muy ocasionalmente, solicitados a la biblioteca municipal.

Entrevisté individuamente a algunas lectoras que se mostraron receptivas a esa interacción. Después recurrí a un grupo focal que produjo resultados muy interesantes de profundización y mejor comprensión de aspectos suscitados en las entrevistas individuales. Dado el contexto, no todas las lectoras que se inscribieron voluntariamente en este grupo pudieron participar en todas las sesiones programadas.

Conversaciones ocasionales entre las detenidas, con la guardia, con la bibliotecaria y conmigo dentro del espacio de la biblioteca fueron tratadas, principalmente por la información que proporcionaban sobre el ambiente penitenciario, el contexto físico y relacional de sus lecturas.

Al interpretar los datos y la información recogida, intenté concentrarme en lo que más se diferenció de mis expectativas iniciales, de los trabajos producidos sobre establecimientos penitenciarios femeninos en otros países y que, como tal, pudieran aportar diversos cambios a la literatura existente. 
Sí, como dice Loïc Wacquant $(2004,217)$ la cárcel es "un aspirador social" orientado a limpiar las sobras de las transformaciones económicas en curso y retirar del espacio público el desecho de la sociedad de mercado - los pequeños delincuentes ocasionales, los desempleados o los indigentes, las personas sin techo $\mathrm{e}$ indocumentadas, los toxicómanos, los discapacitados y enfermos mentales marginados por falta de protección sanitaria y social, así como los jóvenes de origen popular condenados a una (súper)vivencia hecha de expedientes y de hurtos para suplir la precariedad de los salarios.

La investigación en ciencias sociales ciertamente tiene aún muchas contribuciones que hacer a este tema.

Dejo, por último, el final pedido por Celeste, la detenida que presenté antes: "No se olviden de nosotras. Aquí adentro, y en estos tiempos, tenemos siempre un inmenso miedo de que se olviden de que nosotras existimos".

\section{Bibliografía}

Bosworth, M., Campbell, D., Demby B., Ferranti S. M. y Santos, M. (2005). Doing prison research: views from inside. Qualitative inquiry, 11(2), 249-264.

Bosworth, M. (2000). Confining femininity: a history of gender, power and imprisonment. Theoretical criminology, 4(3), 265-284.

Burawoy, M. (1998). The extended case method. Sociological theory 16433.

Disponible en http://burawoy.berkeley.edu/Methodology/ECM.ST.pdf.

Cunha, M. I. (2002). Entre o bairro e a prisão. Lisboa: Fim de Século. Donmoyer, R. (2000). Generalizability and the single case study. EnR.

Gomm, M. Hammersley, y P. Foster, (eds.) Case study method: key issues, key texts. (pp. 45-68). London: Sage.

Ferraro, K. J. y Moe, A. M. (2003). Women's stories of survival and resistance. En B. H. Zaitzow, y J. Thomas, (eds) Women in prison, (pp. 65-93). London: Lynne Rienner. 
Fonseca, C. R. (2010). Crime e castigo: as mulheresnaprisão. Coimbra: Almedina.

McRobbie, A. (2009). Post feminism and popular culture. En A. McRobbie, (ed.) The Aftermath of feminism, London: Sage.

Myers, T. (1996). Criminal women and bad girls: regulation and punishment in Montréal, 1890-1930. Montréal: McGill University. Disponible en http://digitool.library.mcgill.ca/R/?func=dbin-jumpfullyobject_id=40209ylocal_base=GEN01-MCG02.

Ritzer, G. y Ryan, J. M. (eds) (2011). The concise encyclopedia of sociology. Chichester: Wiley-Blackwell.

Seale, C. (2004). Researching society and culture. London: Sage.

Sequeiros, P. (2016). Leitura na prisão feminina: da biblioteca ao questionamento dos gostos. Caderno CRH, 29(76), 165-79.

Sequeiros, P. (2018). 'Holding the dream': women's favorite readings in a Portuguese prison." Qualitative sociology review 14(1),110-28.

Silva, V. A. Barreto da. (2018). A epistemologia de Michael Burawoy e seus desdobramentos metodológicos. Revista direito e praxis, 9(3), 1503-30 Disponible en http://www.epublicacoes.uerj.br/index.php/revistaceaju/article/view/28989.

Sweeney, M. (2008). Reading and reckoning in a women's prison. Texas studies in literature and language, 50(3), 304-328.

Sweeney, M. (2010). Reading is my window: books and the art of reading in women's prisons. Chapel Hill: University of North Carolina Press.

Wacquant, L. (2004). A aberração carcerária à moda francesa. Dados 47215-232. Disponible en http:/ / www.scielo.br/scielo.php?script=sci_arttextypid=S001152582004000200001 ylng=enynrm=isoytlng=pt.

Zaitzow, B. H. y Thomas J. (eds.) (2003). Women in prison: gender and social control. London: Lynne Rienner. 



\title{
La técnica de entrevista appreciative inquiry como método cualitativo para el estudio de la función de comunicación
}

\author{
Jérôme Thomas \\ Docente e investigador (Maître de conférences) en ciencias de la \\ información y de la comunicación. \\ Universidad de Reims Champagne-Ardenne (Francia)
}

\section{Resumen}

En este capítulo se describen las razones por las cuales se eligió una técnica de entrevista muy original, llamada appreciative inquiry, para investigar los valores y prácticas profesionales de los vigilantes penitenciarios de una cárcel francesa de máxima seguridad. Entre las prácticas que nos interesaron más, figuran las capacidades relacionales y comunicacionales de los vigilantes. Esta técnica original, aunque conlleva sesgos que enumeramos y asumimos, se plantea como un método cualitativo muy interesante y relevante para estudiar una profesión que adolece de representaciones negativas en la sociedad y, en particular, para estudiar las formas de la comunicación que pueden desarrollarse en un contexto tan difícil como el de las cárceles. En especial, nos interesamos por el delicado desarrollo de la relación con los internos y por la gestión de la distancia adecuada con respecto a ellos. La técnica permite superar la intimidante barrera entre el investigador y el sujeto investigado y, así, provocar relatos íntimos, auténticos y positivos sobre las prácticas y los trucos profesionales habitualmente omitidos en los discursos públicos de los vigilantes o en las investigaciones que usan métodos comprensivos más clásicos. Esta 
técnica permite obtener resultados inéditos sobre una profesión quela investigación o los medios de comunicación suelen mostrar únicamente bajo la forma del sufrimiento, de lo negativo (denuncia de actos represivos en contra de los internos) o de las dificultades psicosociales a las que se enfrentan los vigilantes en el trabajo cotidiano. Se trata de describir la relevante elección del método para los objetivos de la investigación y con respecto a su contexto; y, asimismo, los aspectos concretos de su uso y los tipos de resultados que se pueden obtener a partir de su implementación.

\section{Introducción}

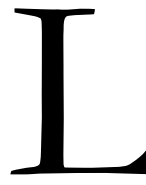

A ELECCIÓN de una metodología de investigación se basa en varios criterios: unos dependen directamente del objeto y de las hipótesis que queremos poner a prueba o de una tradición de investigación en un campo disciplinario definido; otros dependen de una decisión propia y singular del investigador, en función de sus preferencias personales (su afinidad con la estadística o con la inmersión etnográfica, por ejemplo) o, a veces, por motivos de "compromiso epistemológico", casi político. Así, un investigador puede decidir rechazar todas las metodologías experimentales con seres humanos porque considera que son manipuladoras o que reproducen situaciones ficticias que no podrían ocurrir en la realidad. Este capítulo pretende mostrar cómo un investigador elige paulatinamente un método de investigación según un proceso racional minucioso de justificaciones sucesivas y también con sus convicciones científicas sobre la realidad social; lo que solemos llamar los presupuestos antropológicos de las ciencias sociales.

$\mathrm{Al}$ abordar el caso específico del estudio de la función de comunicación en la profesión de vigilante penitenciario, mostramos el proceso de elección de la técnica de entrevista llamada appreciative inquiry (AI). Este método, que consiste globalmente en alentar al sujeto investigado a producir una lectura positiva de su experiencia social para transmitirla al investigador, se puede utilizar con ciertas condiciones que enumeramos para el caso concreto de nuestra investigación en una cárcel francesa de máxima seguridad. Veremos de qué modo tanto la configuración del terreno como el objetivo de convalidar hipótesis sobre la satisfacción laboral nos llevaron a elegir la AI. En efecto, este 
método ofrece la ventaja de cambiar la perspectiva científica en campos que suelen estar representados de manera pesimista en las investigaciones. En este sentido, la AI permite cuestionar la opción de presentar algunas profesiones siempre a través del concepto resobado de trabajo sucio. Después de la presentación de los principios generales del método, mostraremos cómo se puede implementar en un guion de entrevista. En la última parte, consideraremos los tipos de resultados que conseguimos obtener gracias al método.

Para que esta técnica no parezca mágica, a lo largo del texto subrayamos los sesgos que conlleva y la manera de franquearlos o de incluirlos en la interpretación de los resultados.

\section{Elegir un método de investigación: criterios objetivos y criterios de oportunidad en la selección de la técnica de entrevista appreciative inquiry}

Por más que el investigador tenga a su disposición un surtido casi infinito de métodos cuantitativos y cualitativos para llevar a cabo sus investigaciones, nunca los utiliza todos. Intenta elegir sus métodos y técnicas en función de varios criterios. Unos se justifican de manera muy objetiva (o por eliminación sistemática) y otros resultan, en mayor medida, de una decisión propia, subjetiva y oportuna del investigador. Así, se pueden rechazar los métodos cuantitativos por motivos epistemológicos: cuando se considera que el objeto que estudiar no puede reducirse a una lógica estadística o cuando uno quiere acercarse a la realidad social de manera comprensiva restituyendo el sentido preciso que los actores sociales dan a su acción (lo que exige una presencia etnográfica a largo plazo en un campo o efectuar entrevistas a fondo) etc. Asimismo, se puede elegir un método diferente del que se usa tradicionalmente en una disciplina científica, a fin de cambiar de perspectiva sobre una misma realidad social. En nuestro ámbito de las ciencias de la información y de la comunicación, somos muy conscientes de que no se interpreta siempre igual el discurso de la prensa, sino que depende de si efectuamos un análisis semiótico de los artículos de prensa (dentro de las fronteras estrictas del texto, sin tomar en cuenta su contexto de producción o de recepción y buscando los efectos de significación) o si estudiamos las prácticas profesionales de los periodistas desde un punto de vista sociológico. En todos los casos, 
conseguimos saber algo de la realidad social del discurso periodístico, pero son verdades científicas parciales, con sus condiciones de validez, dependiendo del método.

Siguiendo este razonamiento, el hecho de que uno pueda elegir, entre todas, la técnica de entrevista llamada appreciative inquiry (AI) debe entenderse así: se puede justificar objetivamente, pero también se trata de una selección propia y estratégica del investigador, que ve en ella una oportunidad de obtener datos y resultados inéditos de una realidad social que nunca fue estudiada desde el punto de vista ofrecido por esta herramienta. Es lo que pretendemos mostrar en esta primera parte al plantearnos esta pregunta: ¿en qué medida la AI se hizo necesaria y oportuna para el estudio de la función de comunicación en la profesión de vigilante penitenciario? En nuestro caso, la elección de la AI se justificaba primero por el contexto muy difícil de la investigación (la crisis vinculada al cierre definitivo de una cárcel y la consiguiente solicitud del Ministerio de Justicia). Sin embargo, en segundo lugar, se trataba de cambiar, por el método de acercamiento a esta realidad social, el punto de vista sobre la profesión de vigilante. Nuestra hipótesis planteaba que el trabajo de los vigilantes puede brindarles satisfacción y orgullo, en contra de lo que describían muchas investigaciones sobre la profesión, efectuadas con otras metodologías que, sin embargo, eran comprensivas; y, desde este punto de vista de lo positivo (orgullo y satisfacción) queríamos poner a prueba la cuestión de las habilidades de comunicación y de psicología de los vigilantes como fuente de una satisfacción oculta en el trabajo y como criterio esencial de la identidad profesional.

\subsection{Analizar el contexto de investigación para seleccionar un método adaptado y relevante}

Muy a menudo, en las investigaciones que privilegian lo cualitativo, es el contexto de investigación el que determina en gran medida la selección de tal o cual método. En parte, este fue el caso del presente trabajo sobre la profesión de vigilante penitenciario. Todo partió de una convocatoria del Ministerio de Justicia francés (que es el ministerio que tutela la administración penitenciaria en Francia) para investigadores, a fin de que trabajaran sobre la memoria y la cultura 
profesional de los vigilantes penitenciarios de una prisión francesa de máxima seguridad muy famosa en el país. Por aquel entonces, se había anunciado el cierre de la prisión, los vigilantes se declararon en huelga y hubo movimientos de protesta importantes. No cabía la menor duda de que la convocatoria de proyectos de investigación pretendía apaciguar el movimiento de rebelión de los funcionarios penitenciarios. Se les enviaba investigadores para demostrarles su importancia. Este contexto de crisis muy particular tenía que tomarse en cuenta para elegir una técnica de investigación apropiada que pudiera tanto aprovechar el deseo de expresarse (muy escaso en la profesión) de los vigilantes como evitar la potencial instrumentalización política de la investigación por todas las partes implicadas (los vigilantes, la prisión y el ministerio responsable).

Así, reflexionamos mucho para saber cuál podría ser la mejor técnica de investigación en un contexto en el cual los vigilantes querrían quejarse contra el ministerio responsable e incluso, quizá, utilizarnos para que se conocieran y publicaran sus reivindicaciones. Por un lado, no queríamos ser los altavoces o portavoces de los vigilantes; pero, por otro lado, se nos brindaba la oportunidad, muy poco habitual, de entrevistar a vigilantes que sin duda querían hablar y expresarse, mientras que, de costumbre, se trata de una profesión bastante inexpresiva o discreta y que no se abre mucho con los investigadores.

Además, durante los primeros encuentros preparatorios de la investigación, nos dimos cuenta de que los vigilantes tenían la impresión, bastante imaginaria, de disponer de un saber profesional excepcional debido a la historia tumultuosa de la cárcel, en la cual ocurrieron, en el pasado (incluso en un pasado reciente) muchos acontecimientos traumáticos (los actos de un asesino de vigilantes, una toma de rehenes, incendios, motines, etc.).

Entonces, si elegimos la técnica de la AI fue para adaptarnos a este contexto. En efecto, se trataba de aprovechar la voluntad de hablar de los vigilantes, pero, al mismo tiempo, también de evitar las quejas automáticas debidas al contexto del cierre de la prisión. No en vano, y como precisamente observaremos más adelante, dado que la técnica de la AI consiste en valorizar a la persona investigada a medida que avanzamos en la entrevista, pensábamos evitar el surgimiento del pesimismo y recopilar, por el contrario, un discurso "de combate", 
positivo y de manifestación de orgullo, cuya presencia potencial percibíamos. También se trataba de sorprender a los vigilantes, que están acostumbrados a describir siempre el lado difícil y penoso de su profesión, con quejas sistemáticas y crónicas (carencia de personal y limitación de su acción por un derecho penitenciario demasiado protector del preso). La AI es, ante todo, la elaboración de una posición positiva del investigador frente al sujeto investigado.

El último punto de contexto era la imposibilidad de hacer observaciones etnográficas en la cárcel para observar el trabajo de los vigilantes (por razones de seguridad, ya que se trata de una prisión de máxima seguridad, y por razones materiales de distancia respecto de la cárcel, que se sitúa en una zona rural muy aislada). Por eso, priorizamos una investigación mediante entrevistas, pero necesitábamos una técnica de entrevista que brindara un acceso íntimo al trabajo (para evitar de recopilar meramente el discurso sindical) algo que, de nuevo, permite la AI, que posiciona al investigador en una relación de "simpatía profunda" con el sujeto investigado.

Por lo tanto, vemos hasta qué punto, en este caso, la elección de una metodología se basa en una serie de criterios que dependen tanto de un contexto oportuno como de la necesidad de franquear obstáculos. La AI concuerda perfectamente con situaciones en que los sujetos investigados desean demostrar y manifestar algo a los investigadores (aprovechar una oportunidad); y con situaciones en las que los sujetos investigados suelen describir su actividad profesional por su lado negativo (por motivos sindicales o políticos) a fin de acompañarlos para que traten de ver el lado positivo de su actividad, como fuente nueva de datos (franquear un obstáculo).

\subsection{Conectar las técnicas con los objetivos e hipótesis de la investigación}

Uno de los ejes de la investigación consistía en entender cómo los vigilantes, más allá del uso de la disciplina y de los dispositivos coercitivos de la cárcel, lograban movilizar habilidades relacionales, psicológicas y comunicacionales para gestionar los espacios de reclusión. 
Sin embargo, suponíamos que los vigilantes no iban a confesar de manera espontánea que tenían relaciones humanas pacificadas y normales con los internos, basadas en una comunicación que fuera abierta o que tomara la forma de una ayuda psicológica.

La investigación en el tema muestra que los vigilantes, para soportar su trabajo, necesitan establecer una frontera clara entre los internos y sí mismos. Los trabajos de sociología clínica, ${ }^{1}$ al emplear, en particular, el concepto de trabajo sucio, muestran que el hecho de que los vigilantes trabajen al lado de los presos durante muchos años aumenta el riesgo imaginario de identificarse con el preso (es decir, con su dimensión de desecho social) y de no saber ya diferenciarse del mismo.

El concepto de trabajo sucio (Hughes, 1996; Lhuillier, 1997, 2005; Chauvenet, 1994; y Fassin, 2017) abarca, entre otros, los criterios claves para identificarlo: se aplica al trabajo de sujetos que se encargan de los desechos de los demás (por ej., los basureros o las señoras de la limpieza); se aplica a agentes cuya profesión consiste en dañar, controlar, reprimir o contener el cuerpo de los otros (por ej., policías, vigilantes penitenciarios, matarifes en los mataderos o auxiliares de enfermería); y concierne, asimismo, a trabajadores que se encargan, de manera general, de tareas secundarias o sin legitimidad en la sociedad.

Los vigilantes penitenciarios acumulan varios de estos criterios. La elección de la AI nos pareció, de nuevo, oportuna para ver cómo logran evitar este sentimiento de desprestigio o cómo inventan "trucos laborales" para aguantar mejor el sentimiento de efectuar un "trabajo sucio". Dicho de otra manera, se trata de entender los intentos específicos que realizan los agentes para contrarrestar, neutralizar o administrar concepciones degradadas del trabajo y, más allá, construir identidades vinculadas al trabajo que sean valoradas positivamente.

Además, en este contexto de riesgo de identificación al preso y de sentimiento de cumplir un trabajo sucio, nos interesaba investigar cómo los vigilantes conseguían establecer una distancia "justa" o "adecuada" con los internos (ni demasiado alejados, ni demasiado cercanos). Evidentemente, nunca se puede definir esta distancia, que

\footnotetext{
${ }^{1}$ Lhuilier, D., y Aymard N. (1997)

${ }^{2}$ Véase De Certeau, M. (2004) para una teorización del concepto de trucos y tácticas laborales.
} 
depende de cada vigilante, porque no se trata de una distancia física, sino psicológica. Se trata de la elaboración de una relación tanto de autoridad como de ayuda. De hecho, desde 2009 (nueva ley penitenciaria) se renovó el estatus de los vigilantes y se indicó en la normativa que los vigilantes tenían que cumplir tanto misiones de custodia como de ayuda a la reinserción, según los principios de la seguridad dinámica (Icard, 2016). En efecto, aunque la cárcel francesa era una institución bastante arbitraria hace 10 años, se ha transformado mucho, para convertirse en una institución cada vez más normativa, protegiendo así la humanidad y la dignidad de las condiciones de reclusión.

Aunque la autoridad y la fuerza siguen representando valores importantes para los vigilantes penitenciarios, la evolución jurídica, que ha permitido garantizar cada vez mejor los derechos de los internos, ha suavizado las relaciones entre los presos y los vigilantes. Precisamente en este contexto, nos pareció que cabía estudiar el uso de la comunicación, ya que ella sirve y resulta imprescindible para negociar el equilibrio débil entre, por un lado, la garantía de los derechos de los internos $y$, por otro lado, la necesaria tranquilidad y seguridad en las zonas de reclusión frente a internos muy peligrosos.

Se suponía que, según el perfil de los vigilantes, este uso se distribuiría entre un uso pragmático y utilitarista para mantener el orden (transformación de la fuerza usada en el pasado) por un lado, y un uso social-psicológico, por otro lado (siguiendo la evolución teórica y jurídica, anteriormente mencionada, de las misiones de los vigilantes) Gilles Chantraine (2006) que estudió el trabajo de los vigilantes en una prisión canadiense, mostró que las prisiones de Europa y de América del Norte ya no son disciplinarias (Foucault, 1975) sino que se están transformando según un modelo "post disciplinario" en el cual la comunicación tiene mucha importancia (inteligencia penitenciaria $\mathrm{y}$ negociación del orden). Sin embargo, Chantraine (2006) al igual que Valérie Icard (2016) demostró las dificultades vinculadas a esta evolución. Nuestra meta era buscar otros efectos que no fueran necesariamente negativos. De nuevo, la AI, que prioriza la expresión de lo positivo, era una técnica que nos permitía posicionarnos en este campo de investigación, ya explorado, para mirarlo de un modo distinto. 
Por último, además, la AI, que alienta a desarrollar un punto de vista subjetivo revelando las costumbres personales, nos pareció otra vez muy oportuna, dado que el desarrollo de la distancia "adecuada" es un asunto muy subjetivo dentro de este nuevo "orden comunicacional" de la cárcel (Chantraine, 2006).

Ya hemos presentado algunas propiedades de la AI y, sobre todo, algunos criterios que pueden llevarnos a elegirla en el contexto de una investigación específica. A continuación, nos disponemos a describir sus principios generales.

\subsection{Principios generales de la appreciativeinquiry}

La AI nació primero en el ámbito de la empresa. Se trataba de un método de gestión del cambio en las organizaciones. La investigadora Alison Liebling (1999) en Inglaterra, y luego Martine Herzog-Evans (2015) inspirada en aquella y que abordaba el caso de Francia, decidieron retomar las ideas principales de la AI para traducirlas en técnicas de entrevista que pudieran aplicarse a las investigaciones tanto sobre los presos como sobre los vigilantes.

\subsubsection{Una técnica usada al principio en las empresas para llevar a cabo el cambio}

Al principio, la AI se desarrolló en el ámbito de las empresas para gestionar el cambio en las organizaciones. Antes del uso de este método, se solía utilizar un modelo que priorizaba la resolución de los problemas. Se consideraba que el ritmo de vida de la empresa comportaba enfrentarse, a intervalos regulares, con problemas. La perspectiva de los directivos de empresa se enfocaba a la anticipación de los problemas y a la consiguiente movilización continua de los empleados para resolverlos en grupo de trabajo y avanzar en el cambio, es decir, hacia la renovación de las costumbres para seguir respondiendo a las exigencias de la competencia. Este método, que parece muy racional, se sustituyó por el de la AI. Ya no se trataba de considerar la empresa como un problema perpetuo que resolver, sino, de manera optimista, y positiva, de considerarla según sus éxitos (Cooperrider, 2019).

Los promotores de la AI destacaron que el hecho de tratar de los problemas e insuficiencias de la empresa tiende a generar resistencia, 
pesimismo, duda y acusaciones reciprocas entre los miembros de la organización, lo que lo bloquea todo e impide, al final, que ocurra el cambio. Por el contrario, se demostró que esforzarse en poner de relieve las fortalezas y los éxitos de la organización y de sus miembros desencadena el entusiasmo, la creatividad, la motivación y el compromiso por la empresa. A continuación, se trata de aprovechar la oportunidad de este ambiente positivo para inventar las soluciones correspondientes en lugar de intentar resolver los problemas, lo cual enfocaría demasiado la mirada en todos en sus fracasos.

Los investigadores que trabajaron en efectuar la AI en las empresas notaron varios efectos: el método permite crear relaciones positivas en la empresa, compañerismo y responsabilidad compartida; permite que la gente comparta sus ilusiones y visión del futuro; y posibilita que surjan vías de acción para el futuro.

\subsubsection{Aplicación a objetivos de investigación en el ámbito de la cárcel}

Para el investigador sobre la cárcel, no se trata de cambiar la organización de la prisión, sino de retomar la filosofía general de la AI para aplicarla, a la vez, al guion de las entrevistas, como veremos más adelante, y a la posición general que debe adoptar el investigador con respecto a los sujetos investigados y al terreno (es decir, respecto a cada persona que el investigador vaya a conocer en su investigación). Se trata de alentar a los sujetos investigados a que se esfuercen en dar un giro positivo a las representaciones de su propio trabajo, a que se esfuercen por presentarlo al investigador de una manera positiva. De tal modo, hay más probabilidades de que se desvele lo que nunca se dice porque, por costumbre, el sujeto investigado lo considera vergonzoso o no digno de interés cuando se encuentra ante el entrevistador.

Como manifiesta Alison Liebling, esta técnica de entrevista tiene la particularidad de ser "deliberadamente parcial" (Liebling, 1999). Es decir, todo lo contrario de lo que se recomienda habitualmente a los que aprenden las técnicas de investigación (estudiantes de doctorado, por ejemplo) a quienes se suele decir que deben orientarse hacia la mayor objetividad posible controlando los protocolos. 
Con esta técnica, el investigador asume el sesgo, no hace como si no existiera. La idea es que los resultados obtenidos van a ser tan novedosos que autorizan los sesgos, a condición de que estos últimos se anuncien abiertamente en la presentación de la investigación (estableciendo las condiciones de la validez de la misma). Asimismo, estos sesgos permiten evitar otros sesgos más importantes. Es un asunto de equilibrio entre lo que se pierde y lo que se gana al introducir sesgos, que están presentes por naturaleza en la investigación cualitativa (Devereux, 2000).

Liebling (1999) afirma también que el investigador debe obligarse a manifestar una "simpatía profunda" por la persona investigada. En efecto, se trata de una técnica que otorga prioridad a las emociones (positivas) en comparación con los discursos racionales. En realidad, este método que conlleva sesgos de importancia permite, al mismo tiempo, eliminar dos sesgos más importantes cuando uno decide investigar sobre la cárcel, se trate de los internos o de los vigilantes. Primero, como ya mencionamos, se trata de franquear los obstáculos vinculados a la percepción de hacer un trabajo sucio. Muy a menudo, los discursos de los vigilantes denotan un gran sentimiento de culpabilidad. La AI intenta borrar la culpabilidad para que surja el orgullo y la expresión de los puntos de satisfacción laboral, sin por ello negar lo difícil. Segundo, solicitar un discurso demasiado racional obliga al vigilante o al interno a satisfacer las expectativas del investigador, concebido como un sabio o erudito o una persona con conocimientos. El mecanismo-reflejo es entonces repetir el discurso sindical (muy racional, pero a veces no representativo de la experiencia propia del sujeto) o bien que el vigilante guarde silencio, al no sentirse capaz de desarrollar un discurso racional frente al investigador. La orientación parcial y emocional de la AI permite reducir la distancia social entre el investigador y el sujeto investigado, lo cual abre nuevas posibilidades de confidencias.

Entonces esta técnica de entrevista consiste en instaurar una atmósfera de confianza para que el vigilante se abra con el investigador, pese a que haya muchas razones para que no lo haga. Se trata pues de “entrevistas sensibles" (Liebling, 1999).

Por último, una ventaja enorme de esta técnica es que permite incitar a los vigilantes a que cuenten las técnicas que inventan en su puesto de trabajo. Eso es muy importante, tanto más en cuanto un eje de la 
investigación consistía en entender cómo los vigilantes se apropiaban personalmente de las leyes penitenciarias y los reglamentos que constituyen el ámbito más o menos aceptado de su actividad laboral. De acuerdo con las investigaciones, en efecto, al querer aplicar la ley o el reglamento al pie de la letra, resulta imposible conservar la paz en la cárcel (Chauvenet, 1994). Un punto importante de la investigación consistió en recopilar todas las invenciones laborales (en particular, las comunicacionales) elaboradas por los vigilantes para que los internos aceptaran el reglamento.

3. Aspectos concretos del uso de la técnica de entrevista siguiendo el modelo de la appreciativeinquiry

En esta parte, se trata de mostrar cómo se utilizó el método de la AI en concreto, tanto en nuestro guion de entrevista como en el desarrollo de la actitud del investigador.

\subsection{Adoptar una actitud siempre positiva durante la entrevista y en las conversaciones informales}

Cada vez que conocíamos a una persona en la cárcel en la que estábamos investigando, o cada vez que realizábamos una entrevista, procurábamos mantener el comportamiento siguiente:

- Alentar a las personas investigadas a que desarrollaran los puntos positivos de su actividad laboral.

- No reaccionar cuando se evocaba un punto negativo; dejar hablar.

- Mantener el rumbo hacia lo positivo. Reaccionar positivamente y con entusiasmo en los momentos en que las personas investigadas expresaban su orgullo, sus recursos y capacidades personales, las fuentes de satisfacción laboral, etc. Asimismo, alentarlas a desarrollar estos puntos.

Proponer reformulaciones positivas de lo que acababa de decir la persona, para que esta las comentara.

- Detectar los momentos en que las personas investigadas daban cuenta de sus emociones e incitarlas a describirlas. 
- Detectar los momentos en que las personas recitaban un discurso establecido, procedente, por ejemplo, de lo que se enseña en el curso de capacitación, o cuando se repetía al pie de la letra el discurso sindical. No reaccionar y pasar a otra pregunta.

Podemos dar testimonio de que esta posición del investigador dio unos resultados muy interesantes en términos de implicación de los vigilantes en la investigación. Aunque, al principio de la investigación y de nuestra presencia en el terreno, muy pocos querían participar en este estudio, al final los vigilantes que entrevistamos se convirtieron en nuestros embajadores para convencer a los demás de que participaran en la investigación. De hecho, a fin de constituir nuestra muestra, utilizamos la técnica de la "bola de nieve". Además, aunque anunciamos a los vigilantes unas entrevistas de más o menos una hora, muchas duraron mucho más, hasta tres o cuatro horas, lo que sorprendió a los propios vigilantes, que nos confiaron al final que "el tiempo pasó volando" y que les sentaron bien las entrevistas, incluso desde un punto de vista psicológico.

\subsection{Elaborar un guion de entrevista con preguntas orientadas}

Retomamos y adaptamos un cuestionario establecido por Liebling cuando investigaba la calidad de la vida en reclusión (Evans, 2015). El guion de entrevista se componía de temas en torno a los valores profesionales de los vigilantes. Reproducimos aquí abajo algunos ejemplos de preguntas. Se trata sobre todo de ilustrar el giro especial de las preguntas, orientadas a lo positivo, que resultan muy representativas de la AI. En negrita, ponemos de relieve los segmentos de frases que orientan específicamente la entrevista.

Para recopilar y tratar los datos, nos ayudaron estudiantes del máster en derecho penal. Los estudiantes entendieron muy bien la meta de la AI y supieron animar a los vigilantes cuando resultaba necesario. Además, el hecho de que los jóvenes llevaran las entrevistas permitió relajar a los vigilantes, que tenían ganas de promover su profesión y de enseñar cosas. En este sentido, se abrieron mucho más con los estudiantes que con los investigadores, lo que reforzaba los objetivos generales de la AI. 
¿En qué circunstancias especificas da muestras de humanidad en su actividad laboral cotidiana? ¿Me podría dar ejemplos?

¿Me podría hablar de lo que le parece interesante en su trabajo?

¿Cómo calificaría un buen día de trabajo?

¿Representa para usted un motivo de orgullo el hecho de llevar a cabo una actividad laboral al servicio de la sociedad?

¿En su opinión, cómo definiría qué es un vigilante competente?

¿Cómo definiría cuál es la distancia adecuada que mantener con los internos?

¿Contribuir a la seguridad pública es un motivo de orgullo para usted? Por la mañana, ¿qué le hace feliz de ir a trabajar?

¿Cómo describiría el compañerismo o la amistad entre colegas, en la cárcel en la que trabaja usted?

¿Puede generar orgullo ayudar a los internos?

¿Me podría contar su mejor recuerdo laboral aqui?

4. Tipos de resultados que se pueden sacar: la importancia de la función de comunicación en la profesión de vigilante

Como ya mencionamos, varios investigadores, en particular franceses (Chantraine, 2006; Icard, 2016; y Fassin, 2017) mostraron la importancia de la función de comunicación en el ámbito de la cárcel y, en particular, en la relación entre el vigilante y el interno. Sin embargo, los trabajos suelen mostrar que el uso de la comunicación está, la mayor parte del tiempo, más al servicio del mantenimiento del orden (dimensión utilitarista de la comunicación) que concebido según un aspecto que calificaríamos de clínico (función catártica de hablar y de la palabra). En efecto, Rostaing (2014) en su análisis de las relaciones vigilantesinternos para intentar describir la evolución de la gestión disciplinaria en la cárcel, concluye que la comunicación sirve para "negociar el orden". En la misma tónica, Gilles Chantraine (2006) habla de "orden comunicacional", lo que de entrada tiende a asociar la comunicación con 
la imposición de la disciplina. Fassin (2017) refiriéndose a los trabajos de Liebling (1999) y mencionando la evolución del derecho penitenciario francés - la cual, en consonancia con las normas europeas, otorgaba más derechos a los internos (y, por lo tanto, introdujo más situaciones de negociación en las zonas de encarcelamiento)—, sugiere la idea de que los vigilantes van dejando el uso de la fuerza física en provecho del recurso a "la autoridad de la palabra" (Fassin, 2017). Otra vez, la asociación entre "autoridad" y "palabra", desvela que, aunque las habilidades relacionales se usen más, la comunicación parece limitarse a un uso utilitarista. Queríamos analizar esos resultados en nuestra propia investigación, pero también planteábamos la hipótesis de que, a veces, la palabra podría tener una función clínica o terapéutica. Sin duda, la AI podría ayudarnos en este cometido.

En efecto, el método en sí mismo, que, como vimos, establece una relación de "simpatía profunda" entre el investigador y el sujeto investigado, permite que exista una definición implícita y positiva de la comunicación entre las dos partes implicadas. El investigador no elabora sus preguntas como si quisiera propiamente arrancar respuestas y resultados al sujeto investigado, sino como si quisiera hablar con él con amabilidad y admiración. Así, la entrevista no se considera de manera utilitarista como una investigación policial ${ }^{3}$, sino más bien como un momento que compartir para aprender cosas (desde este punto de vista, ya mencionamos la preciosa contribución de los estudiantes que nos acompañaron en esta investigación). De tal modo, esto define de manera implícita el estatus de la comunicación y, por lo tanto, hace más fácil para los vigilantes hablar de un uso profesional de la comunicación que no sea obligatoriamente autoritario o utilitarista. Es como si la forma de comunicación misma de la entrevista permitiera al sujeto investigado una nueva interpretación de su propio uso de la comunicación en otro lugar.

A continuación, presentamos de manera breve (ya que el objetivo de este capítulo es más bien metodológico) los resultados que se pudieron obtener, gracias a nuestro método, en cuanto al uso de la función de

\footnotetext{
${ }^{3}$ Muy a menudo ocurre, en las entrevistas con personas cuya profesión es trabajar con gente y entrevistar a personas (policías, médicos, enfermeros, trabajadores sociales o jueces) que interpretan las intenciones de los investigadores como las de agentes de policía.
} 
comunicación por los vigilantes penitenciarios.

\subsection{Al lado de un uso tradicional y utilitarista de la comunicación, un uso psicológico y casi-terapéutico}

Si la investigación permitió averiguar que existía, efectivamente, un uso utilitarista de la comunicación, nuestro método también nos permitió revelar otros usos, casi-clínicos y psicológicos, que los vigilantes no tienen la costumbre de confiar a los investigadores (aunque, por ejemplo, Fassin ${ }^{4}$ los notó en su gran etnografía del mundo carcelario).

\subsubsection{La dimensión utilitarista de la comunicación}

En el guion de las entrevistas, teníamos varias maneras de poner a prueba la función de comunicación en la profesión de vigilante. Hacíamos preguntas sobre: la facultad de escuchar; la distancia justa que mantener con los internos; las técnicas para conocer a los internos; lo que llamamos self-disclosure (la capacidad de abrirse con su interlocutor, la autorrevelación); el apoyo a los internos; y la empatía que se podía manifestar hacia ellos.

Cuando analizamos las respuestas e intentamos agruparlas se desprendía, conforme a los resultados de investigaciones mencionadas anteriormente, que la profesión de vigilante penitenciario resulta muy relacional y moviliza siempre capacidades de comunicación.

Este extracto ${ }^{5}$ pone bien de manifiesto el cambio en cuanto a la importancia de la comunicación en la cárcel contemporánea:

“en la cárcel de hoy hay más diálogo, nos preocupamos más por los aspectos sociales de los internos; en el pasado, priorizábamos la autoridad, decíamos al hampón que cerrara el pico, que no tenía que decir nada, que éramos nosotros los jefes..., pero ya se acabó.”

Sin embargo, los resultados muestran que la comunicación, enmarcada por definición en una relación de autoridad, no puede ser auténtica, sino muy utilitarista y disimétrica. En realidad, son muy pocos los

\footnotetext{
${ }^{4}$ En el capítulo que el autor dedica a los vigilantes penitenciarios, escribe: «De façon informelle et impromptue, s'échangent de brèves informations, se manifestent des inquiétudes, s'expriment des attentions», en Fassin D, 2017, p. 305.

${ }^{5} \mathrm{El}$ autor de este capítulo tradujo todos les extractos de las entrevistas. Se pierden forzosamente los matices que pueda percibir un hablante francés.
} 
vigilantes que usan de la comunicación para aliviar la angustia de los internos, por ejemplo, o los que hablan sin control a los internos. Siempre subrayan el riesgo de decir demasiadas cosas sobre su vida y luego poner en peligro a su familia. Por eso, los vigilantes procuran que la información permanezca disimétrica.

En realidad, cuando es utilitarista, la comunicación con los internos corresponde a dos objetivos.

Primero, comunicarse con los internos permite simplificar unos actos delicados, como el cacheo con desnudo integral. Los vigilantes observan que es uno de los momentos en el que más hablan. En realidad, tanto el interno como el vigilante intentan distraer la atención o crear una distracción alrededor de un momento que ambos odian. Un cacheo que sale mal puede perturbar mucho después el trabajo en la zona de reclusión. Entonces, los vigilantes explican que, si están con internos a quienes conocen muy bien, cambiarán de tema de conversación: fútbol, bromas o actividades rurales. De algún modo, sin embargo, aquí se hace un uso psicológico de la palabra, porque en este caso las palabras remplazan a la focalización única de la mirada sobre el cuerpo desnudo.

Segundo, los vigilantes confiesan que conversan mucho con los internos (en las cárceles de alta seguridad, no hay muchas opciones para matar el tiempo, aparte de conversar, tanto para los vigilantes como para los internos; hay mucho aburrimiento en ambas partes) en pos de objetivos estratégicos. No obstante, para justificarse a sí mismos el hecho de hablar cotidianamente con "monstruos" o con personas con las que el resto de la sociedad no quiere relacionarse, ${ }^{6}$ explican al investigador que no se trata de una conversación auténtica, sino orientada, disimétrica (intentando que esta disimetría no se perciba por el interno); hablan, escuchan y charlan para recopilar información estratégica (vinculada a proyectos terroristas, por ejemplo). La AI permitió observar hasta qué punto los vigilantes sienten orgullo al contribuir a la seguridad nacional, lo que les permite reevaluar positivamente su propio trabajo y sacarlo de la concepción de "trabajo sucio".

${ }^{6}$ Son dimensiones propias del sentimiento de realizar un "trabajo sucio". 


\subsubsection{La gestión de la distancia justa con el interno: un uso más psicológico de la comunicación}

Varios vigilantes, después de una experiencia larga, confiesan que el trabajo en las cárceles de alta seguridad es mucho más relacional que autoritario. Aún más, consideran que la autoridad radica en el buen manejo de la relación y de la comunicación con el interno, mucho más que en la imposición de la fuerza o en las manifestaciones de virilidad. ${ }^{7}$

Por lo tanto, el problema para los vigilantes que se sitúan en esta concepción más psicológica de la comunicación, es saber dosificar la implicación personal con los internos, es decir, definir la distancia justa con respecto a ellos. Fue lo más interesante de todo lo que nos permitió descubrir la AI, porque los vigilantes se esforzaron mucho en describir con mucha precisión este reto casi imposible de regulación de la distancia con el preso.

Primero, para algunos vigilantes, comunicar significa ante todo escuchar las dificultades de los internos, ya se trate de asuntos materiales o de sufrimientos psíquicos. Por eso, muchos dicen que se ven como psicólogos y que es una parte del trabajo que les gusta mucho:

"no se trata de ser autoritario, sino de ser psicólogo";

"Es psicología, es totalmente psicología. En la escuela, nunca aprendí psicología, se aprende sobre la marcha”.

Otra vez, es una manera de revalorizar el trabajo dado el sentimiento de hacer un trabajo sucio. De hecho, fueron numerosos los vigilantes que nos contaron que el mayor reconocimiento procede mucho más de los internos que de la administración o de la sociedad.

\footnotetext{
${ }^{7}$ Aunque los valores viriles aparecen siempre, en diferentes grados, en el discurso de los vigilantes investigados. Sin embargo, los valores viriles aparecen menos en el discurso de las vigilantes penitenciarias. Véase la investigación de psicosociología de Anne-Christine Legendre (Legendre, 2017) en la cual se analiza el vínculo con la comunicación del hecho que el vigilante sea un hombre o una mujer, con los estereotipes de género asociados.
} 
Esto también es un riesgo porque, a veces, los vigilantes se refieren a los internos como "familia" o "amigos": 8

"el lado familiar, lo tenemos con los internos y con los colegas, los dos";

"Se puede decir que somos una familia, incluso con los internos";

"voy a hablar con internos que cometieron cosas enormes y voy a olvidarlas para trabajar con ellos; y también voy a reírme con ellos, vamos a hacer bromas y son momentos estupendos, los dos nos relajamos así. Sin embargo, no iré a tomar un café con él, de esto estoy seguro".

Segundo, los vigilantes mencionan trucos y artimañas comunicacionales para regular la distancia con los internos, en particular jugando con el "usted" y el "tú", que es algo muy francés. La elección del uso del usted o del tú ("vous" y "tu") o la oscilación entre ambos, es una manera de regular las relaciones e indicar el estado de la relación entre el interno y el vigilante. Algo muy interesante es que el tuteo sirve tanto para señalar al interno más proximidad, como para señalarle que algo está enojando al vigilante. Tenemos que saber que la regla oficial es el uso del "usted", como suele hacerse en Francia con cualquier persona con la cual tenemos una relación formal. Pasar al tuteo puede significar dos cosas: te hablo como si fueras mi amigo (podemos dejar el "usted" a partir de ahora); o te llamo de "tú" para despreciarte. Los vigilantes explican cómo señalan de manera implícita (lo cual es, de nuevo, psicología) la distancia que mantienen con los internos gracias a la modulación del uso del tuteo y del ustedeo:

"Decirle usted a un interno, eso es muy importante [...] pero tampoco le diría señor";

"El problema aquí es que, a fuerza de verlos, nos tuteamos un poco".

${ }^{8}$ El hecho de que se revele esto, que podría considerarse como una falta profesional, es, de nuevo, un efecto de la técnica AI. 
Por último, por más que haya un uso psicológico de la comunicación, los vigilantes procuran limitarse a sacar temas que no tienen que ver con la vida personal, pero que permiten instaurar una humanidad común con el interno:

"No podemos evitar charlar con ellos. Podemos contar nuestra vida, pero con temas generales. Yo hablo mucho de pesca o de caza. Otros hablan con ellos de videojuegos. Hay que elegir temas básicos. Pero nuestra vida privada no les incumbe. Si un vigilante cuenta demasiado su vida, si por ejemplo dice su nombre o habla de su esposa, esto va a volverse peligroso";

"si me comunico con un interno, es sobre todo para que no me suceda nada, para que él se quede tranquilo".

\subsection{Traumas y comunicación}

Aunque la comunicación resulta ser una herramienta importante en la profesión de vigilante (herramienta utilitarista y/o psicológica) hay una zona en la que la palabra y la comunicación son muy difíciles: en el hogar o a la hora de contar los traumas. Los vigilantes confiesan, en efecto, que hay momentos en los que el empleo de la palabra les resulta imposible.

Primero, en el hogar, los vigilantes nunca hablan de la cárcel a su familia, es como si fuera un tema tabú. Los vigilantes lo justifican primero diciendo que, incluso aunque quisieran sacar el tema, deben respetar el secreto profesional. Cuando más profundizamos las entrevistas, más nos damos cuenta de que sería demasiado difícil para ellos dar cuenta de un trabajo sucio, estresante, penoso, con la repetición de traumas puntuales (insultos, amenazas, escupitajos, agresiones, etc.).

Segundo, cuando acontece un problema importante, los vigilantes prefieren tratar el trauma dentro del colectivo laboral antes que acudir al psicólogo:

"El problema es que estamos en un entorno... un poco como el ejército o la policía, a la antigua, pues, los psicólogos, nosotros creemos que sirven para los locos, no para nosotros..." 
Podemos por lo tanto destacar esta paradoja: aunque algunos vigilantes se consideran a veces como psicólogos para los internos, no consideran que el psicólogo sea alguien a quién puedan recurrir para sí mismos.

\section{Conclusiones: combinar la appreciative inquiry con otros métodos}

En este capítulo, hemos intentado mostrar el interés de utilizar la técnica AI en las investigaciones cualitativas. Mostramos que este método funciona bien cuando se trata de investigar la profesión de vigilante penitenciario. Habría que ponerla a prueba en otros ámbitos, empezando por el estudio de profesiones que solemos relacionar con la categoría del trabajo sucio. A la hora de concluir este trabajo, es preciso dar unas recomendaciones para que este método no se convierta en algo mágico con efectos secundarios desastrosos. Primero, al aplicar la técnica hay que acordarse de las exigencias éticas de cualquier investigación: se trata de recoger datos inéditos, no de manipular a la gente. La relación de "simpatía profunda" y "deliberadamente parcial" de la AI no significa jugar con los sentimientos de los sujetos investigados, sino hacer que se sientan bien y en confianza con el investigador. Segundo, la AI se adapta mejor a investigaciones sobre objetos de estudio que ya fueron analizados mediante técnicas más clásicas y controladas. La AI interviene cuando uno desea revelar aspectos positivos de objetos que suelen ser estudiados por el lado negativo (dominación, sufrimiento o representaciones negativas en torno a una población específica). Finalmente, se trata de demostrar, al usar esta técnica, que conlleva sesgos patentes que solo se justifican por la necesidad de franquear otros obstáculos metodológicos que impiden la investigación. Se trata de un asunto de dosificación y de mesura.

\section{Bibliografía}

Cooperrider D. y Whitney D. (2019). L'Appreciative inquiry: une révolution positive. Paris: Inter Editions.

Chantraine, G. (2006). La prison post-disciplinaire. Déviance et Société, 30(3), 273-288. doi: 10.3917/ds.303.0273. 
Chauvenet A., Orlic F. y Benguigui G. (1994). Le monde des surveillants de prison. Paris: PUF.

De Certeau, M. (2004). L'invention du quotidien. Tome 1: Arts de faire. Paris: Gallimard.

Devereux, G. (2000). De l'angoisse à la méthode dans les sciences du comportement. Paris: Aubier.

Fassin, D. (2017). L'ombre du monde. Une anthropologie de la condition carcérale. Paris: Seuil.

Foucault M. (1975). Surveiller et punir. Naissance de la prison. Paris: Gallimard.

Herzog-Evans, M. (2015). Les surveillants expérimentés: satisfaction, relations, émotions et légitimité professionnelle: tester en France l'appreciative inquiry. En P. Mbanzoulou, (Ed.) Criminologie et pratiques pénitentiaires: une voie vers la professionnalisation des acteurs? (pp.173-196). Agen: Les Presses de l'ENAP,

Hugues E.-C. (1996). Le Regard sociologique, Essais choisis. Paris: Editions de l'EHESS.

Icard, V. (2016). Vers une conciliation entre sécurité et droit en prison? Questionner la sécurité dynamique. Déviance et Société, 40(4), 433456. doi:10.3917/ds.404.0433.

Legendre, A.-C. (2017). Femmes surveillants, hommes détenus. Paris: L'Harmattan.

Liebling, A., Price, D. y Elliott, C. (1999). Appreciative Inquiry and Relationships in Prison. Punishmenty Society, 1(1), 71-98.

Lhuilier, D. (2005). Le « sale boulot ». Travailler, 14(2), 73-98. doi:10.3917/trav.014.0073.

Lhuilier, D. y Aymard N. (1997). L'univers pénitentiaire. Du côté des surveillants de prison. Paris: Desclée de Brouwer.

Rostaing, C. (2014). L'ordre négocié en prison: ouvrir la boîte noire du processus disciplinaire. Droit et société, 87(2), 303-328. Disponible en https://www.cairn.info/revue-droit-et-societe1- 2014-2-page303.htm. 